Florida International University FIU Digital Commons

FIU Electronic Theses and Dissertations

University Graduate School

$10-2-2017$

\title{
Hybrid Polymer Electrolyte for Lithium-Oxygen Battery Application
}

Amir Chamaani

AmirChamaani, acham027@fiu.edu

DOI: 10.25148 /etd.FIDC004004

Follow this and additional works at: https://digitalcommons.fiu.edu/etd

Part of the Ceramic Materials Commons, Materials Chemistry Commons, Membrane Science Commons, Physical Chemistry Commons, Polymer and Organic Materials Commons, $\underline{\text { Polymer }}$ Chemistry Commons, Polymer Science Commons, and the Transport Phenomena Commons

\section{Recommended Citation}

Chamaani, Amir, "Hybrid Polymer Electrolyte for Lithium-Oxygen Battery Application" (2017). FIU Electronic Theses and Dissertations. 3562.

https://digitalcommons.fiu.edu/etd/3562

This work is brought to you for free and open access by the University Graduate School at FIU Digital Commons. It has been accepted for inclusion in FIU Electronic Theses and Dissertations by an authorized administrator of FIU Digital Commons. For more information, please contact dcc@fiu.edu. 


\section{FLORIDA INTERNATIONAL UNIVERSITY}

Miami, Florida

\section{HYBRID POLYMER ELECTROLYTE FOR LITHIUM-OXYGEN BATTERY APPLICATION}

A dissertation submitted in partial fulfillment of the requirements for the degree of DOCTOR OF PHILOSOPHY

in

MATERIALS SCIENCE AND ENGINEERING

by

Amir Chamaani 
To: Dean John Volakis

College of Engineering and Computing

This dissertation, written by Amir Chamaani, and entitled Hybrid Polymer Electrolyte for Lithium-Oxygen Battery Application, having been approved in respect to style and intellectual content, is referred to you for judgment.

We have read this dissertation and recommend that it be approved.

William Kinzy Jones

Chunlei Wang

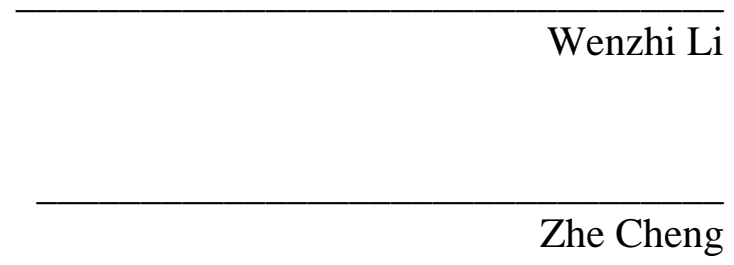

Bilal El-Zahab, Major Professor

Date of Defense: October 02, 2017

The dissertation of Amir Chamaani is approved.

Dean John Volakis

College of Engineering and Computing

Andrés G. Gil

Vice President for Research and Economic Development and Dean of the University Graduate School

Florida International University, 2017 
(C) Copyright 2017 by Amir Chamaani

All rights reserved. 


\section{DEDICATION}

To my lovely wife, parents and parents-in-law,

without their love, patience and support, none of this would have been possible. 


\section{ACKNOWLEDGMENTS}

I would like to express my deepest appreciation to my advisor, Dr. Bilal El-Zahab, for his guidance, inspiration, patience, and encouragement during my Ph.D. study. I would also like to thank my committee members, Dr. William Kinzy Jones, Dr. Chunlei Wang, Dr. Wenzhi Li, and Dr. Zhe Cheng for their support, suggestion and professional and personal guidance during my graduate studies.

I am also grateful to all my friends and labmates, Ata, Meer, Neha, Elnaz, AmirAli, Shervin, Arash and Maedeh, for their invaluable help and support. This research would not have been possible without the support of Advanced Materials Engineering Research Center (AMERI) staff, especially Dr. Alexander Franco and the Center of Study Matter at Extreme Condition (CeSMEC) staff, especially Drs. Vadym Drozd and Andriy Durygin. I would also like to express my appreciations to all the people who have helped me and given me support throughout the completion of my PhD studies. First, to my lovely wife and soulmate, Sepideh who have always supported and loved me unconditionally. I would also like to send my gratitude to my beloved parents and my first teachers, Nahid and Mostafa, who have always loved, supported and encouraged me. I could not have done this without the support and encouragement of my brother, Saeed and my parents-in-law, Nasrin and Nouredin.

Finally, I acknowledge University Graduate School at FIU for supporting me through the Dissertation Year Fellow (DYF) in my last year Ph.D. study. 


\section{ABSTRACT OF THE DISSERTATION \\ HYBRID POLYMER ELECTROLYTE FOR LITHIUM-OXYGEN BATTERY \\ APPLICATION}

by

Amir Chamaani

Florida International University, 2017

Miami, Florida

\section{Professor Bilal El-Zahab, Major Professor}

The transition from fossil fuels to renewable resources has created more demand for energy storage devices. Lithium-oxygen $\left(\mathrm{Li}-\mathrm{O}_{2}\right)$ batteries have attracted much attention due to their high theoretical energy densities. They, however, are still in their infancy and several fundamental challenges remain to be addressed. Advanced analytical techniques have revealed that all components of a $\mathrm{Li}-\mathrm{O}_{2}$ battery undergo undesirable degradation during discharge/charge cycling, contributing to reduced cyclability. Despite many attempts to minimize the anode and cathode degradation, the electrolyte remains as the leading cause for rapid capacity fading and poor cyclability in $\mathrm{Li}-\mathrm{O}_{2}$ batteries.

In this dissertation, composite gel polymer electrolytes (cGPEs) consisting of a UV-curable polymer, tetragylme based electrolyte, and glass microfibers with a diameter of $\sim 1 \mu \mathrm{m}$ and an aspect ratio of $>100$ have been developed for their use in $\mathrm{Li}-\mathrm{O}_{2}$ battery application. The $\mathrm{Li}-\mathrm{O}_{2}$ batteries containing cGPEs showed superior charge/discharge cycling for 500 mAh.g $\mathrm{g}^{-1}$ cycle capacity with as high as $400 \%$ increase in cycles for cGPE over gel polymer electrolytes (GPEs). Results using in-situ electrochemical impedance spectroscopy (EIS), Raman spectroscopy, and scanning electron microscopy revealed that the source of the 
improvement was the reduction of the rate of lithium carbonates formation on the surface of the cathode. This decrease in formation rate afforded by cGPE-containing batteries was possible due to the decrease of the rate of electrolyte decomposition. The increase in solvated to the paired $\mathrm{Li}^{+}$ratio at the cathode, afforded by increased lithium transference number, helped lessen the probability of superoxide radicals reacting with the tetraglyme solvent. This stabilization during cycling helped prolong the cycling life of the batteries. The effect of ion complexes on the stability of liquid glyme based electrolytes with various lithium salt concentrations has also been investigated for $\mathrm{Li}_{-} \mathrm{O}_{2}$ batteries. Charge/discharge cycling with a cycle capacity of $500 \mathrm{mAh} \cdot \mathrm{g}^{-1}$ showed an improvement as high as $300 \%$ for electrolytes containing higher lithium salt concentrations. Analysis of the Raman spectroscopy data of the electrolytes suggested that the increase in lithium salt concentration afforded the formation of cation-solvent complexes, which in turn, mitigated the tetragylme degradation. 


\section{TABLE OF CONTENTS}

CHAPTER

PAGE

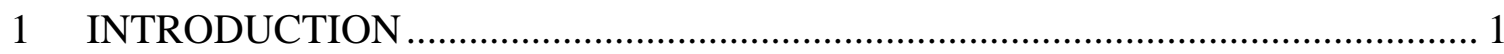

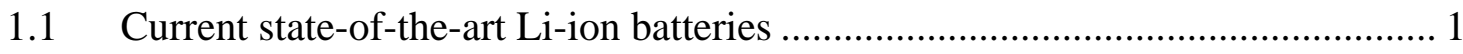

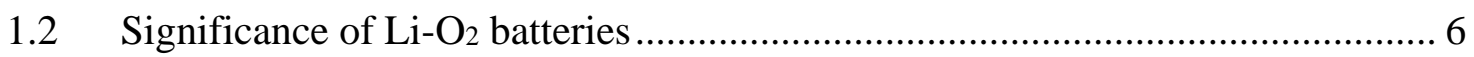

1.3 Fundamental mechanisms of $\mathrm{Li}_{2} \mathrm{O}_{2}$ batteries ............................................... 11

1.4 Challenges and degradation mechanisms in $\mathrm{Li}^{-\mathrm{O}_{2}}$ batteries ............................. 18

1.4.1 Lithium Anode Degradation ................................................................. 19

1.4.2 Cathode Degradation ......................................................................... 20

1.4.3 Electrolyte Degradation ......................................................................... 21

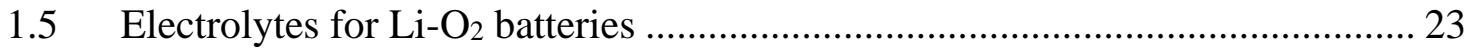

1.5.1 Aprotic Liquid Electrolytes for $\mathrm{Li}_{-} \mathrm{O}_{2}$ batteries ....................................... 23

1.5.2 Solid-State Electrolytes for $\mathrm{Li}^{-} \mathrm{O}_{2}$ batteries ............................................. 26

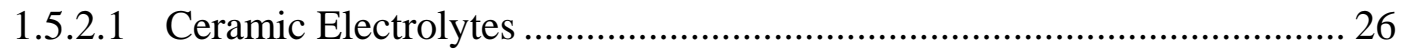

1.5.2.2 Solid polymer electrolytes............................................................... 27

1.5.2.3 Gel polymer Electrolytes............................................................... 28

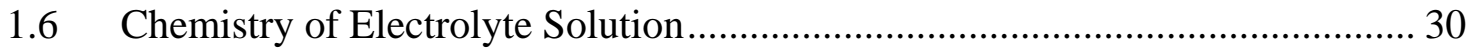

1.6.1 Ion-Solvent Interaction in Electrolytes ................................................. 32

1.6.2 Ion-ion Interaction in Electrolytes ......................................................... 33

1.6.3 Salt-Inorganic Additive Interaction in Electrolytes ..................................... 35

1.6.4 Ionic Transport Properties In Electrolytes ................................................... 39

$1.7 \quad$ Statement of Problems ............................................................................... 40

2 EXPERIMENTAL METHODS AND THEORY ……………….......................... 43

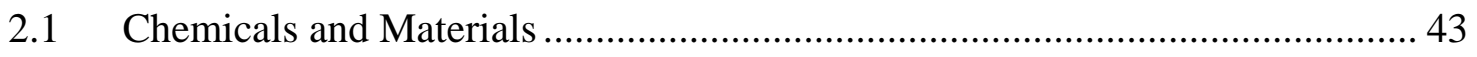

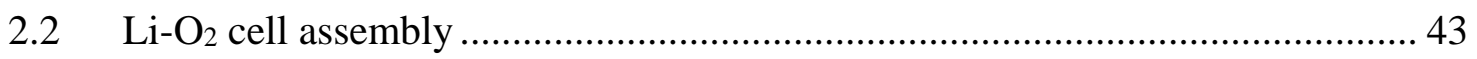

2.2.1 Liquid Electrolyte Preparation............................................................. 43

2.2.2 Gel polymer and composite gel polymer electrolytes preparation .............. 44

2.2.3 Cathode Preparation and whole cell assembly........................................... 45

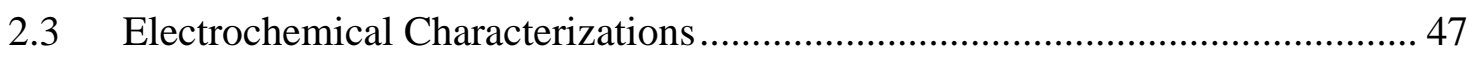

2.3.1 Galvanostatic charge/discharge .......................................................... 47

2.3.2 Voltammetry tests ............................................................................. 48

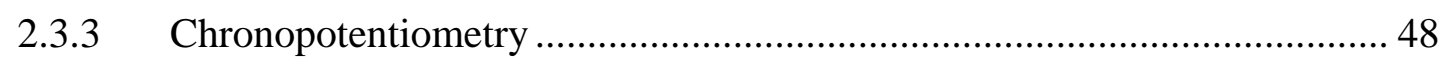


2.3.4 Li-ion transport measurements ............................................................. 49

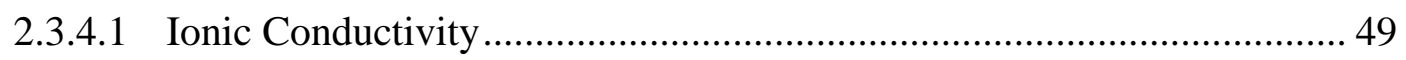

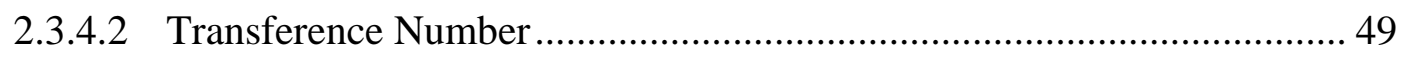

2.3.5 Electrochemical Impedance Spectroscopy (EIS) .......................................... 51

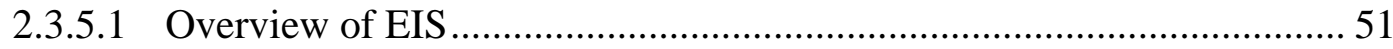

2.3.5.2 Transmission Line Model (TLM) for porous systems ............................ 55

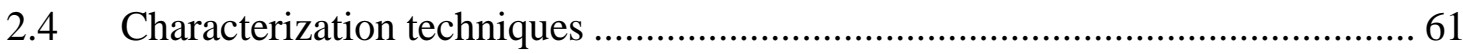

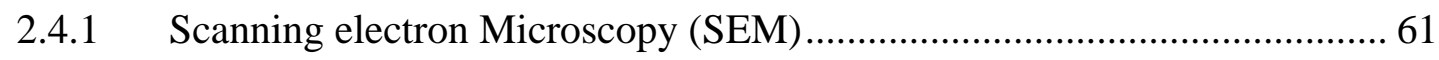

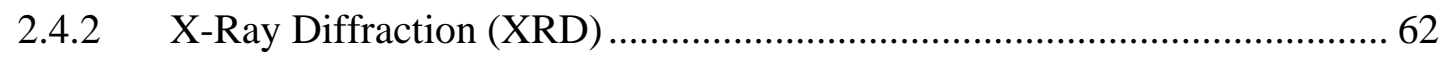

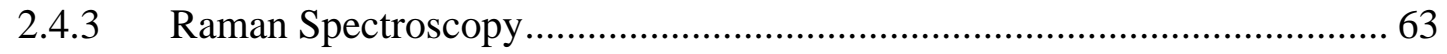

2.4.4 Brunauer-Emmett-Teller (BET) ………………..................................... 63

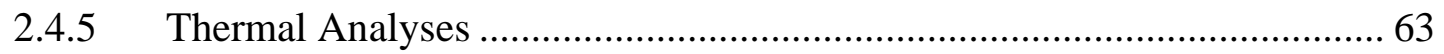

3 COMPOSITE GEL POLYMER ELECTROLYTE: EFFECT OF INORGANIC

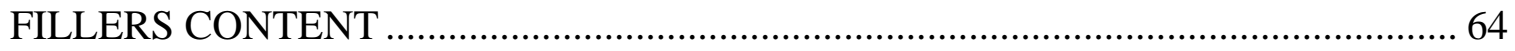

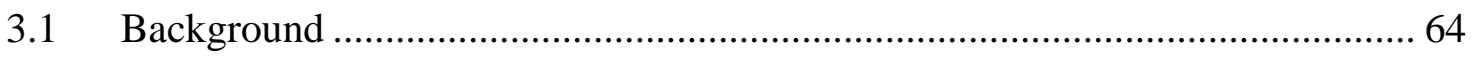

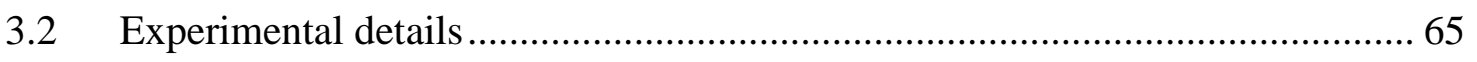

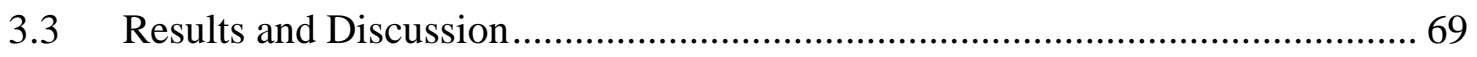

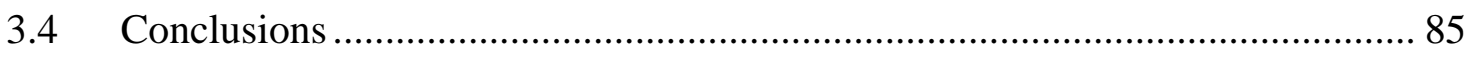

4 COPOSITE GEL POLYMER ELECTROLYTE: EFFECT OF LI SALT

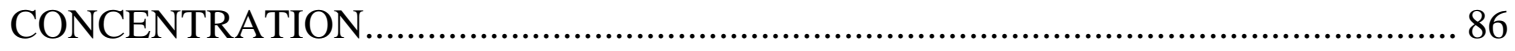

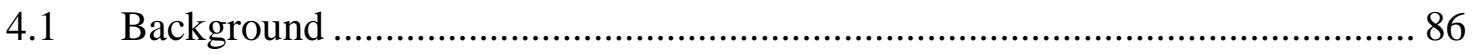

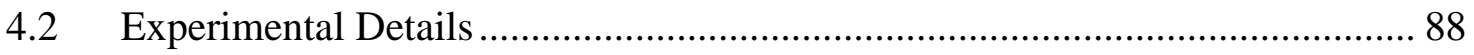

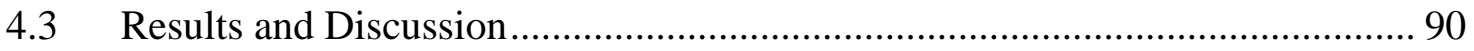

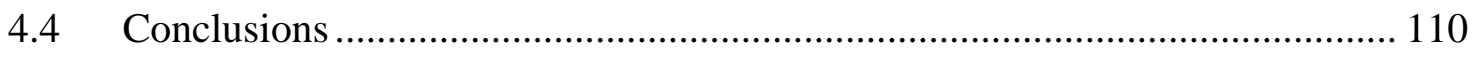

5 EFFECT OF ION PAIRS FORMATION ON THE STABILITY OF GLYME

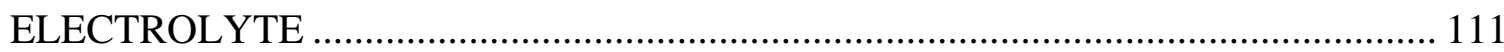

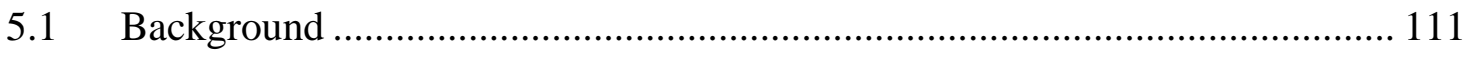

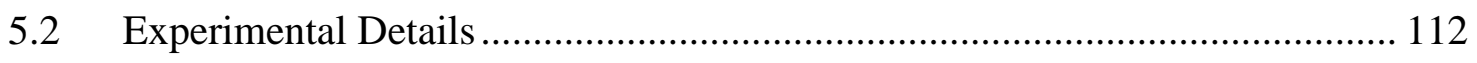

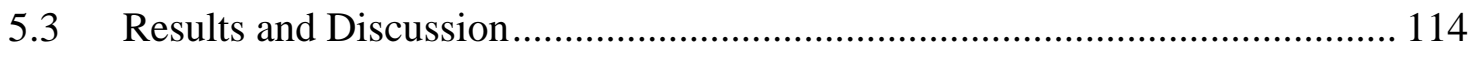

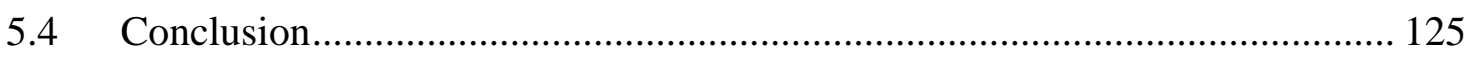

6 CONCLUDING REMARKS AND FUTURE WORKS …..................................... 126 


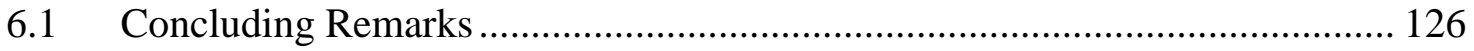

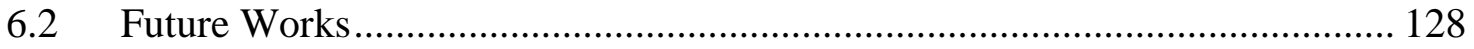

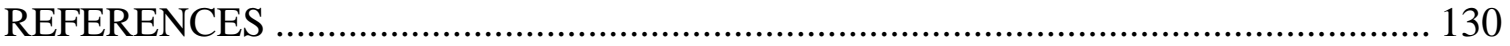

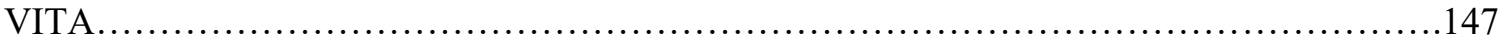




\section{LIST OF TABLES}

TABLE

PAGE

Table 1-1: Specific Energy and Energy Density of Commercial Rechargeable Batteries . 3

Table 1-2: Batteries for Present Battery Electric Vehicles (EVs) sold in US ................... 7

Table 1-3: Requirements on electrolytes for the nonaqueous $\mathrm{Li}-\mathrm{O}_{2}$ battery $\ldots \ldots \ldots \ldots \ldots \ldots . . . . . .23$

Table 1-4: List of SPEs and GPEs used in Li-air $\left(\mathrm{O}_{2}\right)$ batteries .................................. 29

Table 1-5: Different Ion-Solvent interaction along with their contribution percentage ... 32

Table 2-1: Common circuit elements used in EIS equivalent circuit models .................. 55

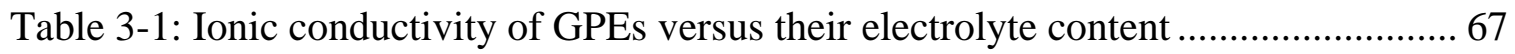

Table 3-2: Summary of ionic conductivity and lithium ion transference numbers of GPE and cGPEs with different glass micro-filler contents.................................. 72

Table 4-1: Summary of ionic conductivity and $\mathrm{Li}^{+}$transference number of GPE and cGPE at different salt concentrations.

Table 5-1: The ionic conductivity $(\sigma)$ and transference number $\left(\mathrm{tLi}^{+}\right)$of electrolytes with various salt concentration 


\section{LIST OF FIGURES}

FIGURE

PAGE

Figure 1-1: Schematic illustration of Li-ion battery consists of graphite as an anode and lithium cobalt oxide $\left(\mathrm{LiCoO}_{2}\right)$ as a cathode separated by a porous polymeric separator and filled with liquid electrolyte ..................................................................... 1

Figure 1-2: The crystal structures of common cathode materials in Li-ion batteries ......... 4

Figure 1-3: Illustration of the typical nanotechnologies applied in various cathodes for improving the Li-ion performance

Figure 1-4: Schematic illustration of active anode materials for the next generation of Li-ion batteries

Figure 1-5: Practical specific energies for some rechargeable batteries, along with estimated driving distances and pack prices

Figure 1-6: The specific energies $\left(\mathrm{Wh} \cdot \mathrm{kg}^{-1}\right.$ ) for various types of rechargeable batteries compared to gasoline

Figure 1-7: Calculated systems-level energy density and specific energy for $100 \mathrm{kWh}$ of useable energy and $80 \mathrm{~kW}$ of net power at a nominal voltage of $360 \mathrm{~V}$................ 10

Figure 1-8: Different types of $\mathrm{Li}^{-\mathrm{O}_{2}}$ batteries based on their electrolytes..................... 13

Figure 1-9: The discharge/charge mechanism of $\mathrm{Li}-\mathrm{O}_{2}$ battery in the liquid nonaqueous electrolyte

Figure 1-10: Typical voltage profile (charge/discharge curve) of $\mathrm{Li}-\mathrm{O}_{2}$ battery along with its overpotentials

Figure 1-11: Reduction mechanisms in a $\mathrm{Li}-\mathrm{O}_{2}$ cell at low overpotentials depending on the donor number (DN) of solvent.

Figure 1-12: Scanning electron micrographs (right) of toroid-shape $\mathrm{Li}_{2} \mathrm{O}_{2}$ (solutionmediated formation) along with the (left) conformal film formation of $\mathrm{Li}_{2} \mathrm{O}_{2}$ (surfacemediated formation) on the Super P carbon black................................................. 17

Figure 1-13: Summary of current challenges in $\mathrm{Li}^{-\mathrm{O}_{2}}$ batteries................................ 18

Figure 1-14: Possible Li metal reactions with electrolyte with/out $\mathrm{O}_{2} \ldots \ldots \ldots \ldots \ldots \ldots \ldots \ldots . . . . . . . . . . .19$ 
Figure 1-15: Proposed carbonate formation mechanism due to the reactivity of discharge products with carbon and electrolyte

Figure 1-16: Schematic pathways of electrolyte decomposition by reactive oxygen species 22

Figure 1-17: List of common polymers and their structures used in SPEs 28

Figure 1-18: Schematic of dissolution process of solute MX in a solution 30

Figure 1-19: Schematic representation of different ion-pairs (a) Contact ion pair (b) Solvent shared ion pair (c) Solvent separated ion pairs (d) Free solvated ions (Shaded circles denote the solvent molecules)

Figure 1-20: Schematic of the filler ion transport mechanisms in SPEs (a) Ion pair dissociation ( b) surface transport (c) anion attraction (d) PEO chain promoted surface transport

Figure 1-21: The inorganic filler in liquid electrolyte (a) below threshold filler loading (no percolation) (b) above or at threshold filler loading (percolation formed). 38

Figure 2-1: The modified Swagelok cell designed for $\mathrm{Li}^{-} \mathrm{O}_{2}$ batteries in disassembled (left) and assemble (right) mode.

Figure 2-2: The flowing mode $\mathrm{Li}-\mathrm{O}_{2}$ battery testbed designed and built in this study..... 46

Figure 2-3: Example of typical galvanostatic charge/discharge cycling showing both the applied current and voltage response

Figure 2-4: A typical Nyquist Plot and Bode Plot

Figure 2-5: Typical circuit model (Randles model) describing the faradic process at planer electrode/electrolyte interface.

Figure 2-6: Schematic illustration of different resistances in porous electrodes 56

Figure 2-7: Different interfaces in porous electrode structure 57

Figure 2-8 Scheme of a generic transmission line model 58

Figure 2-9: (a) Simplified TLM for porous cathodes describing faradic reactions at the active surface area (b) Simplified TLM for porous cathodes describing nonfaradic reactions at the active surface area. 
Figure 2-10: Typical Nyquist plots for cylindrical pores in (a) nonfaradic reactions and (b) faradic reactions

Figure 3-1: Schematic representation illustrating the GPE and cGPEs preparation along with photographs depicting the physical appearance of GPE and cGPE-1\% 66

Figure 3-2: GPEs with 85 wt.\% electrolyte content showing poor mechanical properties.

Figure 3-3: (a) Optical image of pristine CCGDL showing the woven carbon fibers (b) SEM micrograph of individual carbon fibers of pristine CCGDL (c) SEM micrograph of one carbon fiber coated with CNTs (d) Higher magnification of pre-coated carbon fiber with CNTs

Figure 3-4: (a) SEM micrograph (b) XRD pattern (c) TGA analysis (d) BET surface area measurement of glass microfibers (e-d) the SEM micrographs of cross-sectional cGPE- $1 \%$.

Figure 3-5: Thermal properties of ETPTA polymer (a) TGA analysis showing the thermal stability of polymer (b) DSC analysis showing the glass transition $\left(\mathrm{T}_{\mathrm{g}}\right)$ of ETPTA polymer.

Figure 3-6: Chronoamperometric curves of Li/GPE and cGPE-1\% /Li cell after $10 \mathrm{mV}$ of DC polarization at $25^{\circ} \mathrm{C}$ where the electrolyte films contain $1 \mathrm{~mol} \cdot \mathrm{kg}^{-1} \mathrm{LiTFSI}$ salt. Insets: electrochemical impedance spectra before and after polarization.

Figure 3-7: (a) Linear sweep voltammograms for $\mathrm{Li}^{-} \mathrm{O}_{2}$ batteries using GPE and cGPE-1\% with the scanning rate of $1 \mathrm{mV} \cdot \mathrm{s}^{-1}$ under oxygen. (b) Chronopotentiometric test of $\mathrm{Li}-\mathrm{O}_{2}$ batteries using GPE and cGPE- $1 \%$ at $250 \mathrm{~mA} \cdot \mathrm{g}^{-1}$ for 10 hours.

Figure 3-8: Linear sweep voltammogram of $\mathrm{Li}^{-} \mathrm{O}_{2}$ battery using liquid electrolyte with $1 \mathrm{~mol} \cdot \mathrm{kg}^{-1}$ LiTFSI salt

Figure 3-9: Open circuit voltage (OCV) of $\mathrm{Li}_{-} \mathrm{O}_{2}$ cells using GPE and cGPE-1\% under oxygen versus time

Figure 3-10: Cyclability of the $\mathrm{Li}-\mathrm{O}_{2}$ batteries for fixed charge and discharge cycle capacities of $500 \mathrm{mAh} \cdot \mathrm{g}^{-1}$ at a current density of $250 \mathrm{~mA} \cdot \mathrm{g}^{-1}$ with voltage cutoffs of 2.0-4 .5 V for GPE and cGPEs with various glass microfibers contents.

Figure 3-11: The voltage profile of $\mathrm{Li}_{-} \mathrm{O}_{2}$ batteries using GPE and cGPE with different glass microfiber content

Figure 3-12: Cyclic voltammograms of $\mathrm{Li}^{-\mathrm{O}_{2}}$ batteries using GPE and cGPE-1\% in voltage windows of $2.0-4.5 \mathrm{~V}$ and scan rate of $1 \mathrm{mV} \cdot \mathrm{s}^{-1}$ 
Figure 3-13: XRD patterns (left) and Raman spectra (right) of oxygen cathodes after a $500 \mathrm{mAh} \cdot \mathrm{g}^{-1}$ discharge of $\mathrm{Li}-\mathrm{O}_{2}$ batteries using GPE and cGPE-1\%...

Figure 3-14: The voltage profile of $\mathrm{Li}^{-\mathrm{O}_{2}}$ cell using CNT-free CCGDL in full discharge/charge mode along with cell using CCGDL-0.5 mg of CNTs in partial 500 $\mathrm{mAh} \cdot \mathrm{g}^{-1}$ charge/discharge capacity mode at $125 \mu \mathrm{A}$ current and voltage windows of 2.0-4.5 V .

Figure 3-15: AC impedance Nyquist plots of $\mathrm{Li}^{-} \mathrm{O}_{2}$ batteries using GPE (a) and cGPE-1\% (b) during cycling after discharge and (c) Evolution of interfacial resistance of all $\mathrm{Li}-\mathrm{O}_{2}$ batteries using GPE and cGPEs against select cycle numbers.

Figure 3-16: The EIS spectra of $\mathrm{Li}-\mathrm{O}_{2}$ cells using GPE and cGPE-1\% before charging under Ar atmosphere

Figure 3-17: Voltage profile of the Li plating/stripping measurements performed using the symmetrical $\mathrm{Li} / \mathrm{cGPE}-1 \% / \mathrm{Li}$ cell and $\mathrm{Li} / \mathrm{GPE} / \mathrm{Li}$ cell at a current density of 0.125 $\mathrm{mA} \cdot \mathrm{cm}^{-2}$ and a plating and stripping times of 2 hours each.

Figure 4-1: Chronoamperometric curves of Li/GPE and cGPE /Li cell after $10 \mathrm{mV}$ of DC polarization at $25^{\circ} \mathrm{C}$ where the electrolyte films contain 0.1 and $3 \mathrm{~mol} \cdot \mathrm{kg}^{-1} \mathrm{LiTFSI}$ salt. Insets: electrochemical impedance spectra before and after polarization

Figure 4-2: Raman spectra of Liquid electrolytes, GPEs and cGPEs with various LiTFSI salt concentrations showing Raman shifts of bounded and unbounded $\mathrm{TFSI}^{-}$ anions.

Figure 4-3: DSC profile indicating the glass transition (Tg) of (left) GPE containing 50:50 wt.\% of ETPTA: Electrolyte with $1 \mathrm{~mol} \cdot \mathrm{kg}^{-1}$ salt concentration (right) cGPE-1\% with the same ETPTA and polymer content.

Figure 4-4: Voltage profile of $\mathrm{Li}_{-} \mathrm{O}_{2}$ batteries using GPE and cGPE with different salt concentrations with a limited capacity of $500 \mathrm{mAh} \cdot \mathrm{g}^{-1}$ per cycle at current density of $250 \mathrm{~mA} \cdot \mathrm{g}^{-1}$

Figure 4-5: Raman spectra of $500 \mathrm{mAh} \cdot \mathrm{g}^{-1}$ predischarged cathode using GPE and cGPE with different salt concentration. (Raman shifts at $1350 \mathrm{~cm}^{-1}$ and $1580 \mathrm{~cm}^{-1}$ correspond to the $\mathrm{D}$ and $\mathrm{G}$ bands of CNTs)

Figure 4-6: (a) Typical Nyquist plots of $\mathrm{Li}_{-} \mathrm{O}_{2}$ batteries using GPE with $1.0 \mathrm{~mol} \cdot \mathrm{kg}^{-1}$ salt concentration at OCV after first and failure cycle along with cycle $10^{\text {th }}$ and $25^{\text {th }}$ cycle (inset: shows close-up of Nyquist plots showing changes in interfacial resistances during cycling). (b) Transmission line model used to interpret the resistances of Nyquist plots. 
Figure 4-7: (a) Modified transmission line model (TLM) circuit model used to interpret the resistance of porous cathode. (b) The circuit model of the full cell $\mathrm{Li}_{-}-\mathrm{O}_{2}$ batteries

Figure 4-8: The change of resistances of $\mathrm{Li}^{-\mathrm{O}_{2}}$ batteries using GPE and cGPE with different salt concentrations during cycling up to their failure

Figure 4-9: Raman spectra of cycled cathodes after discharge using GPEs and cGPEs with 0.1 and $1 \mathrm{~mol} \cdot \mathrm{kg}^{-1}$ salt concentration at cycle number where the batteries using GPEs fails (cycle $12^{\text {th }}$ for $0.1 \mathrm{~mol} \cdot \mathrm{kg}^{-1}$ and cycle $29^{\text {th }}$ for $1 \mathrm{~mol} \cdot \mathrm{kg}^{-1}$ )....

Figure 4-10: XRD patterns of cathodes using GPE and cGPE ( $1 \mathrm{~mol} \cdot \mathrm{kg}^{-1} \mathrm{LiTFSI}$ salt concentration) showing the presence of lithium peroxide and lithium carbonates.

Figure 4-11: SEM micrograph of cycled cathodes in $\mathrm{Li}^{-\mathrm{O}_{2}}$ batteries using cGPE (a) and GPE (b) with $1.0 \mathrm{~mol} \cdot \mathrm{kg}^{-1}$ salt concentration after the failure discharge cycle. 103

Figure 4-12: The change of interfacial resistance $\left(R_{\text {int }}\right)$ of cells using GPE and cGPE with different salt concentrations during cycling up to their failures.

Figure 4-13: (a) EIS spectrum of (a) fresh cathode/cathode symmetrical cell (b) precycled cathode/cathode symmetrical cell (c) $\mathrm{Li} / \mathrm{Li}$ symmetrical cell (d) full $\mathrm{Li}-\mathrm{O}_{2}$ battery

Figure 4-14: EIS spectra of $\mathrm{Li}^{-\mathrm{O}_{2}}$ cells using GPE and cGPE-1\% in different conditions

Figure 4-15: Schematic representation of proposed mechanism of electrolyte stabilization in $\mathrm{Li}^{-} \mathrm{O}_{2}$ batteries in cGPEs over GPEs

Figure 5-1: Chronoamperometric curves of Li/liquid electrolyte /Li cell after $10 \mathrm{mV}$ of DC polarization at $22^{\circ} \mathrm{C}$ where the electrolytes contain different LiTFSI salt concentration. Insets: electrochemical impedance spectra before and after polarization 113

Figure 5-2: Voltage profile of $\mathrm{Li}^{-} \mathrm{O}_{2}$ batteries using TEGDME electrolyte with various LiTFSI salt concentrations with a limited capacity of $500 \mathrm{mAh} \cdot \mathrm{g}^{-1}$ per cycle at current density of $250 \mathrm{~mA} \cdot \mathrm{g}^{-1}$ in a voltage range of $2.0-4.5 \mathrm{~V}$.

Figure 5-3: (a) Typical Nyquist plots of $\mathrm{Li}^{-\mathrm{O}_{2}}$ batteries using TEGDME electrolyte with $\mathrm{X}_{\mathrm{LITFS}}=0.2$ salt concentration at $\mathrm{OCV}$ after first and failure cycle $\left(30^{\text {th }}\right)$ along with $5^{\text {th }}$ and $25^{\text {th }}$ cycle (b) Circuit model of the full cell as described in previous chapter 
Figure 5-4: The change of resistances of $\mathrm{Li}^{-\mathrm{O}_{2}}$ batteries using TEGDME electrolyte with different salt concentrations during cycling up to their failure (cyle $10^{\text {th }}, 30^{\text {th }}$ and $40^{\text {th }}$ for $\mathrm{X}_{\mathrm{LiTFS}}=0.02$ and 0.2 and 0.4 , respectively).

Figure 5-5: Interfacial resistance evolution of $\mathrm{Li}^{-} \mathrm{O}_{2}$ cells using liquid electrolyte with various Li salt concentration versus selected cycles until their failure. 119

Figure 5-6: Raman spectra of cycled cathodes in $\mathrm{Li}^{-\mathrm{O}_{2}}$ cells using TEGDME electrolyte with various salt concentration after thier failure cycles (cycle $10^{\text {th }}$, cycle $30^{\text {th }}$ and cycle $40^{\text {th }}$ for cell using $\mathrm{X}_{\mathrm{LiTFS}}=0.02,0.2$ and 0.4 , respectively).

Figure 5-7: Raman spectra of electrolyte solution with various LiTFSI salt concentrations in the range of $800-900 \mathrm{~cm}^{-1}$ and $720-760 \mathrm{~cm}^{-1}$ at $22^{\circ} \mathrm{C}$. 


\section{INTRODUCTION}

\subsection{Current state-of-the-art Li-ion batteries}

A battery is an electrochemical energy storage device which converts chemical energy into electrical energy. Chemical energy exists inside the electrodes of batteries and converts to the electrical energy via electrochemical reactions known as reduction/oxidation (redox) reactions. Batteries (cells) consist of three major components: a positive electrode (cathode), a negative electrode (anode), and an electrolyte. Figure 1-1 shows a typical representation of Li-ion batteries which consists of graphite as anode, lithium cobalt oxide as a cathode and a porous polymeric separator which electronically isolates the cathode and anode [1].

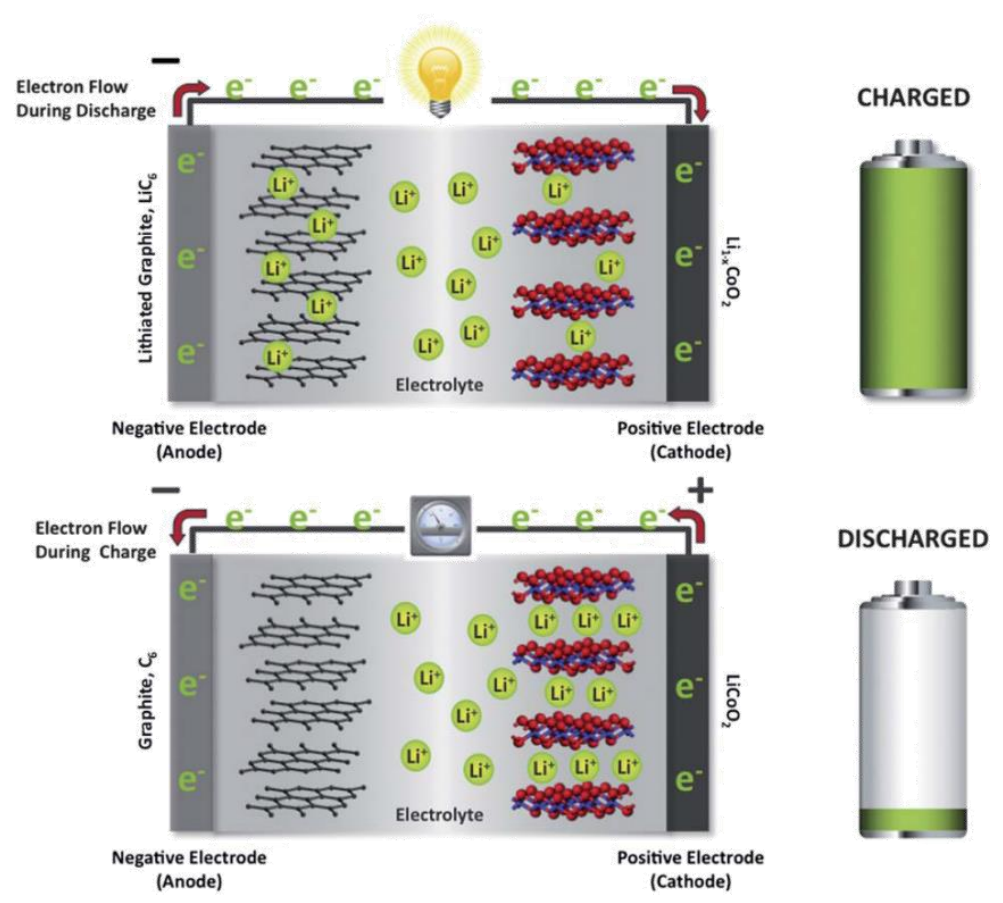

Figure 1-1: Schematic illustration of Li-ion battery consist of graphite as an anode and lithium cobalt oxide $\left(\mathrm{LiCoO}_{2}\right)$ as a cathode separated by a porous polymeric separator and filled with liquid electrolyte [1] 
Each Li-ion cell is also filled with liquid electrolytes which convey the $\mathrm{Li}^{+}$between cathode and anode during cell operation. In $\mathrm{Li}$-ion batteries, the typical electrolyte is a solution of $\mathrm{LiPF}_{6}$ salt dissolved in an organic carbonate-based solvent mixture of ethylene carbonate (EC), dimethyl carbonate (DMC), and diethyl carbonate (DEC) [2]. During the charge process, $\mathrm{Li}^{+}$ions travel from the cathode to the anode and intercalate into a graphite anode crystal structure and electrons transfer from the cathode to anode through an external circuit. During discharge, the direction of $\mathrm{Li}^{+}$ions and electrons is reversed, and the electron moves from anode to cathode in the external circuit and delivers electricity. The reversible electrochemical reactions of electrodes (cathode and anode) happening during charge and discharge of a $\mathrm{Li}$-ion battery involves the intercalation and deintercalation of $\mathrm{Li}^{+}$ions into and from the lattice sites of the anode and cathode active materials and can be expressed as follows [2]:

Cathode:

$\mathrm{LiCoO}_{2} \leftrightarrow \mathrm{Li}_{1-n} \mathrm{CoO}_{2}+n \mathrm{Li}^{+}+n e^{-}$

Anode:

$C_{6}+n L i^{+}+n e^{-} \leftrightarrow L i_{n} C_{6}$

Overall cell reaction:

$\mathrm{LiCoO}_{2}+\mathrm{C}_{6} \leftrightarrow \mathrm{Li}_{n} \mathrm{C}_{6}+\mathrm{Li}_{1-n} \mathrm{CoO}_{2}, E_{0}=4.0 \mathrm{~V}$

Where, the value of $n$ is about 0.6 .

The standard free energy formation $\left(\Delta \mathrm{G}_{0}\right)$ of the overall cell reaction can be related to the standard potential $\left(\mathrm{E}_{0}\right)$ of $\mathrm{C}_{6} / \mathrm{LiCoO}_{2}$ cell via the Nernst relation [2]: 
$\Delta G_{0}=-n F E_{0}$

Where the $\mathrm{F}$ is the faradic constant, and $\mathrm{n}$ is the number of electrons involved the electrochemical reactions.

The specific energy of a Li-ion battery is usually expressed in $\mathrm{W} \mathrm{h} \cdot \mathrm{kg}^{-1}$ as follows $[2,3]$ :

Specific Energy $\left(\mathrm{Wh} \cdot \mathrm{kg}^{-1}\right)=\frac{\text { Cell Voltage }(\mathrm{V}) \times 1000(g) \times 26.8 \mathrm{Ah}}{k g \times e q u i v w t(g)}$

Where $\mathrm{V}$ is the cell voltage and $26.8 \mathrm{Ah}$ is the Faraday constant. The equivalent weight of an electrochemical redox couple is obtained by dividing the weight of the electrode reactants (in grams) by the number of electrons transferred in the reaction. The energy density $\left(\mathrm{Wh} \cdot \mathrm{L}^{-1}\right.$ ) of $\mathrm{Li}$-ion batteries could also be calculated from a formula (5) by using the equivalent volumes of the electrode reactants. Table 1-1 demonstrates the specific energy and energy density of common rechargeable batteries, including Li-ion batteries $[3,4]$.

Table 1-1: Specific Energy and Energy Density of Commercial Rechargeable Batteries $[3,4]$

Battery Chemistry Specific Energy, $\mathrm{Wh} \cdot \mathrm{Kg}^{-1} \quad$ Energy Density, $\mathrm{Wh} \cdot \mathrm{L}^{-1}$

\begin{tabular}{ccc}
\hline Pb-acid & 30 & 80 \\
Ni-Cd & 40 & 90 \\
Ni-MH & 55 & 165 \\
Ni-Zn & 70 & 145 \\
Ag-Zn & 75 & 200 \\
Li-ion & $100-285$ & $320-690$
\end{tabular}


The specific energy and energy density of Li-ion batteries are limited by the reversible capacities of the cathode materials. The cathode materials used in Li-ion batteries are categorized into three major classes [5]: (1) layered lithiated transition metal oxides such as $\mathrm{LiCoO}_{2}$ (LCO), $\mathrm{LiNi} 0.33 \mathrm{Mn}_{0.33} \mathrm{Co}_{0.33} \mathrm{O}_{2}$ (NMC) and $\mathrm{LiNi}_{0 .} \mathrm{Co}_{0.15} \mathrm{Al}_{0.05} \mathrm{O}_{2}(\mathrm{NCA})$; (2) lithiated transition-metal spinel oxides such as $\mathrm{LiMn}_{2} \mathrm{O}_{4}$ and $\mathrm{LiMn}_{1.5} \mathrm{Ni}_{0.5} \mathrm{O}_{2}$; (3) lithiated transition-metal phosphates like $\mathrm{LiFePO}_{4}$. Figure 1-2 depicts the crystal structure of these three cathode materials.
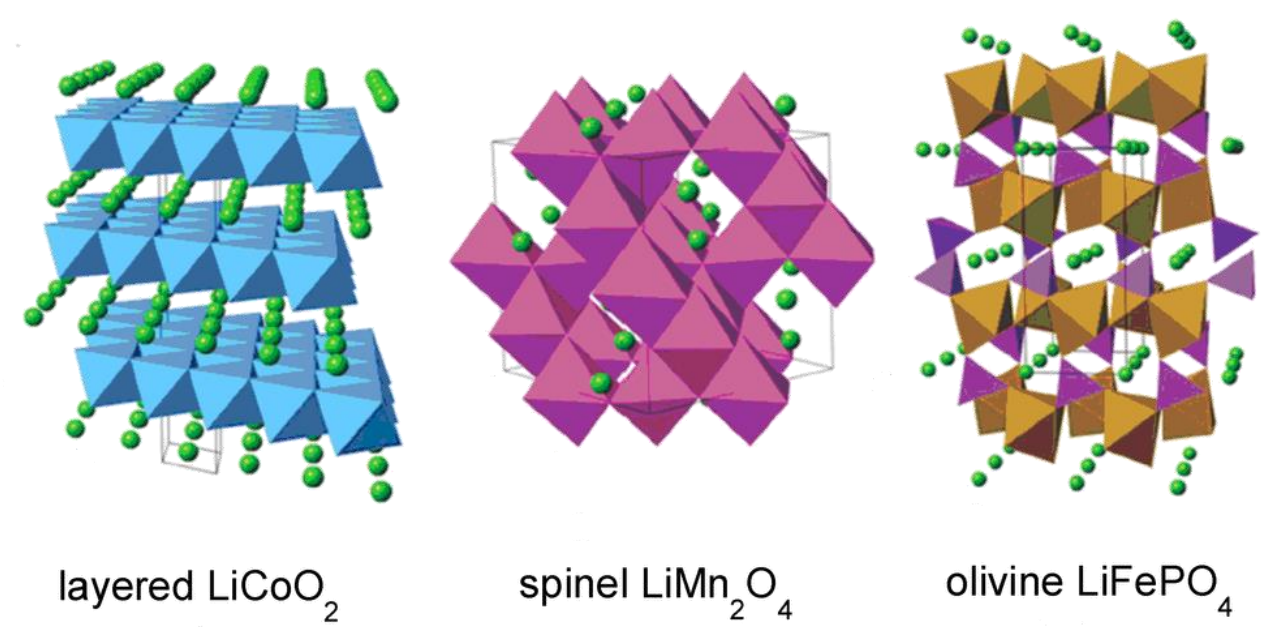

Figure 1-2: The crystal structures of common cathode materials in Li-ion batteries

Nanoarchitectured cathodes with various morphologies, including zero dimension (OD; nanoparticles), one dimension (1D; nanotubes or nanowires), two dimension (2D; nanoplates or nanosheets), and three dimension (3D; hierarchical nanostructures), have also been developed to improve unique lithium storage properties and electrochemical performance (charge/discharge capacity, cycling stability, rate capability), and safety. 
Figure 1-3 summarize some the recent nanostructured cathode materials developed for $\mathrm{Li}$ ion batteries [6].

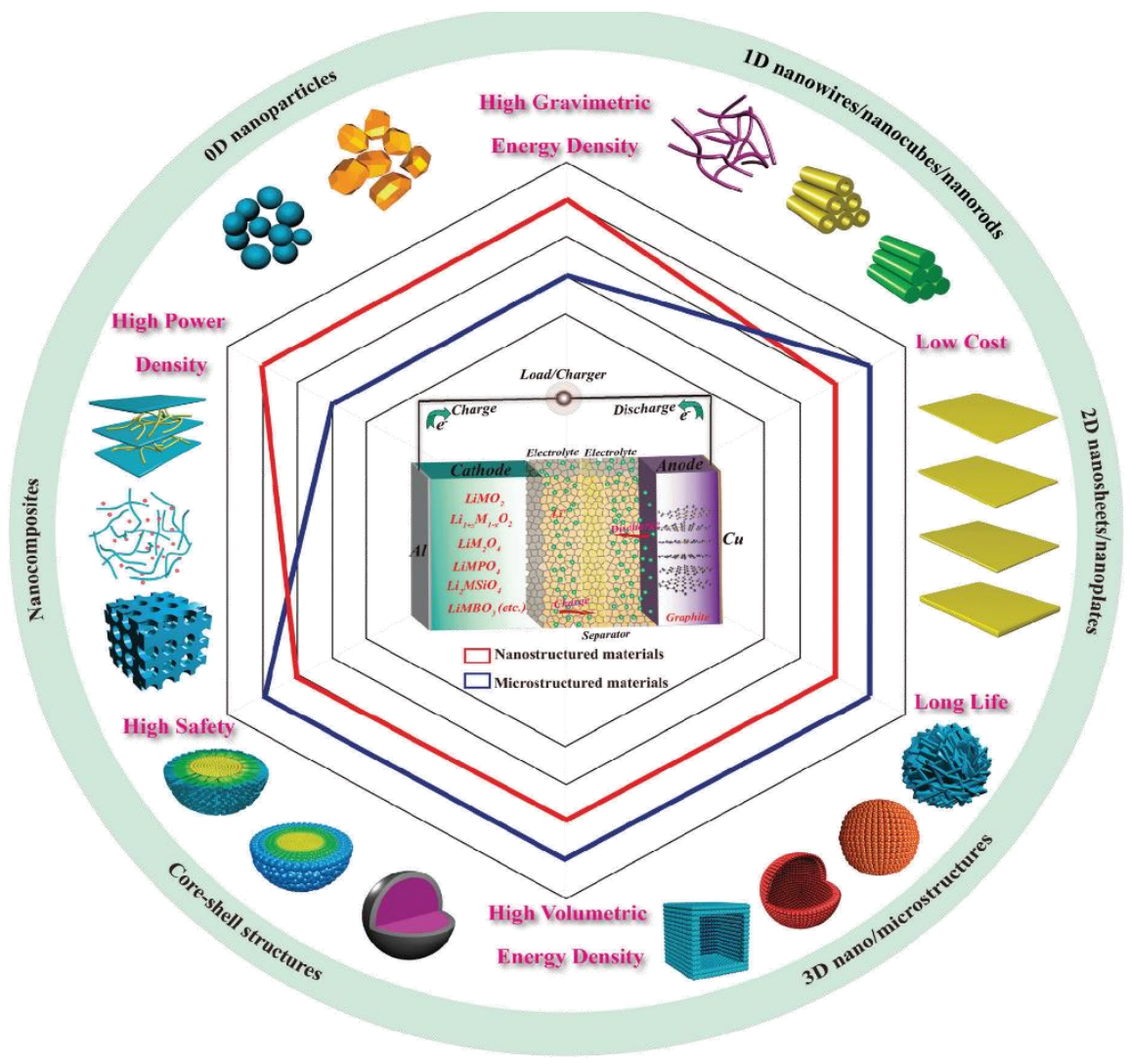

Figure 1-3: Illustration of the typical nanotechnologies applied in various cathodes for improving the Li-ion performance [6]

The graphite is a common material used in Li-ion battery anode with a theoretical specific capacity of $370 \mathrm{mAh} \cdot \mathrm{g}^{-1}$ [2], which involves the transfer of one electron (or one equivalent of Li) per mole of $\mathrm{C}_{6}$. Graphite is used in different forms as active anode materials in Liion batteries including natural graphite, synthetic graphite, meso-carbon microbead (MCMB) graphite [2]. In Li-ion batteries, the power density is mostly limited by the graphite anode as the $\mathrm{Li}^{+}$ions diffusion rate into graphite is in the range of $10^{-9}-10^{-7} \mathrm{~cm}^{2} \cdot \mathrm{s}^{-}$ 
${ }^{1}$ [7]. Therefore, many research studies have been devoted to developing new anode with higher energy and power density [8,9]. Figure 1-4 illustrates the active anode materials which have been used or under development for $\mathrm{Li}$-ion batteries.

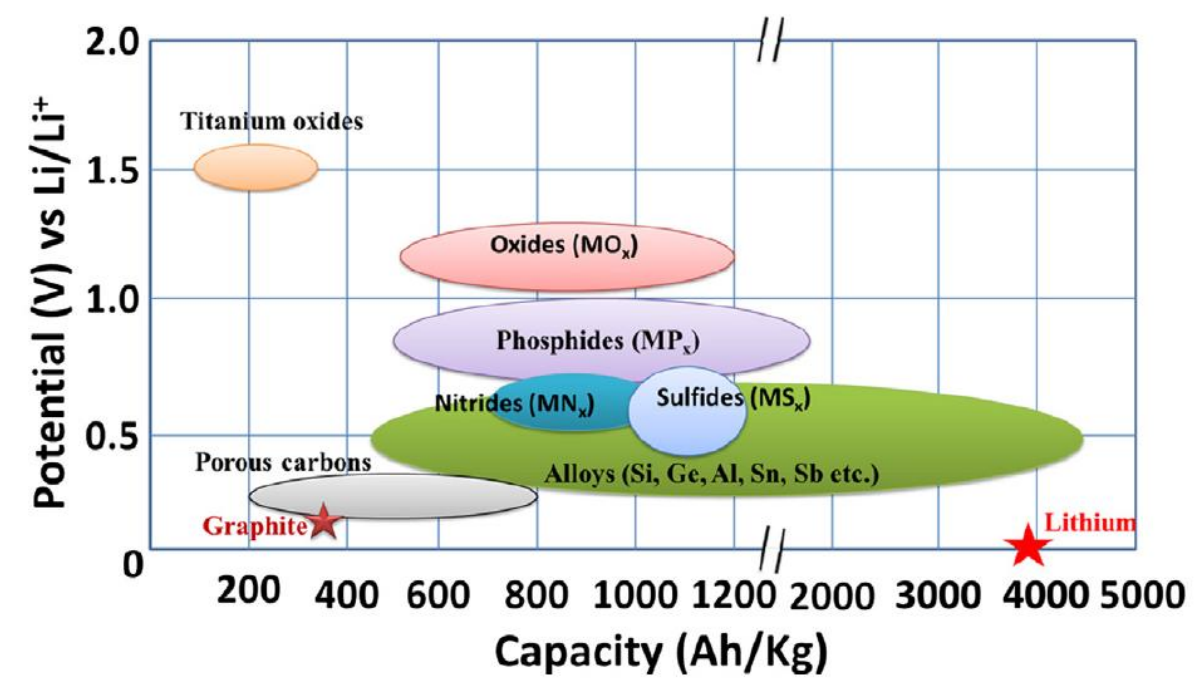

Figure 1-4: Schematic illustration of active anode materials for the next generation of Li-ion batteries [9]

\subsection{Significance of $\mathrm{Li}-\mathrm{O}_{2}$ batteries}

There is an urgency to minimize the consumption of fossil fuel and reduce the $\mathrm{CO}_{2}$ emission due to the severe climate change. Therefore, the transition from gasoline-based vehicles to the partial electric vehicles like hybrid electric vehicles (HEVs) and plug-in hybrids (PHEVs) or fully electric vehicle (EVs) has begun $[1,9,10]$. Li-ion batteries have been in demand for electric vehicles for many years. Table 1-2 shows various Li-ion chemistries developed by different companies, which is currently being used in EVs ranked by present sales in the US [10]. 
Table 1-2: Batteries for Present Battery Electric Vehicles (EVs) sold in US [10]

\begin{tabular}{|c|c|c|c|c|c|c|}
\hline Manufacturer & Model & Battery size (kWh) & Battery Chemistry & Battery Supplier & Vehicle range (mi) & Vehicle range $(\mathrm{km})$ \\
\hline Tesla & S & $60-100$ & $\mathrm{C} / \mathrm{NCA}$ & Panasonic/Tesla & $208-315$ & $334-508$ \\
\hline Tesla & $X$ & $60-100$ & $\mathrm{C} / \mathrm{NCA}$ & Pansonic/Tesla & $208-315$ & $334-508$ \\
\hline BMW & i3 & 22,33 & $\mathrm{C} / \mathrm{NMC}$ & Samsung/Bosch & 80,114 & 129,183 \\
\hline Nissan & Leaf & 24,30 & $\mathrm{C} / \mathrm{LMO}$ (C/NMC) & $\mathrm{AESC}$ and LG Chem ${ }^{\dagger}$ & 84,107 & 135,172 \\
\hline Volkswagen & e-Golf & $24,35.8$ & $\mathrm{C} / \mathrm{NMC}$ & Pansonic (Sanyo Div.) & 83,124 & 135,200 \\
\hline Chevrolet & Spark & 19 & C/LFP & A123 & 82 & 132 \\
\hline Fiat & $500 \mathrm{e}$ & 24 & $\mathrm{C} / \mathrm{NMC}$ & Samsung/Bosch & 87 & 140 \\
\hline $\mathrm{Kia}$ & Soul EV & 27 & $\mathrm{C} / \mathrm{NMC}$ & SK Innovation & 90 & 145 \\
\hline Smart & Fortwo EV & 17.6 & $\mathrm{C} / \mathrm{NMC}$ & LG Chem & 68 & 109 \\
\hline Ford & Focus EV & 35.5 & $\mathrm{C} / \mathrm{NMC}$ & LG Chem & 100 & 160 \\
\hline Mercedes & B-Class Electric & 28 & $\mathrm{C} / \mathrm{NCA},(\mathrm{C} / \mathrm{NMC})$ & Panasonic/Tesla and SK Innovation ${ }^{\dagger}$ & 85 & 137 \\
\hline Mitsubishi & I & 16 & LTO/LMO & Toshiba & 62 & 100 \\
\hline
\end{tabular}

While Tesla Motors and Chevrolet has announced that they will have a battery pack of 60 $\mathrm{kWh}$ and $85 \mathrm{kWh}$, their price is still far from the US Department of Energy ideal number (\$125 per kWh for a battery pack). Therefore, despite many developments in the Li-ion battery field, the current state-of-the-art of Li-ion batteries cannot meet many requirements for emerging applications such as future EVs. The energy density of 2 to 5 times greater of current Li-ion batteries are needed to meet the performance requirements of PHEVs with a 40-80 mile and EVs with a 300-400-mile driving range [1]. The next generation of advanced Li-ion batteries are approaching the performance needed for PHEVs; however, the recent development in energy density and price reduction of $\mathrm{Li}$-ion batteries by Tesla Motors and Panasonic partnership is not sufficient for future EVs. Beyond Li-ion batteries (BLIs) such as Li-Sulfur and Metal-air batteries have been developed to replace the current Li-ion batteries. Figure 1-5 shows some the recent advances in Li-ion energy density and price pack along with the future battery chemistries [11]. 


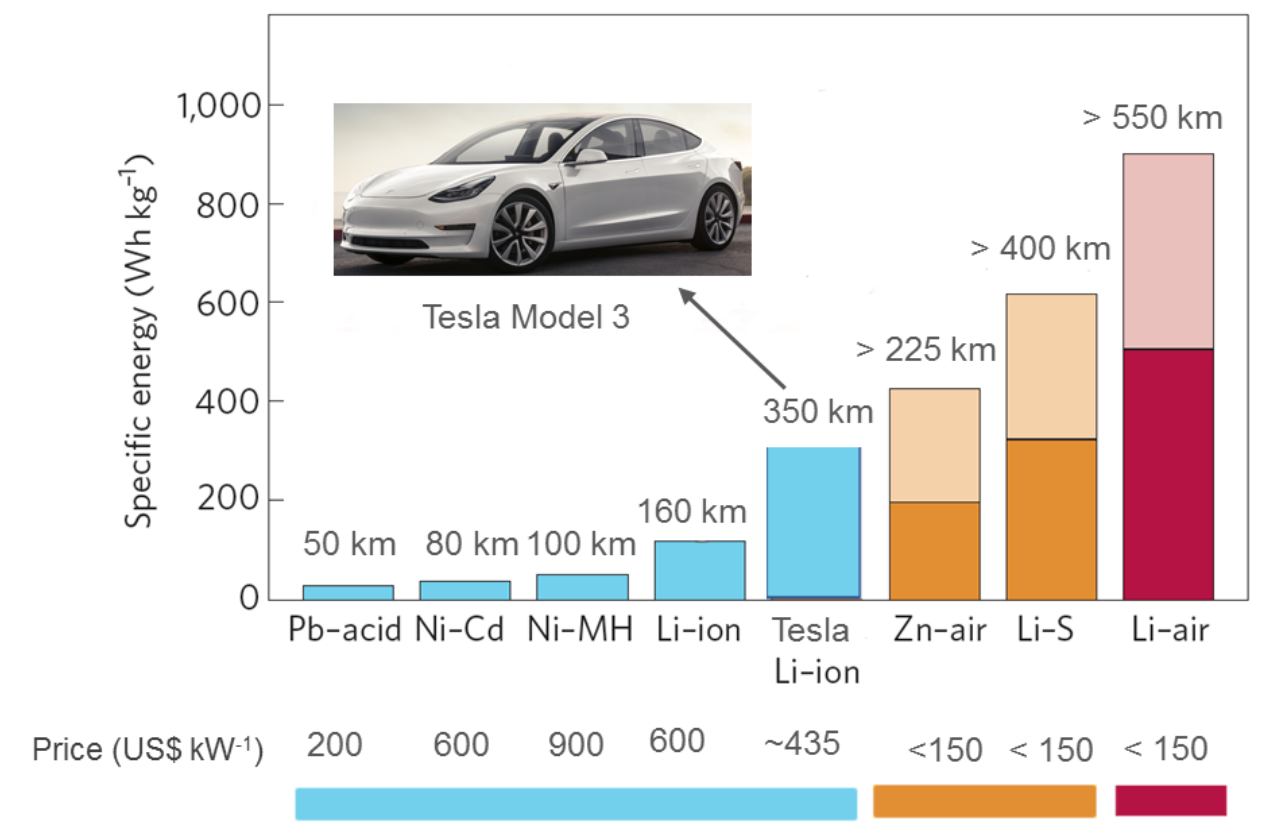

Figure 1-5: Practical specific energies for some rechargeable batteries, along with estimated driving distances and pack prices [11] (Note: some numbers in this Figure has been changed to reflect the recent advances in driving range and price pack of Li-ion batteries made by Tesla Motors.)

Among all BLI chemistries, the Li-air battery has the highest theoretical specific energy, and hence, it has attracted enormous research attention. Figure 1-6 shows the comparison of specific energy of various battery chemistries with gasoline [12]. The practical energy density of gasoline is $1700 \mathrm{Wh} \cdot \mathrm{kg}^{-1}$ considering the average tank to wheel efficiency in the US is $\sim 13 \%$, and theoretical energy density of gasoline is $13000 \mathrm{Wh} \cdot \mathrm{kg}^{-1}\left(13000 \mathrm{Wh} \cdot \mathrm{kg}^{-}\right.$ $1 * 13 \%=1700 \mathrm{Wh} \cdot \mathrm{kg}^{-1}$ ). The battery to wheel efficiency (battery systems) is about $90 \%$, so the current energy density of Li-ion batteries $\left(100-265 \mathrm{Wh} \cdot \mathrm{kg}^{-1}\right)$ needs to be improved roughly 10 -folds to make it competitive with gasoline. However, with the current state-ofthe-art Li-ion batteries, reaching to the $1700 \mathrm{Wh} \cdot \mathrm{kg}^{-1}$ is very optimistic. Since the energy density of lithium metal is $11680 \mathrm{Wh} \cdot \mathrm{kg}^{-1}$, the practical energy density of gasoline (1700 
$\mathrm{Wh} \cdot \mathrm{kg}^{-1}$ ) is only about $15 \%$ of the energy density of lithium metal. Hence, it is very conceivable that lithium-based batteries like Li-air could replace the gasoline easily.

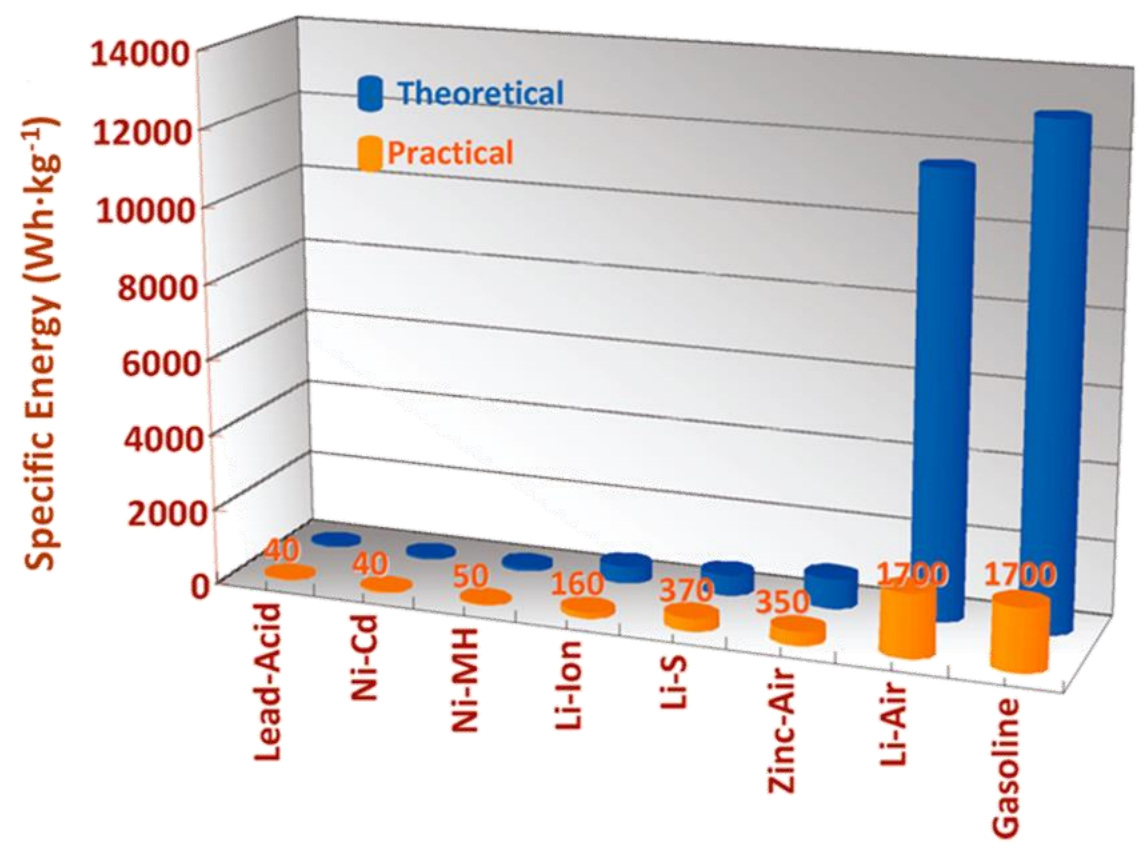

Figure 1-6: The specific energies $\left(\mathrm{Wh} \cdot \mathrm{kg}^{-1}\right.$ ) for various types of rechargeable batteries compared to gasoline [12]

Although theoretical specific energy and energy density of $\mathrm{Li}^{-} \mathrm{O}_{2}$ batteries are very high, the recent calculation has been shown that their practical system-level energy density and specific energy are not that much high considering the existing technologies. For example, Gallagher et. al [13] estimates system's practical specific energy and energy density for the $\mathrm{Li}$-air batteries assuming two different methods for $\mathrm{O}_{2}$ handling: (1) open $\mathrm{Li}-\mathrm{O}_{2}$ batteries with breathing systems with absorbers of humidity and removal of $\mathrm{N}_{2}$ and $\mathrm{CO}_{2}$ of the air and (2) close $\mathrm{Li}-\mathrm{O}_{2}$ batteries with battery packs inside the pressurized Oxygen vessel tank. 
Figure 1-7 shows the comparison of their estimates for $\mathrm{Li}^{-\mathrm{O}_{2}}$ and other possible batteries that are currently in research and development.

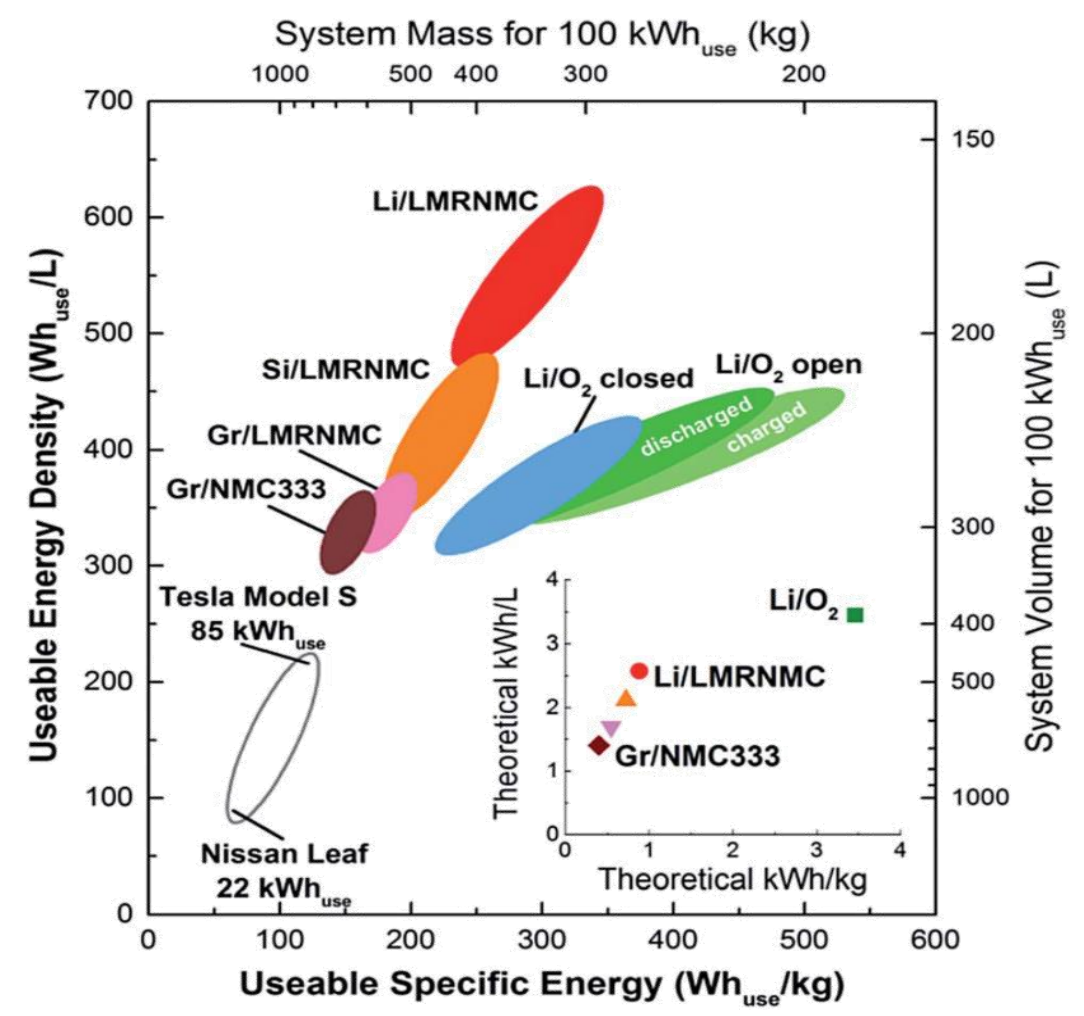

Figure 1-7: Calculated systems-level energy density and specific energy for $100 \mathrm{kWh}$ of useable energy and $80 \mathrm{~kW}$ of net power at a nominal voltage of $360 \mathrm{~V}$. (inset) Theoretical specific energy and energy density considering both anode and cathode active materials [13]

They argued that $\mathrm{Li}-\mathrm{O}_{2}$ batteries still have the highest projected useable specific energy, but are modest in comparison to this hypothetical advanced Li-ion battery using ANL Lirich advanced cathode material (LMRNMC) in terms of energy density. Comparting their usable energy density and specific energy with the theoretical one (inset of Figure 1-7) of Li- $\mathrm{O}_{2}$ batteries, it revealed that their estimated usable energy density and specific energy of $\mathrm{Li}-\mathrm{O}_{2}$ batteries are on order of magnitude smaller than a theoretical one, which is very 
pessimistic. However, it is worth mentioning that their projections are based on the existing oxygen handling technology, and they did not consider any technological improvements in this aspect of the advanced batteries. Furthermore, other battery chemistries will undoubtedly compete with Li-air for the future EV since each of these battery chemistries now has their own technical challenges. For instance, advanced Li-ion batteries mentioned in Figure 1-7 using Li metal anode and Li-rich cathode material might give a practical, specific energy of $\sim 300 \mathrm{Wh} \cdot \mathrm{kg}^{-1}$ and an energy density of $600-800 \mathrm{Wh} \cdot \mathrm{L}^{-1}[14]$. However, this also requires solving technical challenges of Li metal as an anode and the capacity fading in Li-rich cathodes. Thus, at this stage, there are a lot of uncertainties to pick a suitable chemistry among beyond Li-ion and advanced Li-ion batteries for future EVs.

\subsection{Fundamental mechanisms of $\mathrm{Li}^{-} \mathrm{O}_{2}$ batteries}

The first primary lithium-air batteries were introduced by Littauer and Tsai in 1974 in which an aqueous alkaline solution was used as an electrolyte [15]. In their batteries, typical open circuit voltage was about $2.9-3.0 \mathrm{~V}$, and a cell voltage of $2.0 \mathrm{~V}$ was achieved at current densities of approximately $200 \mathrm{~mA} \cdot \mathrm{cm}^{-2}$. The current efficiency of their cell was governed by the ratio of two competing reactions:

(1) Oxygen reduction at the cathode: $2 \mathrm{Li}+\mathrm{O}_{2} \leftrightarrow \mathrm{Li}_{2} \mathrm{O}_{2}$

(2) Corrosion of $\mathrm{Li}$ anode: $2 \mathrm{Li}+2 \mathrm{H}_{2} \mathrm{O} \leftrightarrow 2 \mathrm{LiOH}+\mathrm{H}_{2}$

In their batteries, at OCV and low current density, self-discharge of the lithium anode was rapid, so the electrochemical efficiency of the cell was very low.

The first rechargeable Li-air battery was developed by Abraham and Jang [16] using a gel polymer electrolyte (GPE) containing a nonaqueous electrolyte. The cell consisted of a 
lithium metal as an anode, a GPE and a carbon air electrode with a catalyst. Their GPEs consist of polyacrylonitrile (PAN) and a carbonate-based electrolyte containing LiPF6 lithium salt. The observed OCV was around $3.0 \mathrm{~V}$ at room temperature, and the formation of lithium peroxide $\left(\mathrm{Li}_{2} \mathrm{O}_{2}\right)$ on the surface of cathode after discharge was also confirmed. The capacity of the nonaqueous Li-air battery depends on the weight of the carbon cathode and its surface area as the discharge products $\mathrm{Li}_{2} \mathrm{O}_{2}$ is insoluble in nonaqueous electrolytes. In 2002, Read [17] developed a high capacity carbon air electrode using super P carbon black in a carbonate-based electrolyte (propylene carbonate (PC) and diethyl carbonate (DME)) containing LiPF6 lithium salt. In 2006, Bruce and his coworkers reported the possibility of improved cycling of Li-air battery by using Super P carbon black with an electrolytic manganese dioxide. However, in 2010, Mizuno et al. [18] was reported that the lithium carbonate and lithium alkyl carbonate are the main discharge products, instead of $\mathrm{Li}_{2} \mathrm{O}_{2}$ in carbonate-based electrolytes. In the following years, other electrolytes like etherbased electrolyte $[19,20]$ were developed for Li-air batteries.

Currently, four types of $\mathrm{Li}$-air $\left(\mathrm{Li}-\mathrm{O}_{2}\right)$ are designed or are under development based on the electrolytes used: aprotic nonaqueous, aqueous, solid-state and hybrid (aqueous/nonaqueous) [21]. 

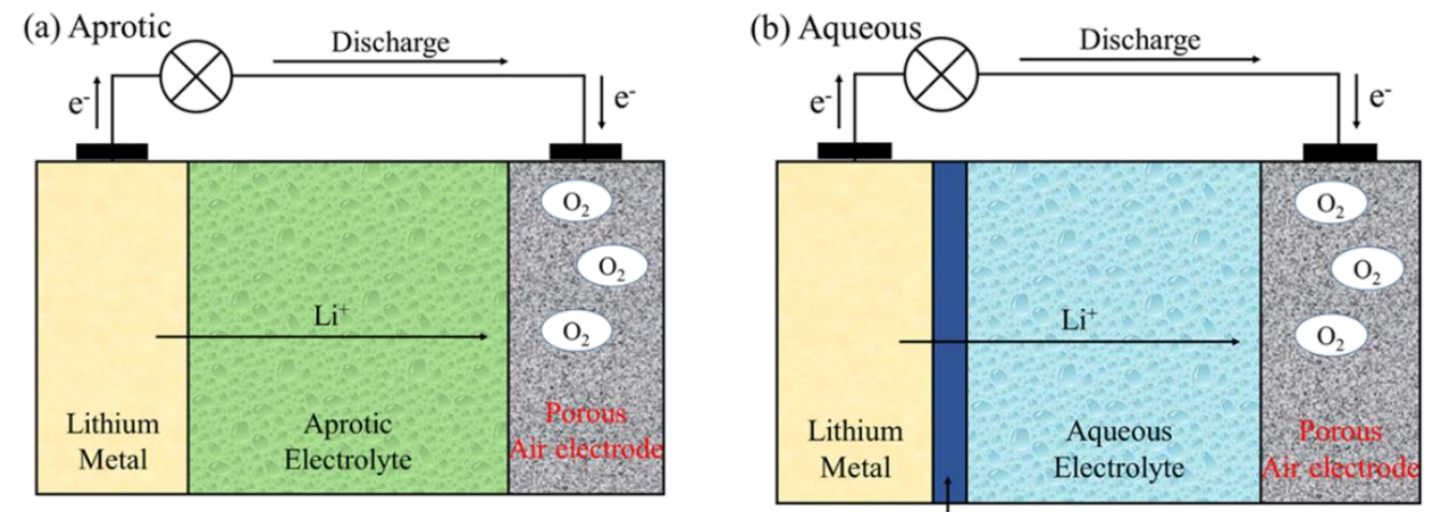

Li metal protection film
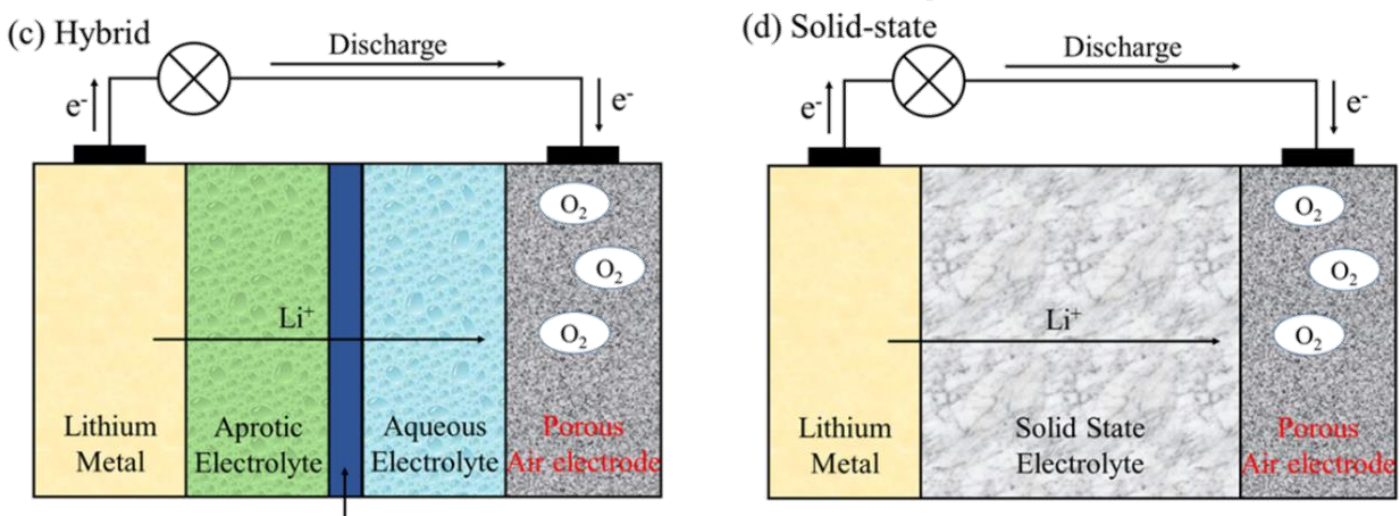

Figure 1-8: Different types of $\mathrm{Li}-\mathrm{O}_{2}$ batteries based on their electrolytes [21]

As can be seen from Figure 1-8, for all types of $\mathrm{Li}-\mathrm{O}_{2}$ batteries, an open system is necessary to get oxygen from the air and Li metal must also be used as the metal anode electrode to provide the lithium source for all the systems at the current stage. The configuration of $\mathrm{Li}-\mathrm{O}_{2}$ cells differs depending on the electrolyte employed. For instance, in the aqueous and hybrid aqueous/aprotic cells, a protective layer for $\mathrm{Li}$ meta is required to prevents the vigorous reaction of lithium with water. In aprotic $\mathrm{Li}^{-} \mathrm{O}_{2}$ cells, porous carbon with sufficient surface area must be used as a cathode to serves as the reservoir for the insoluble discharge products. Of all $\mathrm{Li}-\mathrm{O}_{2}$ batteries, aprotic nonaqueous batteries have 
gained much attention due to their similarities to the conventional Li-ion cells. In a typical $\mathrm{Li}-\mathrm{O}_{2}$ battery, the cell consists of Li metal as an anode and porous carbonaceous air cathode and $\mathrm{Li}^{+}$containing aprotic electrolyte separating the cathode and anode. Figure 1-9 shows the discharge/charge mechanism of $\mathrm{Li}-\mathrm{O}_{2}$ battery in the nonaqueous electrolyte [12].
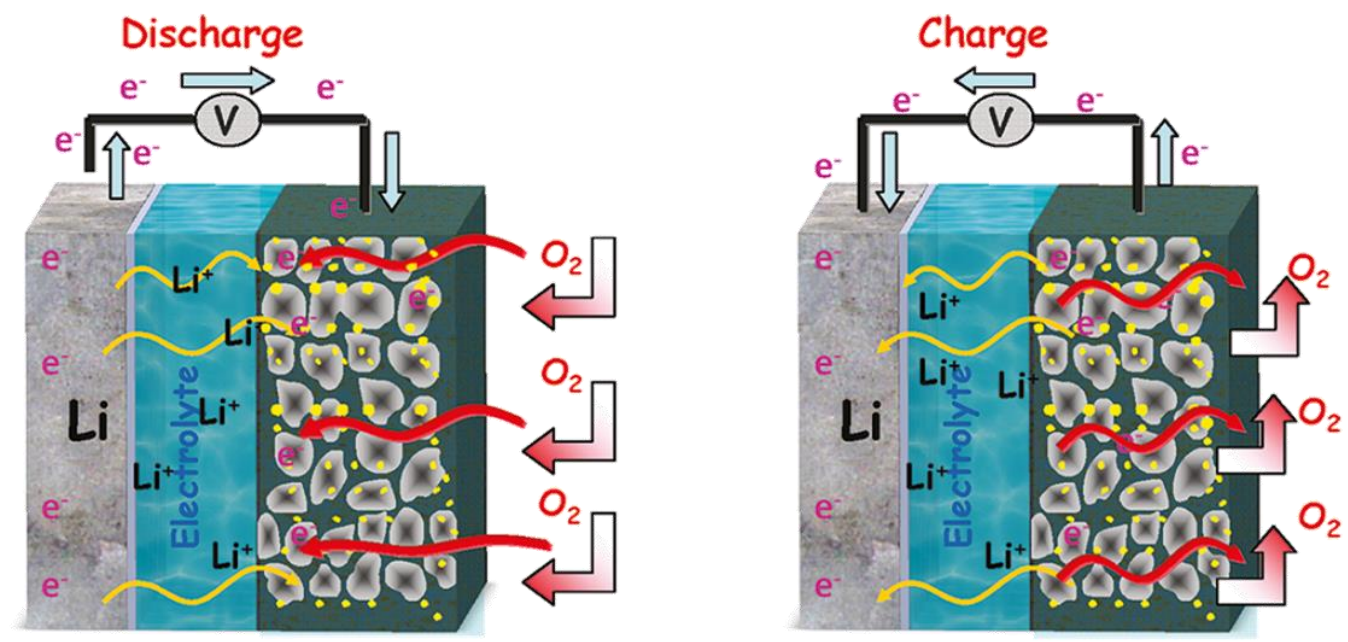

Figure 1-9: The discharge/charge mechanism of $\mathrm{Li}^{-} \mathrm{O}_{2}$ battery in the liquid nonaqueous electrolyte [12]

During discharge, an oxidation reaction occurs at the anode $\left(\mathrm{Li} \rightarrow \mathrm{Li}^{+}+\mathrm{e}^{-}\right)$and electrons flow through an external circuit, and the $\mathrm{Li}^{+}$ions generated from this reaction are transferred to the cathode through the electrolyte. At the cathode, the $\mathrm{Li}^{+}$reduce oxygen to form $\mathrm{Li}_{2} \mathrm{O}_{2}$. Standard potential for the overall cell reaction, $\mathrm{U}_{0}$, can be calculated by the Nernst equation as follows:

$2 \mathrm{Li}(\mathrm{S})+\mathrm{O}_{2}(g) \leftrightarrow \mathrm{Li}_{2} \mathrm{O}_{2}(S), \quad U_{0}=2.96 \mathrm{~V} \quad$ Vs. Li 
In charge, the above reaction is revered, and lithium metal is plated out on the anode, and $\mathrm{O}_{2}$ is evolved at the cathode. The forward reaction happening in discharge is known as oxygen reduction reaction (ORR), and backward reaction is occurring in charge is knows as oxygen evolution reaction (OER). Figure 1-10 shows a typical charge/discharge curve known as voltage profile of $\mathrm{Li}^{-\mathrm{O}_{2}}$ battery [12]. As can be seen, the working voltage of this cell during discharge is approximately between 2.6 and $2.7 \mathrm{~V}$, which is significantly less than the thermodynamical cell voltage, $2.96 \mathrm{~V}$. This difference is called the discharge overpotential $\eta$ dis. During galvanostatic charging of the cell, the voltage increases to approximately $4.0 \mathrm{~V}$. Hence the charge overpotential ( $\eta \mathrm{chg})$ is significantly greater than the discharge overpotential ( $\eta$ dis). The electrical energy efficiency for a charge/discharge cycle is only $65 \%(2.6 \mathrm{~V} / 4.0 \mathrm{~V}=65 \%)$ [12].

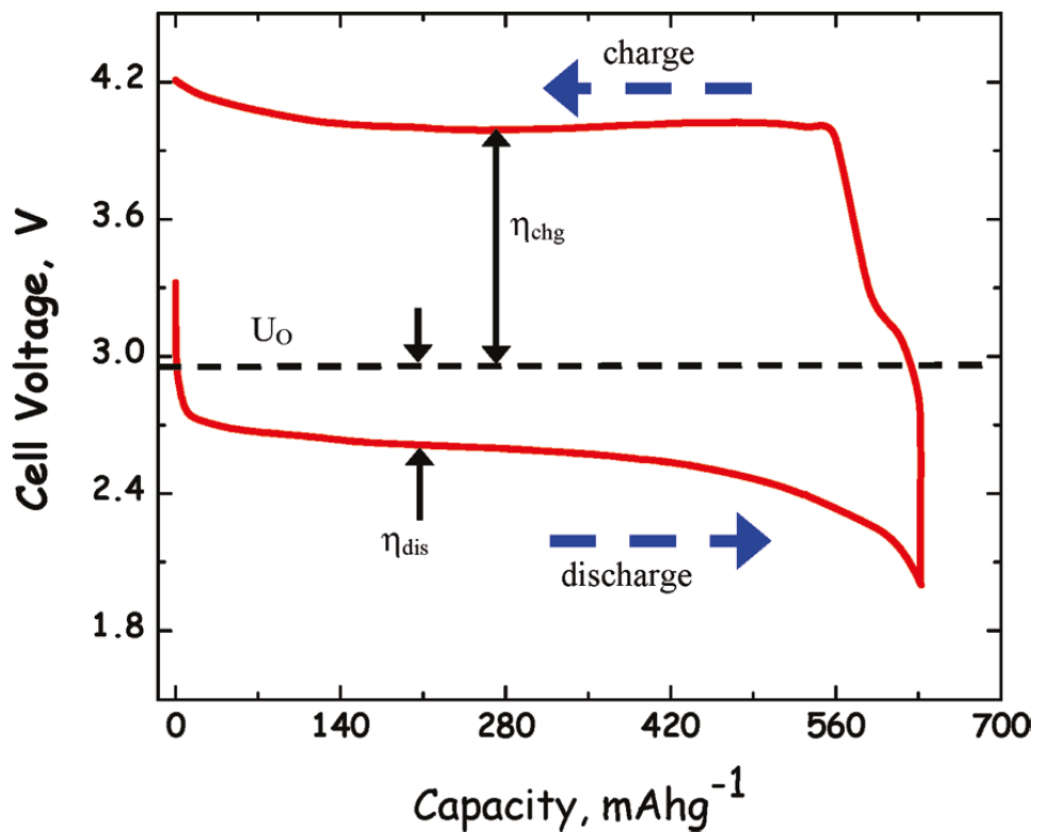

Figure 1-10: Typical voltage profile (charge/discharge curve) of Li-O2 battery along with its overpotentials [12] 
Many factors influence the charge or discharge overpotentials such as the deposition of side reaction products from the electrolyte and electrode degradation [22,23]. For example, the discharge processes depend on some competitive factors such as effective current density and voltage cut-off (overpotential) and whether the $\mathrm{LiO}_{2}$ intermediate which is formed during discharge is dissolved in solution or adsorbed on the electrode surface. At high overpotentials and high current densities, $\mathrm{O}_{2}$ is reduced to form $\mathrm{Li}_{2} \mathrm{O}_{2}$, which grows as a film on the electrode surface [24,25]. However, at low current densities and overpotentials, $\mathrm{Li}_{2} \mathrm{O}_{2}$ can grow as surface films or large toroid-shape particles from a solution process, depending on the solvent or salt from which the electrolyte solution is formed or depending on additives in the electrolyte solution [26,27]. Figure 1-11 illustrates two different $\mathrm{Li}_{2} \mathrm{O}_{2}$ formation mechanism at low current density depending on the donor number of solvent used in electrolyte [23].

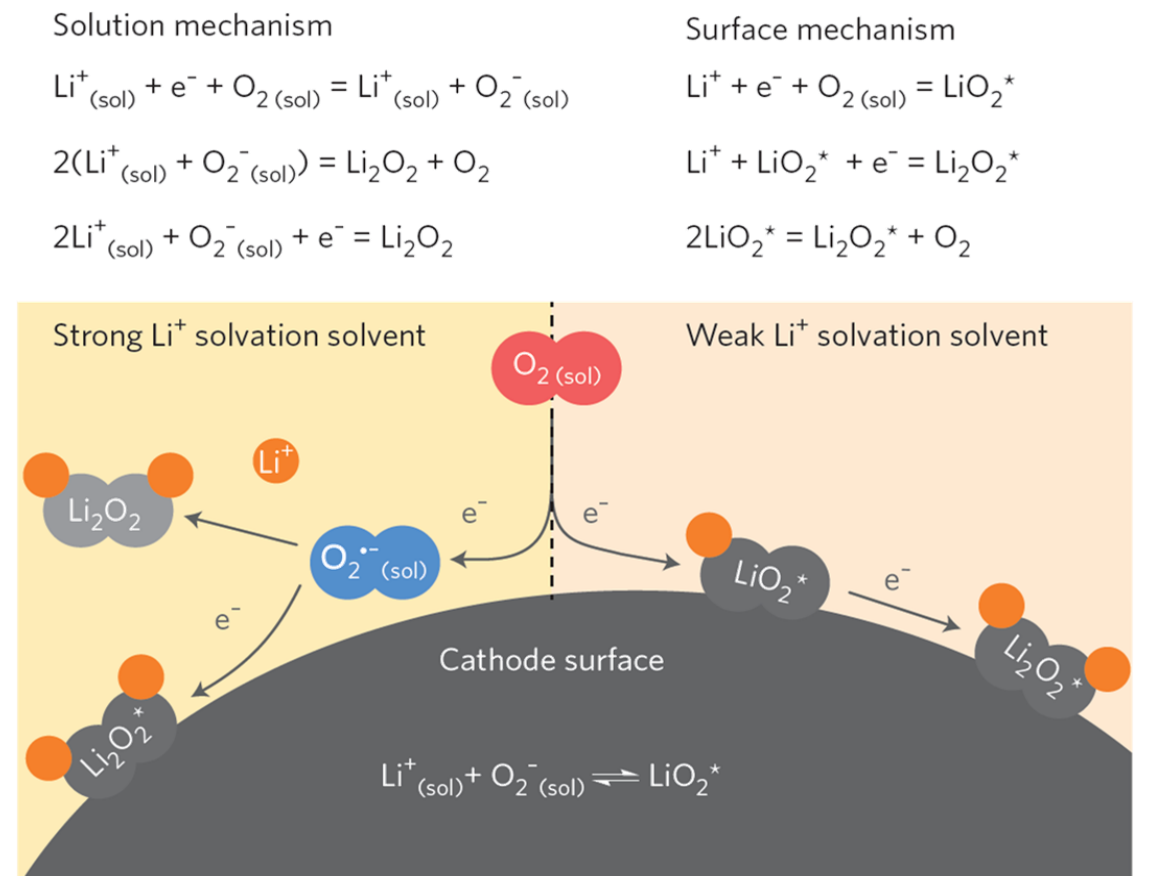

Figure 1-11: Reduction mechanisms in a $\mathrm{Li}-\mathrm{O}_{2}$ cell at low overpotentials depending on the donor number (DN) of solvent [23] 
In a high donor number (DN) solvent, $\mathrm{O}_{2}^{-}$is generated during discharge and dissolved in the electrolyte. Once the concentration of $\mathrm{O}_{2}^{-}$reaches the solubility limit, it precipitates with $\mathrm{Li}^{+}$to produce $\mathrm{LiO}_{2}$ on cathode surface and gets reduced or disproportionate to $\mathrm{Li}_{2} \mathrm{O}_{2}$ (solution-mediated formation). Large toroid-shaped $\mathrm{Li}_{2} \mathrm{O}_{2}$ can be formed via this mechanism, and accordingly, large discharge capacities can be obtained. On the other hand, in a low donor number solvent, $\mathrm{LiO}_{2}$ is generated and deposited on cathode surface and further reduced via a disproportional or electrochemical process to form a $\mathrm{Li}_{2} \mathrm{O}_{2}$ film on the cathode (surface-mediated formation). Figure 1-12 shows the scanning electron micrographs of toroid-shaped $\mathrm{Li}_{2} \mathrm{O}_{2}$ (solution-mediated formation) with the conformal film $\mathrm{Li}_{2} \mathrm{O}_{2}$ (surface-mediated formation) [26].
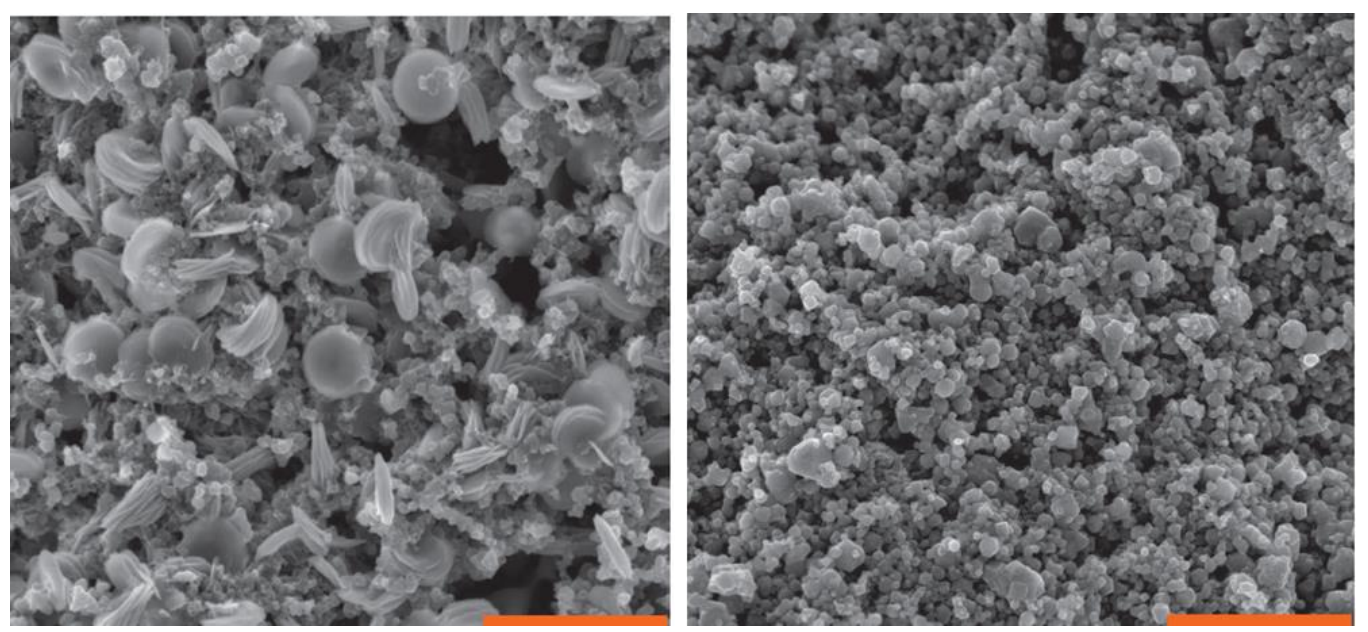

Figure 1-12: Scanning electron micrographs (right) of toroid-shape $\mathrm{Li}_{2} \mathrm{O}_{2}$ (solution-mediated formation) along with the (left) conformal film formation of $\mathrm{Li}_{2} \mathrm{O}_{2}$ (surface-mediated formation) on the Super P carbon black [26] 


\subsection{Challenges and degradation mechanisms in $\mathrm{Li}-\mathrm{O}_{2}$ batteries}

Despite many research studies on the $\mathrm{Li}_{-}-\mathrm{O}_{2}$ batteries, they are still in their infancies, and many technical and fundamental challenges remains to be addressed before their commercialization [28]. Figure 1-13 depicts the summary of current challenges in $\mathrm{Li}^{-} \mathrm{O}_{2}$ batteries.

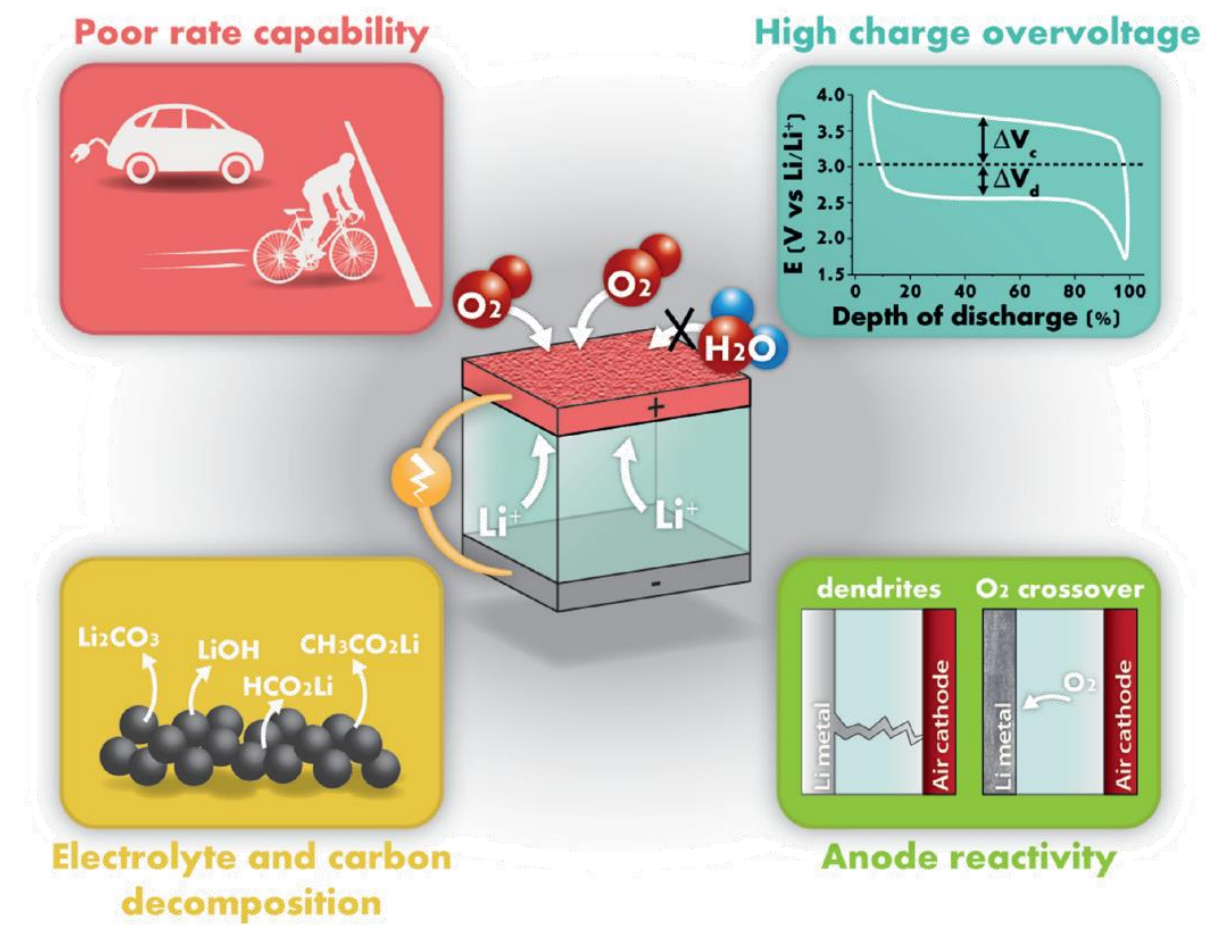

Figure 1-13: Summary of current challenges in $\mathrm{Li}^{-} \mathrm{O}_{2}$ batteries [28]

Up to now, most of the research studies on $\mathrm{Li}-\mathrm{O}_{2}$ batteries have used only limited current densities (one or two orders of magnitude lower than those utilized in commercial Li-ion batteries), so the rate capability of $\mathrm{Li}-\mathrm{O}_{2}$ batteries must improve significantly to make them competitive with current Li-ion batteries. If the higher current densities cannot be achieved, the increase in $\mathrm{O}_{2}$ flow can be considered as an alternative solution for transport 
applications. Advanced chemical and electrochemical techniques have revealed that, to some degree, all components of $\mathrm{Li}^{-\mathrm{O}_{2}}$ battery undergo undesirable chemical/electrochemical changes during discharge/charge cycling.

\subsubsection{Lithium Anode Degradation}

Metallic lithium is the main anode material used in $\mathrm{Li}-\mathrm{O}_{2}$ batteries due to its extremely low weight, the low negative potential (-3.04 vs. standard hydrogen electrode (SHE)) and high specific energy $\left(11680 \mathrm{Wh} \cdot \mathrm{kg}^{-1}\right)$. The usage of Li metal has its own safety concerns as the formation of lithium dendrites during repetitive lithium dissolution/deposition can result in poor cycling stability and internal short-circuiting. However, $\mathrm{Li}^{-} \mathrm{O}_{2}$ battery failure owing to the dendrite growth has not been reported yet [29]. Recent studies have identified the reaction of Li metal with charge/discharge products and $\mathrm{O}_{2}$ cross over from the cathode in $\mathrm{Li}-\mathrm{O}_{2}$ batteries [30-33]. Figure 1-14 illustrates the possible reaction is happening at the surface of the anode in $\mathrm{Li}-\mathrm{O}_{2}$ batteries.

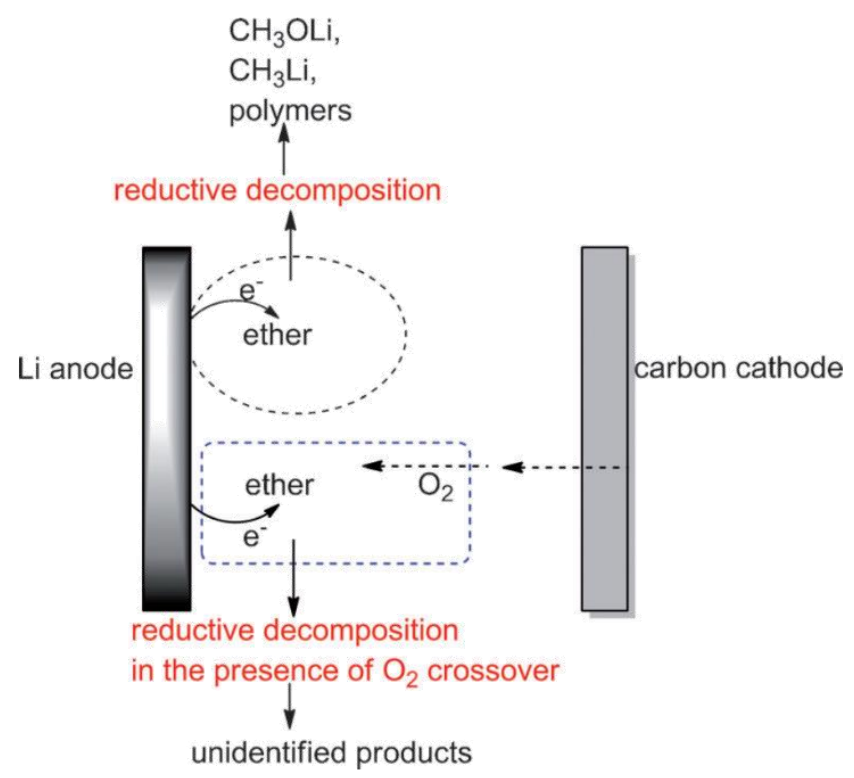

Figure 1-14: Possible Li metal reactions with electrolyte with/out $\mathrm{O}_{2}$ [30] 
Advanced approaches such as using oxygen and humidity impermeable separators [34] and artificial protective films [35] on the lithium have been proposed to minimize the Li anode degradation. Furthermore, replacement of lithium metal anode with lithiated carbon composites has also been proposed [36,37].

\subsubsection{Cathode Degradation}

As the main discharge products $\left(\mathrm{Li}_{2} \mathrm{O}_{2}\right)$ of aprotic $\mathrm{Li}-\mathrm{O}_{2}$ batteries are insoluble in the electrolyte, they must be stored in a porous conductive matrix. Carbon in different allotropes have been used as cathode materials due to their high electronic conductivity, low cost, ease of fabrication and ability to catalyzed the ORR/OER [38,39]. However, recent studies confirmed that carbon can react with discharge products and decompose during both discharge and charge in $\mathrm{Li}-\mathrm{O}_{2}$ batteries. It has been reported that carbon is chemically unstable above $3.5 \mathrm{~V}$ in the presence of $\mathrm{Li}_{2} \mathrm{O}_{2}$ and decompose to the lithium carbonates [22]. McCloskey et al. [22] reported that lithium carbonate $\left(\mathrm{Li}_{2} \mathrm{CO}_{3}\right)$ and lithium alkyl carbonates $(\mathrm{LiRCO} 3)$ could be produced at the carbon- $\mathrm{Li}_{2} \mathrm{O}_{2}$ interface and $\mathrm{Li}_{2} \mathrm{O}_{2}-$ electrolyte interface, respectively due to the reaction of discharge product with Carbon cathode and electrolyte. Carbonate formation leads to an extra overpotential during charge, and subsequently, carbon reacts chemically with $\mathrm{Li}_{2} \mathrm{O}_{2}$ during charge to produce more lithium (Figure 1-15). 


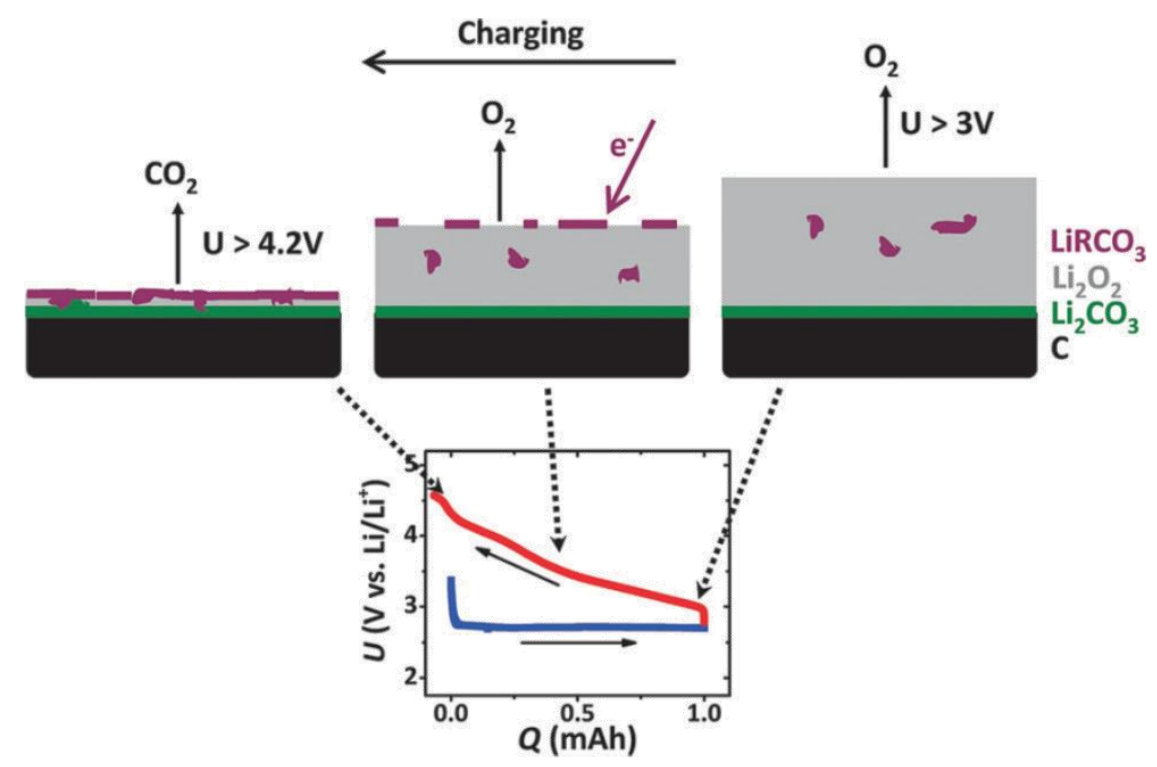

Figure 1-15: Proposed carbonate formation mechanism due to the reactivity of discharge products with carbon and electrolyte [22]

Due to the instability of carbon as cathode materials, many research has been devoted to replacing carbon. Bruce et al. [40] proposed nanoporous gold (NPG) cathode as a stable cathode for $\mathrm{Li}-\mathrm{O}_{2}$ batteries. Although NPG was stable and kinetics of $\mathrm{Li}_{2} \mathrm{O}_{2}$ oxidation was demonstrated to be faster than that of carbon cathodes, NPG cathodes are not suitable for cathode due to their high mass of gold, which in turn reduce the specific energy of $\mathrm{Li}-\mathrm{O}_{2}$ batteries significantly. Metal oxides [41] and metal carbides [42] have also been suggested for cathode materials. However, other side reactions were also reported for non-carbon cathodes [42].

\subsubsection{Electrolyte Degradation}

Despite many technological advanced in the development of stable cathode and anode for $\mathrm{Li}-\mathrm{O}_{2}$ batteries, electrolytes remain as a leading cause of rapid capacity fading and poor 
cyclability [43]. The reactive oxygen species such as $\mathrm{O}_{2}^{-}, \mathrm{LiO}_{2}, \mathrm{Li}_{2} \mathrm{O}_{2}$ and its depravities are expected to coexist with molecular $\mathrm{O}_{2}$ in the electrolyte owing to the ORR/OER and possible reaction between $\mathrm{Li}$ metal and dissolved $\mathrm{O}_{2}[44,45]$. The reaction between these reactive oxygen species with electrolytes has been considered as the main reason for electrolyte decomposition [46]. In general, the electrolyte decomposition pathways can be categorized into five groups as illustrated in Figure 1-16: (1) nucleophilic attacks, (2) autooxidation, (3) acid-base reactions, (4) proton-mediated reactions, and (5) reduction by $\mathrm{Li}$ [45].

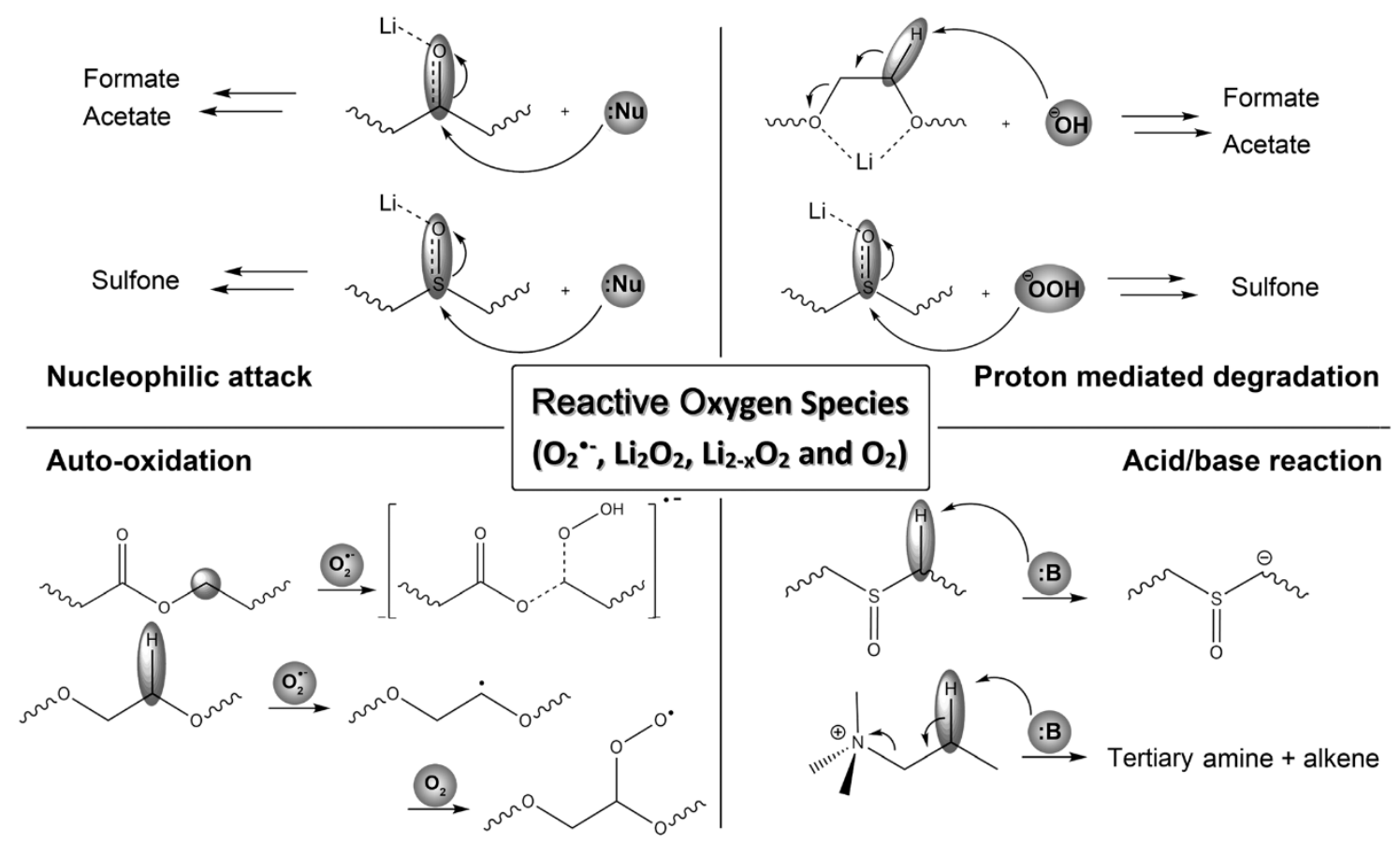

Figure 1-16: Schematic pathways of electrolyte decomposition by reactive oxygen species [45]

The decomposition mechanism is dependent on the chemistry of electrolyte used mostly solvent. In the following section, each of these decomposition pathways will be discussed briefly. 


\subsection{Electrolytes for $\mathrm{Li}-\mathrm{O}_{2}$ batteries}

As mentioned earlier, the electrolyte has a profound influence on the reactions that occur at the anode and cathode and hence the overall cell operation of the nonaqueous $\mathrm{Li}_{-} \mathrm{O}_{2}$ batteries. Electrolytes in $\mathrm{Li}_{-} \mathrm{O}_{2}$ batteries need to have some certain requirements.

Table 1-3: Requirements on electrolytes for the nonaqueous $\mathrm{Li}-\mathrm{O}_{2}$ battery [15]

\begin{tabular}{ll}
\hline Conductivity & - Sufficiently high for the anticipated rate capability \\
Stability & - Within potential window used on discharge and charge \\
& - In contact with $\mathrm{O}_{2}$ and its reduced species on discharge \\
& - In contact with $\mathrm{Li}_{2} \mathrm{O}_{2}$ and its intermediates on charge \\
& - In contact with the anode or a stable $\mathrm{SEI}$ formed on the anode \\
Low volatility & - To minimise evaporation at the porous $\mathrm{O}_{2}$ cathode \\
$\begin{array}{l}\mathrm{O}_{2} \text { solubility and diffusivity } \\
\text { Able to wet the electrode } \\
\text { surfaces }\end{array}$ & - To ensure adequate rate of mass transport to the cathode \\
$\begin{array}{l}\text { Promotes some solubility } \\
\text { of } \mathrm{Li}_{2} \mathrm{O}_{2}\end{array}$ & $\begin{array}{c}\text { Interaction with intermediates for high rate and packing density } \\
\text { Safety, low cost and toxicity }\end{array}$ \\
\hline
\end{tabular}

In the early stages of $\mathrm{Li}-\mathrm{O}_{2}$ battery research, organic carbonate-based electrolytes were widely used. However, it has been shown that the organic carbonates are unstable in $\mathrm{Li}^{-} \mathrm{O}_{2}$ cells and a little or no evidence for $\mathrm{Li}_{2} \mathrm{O}_{2}$ formation on discharge was reported [47]. The nucleophilic attacks by $\mathrm{O}_{2}^{-}$to the $\mathrm{C}=\mathrm{O}$ groups of carbonate-based electrolyte produce $\mathrm{Li}$ alkyl carbonates and $\mathrm{Li}_{2} \mathrm{CO}_{3}[45,47]$. Therefore, much attention shifted to other aprotic electrolytes for a $\mathrm{Li}-\mathrm{O}_{2}$ battery application.

\subsubsection{Aprotic Liquid Electrolytes for $\mathrm{Li}_{-} \mathrm{O}_{2}$ batteries}

Ether solvents have been intensively studied for $\mathrm{Li}-\mathrm{O}_{2}$ batteries owing to their intermediate $\mathrm{DN}$, which leads to the formation of both surface- and solution-mediated $\mathrm{Li}_{2} \mathrm{O}_{2}$ formation. They are also compatible with a lithium metal anode, stable to oxidation potentials up to 4 
$\mathrm{V}$ versus $\mathrm{Li} / \mathrm{Li}^{+}$, safe, low cost and low vapor pressure for higher molecular weights, such as tetraglyme (TEGDME) [15]. Various ether-based electrolytes in a linear form (glyme family) and a cyclic form such as 1,3-dioxolane have been explored. However, recent studies have confirmed that the decomposition of ether-based electrolytes also takes place gradually during cycling of $\mathrm{Li}-\mathrm{O}_{2}$ batteries to form lithium carbonates. The parasitic formation of these carbonates on the cathode eventually causes the battery failure [48]. It has been shown that the ether-based electrolyte undergoes decomposition by autooxidation mechanism in which superoxide radicals react with $\alpha-\mathrm{H}$ in ethers [45].

Esters could also have been considered a good choice as electrolytes in the $\mathrm{Li}^{-} \mathrm{O}_{2}$ batteries due to their high dielectric constant and low viscosity. However, most of the Ester solvents are prone to reaction with lithium metal [46]. Further, it has been shown that the Esters can be decomposed by the nucleophilic attacks [45].

Amides also are a major class of solvent that are known to be highly stable against nucleophilic attack and have been extensively studied for $\mathrm{Li}_{2} \mathrm{O}_{2}$ batteries. Dimethylformamide (DMF) and N, N-dimethylacetamide (DMA) were investigated for the $\mathrm{Li}-\mathrm{O}_{2}$ battery applications. DMF could form $\mathrm{Li}_{2} \mathrm{O}_{2}$ upon discharge, and it decomposed upon charge, but some degree of side reactions upon cycling with the accumulation of $\mathrm{Li}_{2} \mathrm{CO}_{3}, \mathrm{HCO}_{2} \mathrm{Li}$, and $\mathrm{CH}_{3} \mathrm{CO}_{2} \mathrm{Li}$ were also reported [46,49]. In the case of DMA, high reactivity toward $\mathrm{Li}$ anode has been reported, which leads to the formation of unstable solid-electrolyte interphase (SEI). Unstable SEI formation on the anode could result in the formation of soluble decomposition products that are oxidized at the cathode surface upon charging [46]. Different approaches such as adding lithium salt additives $\left(\mathrm{LiNO}_{3}\right)$ to form 
stable SEI on the anode was also proposed to make the amide-based electrolytes compatible with $\mathrm{Li}$ anode [50].

Sulfone-based electrolytes were also proposed as stable electrolytes against the superoxide attack $\left(\mathrm{O}_{2}^{-}\right)$by theoretical calculation. However, many of sulfone-based electrolytes such as ethylmethylsulfone and tetramethylenesulfone have a low melting temperature around the room temperature $\left(\sim 27^{\circ} \mathrm{C}\right)$ which make them difficult to use in ambient temperature [46]. Further, some studies have shown sulfones are not stable against superoxide attacks and also they react with Li metal anode [15].

Dimethyl Sulfoxide (DMSO) electrolytes were also considered for $\mathrm{Li}-\mathrm{O}_{2}$ battery applications. Although the formation of $\mathrm{Li}_{2} \mathrm{O}_{2}$ was confirmed in cells using DMSO, other side products resulting from electrolyte decomposition such as $\mathrm{DMSO}_{2}, \mathrm{Li}_{2} \mathrm{SO}_{3}$, and $\mathrm{Li}_{2} \mathrm{SO}_{4}$ could be formed on the surface of cathode [51]. Li metal cycling efficiency of DMSO is low due to the reactivity of DMSO with Li metal [46].

Ionic liquids with different cations such as piperidinium, imidazolium, pyrrolidinium have also been studied for $\mathrm{Li}-\mathrm{O}_{2}$ battery applications due to their negligible vapor pressure, low flammability, high ionic conductivity and superior hydrophobicity and wide electrochemical window [52]. Some recent studies have proven the improved stability of ionic liquid over organic carbonate solvents for $\mathrm{Li}-\mathrm{O}_{2}$ batteries. However, some spectroscopic investigation on the discharge/charge products of cells using ionic liquids have also confirmed the existence of lithium carbonates. The limited cyclability of $\mathrm{Li}-\mathrm{O}_{2}$ cells using IL-based electrolytes and carbon electrodes suggests that side reactions are an issue that requires deeper investigation to confirms that these side reactions come from carbon decomposition or electrolyte decomposition [15]. 


\subsubsection{Solid-State Electrolytes for $\mathrm{Li}-\mathrm{O}_{2}$ batteries}

Solid-state electrolytes are considered competitive alternatives to liquid electrolytes for $\mathrm{Li}$ $\mathrm{O}_{2}$ batteries as they are safe, low cost, durable and flexible. They could also offer wider operational temperature range, and possibly longer cycle life owing to their ability to prevent lithium dendrite formation. The solid-state electrolytes are generally categorized into two general classes depending on their materials used: (1) $\mathrm{Li}^{+}$ion conducting inorganic ceramics and (2) organic polymers. In the $\mathrm{Li}-\mathrm{O}_{2}$ cells, the advantage of solid-state electrolytes is that they act as a substantial barrier against diffusion of ambient gases and moisture toward the Li metal anode, and can also sustain a high operational temperature. These attractive features are the main driving force behind the development of $\mathrm{Li}^{-} \mathrm{O}_{2}$ cells with solid electrolytes [46,53].

\subsubsection{Ceramic Electrolytes}

Ceramic electrolytes have also been explored for $\mathrm{Li}_{-} \mathrm{O}_{2}$ batteries due to their relatively high $\mathrm{Li}^{+}$conductivity, high thermal and chemical stability. Various types of ceramic electrolytes including sulfide, oxides, and phosphate were investigated in Li-ion batteries; however, only a few of them are employed in $\mathrm{Li}^{-} \mathrm{O}_{2}$ batteries [54]. A family of ceramic electrolytes belong to $\mathrm{Li}-\mathrm{Al}-\mathrm{Ge}-\mathrm{PO}_{4}(\mathrm{LAGP})$ and $\mathrm{Li}-\mathrm{Al}-\mathrm{Ti}-\mathrm{PO}_{4}$ (LATP) systems, which possess relatively high ionic conductivity in the range of $10^{-4}-10^{-5} \mathrm{~S} \cdot \mathrm{cm}^{-1}$ are a good fit for $\mathrm{Li}-\mathrm{O}_{2}$ batteries. The first ceramic electrolyte in $\mathrm{Li}_{-} \mathrm{O}_{2}$ batteries was reported by Kumar et al. [55] in which they investigated a LAGP ceramic electrolyte with a chemical composition of $\mathrm{Li}_{1+x} \mathrm{Al}_{x} \mathrm{Ge}_{2-\mathrm{x}}\left(\mathrm{PO}_{4}\right)_{3}(\mathrm{x}=0.5)(\mathrm{LAGP})$ as a solid-state electrolyte for $\mathrm{Li}^{-\mathrm{O}_{2}}$ batteries. They suggested that LAGP-type ceramic electrolytes could also participate in $\mathrm{Li}_{2} \mathrm{O}_{2}$ formation [56]. Despite many attempts in the development of ceramic electrolytes with high ionic 
conductivity, the high interfacial resistance between ceramic electrolyte/electrodes prevented the practical use of the solid-state ceramic at ambient temperature.

\subsubsection{Solid polymer electrolytes}

The first concept of solid polymer electrolytes (SPEs) was introduced by Prof. Peter Wright [57] in early 1973, and then their technological importance as a new class of electrolytes was discovered in the 1990s by Prof. M. Armand [58]. Since then, numerous polymer systems have been studied for lithium batteries, such as poly(ethylene) oxide (PEO). The PEO-based solid polymer electrolytes showed low ionic conductivity, poor mechanical properties, and narrow electrochemical window. Hence, many attempts have been made to explore solid new solid polymer electrolytes for lithium battery applications, such as composite polymer electrolytes, block copolymer electrolytes, and single-ion polymer electrolytes [53]. Solid polymer electrolytes (SPEs) have also been explored for $\mathrm{Li}^{-\mathrm{O}_{2}}$ battery applications as they could offer a relatively high stability compared to the nonaqueous liquid electrolytes and a good protection for lithium anode to directly react with $\mathrm{O}_{2}$ or $\mathrm{H}_{2} \mathrm{O}$. However, recent studies have shown that the chemical stability of polymers used in SPEs is questionable in the presence of discharge products [59]. Figure 1-17 illustrates the common polymer and their structures used in SPEs. 


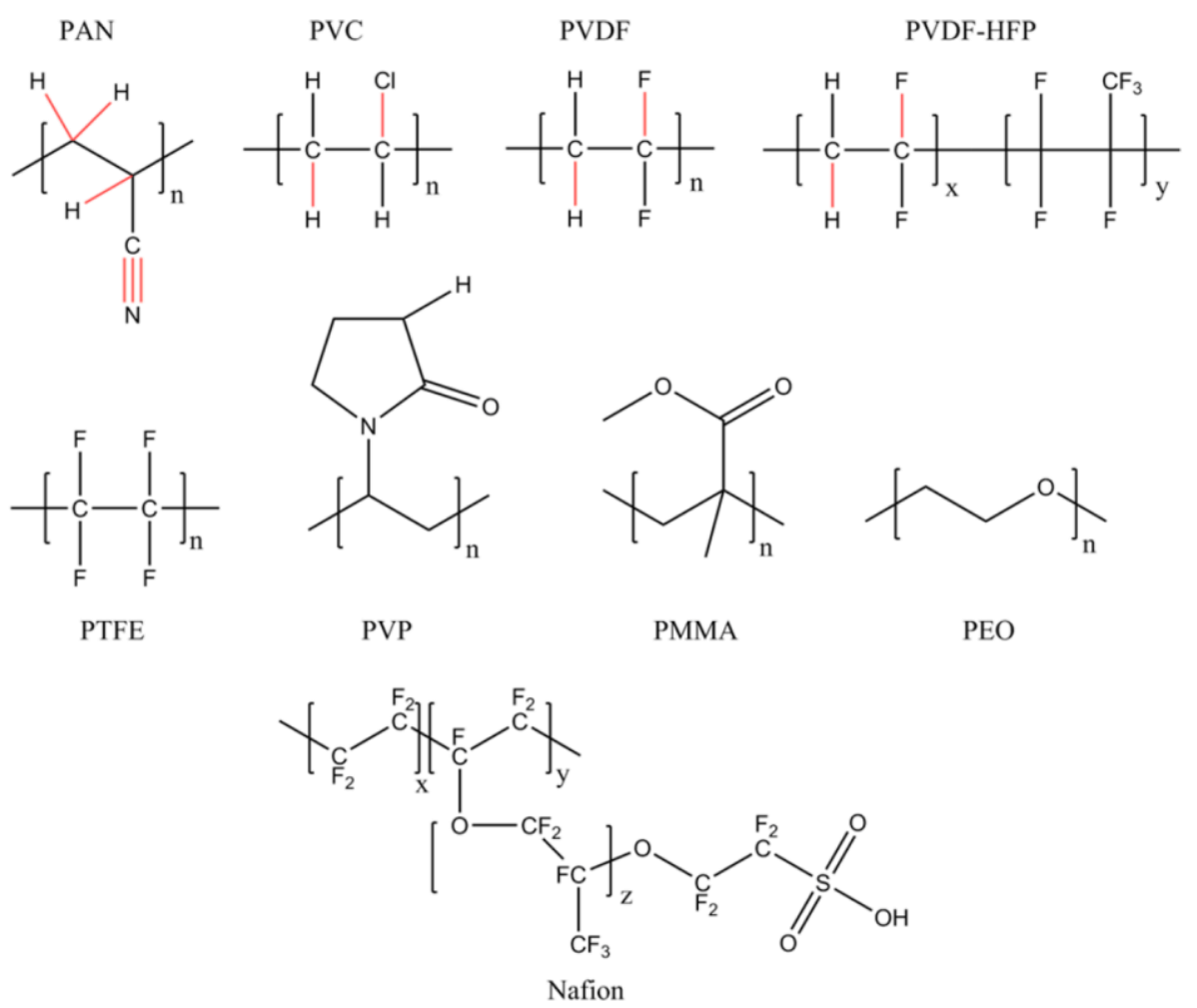

Figure 1-17: List of common polymers and their structures used in SPEs [59]

In SPE-based $\mathrm{Li}_{-} \mathrm{O}_{2}$ batteries, the overall capacity is limited due to the absence of a liquid solution. Thus, most reported SPE-based $\mathrm{Li}_{-} \mathrm{O}_{2}$ batteries were fabricated with thin and large-area carbon electrodes to obtain an acceptable capacity. Although impressive progress has been made on SPEs, the mechanism of ORR and OER in SPE-based $\mathrm{Li}^{-\mathrm{O}_{2}}$ batteries is not yet identified. Moreover, the low ionic conductivity of SPEs shows poor reversible capacity [53].

\subsubsection{Gel Polymer Electrolytes}

Solid polymer electrolytes (SPEs) can be swollen with a liquid plasticizer to form gel polymer electrolytes (GPEs). These GPEs offer the ideal mechanical properties of SPEs 
along with high ion conductivity of liquid counterparts. The first reported non-aqueous LiO2 battery was based on GPE containing polyacrylonitrile (PAN) polymer and carbonate electrolytes [16]. Other GPEs swallow by carbonates for $\mathrm{Li}^{-\mathrm{O}_{2}}$ batteries was also reported [60]. However, using organic carbonates in their GPEs as plasticizers are questionable due to their tendency to decompose in the presence of oxygen radicals as mentioned earlier in this dissertation. Different GPEs using various polymer hosts and aprotic liquid electrolytes have been developed for $\mathrm{Li}_{2} \mathrm{O}_{2}$ batteries [61].

Table 1-4: List of SPEs and GPEs used in Li-air $\left(\mathrm{O}_{2}\right)$ batteries [61]

\begin{tabular}{|c|c|c|c|c|c|}
\hline $\begin{array}{l}\text { Electrolyte } \\
\text { type }\end{array}$ & Polymer matrix & $\begin{array}{l}\text { Ionic conductivity } \\
\left(\times 10^{-4} \mathrm{~S} \mathrm{~cm}^{-1}\right)\end{array}$ & $\begin{array}{l}\text { Electrochemical } \\
\text { window }(\mathrm{V} v \text { s. Li/Li') }\end{array}$ & $\begin{array}{l}\text { Operating } \\
\text { atmosphere }\end{array}$ & Cycle life/cycle capacity \\
\hline SPE & PAN & - & - & $\mathrm{O}_{2}$ & 3 cycles $/ \approx 100 \mathrm{mAh} \mathrm{g}^{-1}$ \\
\hline SPE & PVA & $2.85(\mathrm{RT})$ & - & Ambient air & - \\
\hline SPE & PEO & $3.2\left(55^{\circ} \mathrm{C}\right)$ & Over $4.25 \mathrm{~V}$ & $\mathrm{O}_{2}$ & - \\
\hline SPE & PEO & - & - & $\mathrm{O}_{2}$ & 40 cycles $/ \approx 210 \mathrm{mAh} \mathrm{g}^{-1}$ \\
\hline SPE & PEO & $3(\mathrm{RT})$ & Up to $4.6 \mathrm{~V}$ & $\mathrm{O}_{2}$ & 20 cycles $/ 500 \mathrm{mAh} \mathrm{g}^{-1}$ \\
\hline GPE & Natural rubber & $4.92(\mathrm{RT})$ & - & $\mathrm{O}_{2}$ & - \\
\hline GPE & $\mathrm{P}(\mathrm{VDF}-\mathrm{HFP})$ & - & - & $\mathrm{O}_{2}$ & 30 cycles/10 mAh \\
\hline GPE & $\mathrm{P}(\mathrm{VDF}-\mathrm{HFP})$ & $10(\mathrm{RT})$ & Up to $4.6 \mathrm{~V}$ & $\mathrm{O}_{2}$ & 50 cycles $/ 500 \mathrm{mAh} \mathrm{g}^{-1}$ \\
\hline GPE & $\mathrm{P}(\mathrm{VDF}-\mathrm{HFP})$ & $5.49(\mathrm{RT})$ & Up to $4.7 \mathrm{~V}$ & $\mathrm{O}_{2}$ & 40 cycles $/ 500 \mathrm{mAh} \mathrm{g}^{-1}$ \\
\hline GPE & PMMA/PSt & 1.27 (RT) & Up to $5.3 \mathrm{~V}$ & Ambient air, $\mathrm{RH}=5 \%$ & 100 cycles $/ 500 \mathrm{mAh} \mathrm{g}^{-1}$ \\
\hline GPE & PVDF & & Up to $4.7 \mathrm{~V}$ & $\mathrm{O}_{2}$ & 6 cycles $/ 500 \mathrm{mAh} \mathrm{g}^{-1}$ \\
\hline GPE & PEO & - & - & $\mathrm{O}_{2}$ & 35 cycles $/ 2.54 \mathrm{mAh}$ \\
\hline GPE & $\mathrm{PVDF} / \mathrm{pBQ}$ & 49.8 (RT) & - & $\mathrm{O}_{2}$ & 40 cycles $/ 500 \mathrm{mAh} \mathrm{g}^{-1}$ \\
\hline GPE & P(VDF-HFP) & - & - & Ambient air, $\mathrm{RH}=5 \%$ & 180 cycles $/ 500 \mathrm{mAh} \mathrm{g}^{-1}$ \\
\hline GPE & $\mathrm{P}(\mathrm{VDF}-\mathrm{HFP}) / \mathrm{ETPTA}$ & $2.843\left(30{ }^{\circ} \mathrm{C}\right)$ & - & $\mathrm{O}_{2}$ & 100 cycles $/ 500 \mathrm{mAh} \mathrm{g}^{-1}$ \\
\hline GPE & $\mathrm{P}(\mathrm{VDF}-\mathrm{HFP}) / \mathrm{ETPTA}$ & $2.843\left(30^{\circ} \mathrm{C}\right)$ & - & $\mathrm{O}_{2}$ & 90 cycles $/ 500 \mathrm{mAh} \mathrm{g}^{-1}$ \\
\hline GPE & PFSA-Li & $6.4(\mathrm{RT})$ & - & $\mathrm{O}_{2}$ & 100 cycles $/ 1000 \mathrm{mAh} \mathrm{g}^{-1}$ \\
\hline
\end{tabular}

GPEs can improve the $\mathrm{Li}-\mathrm{O}_{2}$ battery performance in many ways. For example, it has been reported that the GPEs in $\mathrm{Li}-\mathrm{O}_{2}$ cell could minimize the electrolyte evaporation. GPEs could hinder the Li dendrite growth and form stable SEIs on the surface of Li metal anode [62]. They could also prevent $\mathrm{Li}$ metal corrosion by inhibiting the $\mathrm{O}_{2}$ and humidity crossover $[34,63,64]$ 


\subsection{Chemistry of Electrolyte Solution}

Solvation is a process in which solute particles (molecules or ions) in a solution interact with the solvent molecules. The solvation of a solute has a significant influence on its dissolution and on the chemical reactions in which it participates [65]. The solvation energy can be defined as the standard chemical potential differences between solute in the solution state to their gaseous state as depicted in Figure 1-18.

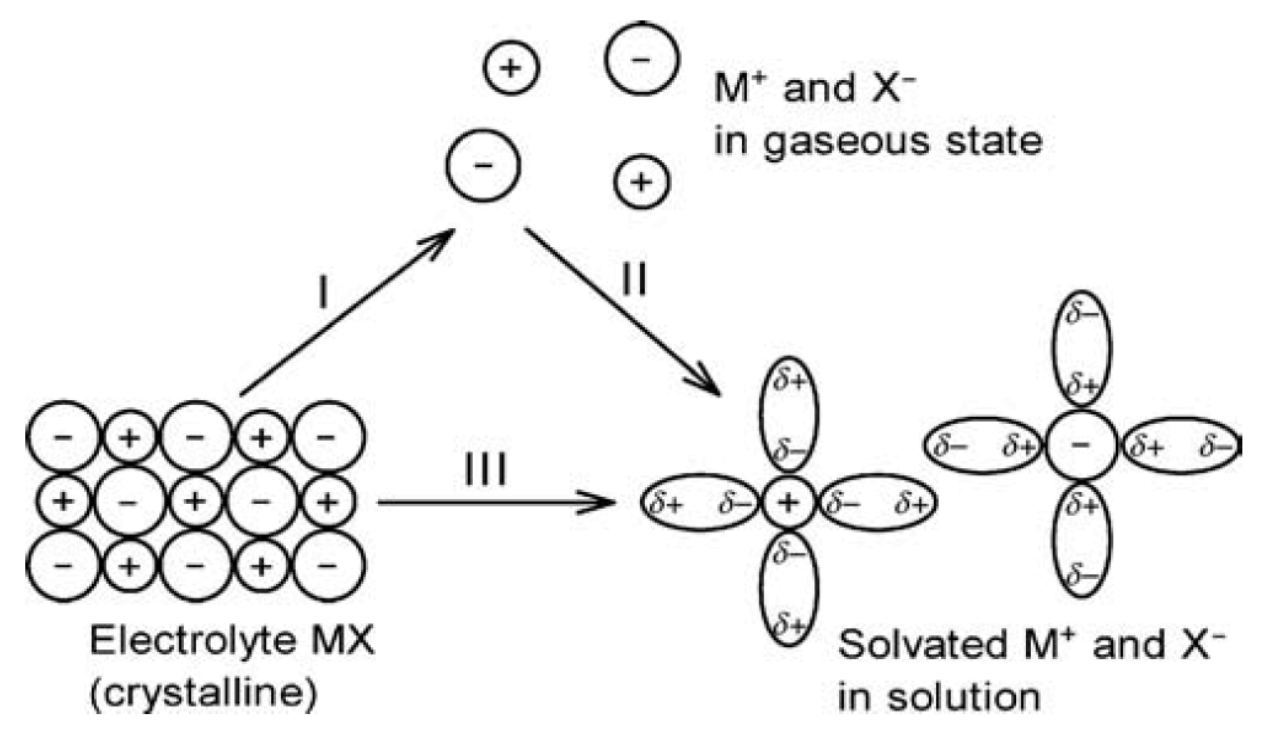

Figure 1-18: Schematic of dissolution process of solute MX in a solution [65]

As can be seen in process $\mathrm{I}, \mathrm{M}^{+}$and $\mathrm{X}^{-}$ions, which are strongly bound by electrostatic force in the crystal, are dissociated and converted to a gaseous state. In the process II, the $\mathrm{M}^{+}$and $\mathrm{X}^{-}$ions in the gas phase dissolve into the solvent by solvation process. In Process III, the crystal of MX directly dissolves into the solvent and form solvated $\mathrm{M}^{+}$and $\mathrm{X}^{-}$ions.

The Gibbs free energy of above-mentioned processes can be defined as follows: 
$\Delta G_{\mathrm{III}}^{0}=\Delta G_{\mathrm{I}}^{0}+\Delta G_{\mathrm{II}}^{0}$

If the Gibbs energy of crystal lattice $\mathrm{MX}$ is denoted by $\Delta \mathrm{G}_{\text {lat }}, \Delta \mathrm{G}_{\mathrm{I}}$ is equal to $-\Delta \mathrm{G}_{\text {lat. }}$ Also, once MX is completely dissociated into free ions in the solution, $\Delta \mathrm{G}_{\mathrm{III}}$ could be obtained as the sum of the solvation energies of $\mathrm{M}^{+}$and $\mathrm{X}^{-}$ions $\Delta \mathrm{Gsol}$. $\Delta \mathrm{G}$ III corresponds to the Gibbs energy of dissolution of MX, which is defined as $\Delta \mathrm{Gs}$, so the equation (9) can be rewritten as follows:

$\Delta G_{\mathrm{s}}^{0}=\Delta G_{\mathrm{sol}}^{0}+\Delta G_{\text {lat }}^{0}$

Generally, $\Delta G_{\text {sol }}^{0}$ and $\Delta G_{\text {lat }}^{0}$ have large negative values, yet their magnitude close to each other in magnitude. Thus, $\Delta G_{\mathrm{s}}^{0}$ is relatively small. Moreover, the solute is easily soluble if the sum of the solvation energies of the ions constituting the solutes is larger than the lattice Gibbs energy (in absolute value) or very near to it.

Equation (10) could also be expressed by the solubility constant of MX ( $\left.\mathrm{K}_{\mathrm{sp}}(\mathrm{MX})\right)$ :

$\Delta G_{\mathrm{s}}^{0}=-R T \ln K_{s p}(M X)$

In the electrolyte solutions, the interaction between ions (cations and anions) of salt and solvent molecules play a significant role in electrolyte properties such as ion transports and chemical and electrochemical behavior of electrolytes. 


\subsubsection{Ion-Solvent Interaction in Electrolytes}

As described in the previous section, the solvation is an important parameter in the dissolution of solute (MX). It has been reported that ions of solute (MX) can interact with solvent molecules in different ways $[65,66]$. Hence the solvent properties can significantly affect the electrolyte solution properties. The most important solvent properties in considering solvent effects are the solvent permittivity and the solvent acidity and basicity. For instance, if the permittivity of one solvent is high $\left(\varepsilon_{r}>40\right)$ and that of the other is low $\left(\varepsilon_{r}<10\right)$, the difference in a chemical process in the two solvents is usually attributable to the influence of permittivity. On the other hand, in two high-permittivity solvents $\left(\varepsilon_{r}>40\right)$ is often attributable to the influence of the acidity or basicity of the two solvents rather than the influence of permittivity. Table 1-5 shows ion-solvent interaction with their contribution percentage of total ionic solvation energy.

Table 1-5: Different Ion-Solvent interaction along with their contribution percentage [65]

1. Electrostatic interactions as expressed by the Born equation

2. Electron (-pair) donor-acceptor interactions

3. Interactions of anions with hydrogen bond donor solvents

4. Interactions based on HSAB concept

5 . Interactions by back-donation from $\mathrm{d}^{10}$-cation to solvent molecules

6. Interactions related to the structure-making and breaking of solvents

As it is clear the electrostatic interaction has the major contribution in ion-solvent interaction and can be defined as the difference between the electrostatic free energy of an ion in vacuum and that of the ion in a solution of relative permittivity. It has been shown that the difference between the electrostatic ion-solvent solvation energy in two high- 
permittivity solvents is often less important than the difference in the solvation energies caused by other interactions $[65,66]$.

Another important contribution in ion-solvent interaction is electron pair donor (EPD) and electron pair acceptor (EPA) interactions. In ion solvation process, the solvent molecules approach a cation with their negative charge and approach an anion with their positive charge. Therefore, cation solvation is mainly related to the electron pair donor capacity (Lewis basicity) of the solvents and becomes stronger with the increase in donor number (DN) of solvent. The anion solvation, on the other hand, is closely associated with the electron pair acceptability (Lewis acidity) of the solvents and again becomes stronger with the increase in acceptor number (AN) $[65,66]$.

The ion-solvent interactions can be studied by spectroscopic techniques like Infrared (IR), Raman and nuclear magnetic resonance (NMR) spectroscopy[67].

\subsubsection{Ion-ion Interaction in Electrolytes}

The coulombic force of attraction between two oppositely charged ions $\left(\mathrm{M}^{+}\right.$and $\left.\mathrm{X}^{-}\right)$is inversely proportional to the relative permittivity of the solvent. Thus, solvents with high relative permittivity $\left(\varepsilon_{r}>40\right)$ will be able to reduce the strong electrostatic attraction between oppositely charged ions and dissociate them into free solvated ions [66]. However, in relative low permittivity solvents, the complete dissociation becomes difficult, and part of the dissolved solute (MX) is not dissociated. The undissociated ions in low permittivity solvents contribute to chemical reactions and ion transport in the electrolyte solution. The ion association/dissociation of solute (MX) is strongly depended on the ion-association constant $\left(\mathrm{K}_{\mathrm{A}}\right)$ which could be defined as follows: 
$M^{+}+X^{-} \leftrightarrow M^{+} X^{-}$(ion pair)

$K_{A}=\frac{\left[M^{+} X^{-}\right]}{\left[M^{+}\right]+\left[X^{-}\right]}$

Upon solvation, based on the mutual geometric arrangement of the two ions and the solvent molecules different ion pairs can be formed. Figure 1-19 shows different ion pairs formed in the electrolyte solution.

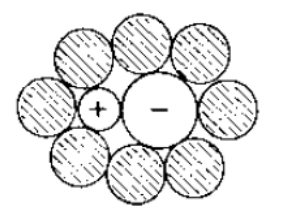

(a)

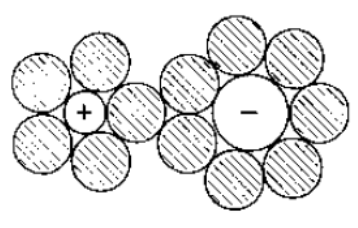

(c)

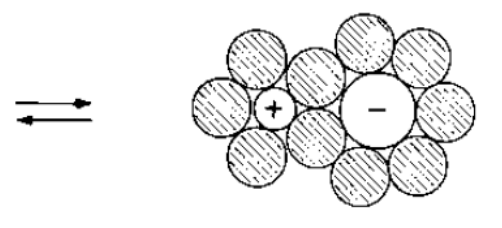

(b)

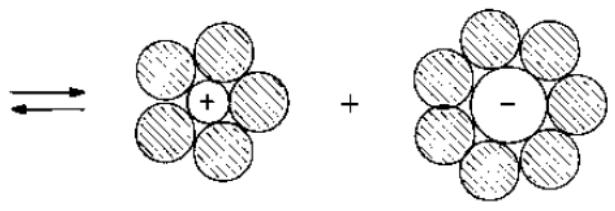

(d)

Figure 1-19: Schematic representation of different ion-pairs (a) Contact ion pair (b) Solvent shared ion pair (c) Solvent separated ion pairs (d) Free solvated ions (Shaded circles denote the solvent molecules) [66]

In contact ion pairs (CIPs), no solvent molecules intervene between the two ions that are in close contact. The ion pair separated by the thickness of only one solvent molecule is called a solvent-shared ion pair. In solvent-separated ion pairs (SSIPs) the primary solvation shells of the two ions are in contact so that some overlap of secondary and further solvation shells takes place. Further dissociation of the two ions leads to unpaired (free) solvated ions with independent primary and secondary solvation shells. In dilute solution 
using low-permittivity solvents, the presence of ion-pairs even in dilute solutions were reported. With the increase of solute concentration, the formation of aggregate ions was also observed in high-permittivity aprotic solvents. For an alkali salts (LiX), ionic association strength can be affected by the negative charge delocalization, size, and steric effects of the anion $X^{-}$. They could be categorized in three different classes [68]: (1) dissociated salts: $\mathrm{LiN}\left(\mathrm{SO}_{2} \mathrm{CF}_{3}\right)_{2}$ (2) intermediate salts: $\mathrm{LiClO}_{4}$ and $\mathrm{LiBF}_{4}$ and (3) associated salts: $\mathrm{LiCF}_{3} \mathrm{SO}_{3}, \mathrm{LiNO}_{3}$ and $\mathrm{LiCF}_{3} \mathrm{CO}_{2}$.

\subsubsection{Salt-Inorganic Additive Interaction in Electrolytes}

The first introduction of inorganic fillers in electrolyte solution for battery application was reported by Weston and Steele in 1982 [69], in which $\mathrm{Al}_{2} \mathrm{O}_{3}$ filler particles were added into PEO-based polymer electrolytes. They reported a significant improvement in the mechanical stability of a polymer electrolyte upon the addition of an inert filler, yet negligible reductions in ionic conductivity at low loadings. Their observation led to more research work to investigate the beneficial influence of inorganic fillers on an ion transport properties of electrolytes. Scrosati et. al [70] reported the increase in ionic conductivity of PEO-based solid polymer electrolyte (SPE) by incorporating nanosized $\mathrm{TiO}_{2}$ and $\mathrm{Al}_{2} \mathrm{O}_{3}$ fillers. Since then many attempts have been made to improve the ionic transport properties of SPEs by ceramic fillers. Fillers can influence the ion transport mechanisms in SPEs in a variety of indirect or direct ways [71]. For example, one of the main concerns in SPEs is their low ionic transport properties at low temperatures due to lack of the amorphous phase in polymer structures. Ion transport in polymer electrolyte is due to segmental motion of polymer chains, which are significantly higher in the amorphous regions compared to crystalline counterparts [72]. Analogous to liquid plasticizers, small fillers may also add 
free volume and speed up segmental dynamics and in turn improve the ion transports. Inorganic fillers could also directly participate in ion transport by increasing free $\mathrm{Li}^{+}$ concentrations, $\mathrm{Li}^{+}$surface conduction, anion attraction, or as a $\mathrm{Li}^{+}$source [71].

The mechanism of filler participation in ion conduction can be expresses as follows: (1) fillers actively interact with the ion pairs. In this case, fillers with specific surface chemistries promote ion-pair dissociation level and increase the number of ions able to participate in conduction. It has been shown that acidic surface groups could attract anions, while basic surface groups attract cations. In either case, the corresponding counter-ion acts as mobile species. (2) The surface of the fillers provides an additional site for anion and/or cation migration, due to Lewis acid-base interactions between the salt and the particle surface. (3) The filler surface attracts either the anion or cation, which reduce the ion mobility. (4) Fillers can also behave as crosslinking sites for EO-segments and anions, changing the polymer chain structure at the interface and creating pathways for $\mathrm{Li}^{+}$ transport independent of segmental motion. 

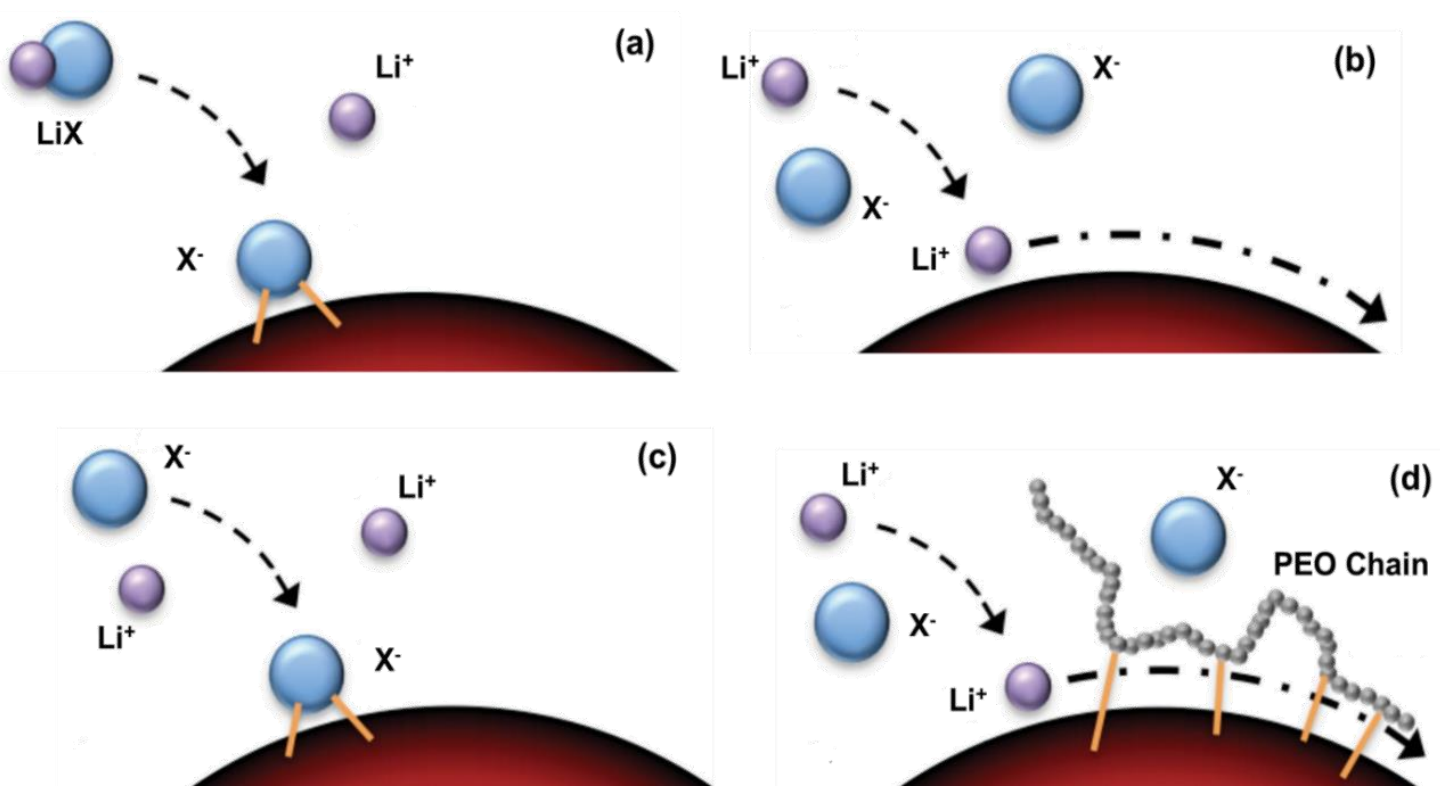

Figure 1-20: Schematic of the filler ion transport mechanisms in SPEs (a) Ion pair dissociation (b) surface transport (c) anion attraction (d) PEO chain promoted surface

Interaction between lithium salt and inorganic fillers in liquid electrolytes was also reported. Bhattacharyya and Maier in 2004 showed that active $\mathrm{Li}^{+}$surface conduction also occurs in liquid-based electrolytes with fillers known as soggy-sand electrolyte [73]. The liquid matrix allows for percolation of spherical particles at a lower loading, as in the absence of an adsorbed polymer layer the particles readily aggregate to form networks of complex fractal dimensionalities. Because of the low particle loading ( $<1-3$ wt.\%), soggy sand electrolytes with significant $\mathrm{Li}^{+}$surface transport display ionic conductivity above that of the pure liquid electrolyte. The mechanism of ion transport in soggy-sand electrolytes could be attraction of the ion pair at the surface of fillers and facilitates the ion pair dissociation. The counter-ion will then exist in the space charge region at the vicinity of particle liquid interface. At a threshold filler loading, ionic conductivity increases as percolation allows for long-range transport of the free ions in the space charge layer. Below 
the threshold filler loading, the ionic transport properties will not change as percolation does not exist. Beyond threshold filler loading, he conductivity will continue to increase with increasing filler content until the a given filler loading (maximum loading). Beyond this maximum filler loading, conductivity decreases due to blocking of the percolative pathways and volume depletion effects [71]. Figure 1-21 shows the spaces charge at the vicinity of fillers and electrolyte interface with with/o filler percolation.
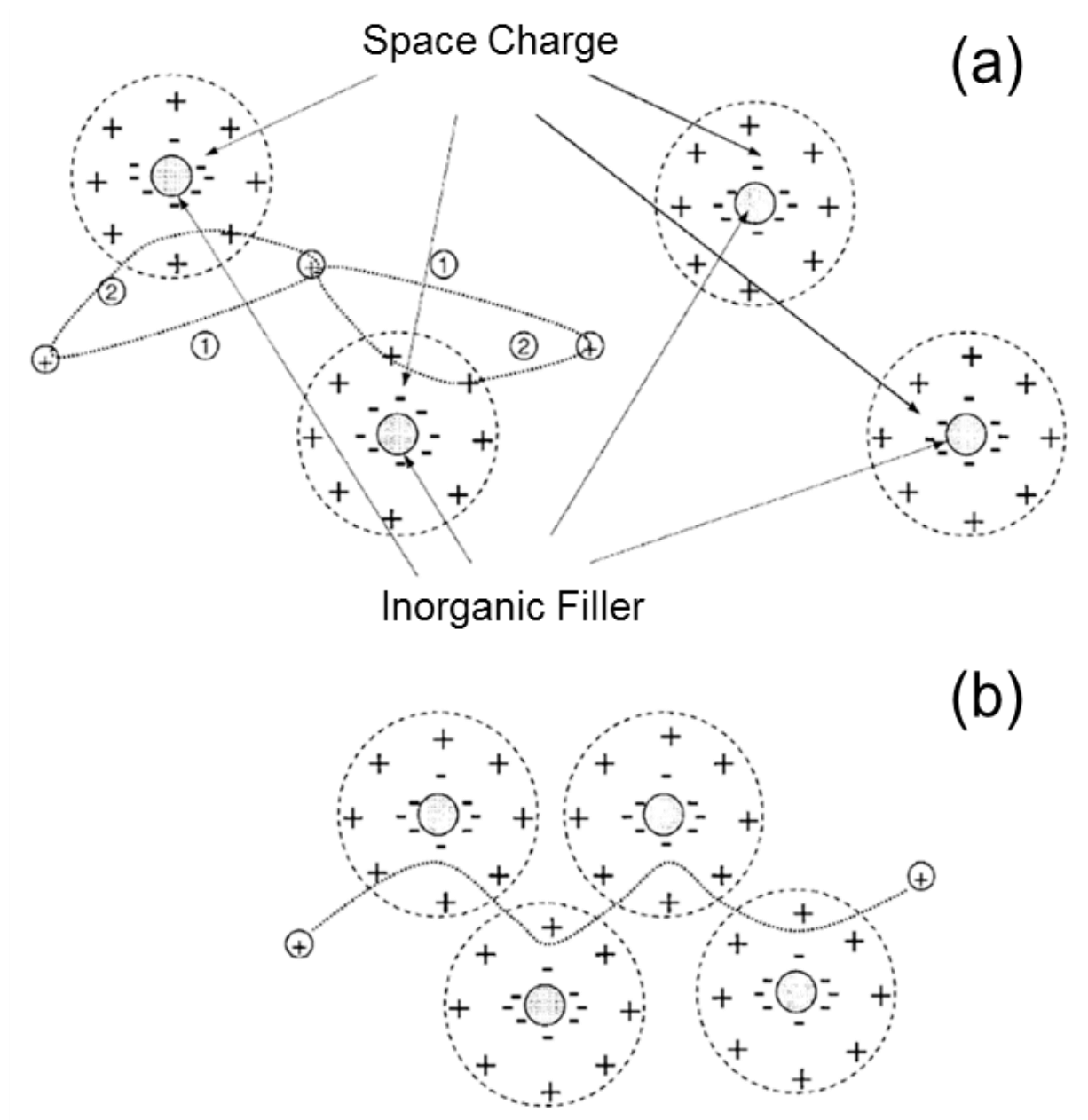

Figure 1-21: The inorganic filler in liquid electrolyte (a) below threshold filler loading (no percolation) (b) above or at threshold filler loading (percolation formed) 


\subsubsection{Ionic Transport Properties in Electrolytes}

The value of conductance, L for a segment of solution immersed in an electric field is directly proportional to the cross-sectional area perpendicular to the field vector and is inversely proportional to the length of the segment along the field. The proportionality constant is the conductivity, $\sigma$, which is an intrinsic property of the solution [74]:

$L=\sigma \frac{A}{l}$

The conductance, $\mathrm{L}$, is given in units of Siemens $\left(\mathrm{S}=\mathbf{\Omega}^{-1}\right)$, and $\sigma$ is expressed in $\mathrm{S} \cdot \mathrm{cm}^{-1}$. Ionic conductivity, $\sigma$ is the sum of contributions from all ionic species as the passage of current through the solution is accomplished by the independent movement of different species. Therefore, it is acceptable that each component of $\sigma$ is proportional to the concentration of the ion, the magnitude of its charge $\left|\mathrm{Z}_{\mathrm{i}}\right|$, and the mobility, which is the limiting velocity of the ion in an electric field of unit strength. Once an electric field in the strength of $\xi$ is applied to an ion, it accelerates under the force imposed by the field until the frictional drag force exactly counterbalances the electric force. Then, the ion continues its motion at that terminal velocity. The magnitude of the force applied by the field is equal to $\left|Z_{i}\right|$ e $\xi$, where e is the electronic charge. The frictional drag force can also be approximated using Stokes law as $6 \pi \eta r v$ where $\eta$ is the viscosity of the medium, $\mathrm{r}$ is the radius of the ion, and $\mathrm{v}$ is the velocity. When the terminal velocity is reached, the ion mobility can be defined as [74]:

$u_{i}=\frac{v}{\xi}=\frac{\left|Z_{i}\right| e}{6 \pi \eta r}$

The proportionality factor relating an individual ionic conductivity to charge, mobility, 
and concentration turns out to be the Faraday constant so that the ionic conductivity can be defined as $[65,74]$ :

$\sigma=F \sum\left|Z_{i}\right| u_{i} C_{i}$

The transference number for species $i$, which the fractions of the current carried by species $I$ and $J$ are called their transference numbers and is merely the contribution to conductivity made by that species divided by the total conductivity:

$t_{i}=\frac{\left|z_{i}\right| u_{i} C_{i}}{\sum_{j}\left|z_{j}\right| u_{j} C_{j}}$

\subsection{Statement of Problems}

Despite the high theoretical energy density of Li-air $\left(\mathrm{O}_{2}\right)$ batteries, they are far away from ideal energy storage systems for emerging applications such as electric vehicles (EVs). Li$\mathrm{O}_{2}$ batteries suffer from poor cyclability and quick capacity fading. Many fundamental research studies have been performed on the cathode and anode of $\mathrm{Li}-\mathrm{O}_{2}$ batteries to improve their performance; however, the electrolytes used in this field remains as one the leading causes of poor battery performance. Electrolytes with various solvents and lithium salts have been utilized for $\mathrm{Li}_{-} \mathrm{O}_{2}$ batteries. Nonetheless, up to date, the choice of solvent and salt for chemical and electrochemical stable electrolytes remain a big challenge in this field. The aim of this dissertation was on the development of stable electrolytes for a Li$\mathrm{O}_{2}$ battery application. Recently, it has been shown that the stability of glyme-based electrolytes (common electrolytes used in the $\mathrm{Li}-\mathrm{O}_{2}$ battery) can be enhanced to some extent by changing the solvation of solvent and lithium salt. Some other research studies

have also reported the improved performance of $\mathrm{Li}-\mathrm{O}_{2}$ batteries using gel polymer 
electrolytes (GPEs) over liquid counterparts. The introduction of inorganic fillers in electrolytes (liquid and polymer electrolytes) have also been shown to enhance the transport properties of electrolytes by changing the ion pair association/dissociation. This research study aims to investigate the addition of inorganic filler materials to the electrolyte as a possible method to change the electrolyte properties for improved $\mathrm{Li}^{-} \mathrm{O}_{2}$ battery performance. For this purpose, composite gel polymer electrolytes (cGPEs) and GPEs using common glyme-based liquid electrolyte and UV-curable polymer with and without one-dimensional (1D) borosilicate glass microfillers were developed, and their performance metrics were studies for $\mathrm{Li}_{-} \mathrm{O}_{2}$ batteries.

In chapter 3, the performance of batteries using GPEs and cGPEs with different content of glass microfillers were investigated using different electrochemical characterization and spectroscopic techniques to obtain the optimum loading of glass microfillers. This work has been published:

Amir Chamaani, Neha Chawla, Meer Safa, Bilal El-Zahab, "One-Dimensional Glass Micro-Fillers in Gel Polymer Electrolytes for Li-O2 Battery Applications", Electrochimica Acta 235 (2017) 56-63.

In chapter 4, the loading of glass microfillers was fixed to the optimum amount obtained in chapter 3 and lithium salt concentration were changed to investigate the sources and mechanism of improvement of cGPE-containing batteries. This chapter revealed that the glass microfillers reduce the rate of lithium carbonates formation originating from electrolyte decomposition. Using different spectroscopic and electrochemical techniques, a possible mechanism of improvement was also proposed. 
Amir Chamaani, Meer Safa, Neha Chawla and Bilal El-Zahab, "Composite Gel Polymer Electrolytes for Improved Cyclability of Li-O⿰冫⿰亻⿱丶⿻工二2 batteries" ACS Applied Materials and Interface 9 (2017) 33819-33826

In chapter 5 , the performance of $\mathrm{Li}-\mathrm{O}_{2}$ batteries using glyme-based electrolytes with different salt concentrations was also investigated. Th results confirmed that the increase in lithium salt concentrations would improve the battery performance by reducing the electrolyte decomposition. The spectroscopic results showed that increase in lithium salt concentration increases the formation of cationic complexes and in turn mitigate the electrolyte decomposition. This work was submitted to the Journal of Electroanalytical Chemistry, and it is still under review Amir Chamaani, Meer Safa, Neha Chawla and Bilal El-Zahab, "Stabilizing Effect of Ion Complex Formation in Lithium-Oxygen Battery Electrolytes" (Journal of Electroanalytical Chemistry, Under review) 


\section{EXPERIMENTAL METHODS AND THEORY}

\subsection{Chemicals and Materials}

The following is a list of all chemicals and materials used throughout this thesis:

Ethoxylated trimethylolpropane triacrylate (ETPTA, Mw=428, purity $>99.00 \%$, Sigma Aldrich), 2-hydroxy-2-methyl-1-phenyl-1-propanon (HMPP, Photo-initiator, purity $>97.00 \%$, Sigma Aldrich), lithium bis(trifluoromethane) sulfonamide (LiTFSI, purity > 99.95\%, Alfa Aesar), tetraethylene glycol dimethyl ether (TEGDME, purity > 99.00\%, Alfa Aesar), N-Methylpyrrolidine (NMP, purity $>97.00 \%$, Sigma Aldrich), Polyvinylidene fluoride (PVDF, Alfa Aesar), multiwalled carbon nanotubes (CNTs, D=5-20 nm, L=5 $\mu \mathrm{m}$, purity $>95.00 \%$ carbon basis, Sigma Aldrich) and Whatman glass microfiber filters (Binder free, Grade GF/B, Sigma Aldrich), Carbon cloth gas diffusion layer (CCGDL, thickness $\sim 300 \mu \mathrm{m}$, FuelCell Earth), Polypropylene separator (Thickness $\sim 25 \mu \mathrm{m}$, Celgard

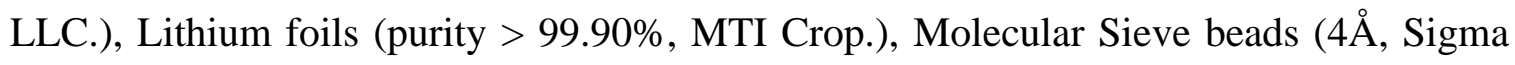
Aldrich). Polydimethylsiloxane (PDMS, SYLGARD 184 and curing agent, Dow Corning).

\section{$2.2 \quad \mathrm{Li}-\mathrm{O}_{2}$ cell assembly}

\subsubsection{Liquid Electrolyte Preparation}

All liquid solvents used for liquid electrolytes and polymer electrolytes (gel polymer electrolytes (GPEs) and composite gel polymer electrolytes (cGPEs)) preparation were first

dried over molecular sieve beads (4£) for at least two weeks before use. The molecular sieves were always activated before use by heating at $250{ }^{\circ} \mathrm{C}$ under vacuum for 24 hours. Liquid electrolytes with different LiTFSI salt concentrations were prepared by dissolving an appropriate amount of LiTFSI salt $\left(0.1,1\right.$ and $\left.3 \mathrm{~mol} \cdot \mathrm{kg}^{-1}\right)$ into TEGDME solvent in the 
Ar-filled glove box with control $\mathrm{O}_{2}$ and humidity content (Mbraun, $<0.1 \mathrm{ppm} \mathrm{O}_{2}$ and $<0.1$ ppm $\left.\mathrm{H}_{2} \mathrm{O}\right)$.

\subsubsection{Gel polymer and composite gel polymer electrolytes preparation}

The glass microfibers used in this thesis as one-dimensional fillers for cGPEs preparation obtained by cutting Whatman glass microfiber discs (Binder-free, grade GF/B) and further fragmented by probe sonication in acetone for 3 hours. After fragmentation process, the glass microfibers were dried under high vacuum at $300^{\circ} \mathrm{C}$ for 48 hours and then stored in the Ar-filled glovebox for at least 2 weeks before use. GPEs with different LiTFSI salt concentrations were prepared by mixing of ETPTA monomer into liquid electrolytes $(0.1$, 1, and $3 \mathrm{~mol} \cdot \mathrm{kg}^{-1}$ ) solution (80:20 wt.\% of ETPTA/liquid electrolyte with 1:99 by weight HMPP: ETPTA monomer content as a curing agent). The cGPE preparation followed the same procedure with the addition of different fillers concentrations ranging from $0.5,1,2$ and $5 \mathrm{wt} . \%$ of shredded glass microfibers. For cGPEs preparation, the appropriate amount of glass microfibers first was added to the liquid electrolytes in the Ar-filled glove box in sealed small vials and sonicated for 1 hours. The solution of ETPTA monomer and curing agent was then added to the sonicated mixture (glass fibers and liquid electrolytes) and further stirred inside the glove box for extra 1 hour to well-dispersed microfibers. The dispersed mixture solutions were transferred form vials by syringe and cast on 0.5 " circular

PDMS templates with the thickness of 150-200 $\mu$ m layered on glass slides and exposed to UV-radiation (UVL-56 Lamp, $\lambda=365 \mathrm{~nm}$ ) in the Ar-filled glove box for 10 minutes which yielded free-standing and flexible films $150-200 \mu \mathrm{m}$ in thickness. 


\subsubsection{Cathode Preparation and whole cell assembly}

For cathode preparation, a carbon cloth gas diffusion layer (CCGDL) was first cut into 7/16" circular shape and dip coated by CNTs/PVDF (90:10 wt.\% in NMP) slurry. Then all coated cathodes were dried at $120^{\circ} \mathrm{C}$ under vacuum overnight. The loading of CNTs was $0.5 \pm 0.03 \mathrm{mg} \cdot \mathrm{cm}^{-2}$. For slurry preparation, $5 \mathrm{mg}$ of PVDF was first dissolved in $15 \mathrm{~mL}$ of NMP, and then $50 \mathrm{mg}$ of CNTs added to PVDF/NMP solution. The CNTs/PVDF suspension in NMP was first mechanically mixed followed by bath sonication of 90 mins. The Li- $\mathrm{O}_{2}$ batteries were prepared using modified Swagelok cells. For cell assembly, asprepared 1/2" diameter GPEs/cGPEs or soaked Celgard polypropylene separators with liquid electrolyte was placed between 1/2" diameter lithium foil as an anode and 7/16" diameter CNT-CCGDL cathode. Before cell assembly, all cathodes were soaked with 20 $\mu \mathrm{L}$ liquid electrolyte. The amount of liquid electrolyte $(20 \mu \mathrm{L})$ added to soak the cathodes were obtained based on trial and error. The whole cell was air-tight except for cathode side, which was fitted with stainless steel tube served as oxygen gas inlet. Ultra-high purity oxygen gas (Airgas, purity > 99.994\%) was delivered into individual cell via gas manifolds containing humidity-resistant tubing. Throughout all tests under oxygen atmosphere, the flowing oxygen gas was kept at 5 psi gauge pressure via series of humidity-resistant valves/regulators. Figure 2-1 shows the modified Swagelok cell used in this study in assemble and disassemble mode. Figure 2-2 also showed the flowing-mode $\mathrm{Li}-\mathrm{O}_{2}$ battery testbed designed and built in the Lab. 


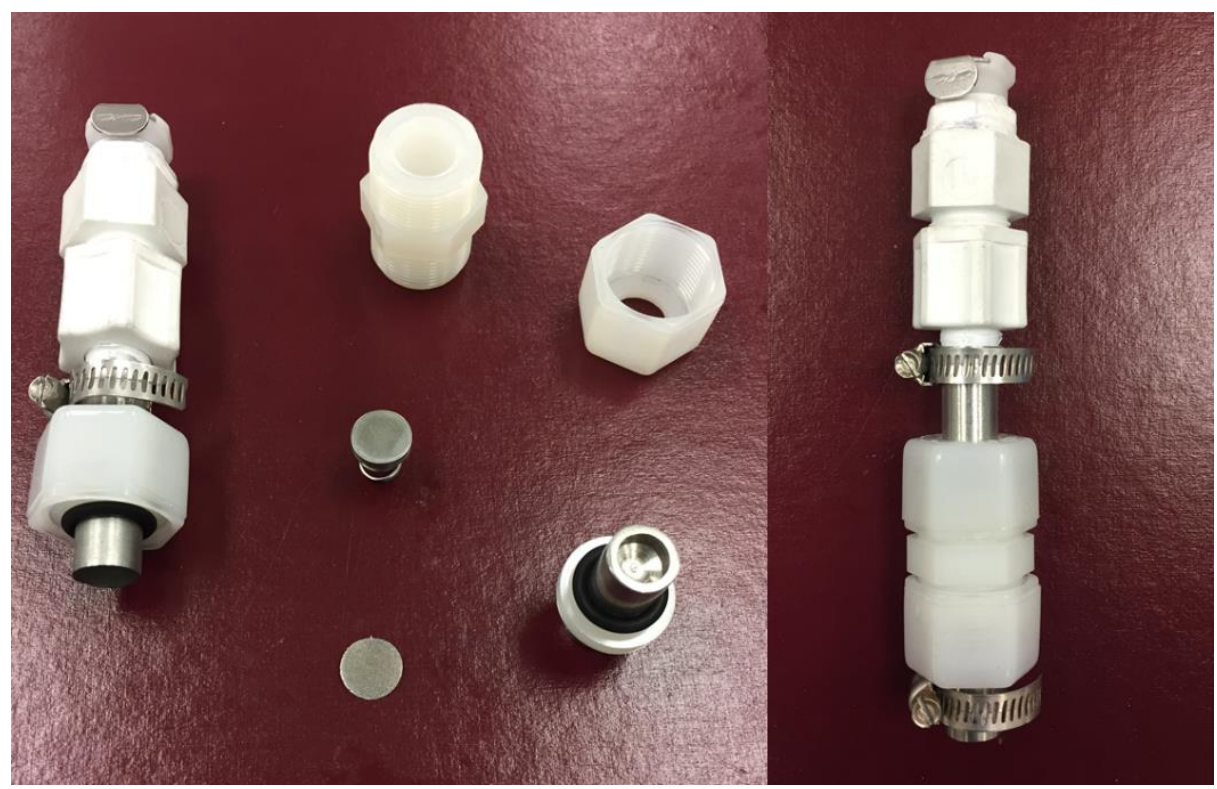

Figure 2-1: The modified Swagelok cell designed for $\mathrm{Li}^{-} \mathrm{O}_{2}$ batteries in disassembled (left) and assemble (right) mode.

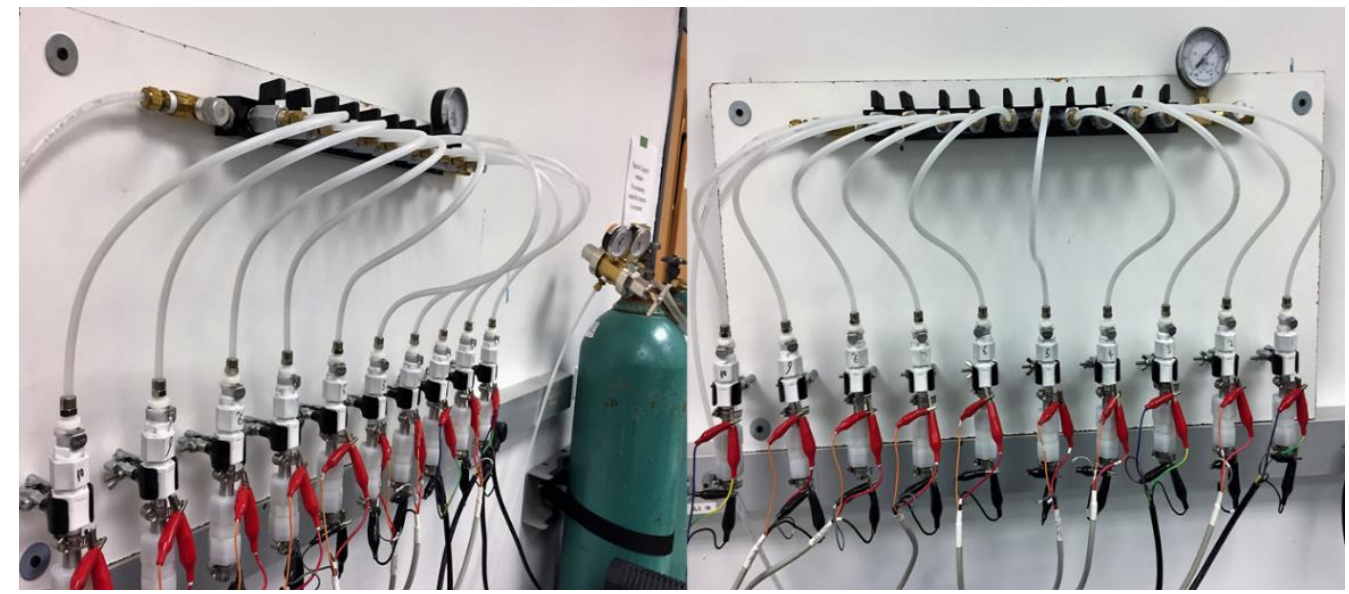

Figure 2-2: The flowing mode $\mathrm{Li}-\mathrm{O}_{2}$ battery testbed designed and built in this study 


\subsection{Electrochemical Characterizations}

\subsubsection{Galvanostatic charge/discharge}

Galvanostatic charge/discharge is an electrochemical test to determine the capacity of the batteries. In a discharge process, a constant negative current is applied to the cell until a predefined cut-off voltage is reached and then during charging a current is reversed, and a positive current is applied to the cell. By this technique, the electrochemical performance of cell can be defined in a plot of cell voltage (volt) versus capacity (mAh). For the sake of consistency, the capacity of $\mathrm{Li}_{-} \mathrm{O}_{2}$ batteries was normalized to the mass of active materials (CNTs) of the cathode and defined in $\mathrm{mAh} \cdot \mathrm{g}^{-1}$. In this dissertation, the $\mathrm{Li}-\mathrm{O}_{2}$ batteries underwent the galvanostatic charge/discharge cycling at a current density of $250 \mathrm{~mA} \cdot \mathrm{g}^{-1}$ to the cut-off voltages of 2.0-4.5 V or cut-off capacity of $500 \mathrm{mAh} \cdot \mathrm{g}^{-1}$. Figure $2-3 \mathrm{shows}$ a single galvanostatic charge/discharge cycle of the $\mathrm{Li}-\mathrm{O}_{2}$ battery using CNTs-coated CCGDL in a voltage window of $2.0-4.5 \mathrm{~V}$ at a constant current density of $250 \mathrm{~mA} \cdot \mathrm{g}^{-1}(250$ $\mathrm{mA} \cdot \mathrm{g}^{-1 *} \sim 0.5 \mathrm{mg}$ of $\left.\mathrm{CNTs}=\sim 125 \mu \mathrm{A}\right)$.

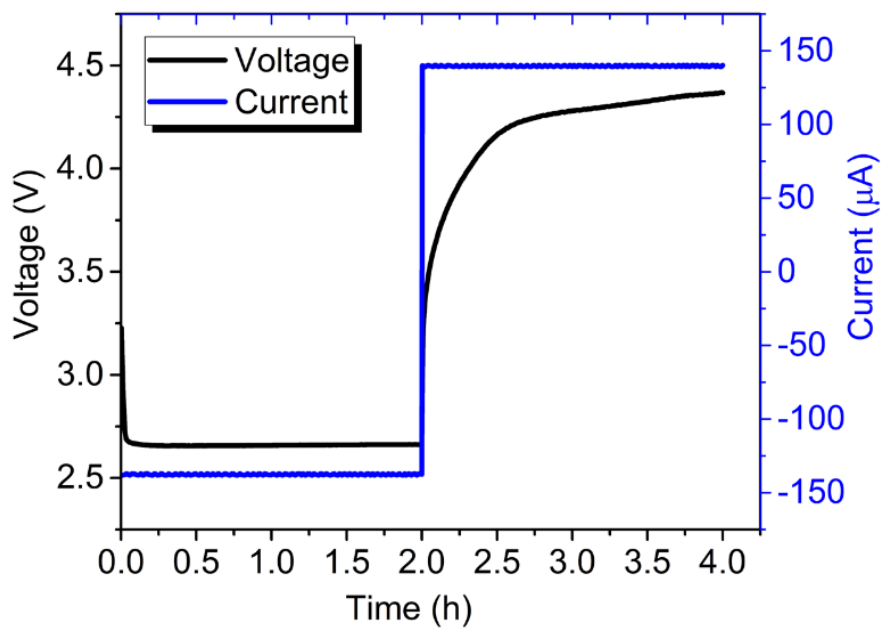

Figure 2-3: Example of typical galvanostatic charge/discharge cycling showing both the applied current and voltage response 


\subsubsection{Voltammetry tests}

Voltammetry is the potentiodynamic technique where the potential is swept at a constant scan rate $(\mathrm{V} / \mathrm{s})$. A voltammogram is a plot of current versus voltage. Voltammetry technique is divided into two categories: Linear sweep voltammetry (LSV) and cyclic voltammetry (CV). In LSV, the voltage is only swept in one direction (cathodic or anodic) to investigate the one electrochemical reaction. However, in $\mathrm{CV}$ test, the voltage first is swept in one direction (forward direction) and then it is swept in a revered direction (backward direction) to investigate the reversibility of electrochemical reactions. In this dissertation, LSV in forwarding reaction (anodic) was performed to study the electrochemical anodic stability of electrolytes when they are in contact with other components of the $\mathrm{Li}-\mathrm{O}_{2}$ cell. $\mathrm{CV}$ test was also performed on whole $\mathrm{Li}-\mathrm{O}_{2}$ cell to investigate the ORR and OER of cells using different electrolytes.

\subsubsection{Chronopotentiometry}

Chronopotentiometry is an electrochemical technique where the constant current is applied, and the voltage response is measured. In this dissertation, chronopotentiometry was also performed to investigate the oxidation stability of electrolytes. The $\mathrm{Li}-\mathrm{O}_{2}$ cells were assembled using actual cathodes (CNTs-coated CCGDL), Li anode and different electrolytes. Then the cells were charged without any predefined cut-off voltage before discharge process at the constant current density $\left(250 \mathrm{~mA} \cdot \mathrm{g}^{-1}\right)$ used for galvanostatic charge/discharge cycling. 


\subsubsection{Li-ion transport measurements}

\subsubsection{Ionic Conductivity}

The Ionic conductivity of electrolyte solutions is a measure of electrolyte ability to transport ions. The ionic conductivity measurement was performed by potentiostatic electrochemical impedance spectroscopy (EIS). For liquid electrolytes, the electrolytes were trapped between two stainless steel blocking electrodes by using $1 \mathrm{~mm}$ thick Teflon O-rings. For polymer electrolytes (GPEs and cGPEs), the electrolyte films were placed between two stainless steel electrodes. The ionic conductivity was determined using $\sigma=$ $\mathrm{L} / \mathrm{A} \cdot \mathrm{R}$, where $\mathrm{L}$ is the thickness of electrolyte films or the thickness of O-ring, $\mathrm{A}$ is the area of electrolyte films, or the area of O-ring and $\mathrm{R}$ is the bulk resistance obtained by highfrequency interception of EIS spectrum with abscissa. $\sigma$ is the ionic conductivity in the unit of Siemens per meter $(\mathrm{S} / \mathrm{m})$.

\subsubsection{Transference Number}

One of the most important parameters of battery electrolytes is the lithium transference number. Transference number is a dimensionless parameter which demonstrates the contribution of a particular charged species $\left(\mathrm{Li}^{+}\right)$present in the electrolyte to the overall charge transport across the cell. In typical battery electrolytes, most of the ionic current is carried by anions, instead of cations $\left(\mathrm{Li}^{+}\right)$. In case of a simple binary electrolyte comprising of completely dissociated $\mathrm{Li}$ salt $\left(\mathrm{Li}^{+} \mathrm{X}^{-}\right)$, it can be expressed as follows:

$t_{L i}=\left(I_{L i} /_{I_{L i}}+I_{X}\right)=\left(I_{L i} / I_{\text {total }}\right)=1-t_{X^{-}}$

Where $t_{L i}{ }^{+}$is the lithium transference number, $t_{X^{-}}$is an anion transference number, $I_{L i}$ is a current carried by $\mathrm{Li}^{+}$cations and $I_{X}$ is a current carried by anions. Different methods have 
been proposed to measure the transference number of electrolytes such as Hittorf method [75,76], galvanostatic polarization [77], potentiostatic polarization [78] and NMR method[77]. In this dissertation, DC polarization method modified by Bruce-Vincent has been used to determine the transference number. This method is used due to its compatibility with both liquid electrolytes and polymer electrolytes.

For the DC polarization method, the symmetrical $\mathrm{Li} / \mathrm{Li}$ cell is assembled by placing the electrolyte films (GPEs or cGPEs) or presoaked Celgard separators with liquid electrolytes between two lithium electrodes as follows:

\section{$\mathrm{Li}$ (anode) $\mid \mathrm{Li}^{+} \mathrm{X}^{-}$containing electrolyte $\mid \mathrm{Li}$ (cathode)}

Lithium electrodes are used due to their abilities to reversibly exchange lithium ions, yet block the anions at the same time. If the symmetrical setup is polarized by applying a small DC voltage (usually $10 \mathrm{mV}$ ) across the cell, both the anions and cations start to move initially. Since the $\mathrm{Li}$ electrodes are only reversible for $\mathrm{Li}^{+}$ions, the moving anions are accumulated at the anode lowering the anions concentrations at the cathode, which generates a concentration gradient. Therefore, over time the initial current $\left(I_{0}\right)$ starts to drop until a steady state current $\left(I_{s s}\right)$ is reached which only originates from the non-blocking ionic $\left(\mathrm{Li}^{+}\right)$species. This means that anions and cations at the beginning of polarization migrate together due to a DC voltage. The motion of the anions is reduced by the time during polarization and eventually comes to a complete stop. Thus, the lithium ions are the only moving species in electrolyte whereby the electric current is reduced. The first transference number measurement was made by the following formula: 
$t_{L i}+=I_{S S} / I_{0}$

For the above equation, it is assumed that the current carried by lithium ions is the same at the beginning of the experiment $(\mathrm{t}=0)$ and in steady state $(\mathrm{t}=\infty)$ and furthermore are the only species that carry charge in the steady state. The above equation is for ideal cases when there is no reaction between existing species in electrolyte and Li electrodes. However, in the real cell, there is a reaction between the species in the electrolytes and $\mathrm{Li}$ electrodes, which leads to the formation of passivation layer known as a solid electrolyte interface (SEI) on the electrolytes. This SEI layer contributes to the ionic movement during cell polarization. Bruce and Vincent proposed a correction factor to the equation 2 to accounts this passivation film contribution [78]:

$t_{L i^{+}}=\frac{I_{S S}\left(\Delta V-I_{0} R_{0}\right)}{I_{0}\left(\Delta V-I_{S S} R_{S S}\right)}$

Where $t_{L i}{ }^{+}$is a lithium transference number $\Delta \mathrm{V}$ is an applied DC potential, $R_{0}$ is the initial resistance of the passivation layer, $R_{s s}$ is a resistance of the passivation layer at steady state. So, the $I_{0}$ and $I_{s s}$ are determined by DC polarization curve and $R_{0}$ and $R_{s s}$ are measured by electrochemical impedance spectroscopy (EIS).

\subsubsection{Electrochemical Impedance Spectroscopy (EIS)}

\subsubsection{Overview of EIS}

Electrochemical impedance spectroscopy (EIS) has been extensively used in this dissertation to investigate the failure mechanism of $\mathrm{Li}-\mathrm{O}_{2}$ batteries using different electrolytes. The following describes some of important fundamentals of EIS, and a basic understanding of EIS is assumed. 
Resistance (R) is an ability of a circuit element to resist the flow of electrical current. Based on the Ohm's law, the resistance could be defined as a ratio between voltage (V) and current (I), $\mathrm{R}=\mathrm{V} / \mathrm{I}$. This relationship is for ideal resistance. An ideal resistance is defined based on a couple of assumptions: (1) it follows Ohm's Law at all current and voltage levels (2) its value is independent of frequency (3) AC current and voltage signal are in phase with each other through a resistor. Impedance is a more general circuit parameter like resistance. However, it is not limited by the simplifying properties as described for resistance. Electrochemical impedance is usually measured by applying an AC potential to an electrochemical cell and measuring the current through the cell. Electrochemical impedance is usually measured using a small excitation signal to make sure that cell's response is linear or pseudo-linear. In a linear or pseudo-linear system, the current response to a sinusoidal potential will be a sinusoid at the same frequency but shifted in phase.

If the excitation signal (potential) is expressed as a function of time [79]:

$E_{t}=E_{0} \sin (\omega t)$

Where, $\omega$ is radial frequency. The relation between the radial frequency $(\omega)$ and frequency (f) is

$\omega=\frac{2 \pi}{f}$

In a linear system, the response current is shifted in phase and can be expressed as:

$I_{t}=I_{0} \sin (\omega t+\varphi)$

The impedance $(Z)$ can be expressed as follows based on ohm's law: 
$Z=\frac{E_{t}}{I_{t}}=\frac{E_{0} \sin (\omega t)}{I_{0} \sin (\omega t+\varphi)}=Z_{0} \frac{\sin (\omega t)}{\sin (\omega t+\varphi)}$

So, the impedance is expressed in terms of a magnitude, $\mathrm{Z}_{0}$, and a phase shift, $\varphi$. Using the Euler's relationship, the impedance $(Z)$ can also be defined as:

$Z(\omega)=\frac{E}{I}=Z_{0} \exp (j \varphi)=Z_{0}(\cos \varphi+j \sin \varphi)$

As can be seen in equation (7), the expression for $Z(\omega)$ is composed of a real and an imaginary part. If the real part of $\mathrm{Z}(\omega)$ is plotted on the $\mathrm{X}$-axis and the imaginary part of $\mathrm{Z}(\omega)$ is plotted on the Y-axis of a chart, a Nyquist plot can be obtained. In Nyquist plot, the value of Y-axis is negative and each point on the Nyquist Plot is the impedance at one frequency. Figure 2-4 shows a typical Nyquist plot. Another popular presentation method of impedance is a Bode plot. The impedance is plotted with $\log$ frequency on the $\mathrm{X}$-axis and both the absolute values of the impedance $\left(|\mathrm{Z}|=\mathrm{Z}_{0}\right)$ and the phase-shift on the $\mathrm{Y}$-axis (Figure 2-4)
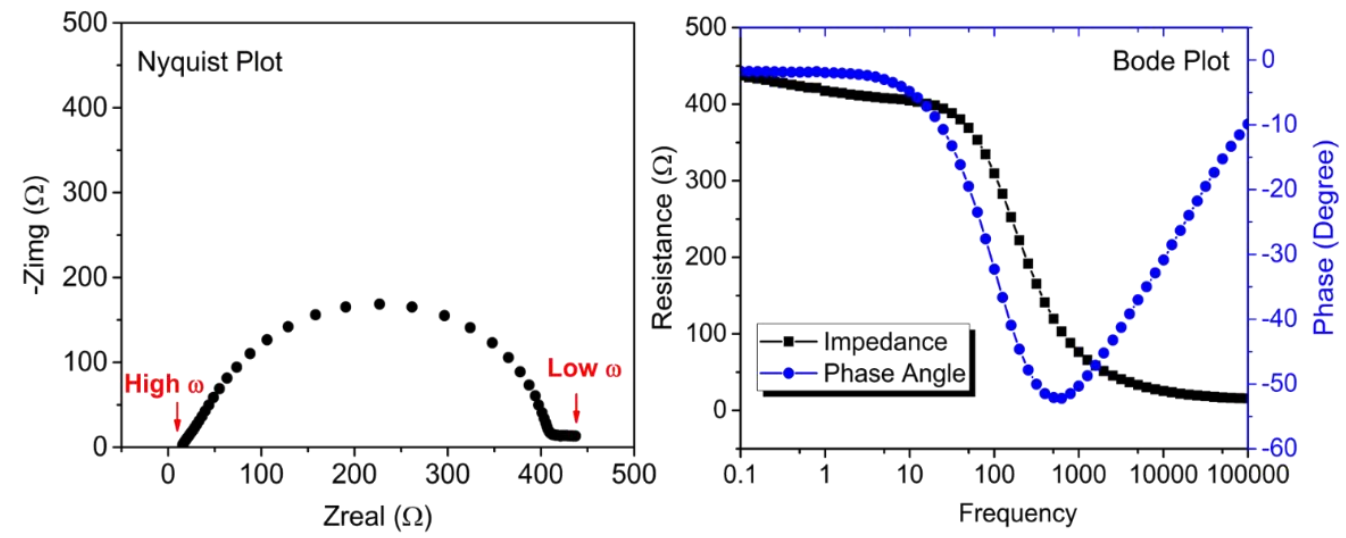

Figure 2-4: A typical Nyquist Plot (left) and Bode Plot (right) 
It is worthy to mention that the EIS data are only valid if they are complied with the following criteria:

1- Linear: the system must obey Ohm's Law, $\mathrm{E}=\mathrm{iZ}$. The value of $\mathrm{Z}$ is independent of the magnitude of the perturbation.

2- Stable: the system does not change with time and returns to its original state after the excitation is removed.

3- Causal: the response of the system is due only to the applied excitation.

The Kramers-Kronig (K-K) relations can be used to evaluate the linearity, stability, and causality of EIS data. The K-K relations demand that causal, complex plane spectral data shows dependence between magnitude and phase. The K-K relations will always be true for EIS data that is linear, causal, and stable. Therefore, if the real and imaginary part of spectral data does not comply with the K-K relations, the data must violate one of these conditions.

EIS spectrum obtained from electrochemical cells can be modeled as a network of electrical circuit elements known as an equivalent circuit model. The EIS response of an equivalent circuit can be measured and compared to the actual EIS response of the electrochemical cells. Based on the EIS response of electrochemical cells, different equivalent circuit model can be estimated. Each equivalent circuit model consists of some electrical elements. Table 2-1 shows some of the circuit elements commonly used to fit the equivalent circuit models [79]. 
Table 2-1: Common circuit elements used in EIS equivalent circuit models

\begin{tabular}{cc}
\hline Electrical Element & Impedance \\
\hline R (Resistance) & $\mathrm{R}$ \\
$\mathrm{C}$ (Capacitance) & $1 / \mathrm{j} \omega \mathrm{C}$ \\
W (infinite Warburg) & $1 / \mathrm{Y}_{0}(\mathrm{j} \omega)^{0.5}$ \\
CPE (Constant phase element) & $1 / \mathrm{Y}_{0}(\mathrm{j} \omega)^{\mathrm{a}}$ \\
\hline
\end{tabular}

\subsubsection{Transmission Line Model (TLM) for porous systems}

In the classical EIS measurement, a faradic electrochemical reaction at the planer electrode/electrolyte interface can be modeled by the Randles model as shown in Figure $2-5$.

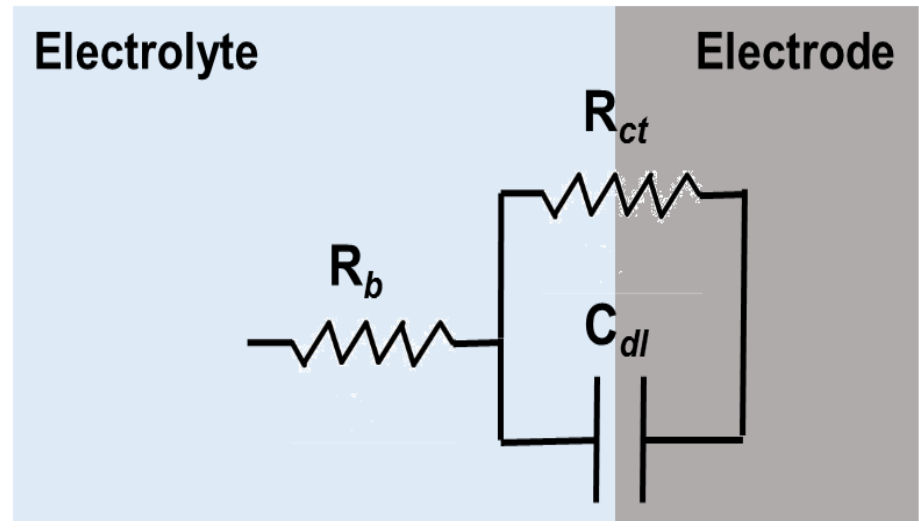

Figure 2-5: Typical circuit model (Randles model) describing the faradic process at planer electrode/electrolyte interface.

In the Randles model, the $R_{b}$ represents the resistances from the electrolyte and $R_{c t}$ represents all faradaic reactions that occur on the electrode's surface. $C_{d l}$ describes nonfaradic capacitive charge storages [80]. The $C_{d l}$ is often replaced by a CPE element for non-ideal capacitive behavior. Although, this model shows electrochemical interfaces of planar electrodes, it describes poorly the effect of porous electrodes that are used in most 
electrochemical cells. In porous electrodes, mainly four electrochemical processes happen as shown in Figure 2-6: (1) mixed ions and electrons conduction as electric resistance $\left(R_{e}\right)$, electrolyte bulk resistance $\left(R_{s o l}\right)$, and ionic resistance in pores $\left(R_{i o n}\right)$; (2) formation of an electric double layer at the electrode/electrolyte interface $\left(C_{d l}\right)$; (3) charge-transfer reaction for faradic reactions as $R_{c t}$; and (4) mass transfer to compensate for charge as diffusion [81].

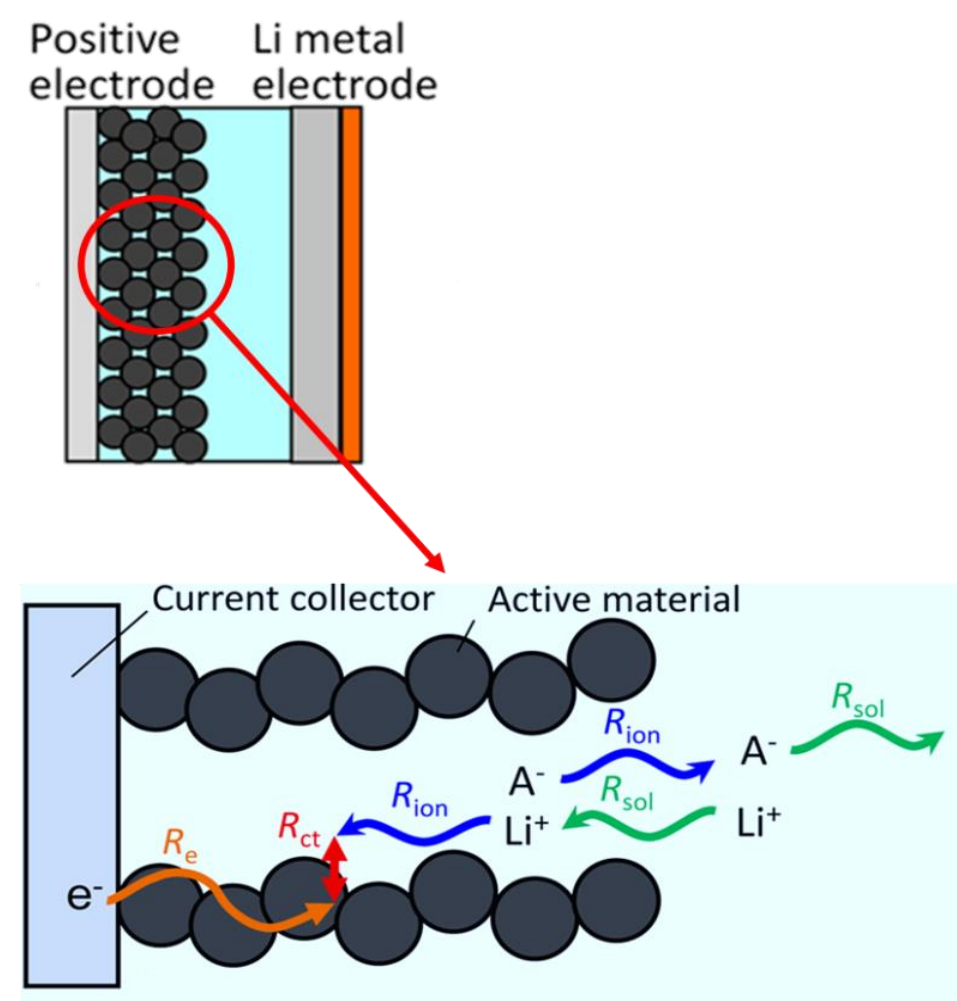

Figure 2-6: Schematic illustration of different resistances in porous electrodes [81]

To address these resistances in porous electrodes, the pores within porous electrode are modeled in a cylindrical shape with the following assumptions: Highly porous cathodes consist of the base electrode and the porous active electrode. The base electrode is an 
inactive conductive material (metal foil or carbon cloth) where the porous active materials (electrodes) are deposited on it. Figure 2-7 shows a typical cylindrical pore of active porous materials on the base electrode flooded by the liquid electrolyte.

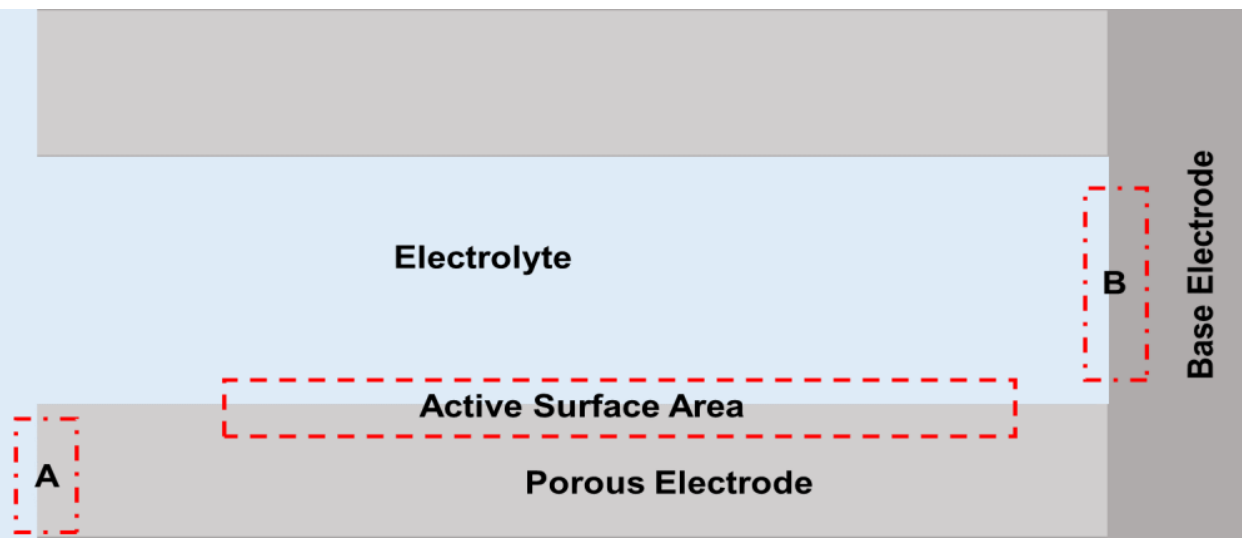

Figure 2-7: Different interfaces in porous electrode structure

Unlike the planner electrode where the electrochemical reaction happens on the surface of electrode, the rate of electrochemical reaction in porous cathodes is limited. This limitation arises from the fact that the accessibility of ions to the active interface is hindered by the small inner volume of the pores. Hence the diffusion rate of the ion in the pore becomes the dominating step in electrochemical reactions. The porous electrode could be categorized into three regions due to the restrictions of the electrochemical reactivity in porous electrodes. These interfaces are labeled as "A", "B", and "Active Surface Area" (see Figure 2-7) [82]. "A" represents the interface between the outer surface of the pores of porous electrode and the electrolyte. "B" describes interactions between base electrode and electrolyte. "Active surface area" describes the interactions between active materials of the porous electrode and electrolyte [80]. Transmission line model (TLM) is one the most promising circuit models to describe the electrochemical behaviors of those interfaces 
existing in porous electrodes. Figure 2-8 shows a TLM model in a generic form. The model consists of several parallel and serially connected elements.

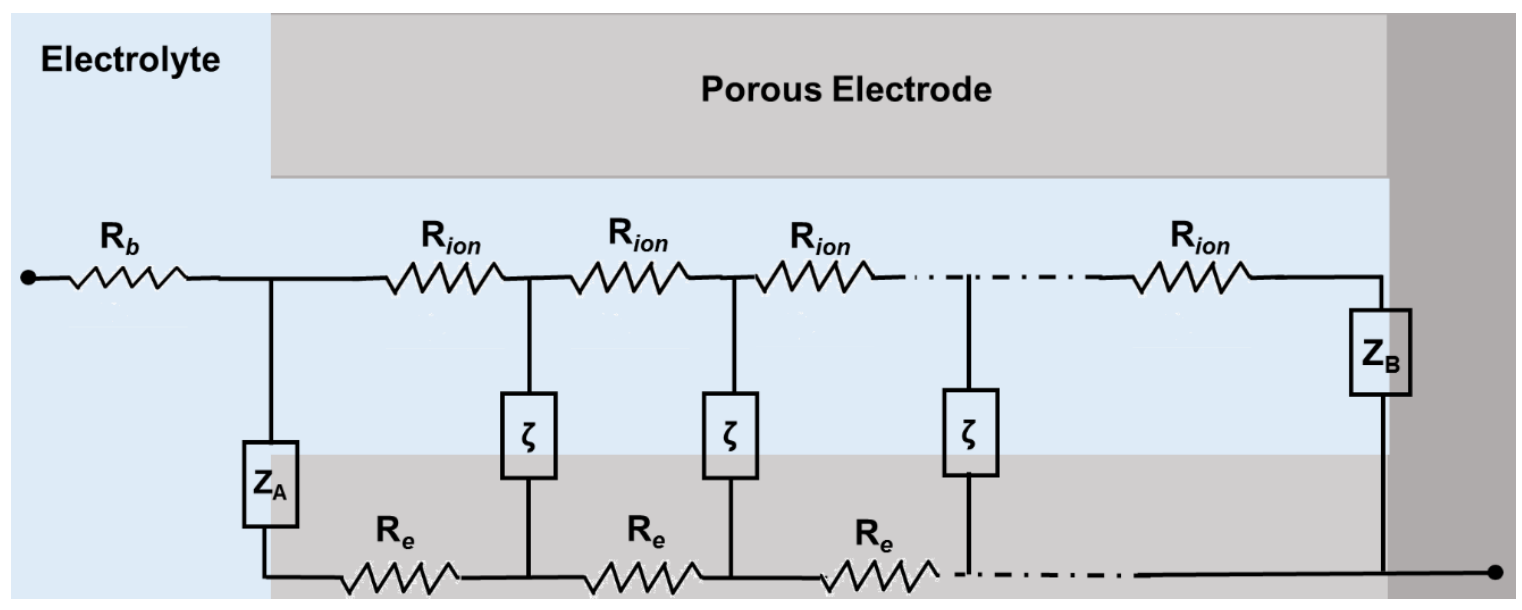

Figure 2-8 Scheme of a generic transmission line model

The interfaces " $A$ " and " $B$ " are represented by impedances $Z_{A}$ on the outer surface of the pore and $Z_{B}$ on the base electrode at the end of the pore, respectively. $R_{i o n}$ is the impedance of the electrolyte within the pore. It is important to mention that this impedance is different from bulk electrolyte resistance $\left(R_{b}\right) . R_{e}$ is the impedance of the porous electrode's solid phase. $\zeta$ describes the impedance at the "Active surface area" as shown in Figure 2-8 [82]. The generic form of TLM is usually simplified due to the existing boundary conditions in real electrochemical cells. Bisquert [83,84] describes the simplified TLM for electrochemical energy storage systems. Based on their assumptions, the ionic resistance inside the pores are much higher than electronic resistance due to the electronic conduction in active materials used in batteries, so the resistive trail of $R_{e}$ can be set as zero. Besides, it is assumed that the electrochemical reactions only happen in the active surface area and 
no reaction occurs on the outer surface of electrode/electrolyte and base electrode/electrolyte interface. Hence both $Z_{A}$ and $Z_{B}$ is infinite (open-circuit). Applying the boundary condition, the generic form of TLM can be described as in Figure 2-9 for both faradic and nonfaradic reactions.

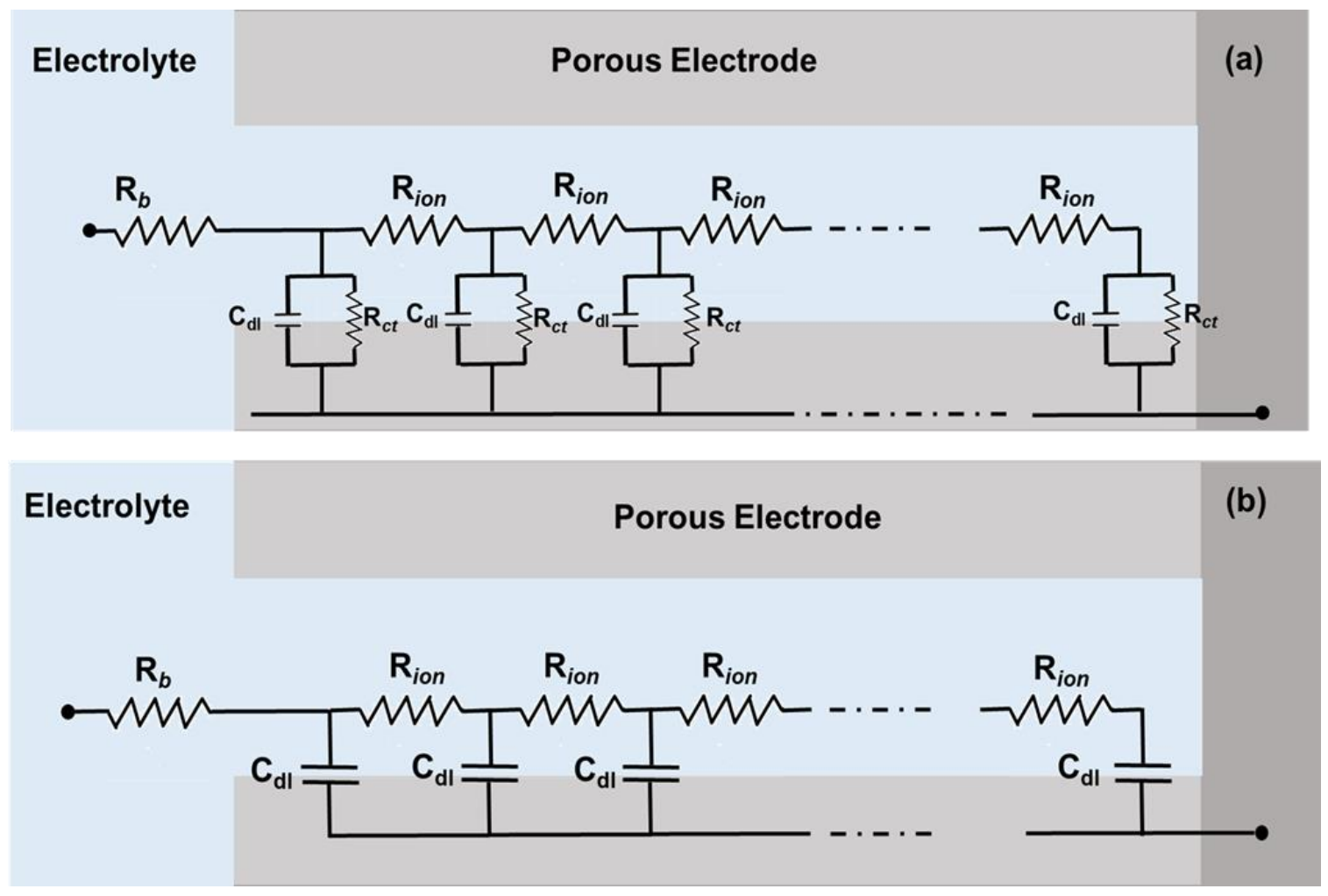

Figure 2-9: (a) Simplified TLM for porous cathodes describing faradic reactions at the active surface area (b) Simplified TLM for porous cathodes describing nonfaradic reactions at the active surface area

For faradic and non-faradic reactions at cylindrical porous electrodes, the overall impedance can be expressed as follows [80,81]:

$$
Z_{\text {faradaic }}=\sqrt{\frac{R_{\mathrm{ion}, L} \cdot R_{\mathrm{ct}, A}}{\left(1+j \omega R_{\mathrm{ct}, A} \cdot C_{\mathrm{dl}, A}\right) \cdot 2 \pi r}} \operatorname{coth} \sqrt{\frac{R_{\mathrm{ion}, L} \cdot\left(1+j \omega R_{\mathrm{ct}, A} \cdot C_{\mathrm{dl}, A}\right) \cdot 2 \pi r}{R_{\mathrm{ct}, A}}} L
$$




$$
Z_{\text {nonfaradaic }}=\sqrt{\frac{R_{\text {ion }, L}}{j \omega C_{\mathrm{dl}, A} \cdot 2 \pi r}} \operatorname{coth} \sqrt{R_{\text {ion }, L} \cdot j \omega C_{\mathrm{dl}, A} \cdot 2 \pi r} L
$$

Where, $\mathrm{L}$ and $\mathrm{r}$ are the length and radius of cylindrical pores, respectively.

For nonfaradic reactions, at the high frequency, the EIS spectrum shows a linear region with a 45-degree slope from the real axis followed by a vertical rise (Figure 2-10). The limiting value for $Z_{\text {real }}$ and $Z_{\text {img }}$ as $\omega \rightarrow 0$ is $[81,85]$ :

$Z_{\text {real }(\omega \rightarrow 0)}=\frac{R_{\text {ion }}}{3}$

$Z_{i m g(\omega \rightarrow 0)}=\frac{1}{\omega C_{d l}}$

For faradic reaction, at high frequency, the EIS spectrum shows a linear region with a 45degree slope from the real axis followed by the semi-circle at the low frequency (Figure 2-10). The limiting value for $Z_{\text {real }}$ and $Z_{\text {img }}$ as $\omega \rightarrow 0$ is $[81,85]$ :

$$
\begin{aligned}
& Z_{\text {real }(\omega \rightarrow 0)}=\frac{R_{\text {ion }}}{3}+R_{c t} \\
& Z_{\text {img }(\omega \rightarrow 0)}=0
\end{aligned}
$$




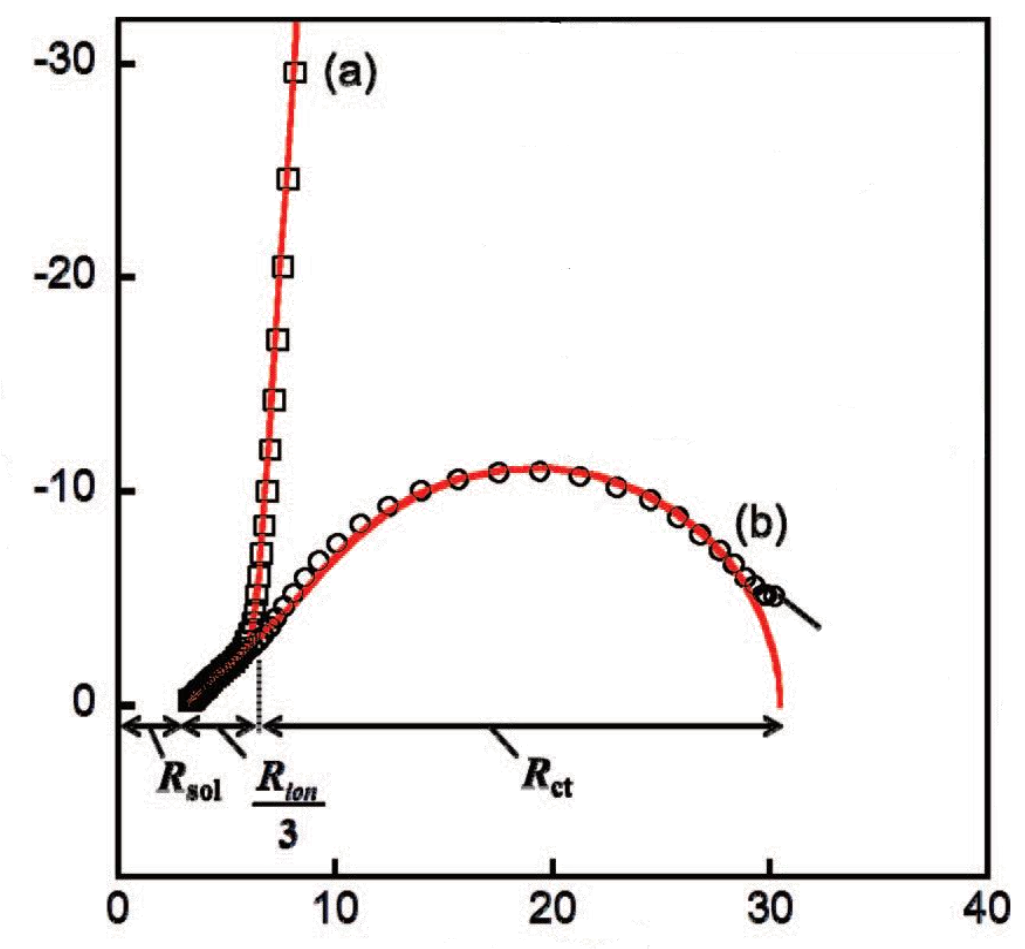

Figure 2-10: Typical Nyquist plots for cylindrical pores in (a) nonfaradic reactions and (b) faradic reactions [85]

\subsection{Characterization techniques}

\subsubsection{Scanning Electron Microscopy (SEM)}

Scanning Electron microscopy (SEM) is powerful imaging technique which could provide vast information about the morphology and topography of samples. In this technique, the sample is bombarded by high energy electrons and different electrons (secondary (SE) and backscattered electrons (BSE)) or characteristic X-rays is produced. These electrons and $\mathrm{X}$ - rays can be used to analyze the sample. In this thesis, SE electrons only used to investigate the morphology of glass microfibers and discharge products. To investigate the morphology of discharge products, the cathodes after discharge/charge process were harvested from $\mathrm{Li}-\mathrm{O}_{2}$ cells in the Ar-filled glovebox and rinse with TGDME solvent to 
remove all residue of LiTFSI salt. Then samples were transferred to the vacuum chamber connected to the glovebox and dried at room temperature. Dried samples were also left in glovebox for a period to make sure that they are completely dried. To avoid any moisture or oxygen contamination, the SEM sample holder was first placed in glovebox and cathodes are fixed on the sample holder by double-sided cupper tape. SEM sample holder with mounted cathode samples was then placed in Ar-filled bags and transferred to the microscopy room. The time from removing the sample from Ar-filled bags to the SEM was less than a minute to avoid any oxygen and humidity exposure. In this thesis, JEOL MultiBeam FIB 4500 SEM at low vacuum was used to take micrographs of glass microfillers and cGPE. JEOL SEM 7000 was also used to investigate the cathodes. For the cGPE investigation, cGPE was first placed in acetone solvent for one day to remove all TEGDME liquid electrolytes inside cGPE. Then cGPE without TEGDME solvent was placed in a vacuum chamber to remove all acetone solvent.

\subsubsection{X-Ray Diffraction (XRD)}

$\mathrm{X}$-ray diffraction $(\mathrm{XRD})$ is very powerful and popular technique to investigate the crystalline structures of materials. In this dissertation, XRD was used to investigate the microstructures of glass microfibers and discharge products. XRD (Siemens 5000D X-ray Diffractometer) was used to obtain the microstructures of glass microfillers. For discharge products investigation, Bruker GADDS/D8 (XRD) with MacSci rotating Molybdenum anode (l= $0.71073 \AA$ ) operated at $50 \mathrm{kV}$ generator, and $20 \mathrm{~mA}$ current was also used to collect the diffraction pattern of discharge products. A parallel X-ray beam in size of 100 $\mu \mathrm{m}$ diameter was directed on to the cathode samples, and diffraction intensities were recorded on large 2D image plate during the exposure time. 


\subsubsection{Raman Spectroscopy}

Raman spectroscopy is a spectroscopic technique commonly used to obtain the fingerprint of different chemical structures. This technique depends on inelastic scattering of monochromatic light, usually a laser. A laser light interacts with molecular vibrations and its energy being shifted. The shift in energy of the laser gives information about the vibrational mode of the chemical species. For experimentation, the sample is illuminated by the laser beam and reflected radiation from that illuminated spot is collected by a lens and transferred to the monochromator. Elastically scattered radiation at the wavelength corresponding to the laser line is filtered out by either a filter, while the rest of the collected light is dispersed onto a detector. In this dissertation, the Raman spectroscopy (BaySpec's Nomadic $^{\mathrm{TM}}$, an excitation wavelength of $532 \mathrm{~nm}$ ) was used to investigate the discharge products on the cathode samples. Raman was also performed on the liquid electrolytes, GPEs, and cGPEs to investigate the interaction of ETPTA polymer and glass microfillers with LiTFSI salt and interaction of LiTFSI salt with TEGDME molecules at different salt concentration.

\subsubsection{Brunauer-Emmett-Teller (BET)}

Brunauer-Emmett-Teller (BET) surface analysis was also used in this dissertation to investigate the surface area of the glass microfillers. The isotherm absorption-desorption of $\mathrm{N} 2$ at 77K was performed using Tri-Star II Micromeritics.

\subsubsection{Thermal Analyses}

Thermogravimetric Analysis (TGA) and Differential scanning calorimetry (DSC) was

performed in this dissertation using SDT Q600. TGA was used to examine the purity of 
glass microfillers used in this study. SDT was also carried out on the ETPTA and GPEs to determine the glass transition of the polymer.

\section{COMPOSITE GEL POLYMER ELECTROLYTE: EFFECT OF INORGANIC FILLERS CONTENT}

\subsection{Background}

As mentioned earlier in this dissertation, the $\mathrm{Li}-\mathrm{O}_{2}$ batteries suffer from poor cyclability due to the reactivity of lithium anode with oxygen crossover, cathode decomposition, and electrolyte evaporation and decomposition [11,22,30,46,86-88]. Electrolyte decomposition has been previously reported to yield the formation of solid by-products covering gradually the surface of electrodes and causing rapid capacity fading in $\mathrm{Li}-\mathrm{O}_{2}$ batteries $[31,48]$. It has been suggested that some electrolyte properties such as ionic conductivity, lithium transference number, and electrolyte-electrodes interface could affect

the electrochemical performance of $\mathrm{Li}^{-} \mathrm{O}_{2}$ batteries $[46,89,90]$. Despite many attempts aiming at developing stable electrolytes for $\mathrm{Li}-\mathrm{O}_{2}$ battery application, the choice of solvent and salt of electrolyte remains one of the biggest challenges to develop reliable $\mathrm{Li}-\mathrm{O}_{2}$ batteries. Ceramic electrolytes and solid polymer electrolytes (SPEs) have been used in Li$\mathrm{O}_{2}$ batteries to overcome the liquid electrolytes' drawbacks. However, their high interfacial resistance and low ionic conductivity limit their practical applications at ambient temperatures [53]. Gel polymer electrolytes (GPEs) composed of liquid electrolytes in polymer matrices have been successfully used in Li-ion battery applications due to their high ionic conductivity and low interfacial resistances [91-94]. GPEs of different polymersolvent pairs have been explored in $\mathrm{Li}-\mathrm{O}_{2}$ batteries and were shown to efficiently protect 
the lithium anode from oxygen crossover, and limit electrolyte evaporation $[63,64,95-$ 100]. The incorporation of inorganic fillers to both liquid and polymer electrolytes (SPEs and GPEs) has been shown to improve the $\mathrm{Li}^{+}$transport properties such as ionic conductivity and lithium transference number through the interaction of fillers with the polymer, solvent, or salt [101-108]. Although the incorporation of some inorganic fillers into different GPEs for $\mathrm{Li}^{-} \mathrm{O}_{2}$ battery application have also been initiated [109-111], most research studies have emphasized on zero-dimensional ceramic particles (e.g., nano and microparticles), and little attention has been given to one-dimensional fillers. In the present study, we investigate the influence of one-dimensional glass micro-fillers in gel polymer electrolytes using ethoxylated trimethylolpropane triacrylate polymer and tetraglymebased solvent for the $\mathrm{Li}^{-} \mathrm{O}_{2}$ battery application. Discharge/charge cycling of $\mathrm{Li}^{-} \mathrm{O}_{2}$ batteries using gel polymer electrolyte with different glass micro-filler contents along with different electrochemical and microstructural characterization techniques have been used to evaluate the performance metrics of composite GPEs.

\subsection{Experimental details}

The GPEs and cGPEs were prepared as described in chapter 2. Figure 3-1 shows the schematic of GPE and cGPEs ( $1 \mathrm{~mol} \cdot \mathrm{g}^{-1}$ LiTFSI salt concentration) preparation with their photographs after UV curing process. The glass microfibers content in cGPEs were changed from $0.5,1,2,5$ wt. $\%$ (hereinafter cGPEs- $0.5 \%$, cGPE-1\%, cGPE- $2 \%$ and cGPE$5 \%)$. 

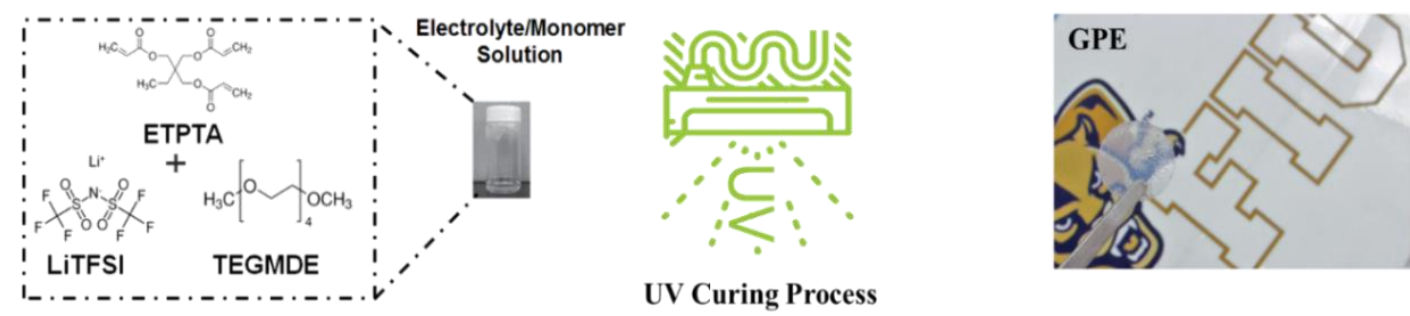

UV Curing Process
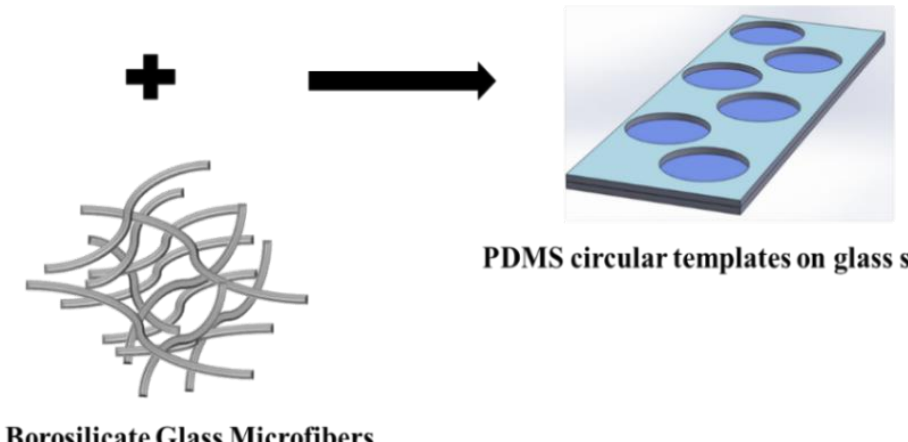

PDMS circular templates on glass slide

Borosilicate Glass Microfibers

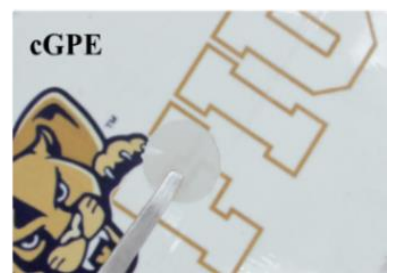

Figure 3-1: Schematic representation illustrating the GPE and cGPEs preparation along with photographs depicting the physical appearance of GPE and cGPE-1\%

The ionic conductivity was measured by trapping the GPE and cGPEs with different content of glass microfibers between two blocking stainless steel as described in chapter 2 . The content of ETPTA monomer to TEGDME electrolyte in all GPEs in this dissertation was optimized based on their ionic conductivity and mechanical properties in such way to have the highest ionic conductivity and free-standing film. Table 3-1 depicts the ionic conductivity of GPEs with their corresponding electrolyte content. As it is clear the ionic conductivity of GPEs increase with the increase in electrolyte content. 85 wt.\% of TEGDME was the highest content of electrolyte in GPEs which gives freestanding films; however, their mechanical properties were very poor, and films were easily torn (Figure 3-2). 
Table 3-1: Ionic conductivity of GPEs versus their electrolyte content

\begin{tabular}{cc}
\hline $\begin{array}{c}\text { Electrolyte content in GPEs } \\
(\mathbf{w t} \%)\end{array}$ & $\begin{array}{c}\text { Ionic conductivity } \\
\left(\mathbf{m S} \cdot \mathbf{c m}^{-\mathbf{1}}\right)\end{array}$ \\
\hline 100 (pure electrolyte) & 2.56 \\
15 & $6.35^{*} 10^{-9}$ \\
20 & $3.4^{*} 10^{-4}$ \\
50 & 0.016 \\
75 & 0.5 \\
80 & 1.0 \\
85 & 1.1 \\
\hline
\end{tabular}

Hence, the GPEs with the ratio of 20:80 (ETPTA: Electrolyte) by weight were prepared and investigated in the entire dissertation.

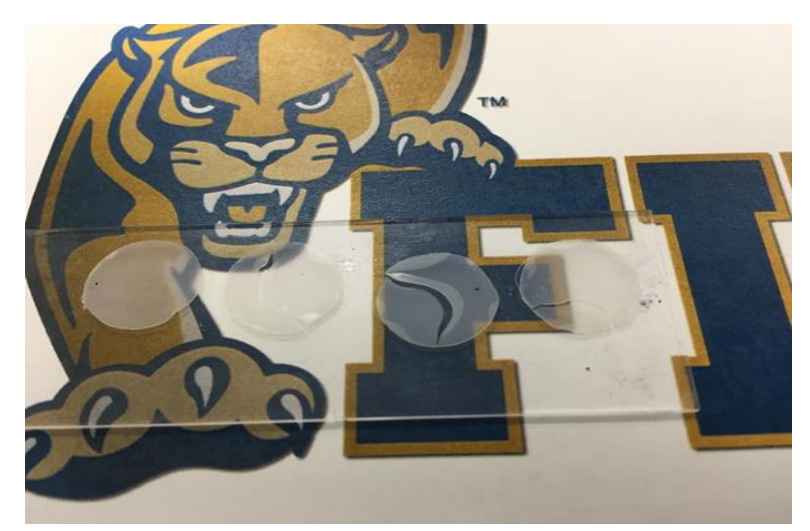

Figure 3-2: GPEs with 85 wt.\% electrolyte content showing poor mechanical properties

$\mathrm{Li}^{+}$transference number was also determined by the Bruce-Vincent method as described in chapter 2. Two-stage DC polarization [112] was utilized in this dissertation to accurately determine the $I_{0}$. The first stage ran with the fast sampling rate (intervals between measurements at $10 \mathrm{~ms}$ ) lasting for 80 seconds. The external potential step is applied with 
a delay of about 20 seconds in respect to starting of this stage to properly determine initial current. The second stage executed immediately after the first stage with the slower sampling rate (intervals between measurements of $1 \mathrm{~s}$ ). This step ran until a steady-state current $\left(\mathrm{I}_{\mathrm{ss}}\right)$ is reached. CNTs coated carbon cloth gas diffusion layer (CCGDL) cathodes were also prepared as described in experimental section. Figure 3-3 illustrates the optical and SEM images of pristine and CNTs-coated CCCGDL.

Galvanostatic charge/discharge tests were performed using MTI battery tester at the constant current density of $250 \mathrm{~mA} \cdot \mathrm{g}^{-1}$ within the voltage range of 2.0-4.5 V. In-situ EIS measurements were also conducted using a Gamry Reference 600 in the frequency range of $100 \mathrm{kHz}$ to $100 \mathrm{mHz}$ using $10 \%$ of DC discharge current during cycling test. All charge/discharge and EIS studies were carried out at $25^{\circ} \mathrm{C}$. Cathodes after charge/discharge were also extracted from $\mathrm{Li}_{-} \mathrm{O}_{2}$ cells and characterized by Raman spectroscopy (BaySpec's Nomadic ${ }^{\mathrm{TM}}$, an excitation wavelength of $532 \mathrm{~nm}$ ) and XRD (Bruker GADDS/D8 with MacSci rotating Molybdenum anode (I= $0.71073 \AA$ ) ). 


\subsection{Results and Discussion}

The SEM micrograph of the glass microfibers in Figure 3-4 confirms the one-dimensional morphology of the glass microfillers with an average diameter of approximately $1 \mu \mathrm{m}$ and an aspect ratio exceeding 100. Figure 3-4 also shows the microstructural characterization of glass microfillers using XRD, BET, and TGA in addition to depicting the cross-section of cGPE- $1 \%$. XRD pattern of the microfibers exhibited a broadened peak, demonstrating that the glass fillers used in this work have an amorphous phase. The surface area of microfibers was measured to be around $0.5 \mathrm{~m} 2 \cdot \mathrm{g}^{-1}$ by $\mathrm{N}_{2}$ adsorption-desorption isotherm at $77 \mathrm{~K}$, indicating that the microfibers were non-porous. The purity of the microfibers was confirmed using TGA analysis up to $1000^{\circ} \mathrm{C}$ with no detectable humidity and impurities. A cross-sectional SEM image of the cGPE-1\% (Figure 3-4 (e-f)) shows that the microfibers are uniformly distributed with no apparent agglomeration in any direction.
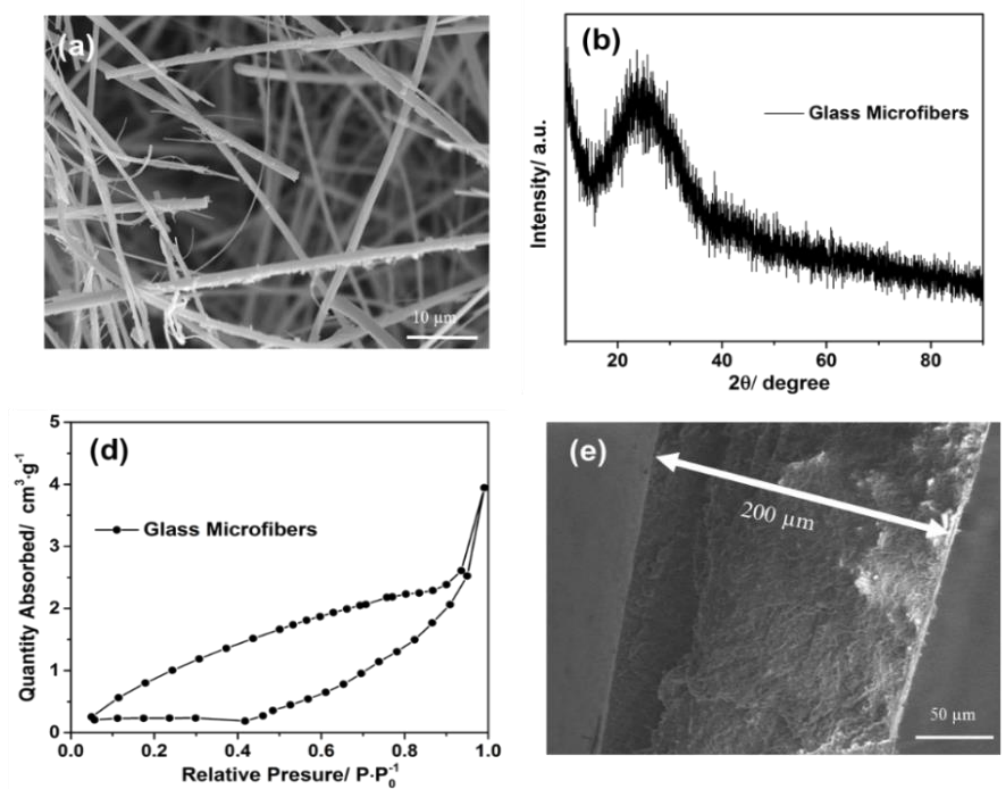
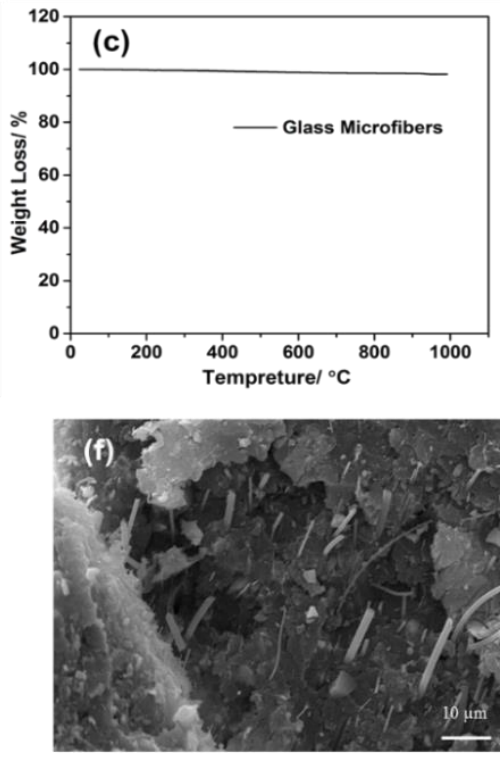

Figure 3-4: (a) SEM micrograph (b) XRD pattern (c) TGA analysis (d) BET surface area measurement of glass microfibers (e-d) the SEM micrographs of cross-sectional cGPE-1\% 
The polymer ETPTA was selected in this dissertation due to its following advantages. (1) The simplicity of the preparation of GPEs [113] (2) electrochemical stability in the voltage range of 2.0-4.5 $\mathrm{V}$ [95] (3) high mechanical properties which afforded high electrolyte contents (80\%) in the GPEs [113] and (4) its demonstrated compatibility with Li-O 2 battery components [97]. Thermal properties of ETPTA polymer was also measured. Figure 3-5 shows the thermal stability and glass transition $\left(\mathrm{T}_{\mathrm{g}}\right)$ of ETPTA polymer used in this dissertation. As it is clear, the ETPTA polymer is stable up to $\sim 350^{\circ} \mathrm{C}$ suggesting that the ETPTA is thermally stable and can protect the battery from thermal runaway. The glass transition of ETPTA is also measured to be $73^{\circ} \mathrm{C}$ [113]. The high glass transition of ETPTA demonstrates a little contribution of ETPTA into ion conduction in GPEs and cGPEs.
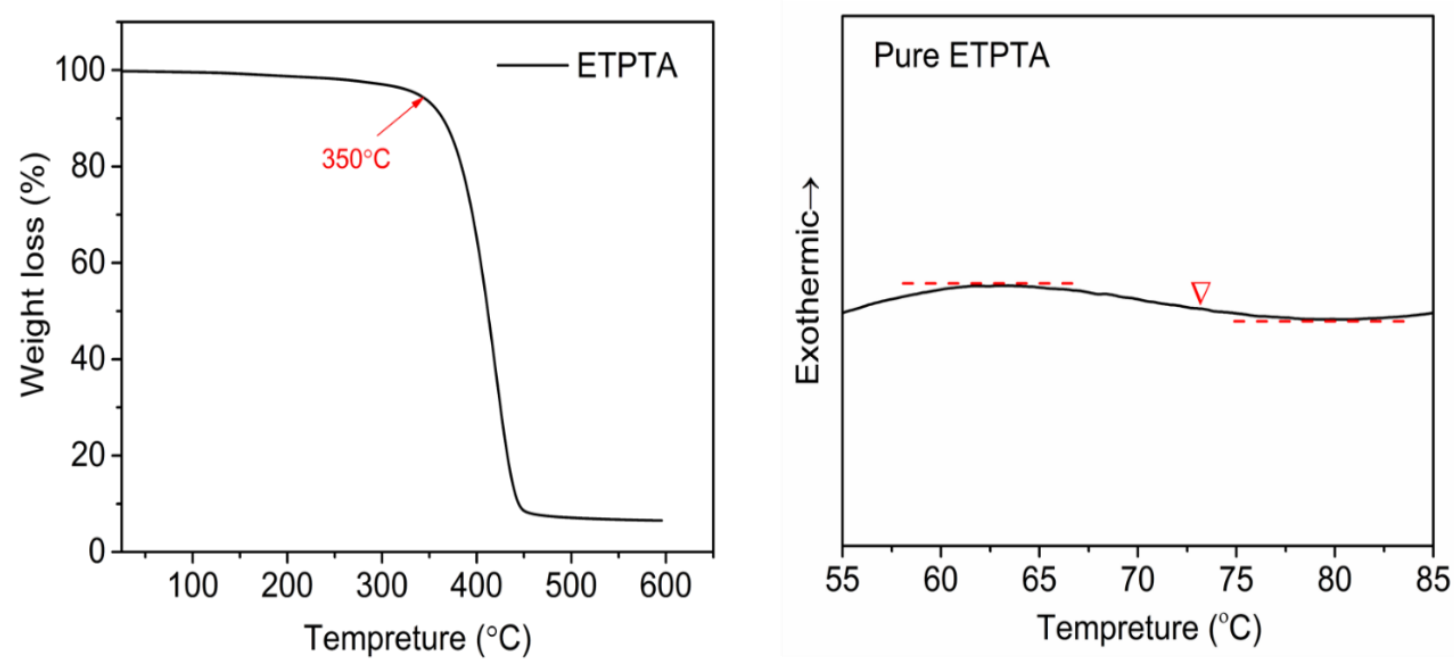

Figure 3-5: Thermal properties of ETPTA polymer (a) TGA analysis showing the thermal stability of polymer (b) DSC analysis showing the glass transition ( $\mathrm{T}_{\mathrm{g}}$ ) of ETPTA polymer

The ionic conductivity $(\sigma)$ and lithium transference number $\left(t_{L i}{ }^{+}\right)$of the GPE and cGPEs were measured at room temperature $\left(25^{\circ} \mathrm{C}\right)$, and the results are summarized in Table $3-2$. 
Figure 3-6 shows typical Chronoamperometric curves of symmetrical Li/Li cells using GPE and cGPE-1\% after $10 \mathrm{mV}$ of DC polarization along with the corresponding impedance spectra before and after polarization.
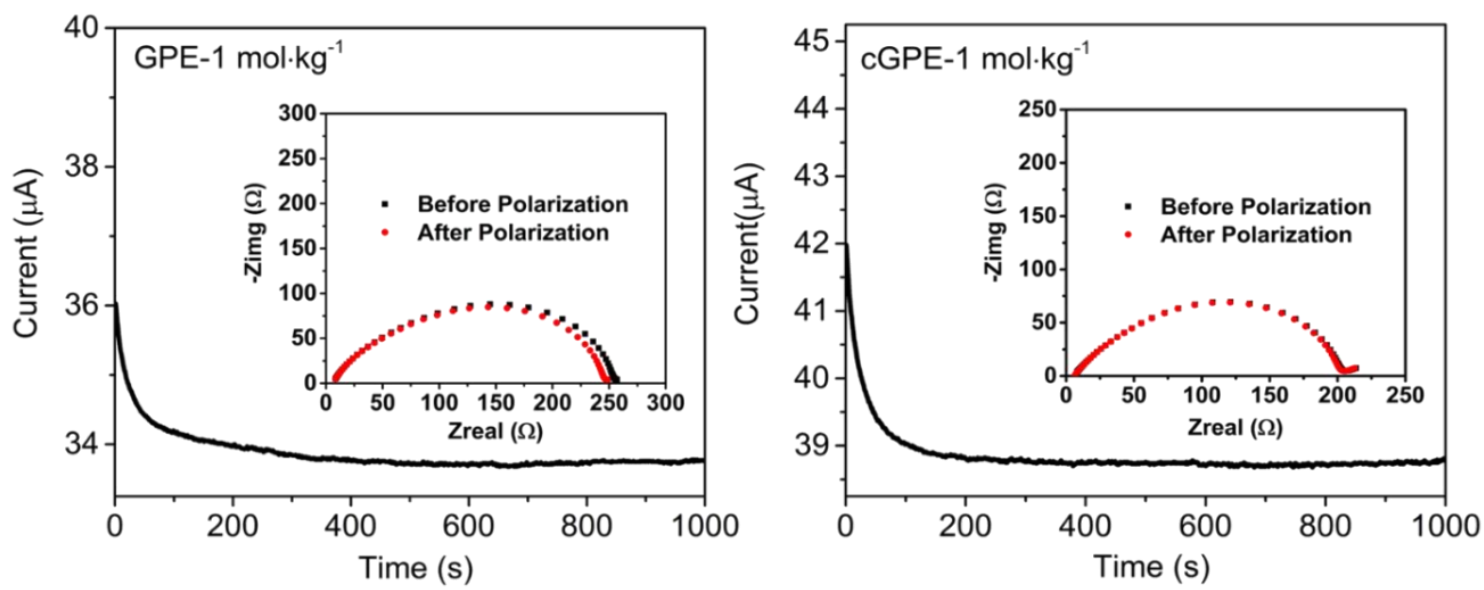

Figure 3-6: Chronoamperometric curves of Li/GPE and cGPE-1\%/Li cell after $10 \mathrm{mV}$ of DC polarization at $25^{\circ} \mathrm{C}$ where the electrolyte films contain $1 \mathrm{~mol} \cdot \mathrm{kg}^{-1} \mathrm{LiTFSI}$ salt. Insets: electrochemical impedance spectra before and after polarization.

As can be seen from Table 3-2, the GPE shows a good ionic conductivity of $1.02 \mathrm{mS} \cdot \mathrm{cm}^{-1}$ and a $t_{L i}{ }^{+}$of 0.53 . The transference number of GPE is in agreement with previously reported values for glyme-based GPEs $[114,115]$. The ion conduction contribution of ETPTA in GPEs was negligible. The LiTFSI salt was added to ETPTA polymer to make solid polymer electrolytes (SPEs), and their ion conductivities were also measured. In the saturated LiTFSI salt concentration, the ionic conductivity of SPE at $25^{\circ} \mathrm{C}$ was measured to be around $0.005 \mathrm{mS} \cdot \mathrm{cm}^{-1}$. Thus, comparing the ionic conductivity of GPE and SPE at $25^{\circ} \mathrm{C}$ confirms that ETPTA does not significantly contribute to ion conduction in GPEs. Upon addition of the micro-fillers, both $\sigma$ and $t_{L i}{ }^{+}$increased with the increase in fillers content until 1\%, then started to drop upon increasing the fillers content. This increase is attributed to the interaction between the filler materials and the ions in the cGPE, namely the 
adsorption of the TFSI counter-ions on the surface of glass microfibers and the formation of ion-ceramic complexes. This interaction increases the ion pair dissociation as previously reported $[73,101,108,116]$. This dissociation increases the free $\mathrm{Li}^{+}$, affording them to be transported easier through the percolating pathways of the microfibers. This means that the $\mathrm{Li}^{+}$transport enhancement is dependent on the formation of continuous filler network $[117,118]$. Hence filler loading more than the percolation threshold is needed. Conversely, excessive filler loading led to their aggregation and thus blockage of the conducting pathways of $\mathrm{Li}^{+}$ions $[108,117,118]$. This trade-off in effect of the addition of fillers suggests the existence of an optimum loading. The optimum loading amount was determined to be $1 \%$ in this work.

Table 3-2: Summary of ionic conductivity and lithium ion transference numbers of GPE and cGPEs with different glass micro-filler contents.

\begin{tabular}{cccc}
\hline $\begin{array}{c}\text { Gel Polymer } \\
\text { Electrolytes }\end{array}$ & $\begin{array}{c}\text { Transference } \\
\text { Number, } \boldsymbol{t}_{\boldsymbol{L} i}{ }^{+}\end{array}$ & $\begin{array}{c}\text { Ionic } \\
\text { Conductivity, } \boldsymbol{\sigma} \\
(\mathbf{m S} / \mathbf{c m})\end{array}$ & $\begin{array}{c}\mathbf{L i}^{+} \text {Conductivity, } \\
\boldsymbol{\sigma}_{L i+}(\mathbf{m S} / \mathbf{c m})\end{array}$ \\
\hline GPE & 0.53 & $1.02 \pm 0.05$ & 0.54 \\
cGPE-0.5\% & 0.58 & $1.12 \pm 0.02$ & 0.65 \\
cGPE-1\% & 0.66 & $1.40 \pm 0.02$ & 0.92 \\
cGPE-2\% & 0.52 & $0.95 \pm 0.05$ & 0.50 \\
cGPE-5\% & 0.48 & $0.75 \pm 0.02$ & 0.36 \\
\hline
\end{tabular}

The oxidation stability limit of GPE and cGPE-1\% was also determined using a chronopotentiometric stability test and linear sweep voltammetry (LSV) under the oxygen atmosphere (Figure 3-7). For the chronopotentiometric test, $\mathrm{Li}^{-} \mathrm{O}_{2}$ batteries using GPE and cGPE- $1 \%$ were assembled and charged with no cutoff voltage at the current density of 250 $\mathrm{mA} \cdot \mathrm{g}^{-1}$ without prior discharging for $10 \mathrm{~h}$. For LSV tests, GPE and cGPE-1\% were placed 
between lithium foil as a reference and counter electrode, and a standard cathode (MWCNTs-CCGDL) as a working electrode. Voltage was scanned at a rate of $1 \mathrm{mV} \cdot \mathrm{s}^{-1}$.
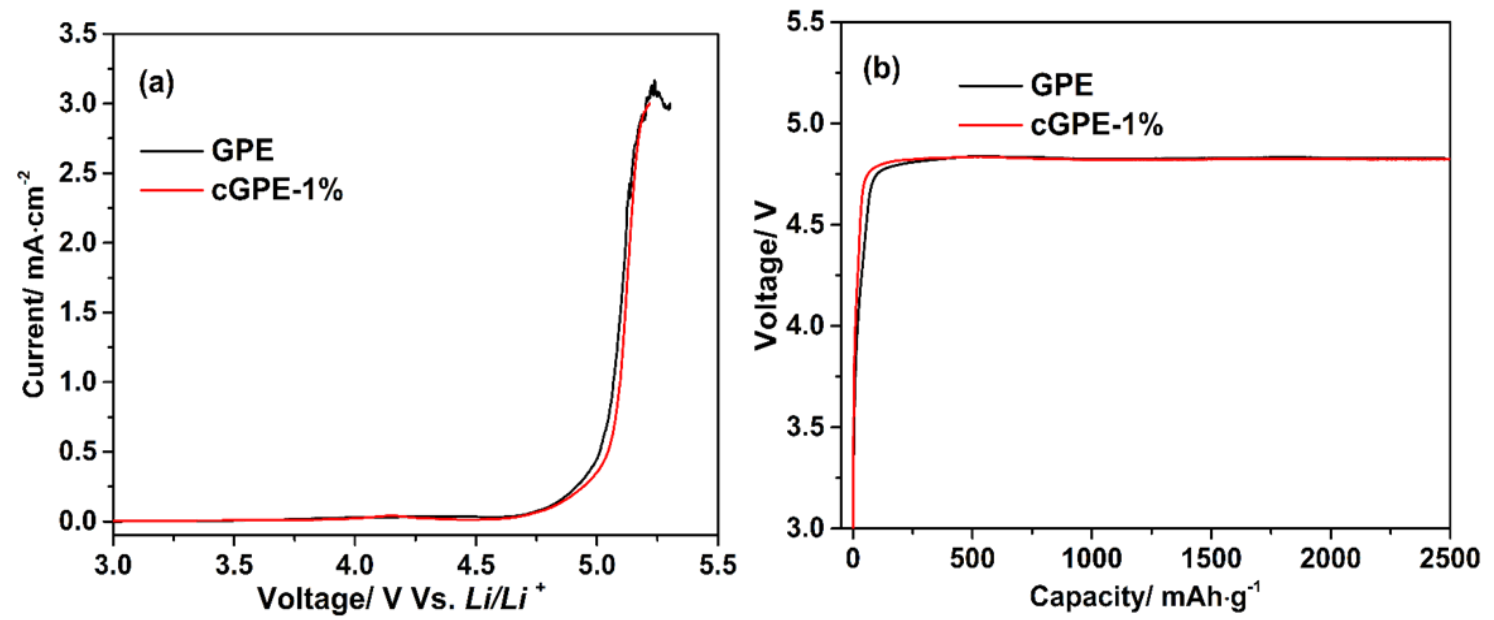

Figure 3-7: (a) Linear sweep voltammograms for $\mathrm{Li}-\mathrm{O}_{2}$ batteries using GPE and cGPE$1 \%$ with the scanning rate of $1 \mathrm{mV} \cdot \mathrm{s}^{-1}$ under oxygen. (b) Chronopotentiometric test of Li$\mathrm{O}_{2}$ batteries using GPE and cGPE- $1 \%$ at $250 \mathrm{~mA} \cdot \mathrm{g}^{-1}$ for 10 hours.

From the voltammograms and chronopotentiometric tests, the microfibers do not change the oxidation stability of GPE [119], as GPE and cGPE-1\% show anodic stabilities up to 4.75 V. Furthermore, anodic stability at around $4.75 \mathrm{~V}$ for GPE and cGPE-1\% suggests that the polymer used in this study is electrochemically stable under oxygen environment since the anodic stability of 1M LiTFSI in TEGMDE has been also reported at 4.75 under oxygen (Figure 3-8) [48]. 


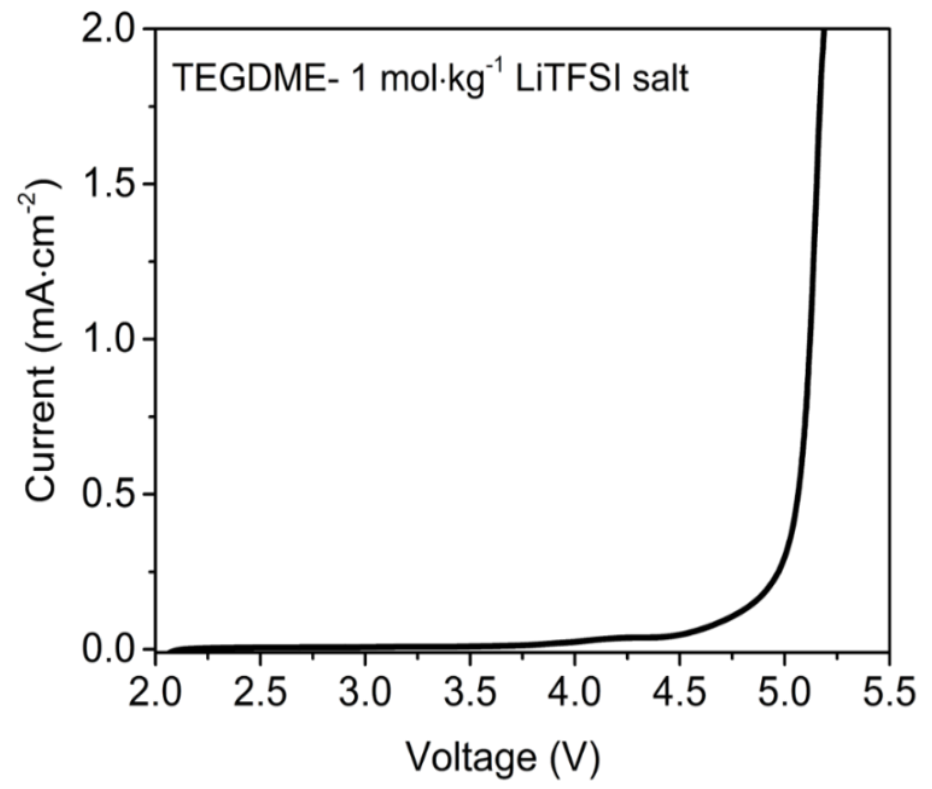

Figure 3-8: Linear sweep voltammogram of $\mathrm{Li}^{-\mathrm{O}_{2}}$ battery using liquid electrolyte with $1 \mathrm{~mol} \cdot \mathrm{kg}^{-1}$ LiTFSI

To provide more details on the contribution of microfibers in GPE on $\mathrm{Li}_{-} \mathrm{O}_{2}$ battery performance, galvanostatic discharge/charge cycling studies were performed at current densities of $250 \mathrm{~mA} \cdot \mathrm{g}^{-1}\left(0.125 \mathrm{~mA} \cdot \mathrm{cm}^{-2}\right)$ and fixed cycle capacities of $500 \mathrm{mAh} \cdot \mathrm{g}^{-1}$ in the voltage window 2.0-4.5. To initiate the charge/discharge experiment, the $\mathrm{Li}_{-} \mathrm{O}_{2}$ cells were rested under pressurized extra pure oxygen gas ( 5 psi gauge pressure), and open circuit voltage $(\mathrm{OCV})$ of cells was monitored. In our experiment, it turned out that the rate of OCV change after 5 hours is less than $5 \mathrm{mV} \cdot \mathrm{h}^{-1}$ (Figure 3-9). 

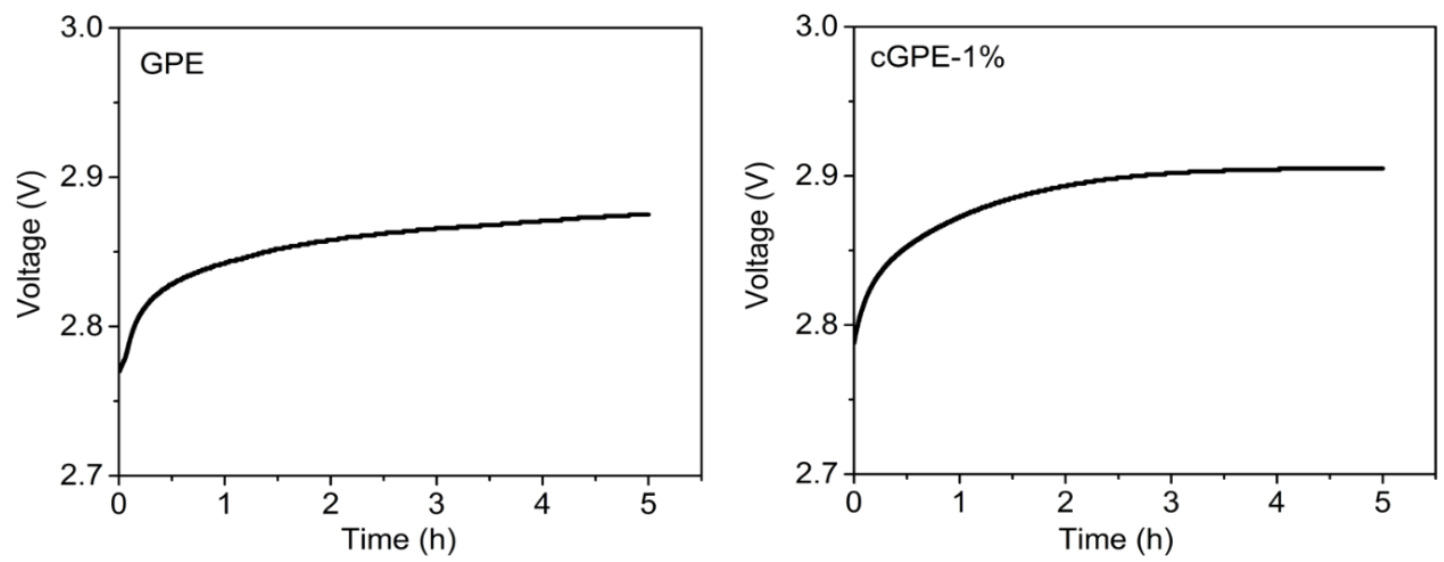

Figure 3-9: Open circuit voltage (OCV) of $\mathrm{Li}-\mathrm{O}_{2}$ cells using GPE and cGPE-1\% under oxygen versus time

Hence, 5 hours of resting was considered as the relaxation time for all $\mathrm{Li}-\mathrm{O}_{2}$ cells before charge/discharge cycling test. From Figure 3-10, cells using cGPE-1\% show the highest discharge cycling performance with a median performance of 54 consecutive discharge cycles comparing to cGPE- $0.5 \%$ of 38 , cGPE- $2 \%$ of 30 cycles, cGPE-5\% of 27 cycles, and the no-filler GPE of 29 cycles. Similar to the ionic conductivity and transference number experiments, cGPE-1\% had the best performance, indicating the impact of the improvement of the ionic conductivity and transference number of the cGPE on the full cell. This observation is in agreement with previous studies showing that electrolytic properties in $\mathrm{Li}-\mathrm{O}_{2}$ batteries such as ionic conductivity, lithium transference number, and stability of interfacial resistances play a significant role in $\mathrm{Li}-\mathrm{O}_{2}$ battery behavior $[46,89,90]$. 

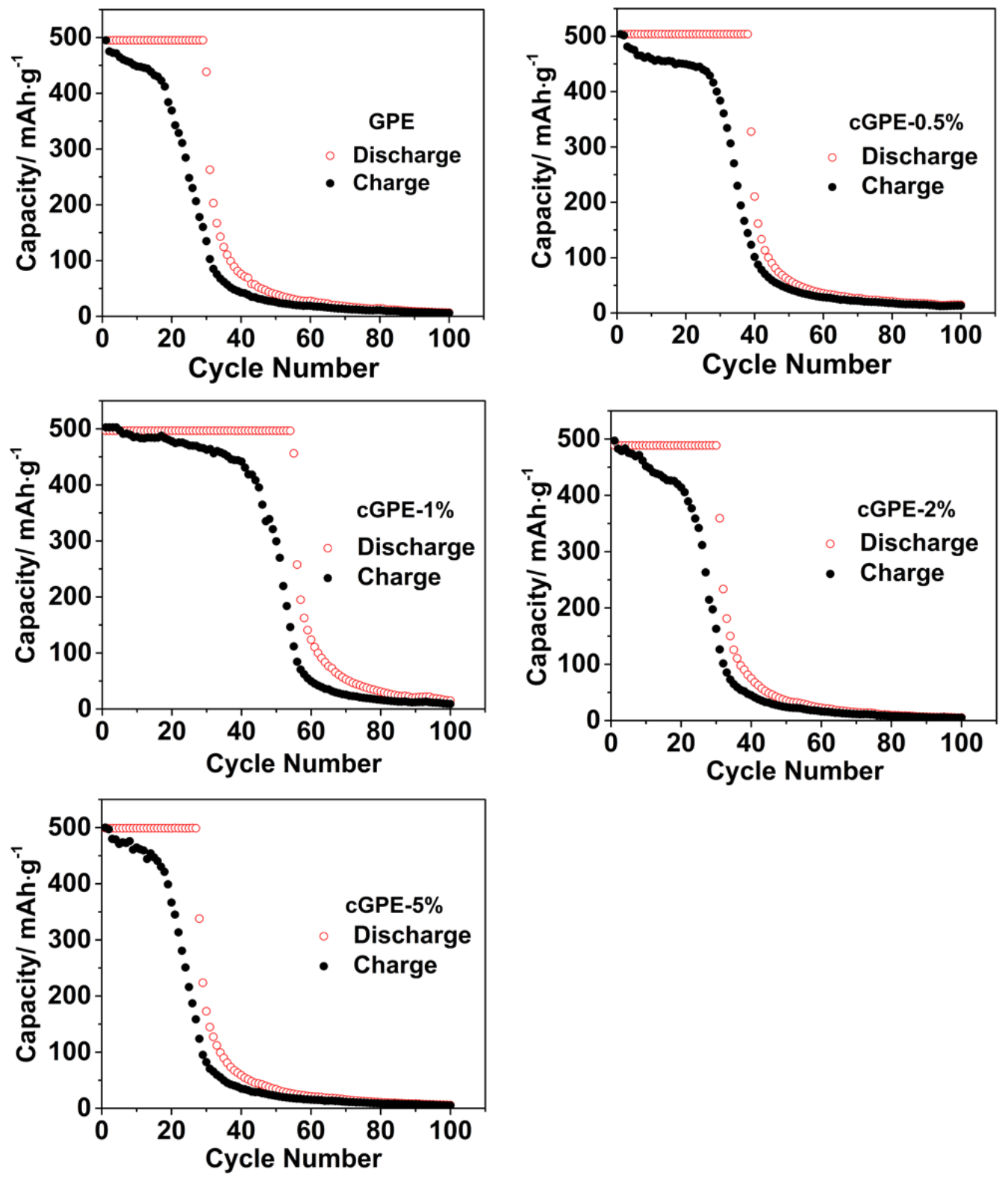

Figure 3-10: Cyclability of the $\mathrm{Li}-\mathrm{O}_{2}$ batteries for fixed charge and discharge cycle capacities of $500 \mathrm{mAh} \cdot \mathrm{g}^{-1}$ at a current density of $250 \mathrm{~mA} \cdot \mathrm{g}^{-1}$ with voltage cutoffs of 2.0 $4.5 \mathrm{~V}$ for GPE and cGPEs with various glass microfibers contents.

Figure 3-11 also shows the voltage profile of $\mathrm{Li}-\mathrm{O}_{2}$ batteries using GPE and cGPEs with different glass microfibers at current density of $250 \mathrm{~mA} \cdot \mathrm{g}^{-1}\left(0.125 \mathrm{~mA} \cdot \mathrm{cm}^{-2}\right)$ and at fixed cycle capacities of $500 \mathrm{mAh} \cdot \mathrm{g}^{-1}$ in the voltage window 2.0-4.5. As can be seen, the charge 
and discharge voltage plateau of cells using GPE and cGPEs does not change significantly confirming that the glass microfibers do not interfere with OER and ORR process.
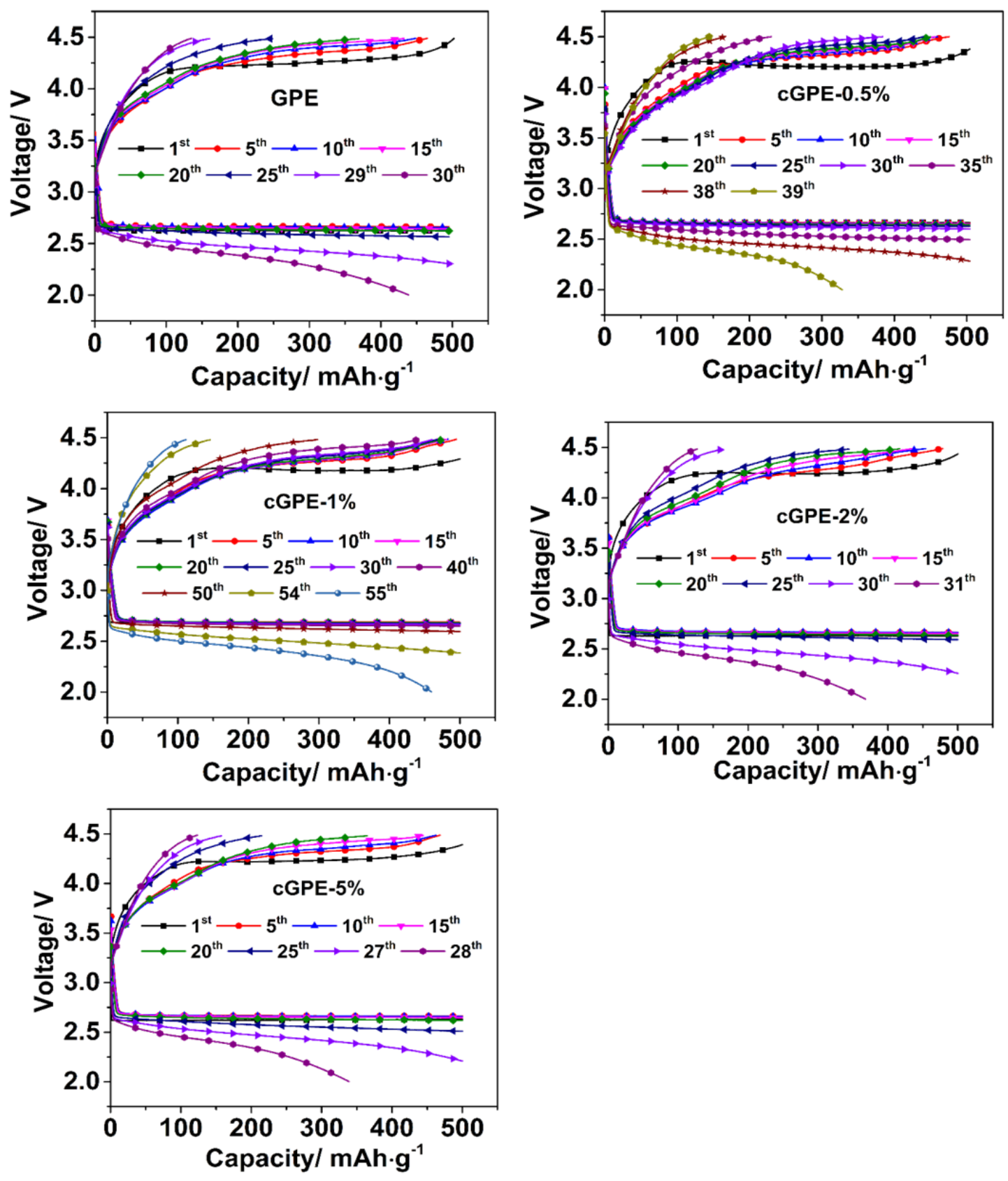

Figure 3-11: The voltage profile of $\mathrm{Li}-\mathrm{O}_{2}$ batteries using GPE and cGPE with different glass microfiber content 
To further confirm the contribution of glass microfibers in ORR and OER, the cyclic voltammetry $(\mathrm{CV})$ was performed on the $\mathrm{Li}-\mathrm{O}_{2}$ batteries using the GPE and cGPE-1\% in a voltage windows of 2.0-4.5 $\mathrm{V}$ at a scan rate of $1 \mathrm{mV} \cdot \mathrm{s}^{-1}$ under oxygen (Figure 3-12).

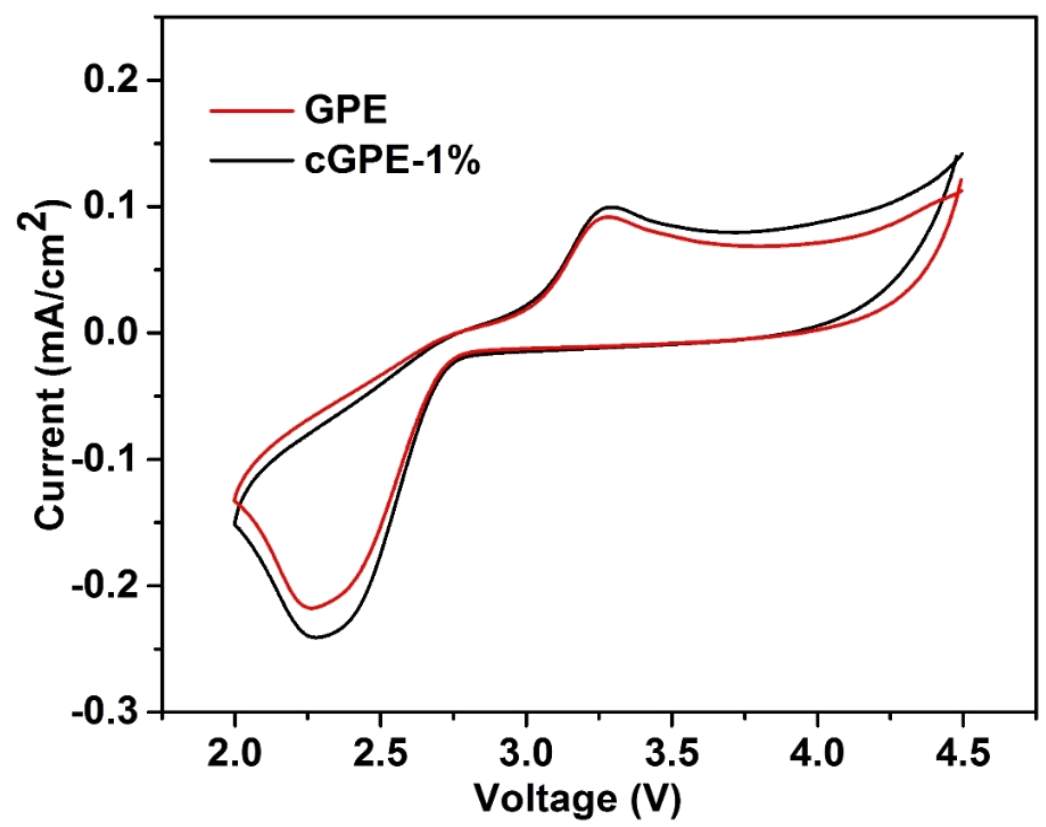

Figure 3-12: Cyclic voltammograms of $\mathrm{Li}^{-\mathrm{O}_{2}}$ batteries using GPE and cGPE-1\% in voltage windows of $2.0-4.5 \mathrm{~V}$ and scan rate of $1 \mathrm{mV} \cdot \mathrm{s}^{-1}$

As can be seen, the onset of ORR peak occurs at $2.8 \mathrm{~V}$ for both GPE and cGPE-1\%. The peak at $3.3 \mathrm{~V}$ could also be attributed to the OER. The similarity between the ORR and OER of cells using GPE and cGPE-1\% proves that the glass microfibers do not alter the $\mathrm{Li}_{2} \mathrm{O}_{2}$ formation/decomposition. The slight higher cathodic and anodic current in the cell using cGPE-1\% could be due to the higher ionic conductivity of cGPE-1\% over GPE.

To confirm the formation of $\mathrm{Li}_{2} \mathrm{O}_{2}$ on the cathode, oxygen cathodes were investigated by XRD and Raman spectroscopy. Figure 3-13 shows the XRD patterns and Raman spectra of oxygen cathodes using both GPE and cGPE-1\%. The diffraction peaks of $\mathrm{Li}_{2} \mathrm{O}_{2}$ can be observed after the discharge process suggesting that $\mathrm{Li}_{2} \mathrm{O}_{2}$ is the main product in the 
discharge process with either electrolyte. Raman spectra of discharged cathodes similarly show Raman shifts at $790 \mathrm{~cm}^{-1}$ which corresponds to $\mathrm{Li}_{2} \mathrm{O}_{2}$ formation [120]. Raman spectra also show the two Raman shifts at $1350 \mathrm{~cm}^{-1}$ and $1580 \mathrm{~cm}^{-1}$ corresponding to the $\mathrm{D}$ and $\mathrm{G}$ bands of carbon nanotubes. The formation of $\mathrm{Li}_{2} \mathrm{O}_{2}$ on the surface of cathodes using GPE and cGPEs suggest that discharge capacities mainly result from the formation of $\mathrm{Li}_{2} \mathrm{O}_{2}$.
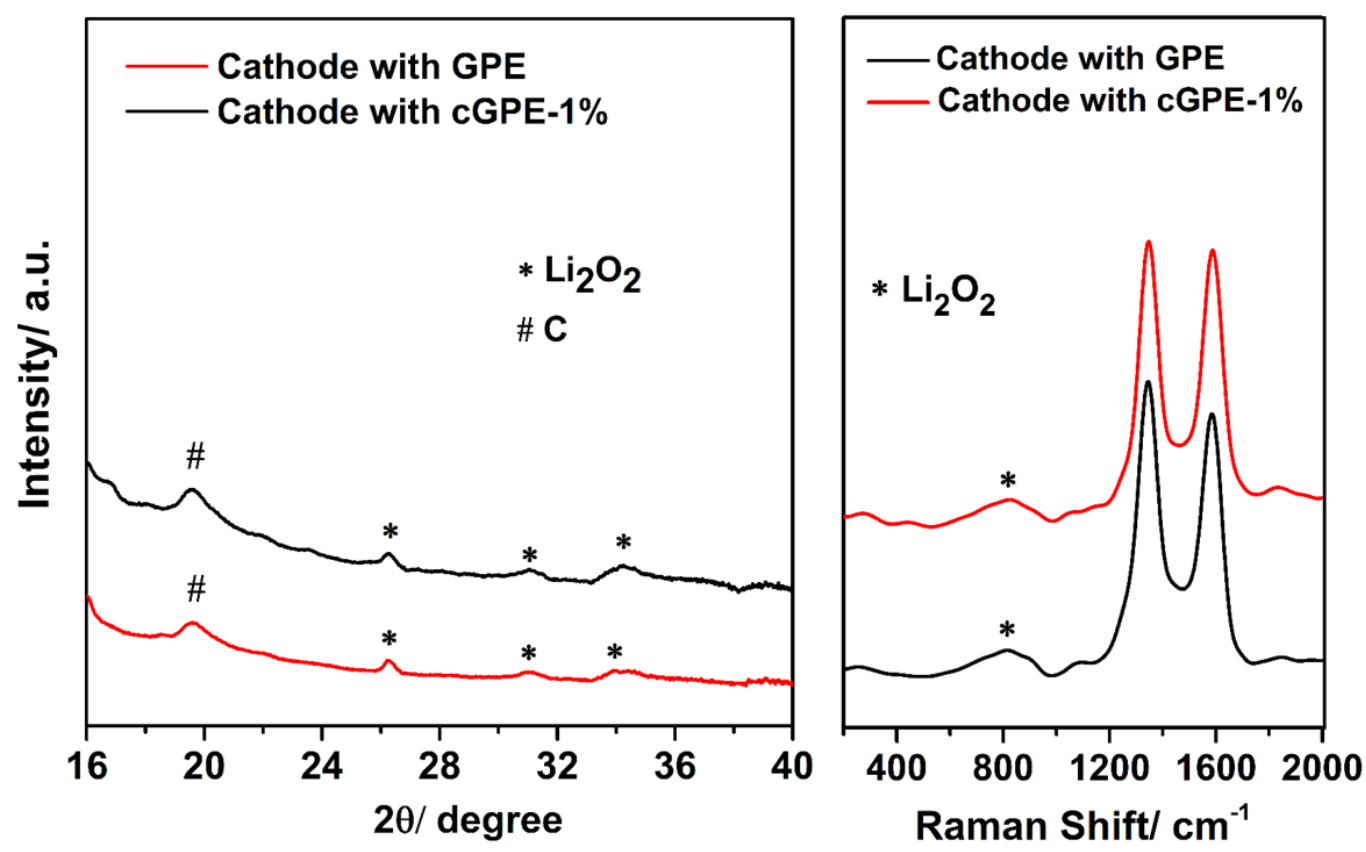

Figure 3-13: XRD patterns (left) and Raman spectra (right) of oxygen cathodes after a $500 \mathrm{mAh} \cdot \mathrm{g}^{-1}$ discharge of $\mathrm{Li}-\mathrm{O}_{2}$ batteries using GPE and cGPE-1\%.

In order to measure the contribution of background capacity of CCGDL to total capacity of $\mathrm{Li}-\mathrm{O}_{2}$ batteries per cycle [121], the $\mathrm{Li}-\mathrm{O}_{2}$ cell was assembled using CNTs-free CCGDL with presoaked Celgard separator with $1 \mathrm{~mol} \cdot \mathrm{kg}^{-1}$ LiTFSI salt electrolyte and charged/discharged in a voltage windows of 2.0-4.5 V at $125 \mu \mathrm{A}$ (equivalent to the 250 $\mathrm{mAh} \cdot \mathrm{g}_{\mathrm{CNT}}{ }^{-1}$ current density of $\mathrm{Li}-\mathrm{O}_{2}$ cells with $\mathrm{CNT}$ loading of $0.5 \mathrm{mg}$, which was the typical loading used in this work). Figure 3-14 shows the voltage profile of cell using CNT- 
free GDL in full discharge mode along with cell using CNT-coated GDL using GPE-1 $\mathrm{mol} \cdot \mathrm{kg}^{-1}$ LiTFSI with partial $500 \mathrm{mAh} \cdot \mathrm{g}_{C N T s}^{-1}$ at $125 \mu \mathrm{A}$ current in a voltage window of 2.0-4.5V. The calculated capacity of cell using GDL up to $2.60 \mathrm{~V}$ was only $1 \mu \mathrm{Ah}$. Moreover, the actual partial capacity of cell using CNT-coated GDL up to the $2.60 \mathrm{~V}$ was $250 \mu \mathrm{Ah}\left(500 \mathrm{mAh} \cdot g_{C N T S}^{-1} * 0.5 \mathrm{mg}\right.$ of CNTs), so the capacity background contribution of GDL to the total capacity per cycle was only $0.4 \%$.

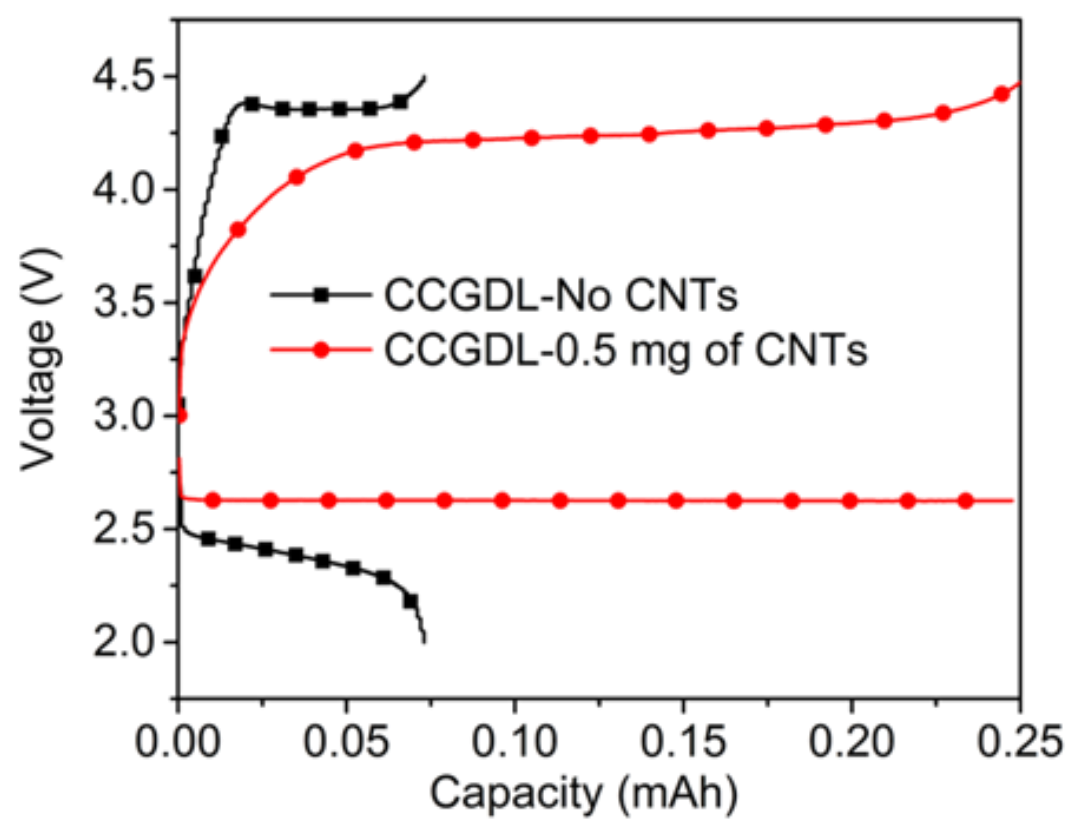

Figure 3-14: The voltage profile of $\mathrm{Li}_{2} \mathrm{O}_{2}$ cell using CNT-free CCGDL in full discharge/charge mode along with cell using CCGDL-0.5 mg of CNTs in partial 500 $\mathrm{mAh} \cdot \mathrm{g}^{-1}$ charge/discharge capacity mode at $125 \mu \mathrm{A}$ current and voltage windows of 2.0-4.5 V

These results confirm that the CCGDL contribution to the total capacity of cells in partial charge/discharge of $500 \mathrm{mAh} \cdot \mathrm{g}^{-1}$ is very negligible. In situ EIS studies have been performed between $100 \mathrm{kHz}$ to $100 \mathrm{mHz}$ on $\mathrm{Li}-\mathrm{O}_{2}$ batteries using GPE and cGPEs after discharge during cycling and the Nyquist plots of cells using GPE and cGPE-1\% are shown 
in Figure 3-15 (a-b). The Nyquist plots consist of a semicircle corresponding to the total interfacial resistance between the electrolyte and the electrodes with a tail in the lowfrequency region representing a semi-infinite Warburg resistance due to a diffusion controlled process of lithium ions and oxygen in the cathode [122,123]. Figure 3-15 (c) shows the change of interfacial resistance for all $\mathrm{Li}^{-\mathrm{O}_{2}}$ batteries using GPE and cGPEs with different microfibers contents versus discharge cycle numbers up to their failure cycle (last discharge cycle with the capacity of at least $500 \mathrm{mAh} \cdot \mathrm{g}^{-1}$ ).
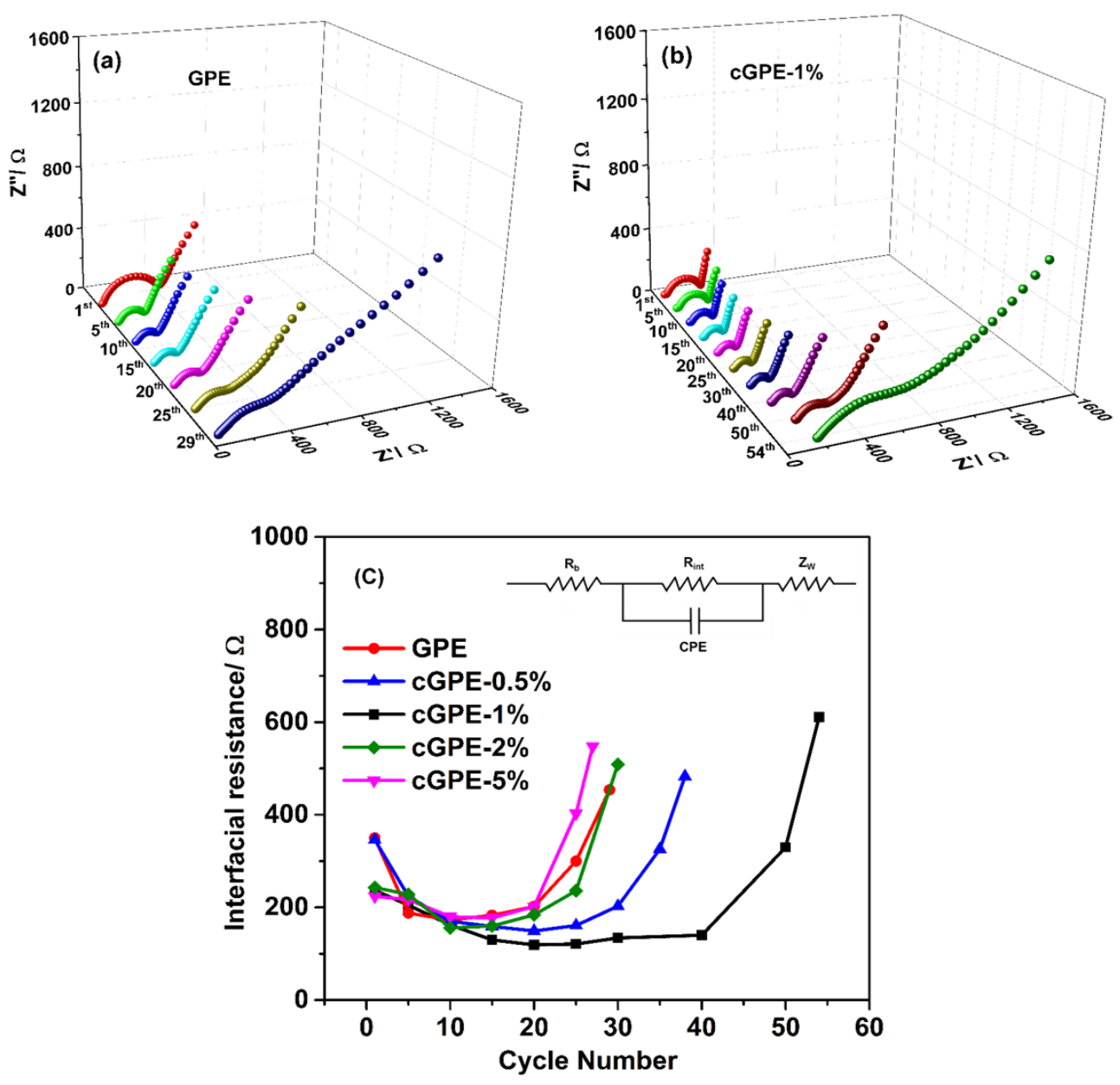

Figure 3-15: AC impedance Nyquist plots of $\mathrm{Li}_{2} \mathrm{O}_{2}$ batteries using GPE (a) and cGPE-1\% (b) during cycling after discharge and (c) Evolution of interfacial resistance of all $\mathrm{Li}-\mathrm{O}_{2}$ batteries using GPE and cGPEs against select cycle numbers. 
As can be seen, adding the glass microfibers into GPE reduces the interfacial resistance of $\mathrm{Li}_{-} \mathrm{O}_{2}$ cell even before cycling (Figure 3-16).

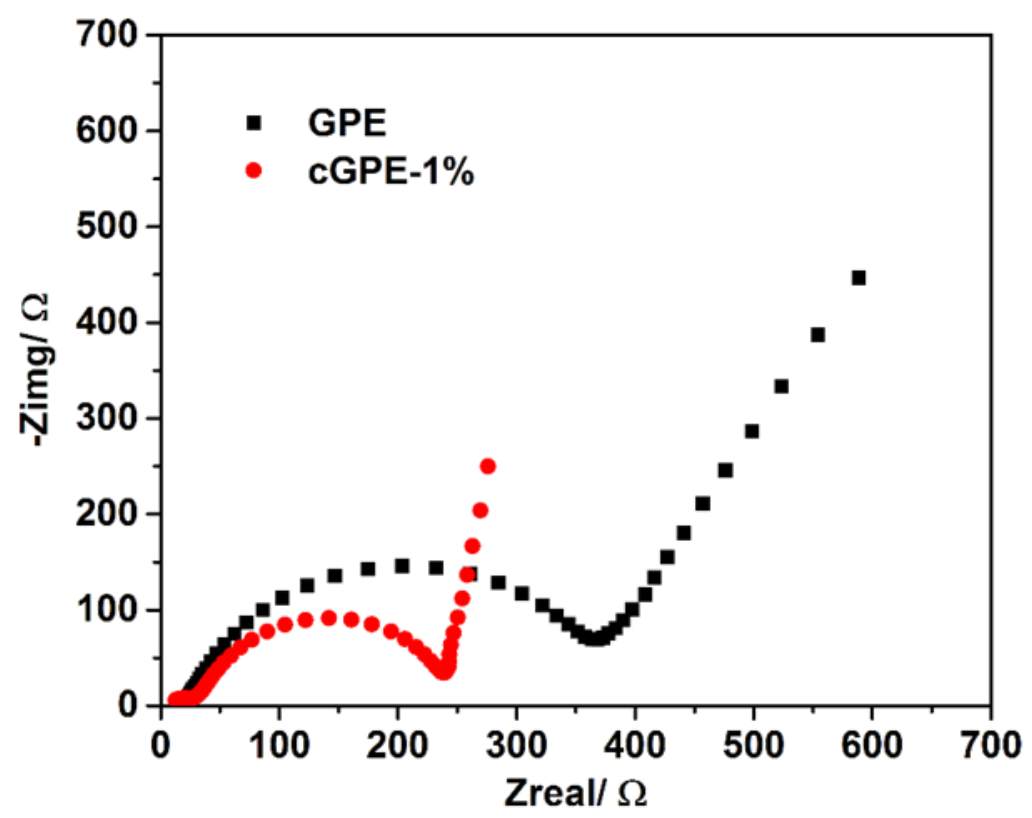

Figure 3-16: The EIS spectra of $\mathrm{Li}-\mathrm{O}_{2}$ cells using GPE and cGPE-1\% before charging under Ar atmosphere

This could be due to the fact that the glass microfibers lead to hold more liquid electrolytes in cGPEs and in turn reduce the contact of liquid electrolyte and Li metals, which react with Li metal. Further, the interfacial resistance for cells started to decrease during the initial cycles and then steadily grew until their failure cycles. A decrease in interfacial resistance upon cycling in metal- $\mathrm{O}_{2}$ and $\mathrm{Li}$-ion batteries has been previously observed due to dendrite growth [124] or partial dissolution of the passivation film on the anodeelectrolyte interface $[125,126]$. In later cycles, the observed increase in the interfacial resistance can be explained by the accumulation of the charge/discharge products/byproducts on the anode-electrolyte [30-32] and cathode-electrolyte interfaces 
$[123,127,128]$. From Figure 3-15 (c), the interfacial resistance of $\mathrm{Li}^{-\mathrm{O}_{2}}$ battery using cGPE-1\% is more stable upon cycling comparing to cells using GPE and other cGPEs leading to 54 stable discharge cycles. This stabilization of interfacial resistance can be attributed to the $\mathrm{Li}^{+}$transport enhancement in cGPE-1\% which did not reduce the contact between the electrolyte and electrodes and maintained the active sites for specific resistance during cycling by providing sufficient $\mathrm{Li}^{+}$ions at interfaces [125]. Excess of fillers in cGPEs $(>1 \%)$ could not stabilize the interfaces due to insufficient $\mathrm{Li}^{+}$ion transport properties. In addition, the formation of poor electronic conductive $\mathrm{Li}_{2} \mathrm{O}_{2}$ and charge/discharge byproducts increases the cathode resistance and cathode-electrolyte interfacial resistance, resulting in high charge overpotentials [109,128]. Therefore, stabilizing the cathode-electrolyte interfacial resistance contributed to improving the charge capacity of cGPE-1\% over GPE and cGPE containing cells, as can be observed in voltage profiles of Figure 3-11. Moreover, it is noteworthy that the poor rechargeability of all $\mathrm{Li}_{2} \mathrm{O}_{2}$ batteries using GPE and cGPEs (Figure 3-10) was mainly due to the low OER activity of MWCNT cathodes as previously observed $[88,129]$. Various catalysts and redox mediators have been proposed to improve the OER and rechargeability of $\mathrm{Li}^{-} \mathrm{O}_{2}$ batteries $[130,131]$.

Lithium plating/stripping tests were also performed using symmetric Li/GPE/Li and Li/cGPE-1\%/Li cells at the same current density used for cycling and plating and stripping cycle times of 2 hours each. From Figure 3-17, the voltage profile of cells using both GPE and cGPE-1\% decreases during the initial cycles and then starts to grow. The decrease in overpotential at initial cycles was due to a heterogeneous Li plating/stripping process [132]. 
The continuous increase in voltage profile of cells is indicative of the growth of passivating layers produced by electrolyte and electrolyte decomposition products' reactivity with lithium [132].
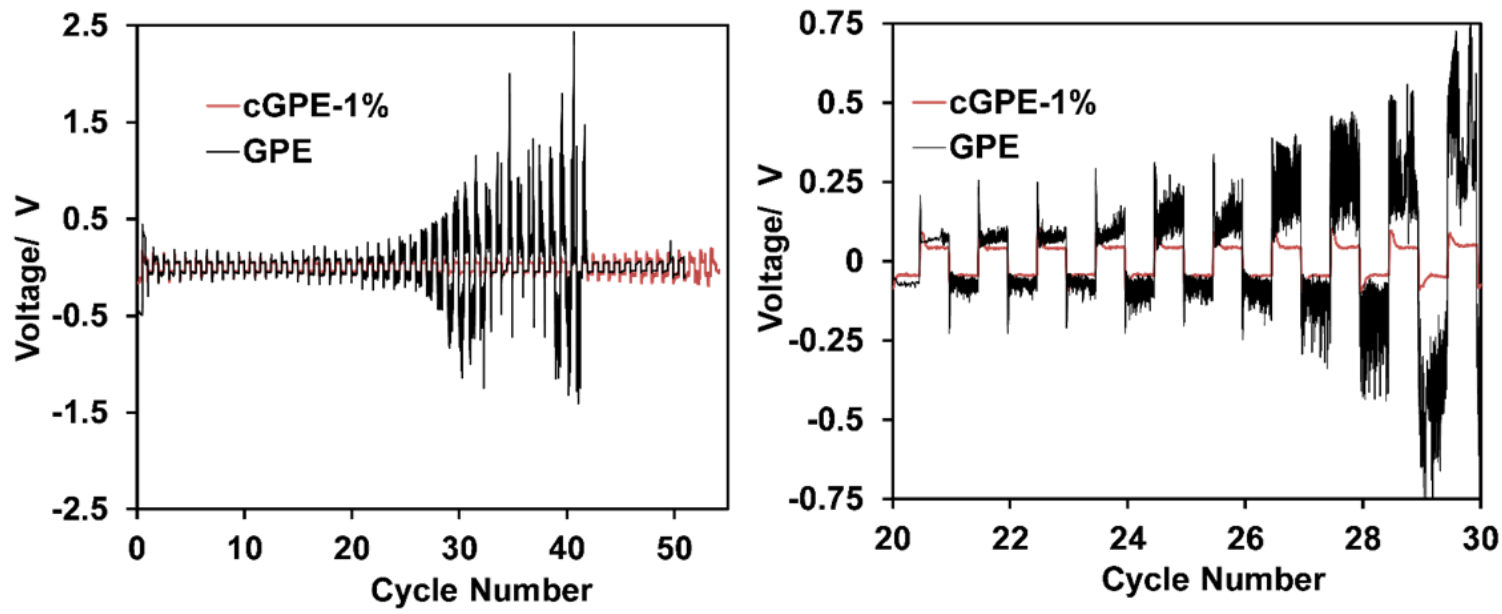

Figure 3-17: Voltage profile of the Li plating/stripping measurements performed using the symmetrical $\mathrm{Li} / \mathrm{cGPE}-1 \% / \mathrm{Li}$ cell and $\mathrm{Li} / \mathrm{GPE} / \mathrm{Li}$ cell at a current density of 0.125 $\mathrm{mA} \cdot \mathrm{cm}^{-2}$ and a plating and stripping times of 2 hours each.

A stable voltage profile is observed for cGPE-1\% containing cell indicates a uniform lithium deposition/stripping and stable SEI formation with no detectable failure for more than 50 cycles. GPE containing cell, however, shows non-uniform lithium deposition/stripping and unstable SEI formation that lead to the internal short-circuiting of the cell at cycle number 40 . This improvement can be attributed to the fact that cGPE-1\%, which has the highest ionic conductivity and transference number improvements, stabilizes the Li interface by promoting uniform Li plating/stripping and stable interfacial layers $[103,133,134]$. These observations are in good agreement with our cycling and EIS results. 
In addition, the inclusion of glass micro-fillers can improve the mechanical properties of GPE and block the dendrite growth [135].

\subsection{Conclusions}

In this chapter, the introduction of 1D glass microfillers to GPE has shown to improve lithium transport properties, namely, ionic conductivity and transference number, under optimized content. $\mathrm{Li}-\mathrm{O}_{2}$ battery using cGPE- $1 \%$ shows $86 \%$ more cycles than battery using GPE. This improvement is attributed to the stabilization of electrolyte-electrode interfacial resistances resulting from increased $\mathrm{Li}^{+}$transport properties. 


\section{COPOSITE GEL POLYMER ELECTROLYTE: EFFECT OF LI SALT CONCENTRATION}

\subsection{Background}

According to recent reports, the electrolyte remains as the leading cause for rapid capacity fading and poor cyclability in $\mathrm{Li}-\mathrm{O}_{2}$ batteries [136-138]. Commonly carbonate-based solvents used in $\mathrm{Li}$-ion batteries have been shown to be unstable during the ORR process [47]. Consequently, ether-based electrolytes have been suggested for $\mathrm{Li}^{-\mathrm{O}_{2}}$ battery applications $[19,20]$. Nonetheless, the stability of ether-based electrolytes remains a concern and recent studies reported on the reactivity between superoxide radical species formed during charge/discharge with the ether-based solvents $[48,139,140]$. The hydrogen abstraction from methylene groups in ether-based solvents by superoxide radical species and subsequent reactions can cause solvent decomposition and the formation of lithium carbonates. The progressive formation of these insulating decomposition products on the surface of the cathode yields high cell polarization, thus causing poor cyclability[39,48,138]. Functionalized ether-based solvents (e.g. 2,3-dimethyl-2,3dimethoxybutane (DMDMB) and tri(ethylene glycol)-substituted trimethylsilane (1NM3)) have been proposed to eliminate the possibility of methylene hydrogen abstraction $[138,141]$. Increasing the concentration of lithium salt in electrolytes was also shown to improve the performance of $\mathrm{Li}_{-} \mathrm{O}_{2}$ batteries [142-144]. The appropriate $\mathrm{Li}^{+}$solvation with solvent molecules may increase the favorable accessibility of superoxides to $\mathrm{Li}^{+}$by increasing the salt concentration, which in turn mitigates the electrolyte decomposition [142-144]. Gel polymer electrolytes (GPE) consisting of liquid electrolyte and polymer has been successfully used in lithium-ion batteries due to their high ionic conductivity and 
mechanical stability $[91,145,146]$. Recently, GPE with different electrolytes and polymers have also been developed for Li- $\mathrm{O}_{2}$ battery applications $[61,64,97,98,147]$. It has been reported that GPE improves the performance of $\mathrm{Li}-\mathrm{O}_{2}$ batteries by reducing the electrolyte evaporation, and preventing the lithium corrosion caused by oxygen crossover from air cathode $[61,63,64]$. Inorganic filler materials have been widely incorporated into electrolytes and were shown to yield an increase in ionic conductivity and $\mathrm{Li}^{+}$transference number $[103,104,108]$. Croce et al. [101] showed that the Lewis acid groups on the surface of ceramic fillers in composite polymer electrolytes strongly adsorb the anions of the lithium salt and enhance its salt dissociation. Bhattacharyya and Maier [73] also observed the same anion adsorption behavior of ceramic fillers in non-aqueous liquid electrolytes. Incorporation of various ceramic fillers in different electrolytes have also been explored for $\mathrm{Li}_{-} \mathrm{O}_{2}$ battery applications $[64,95,99,109,125,128,148]$. It has been shown that the inorganic fillers can improve the performance of $\mathrm{Li}-\mathrm{O}_{2}$ batteries by stabilizing the interfacial resistance and preventing lithium anode corrosion. In this chapter, we investigate the incorporation of one-dimensional glass microfillers into glyme-based GPEs on reducing the formation of parasitic electrolyte decomposition byproducts in $\mathrm{Li}^{-\mathrm{O}_{2}}$ batteries. Charge/discharge cycling, EIS, SEM, and Raman spectroscopy have been used to assess the performance improvement of composite gel electrolyte (cGPE) containing batteries. 


\subsection{Experimental Details}

For this chapter, liquid electrolyte solutions were first prepared by dissolving different concentrations of LiTFSI salt $\left(0.1,1.0\right.$ and $\left.3.0 \mathrm{~mol} \cdot \mathrm{kg}^{-1}\right)$ in TEGDME. The GPE and cGPE with glass microfibers were prepared following the procedure detailed in our previous chapter. The glass microfibers content of cGPEs was chosen to be $1 \mathrm{wt} . \%$, and only the lithium salt concentration was changed. The ionic conductivity and Li transference number were also measured as described in chapter 3. Figure 4-1 shows typical chronoamperometric curves of symmetrical Li/Li cells using GPEs and cGPEs with 0.1 and $3 \mathrm{~mol} \cdot \mathrm{kg}^{-1}$ LiTFSI salt concentration with their corresponding impedance spectra before and after polarization.

Like chapter 3, galvanostatic charge/discharge tests were performed using MTI battery tester at the constant current density of $250 \mathrm{~mA} \cdot \mathrm{g}^{-1}$ within the voltage range of $2.0-4.5 \mathrm{~V}$. However, in-situ EIS measurements in this chapter were also conducted using a Gamry Reference 600, and the frequency range was extended to cover the $100 \mathrm{kHz}$ to $10 \mathrm{mHz}$ using $10 \%$ of DC discharge current during cycling test at OCV condition. All charge/discharge and EIS studies were carried out at $25^{\circ} \mathrm{C}$. The interaction of ETPTA polymer, glass microfibers, and LiTFSI salt was also investigated by Raman spectroscopy. 

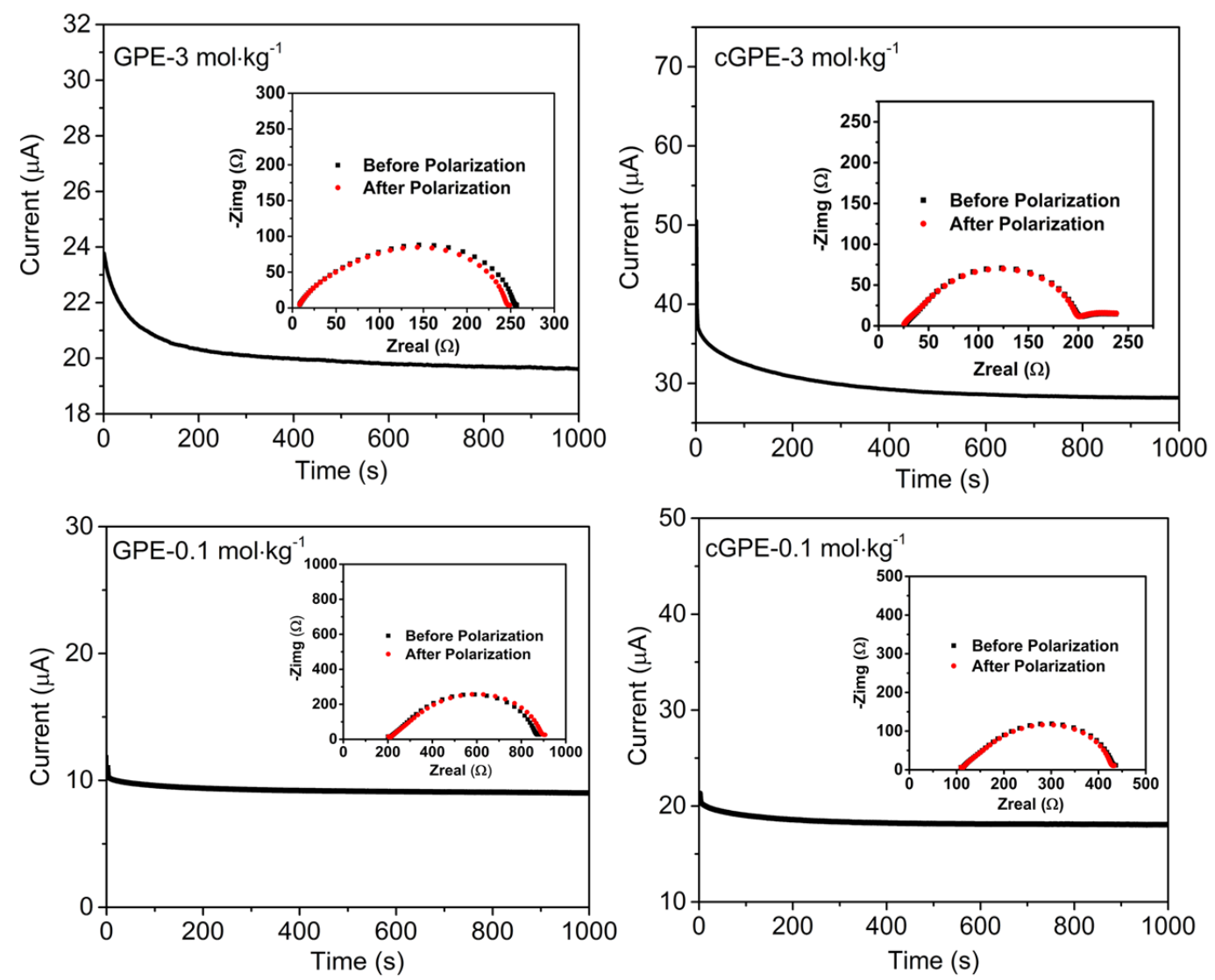

Figure 4-1: Chronoamperometric curves of Li/GPE and cGPE /Li cell after $10 \mathrm{mV}$ of DC polarization at $25^{\circ} \mathrm{C}$ where the electrolyte films contain 0.1 and $3 \mathrm{~mol} \cdot \mathrm{kg}^{-1} \mathrm{LiTFSI}$ salt. Insets: electrochemical impedance spectra before and after polarization

All electrolyte samples including liquid electrolytes, GPEs, and cGPEs with various salt concentration were placed in airtight rectangular quartz cuvettes under argon inside the glovebox and then examined by Raman spectrometer (BaySpec's Nomadic ${ }^{\mathrm{TM}}, 532 \mathrm{~nm}$ ). Each spectrum was recorded with the exposure time of the 20s using the 10x objective lens at $25^{\circ} \mathrm{C}$. Like chapter 3 , the cathodes after different stage of charge/discharge were also characterized by the Raman spectroscopy, XRD, and SEM. 


\subsection{Results and Discussion}

The ion transport properties of the GPE and cGPE prepared using various concentrations of lithium salt were evaluated using their corresponding methods described in the Materials and Methods. Table 4-1 summarizes the ionic conductivity $(\sigma)$ and lithium transference number at room temperature $\left(25^{\circ} \mathrm{C}\right)$.

Table 4-1: Summary of ionic conductivity and $\mathrm{Li}^{+}$transference number of GPE and cGPE at different salt concentrations

\begin{tabular}{lcc}
\hline \multicolumn{1}{c}{ Electrolyte films } & $\begin{array}{c}\text { Transference Number } \\
\boldsymbol{t}_{\boldsymbol{L} i+}\end{array}$ & $\begin{array}{c}\text { Ionic Conductivity } \\
\boldsymbol{\sigma}\left(\mathbf{m S} \cdot \mathbf{c m}^{-1}\right)\end{array}$ \\
\hline & & \\
$\mathrm{GPE}-0.1 \mathrm{~mol} \cdot \mathrm{kg}^{-1}$ & $0.40 \pm 0.02$ & $0.13 \pm 0.02$ \\
$\mathrm{GPE}-1.0 \mathrm{~mol} \cdot \mathrm{kg}^{-1}$ & $0.50 \pm 0.03$ & $1.02 \pm 0.05$ \\
$\mathrm{GPE}-3.0 \mathrm{~mol} \cdot \mathrm{kg}^{-1}$ & $0.54 \pm 0.02$ & $0.68 \pm 0.02$ \\
\hline $\mathrm{cGPE}-0.1 \mathrm{~mol} \cdot \mathrm{kg}^{-1}$ & $0.60 \pm 0.02$ & $0.35 \pm 0.05$ \\
$\mathrm{cGPE}-1.0 \mathrm{~mol} \cdot \mathrm{kg}^{-1}$ & $0.64 \pm 0.02$ & $1.40 \pm 0.02$ \\
cGPE$-3.0 \mathrm{~mol} \cdot \mathrm{kg}^{-1}$ & $0.55 \pm 0.03$ & $0.70 \pm 0.02$ \\
\hline
\end{tabular}

The ionic conductivity of GPE was shown to increase with increasing salt concentration from $0.1 \mathrm{~mol} \cdot \mathrm{kg}^{-1}$ to $1.0 \mathrm{~mol} \cdot \mathrm{kg}^{-1}$ due to the increase in the number of free ions. However, as the salt concentration increases to $3.0 \mathrm{~mol} \cdot \mathrm{kg}^{-1}$, the ionic conductivity decreases as previously reported [149]. This decrease is mostly due to a drop in ion mobility caused by the higher viscosity of the liquid electrolyte soaking the polymer matrix $[150,151]$. The lithium transference number for GPE showed an increasing pattern with increasing salt concentration and followed the similar behavior of glyme-based liquid electrolytes and polyacrylate based GPE [150,151]. In Glyme-based electrolytes containing LiTFSI salt, 
the increase in the salt concentration was shown to decrease the ionic association [152], and in turn, increases the $\mathrm{Li}^{+}$transference number.

The effect of the glass microfillers was demonstrated in increases in both $\sigma$ and $t_{L i}{ }^{+}$for the cGPE. This increase was owed to the immobilization of the TFSI', likely through interactions between Lewis acid groups on filler's surface and TFSI' ${ }^{-}$anions $[108,110,116]$. This ion-ceramic interaction yields an improvement in the ion pair dissociation and increases $\mathrm{Li}^{+}$dissociation [110]. At an optimized filler's content of 1 wt.\% [148], a percolating network of glass microfibers is formed providing $\mathrm{Li}^{+}$transportation pathways. This increase was not apparent for the $3.0 \mathrm{~mol} \cdot \mathrm{kg}^{-1} \mathrm{cGPE}$, indicating insufficient surface groups for the immobilization of TFSI- This indicates that the effect of surface ion adsorption is reduced in environments with an abundance of free ions [153]. Therefore, with a fixed filler's loading, the effect of fillers was only apparent in cGPE with salt concentrations below a certain threshold, that once exceeded, the effect of fillers at that loading is reduced due to excessive amounts of ions in the solution.

Raman spectroscopy study was performed on liquid electrolytes, GPEs, and cGPEs to further investigate the interaction of ETPTA polymer and the microfillers with LiTFSI salt. Figure 4-2 shows that a Raman spectrum of $\mathrm{TFSI}^{-}$anion which is assigned to the contraction and expansion mode of S-N coupled with $\mathrm{CF}_{3}$ bending [154]. This Raman spectrum also represents the $\mathrm{Li}^{+}$and $\mathrm{TFSI}^{-}$association [155]. The Raman shift between $736-742 \mathrm{~cm}^{-1}$ is assigned to the unbounded TFSI- (free anion or solvent-separated ion pairs (SSIPs)) $[155,156]$ and Raman shift $\geq 744 \mathrm{~cm}^{-1}$ show the bounded TFSI $^{-}$(contact ion pairs (CIPs) and ion aggregates) [155,156]. 

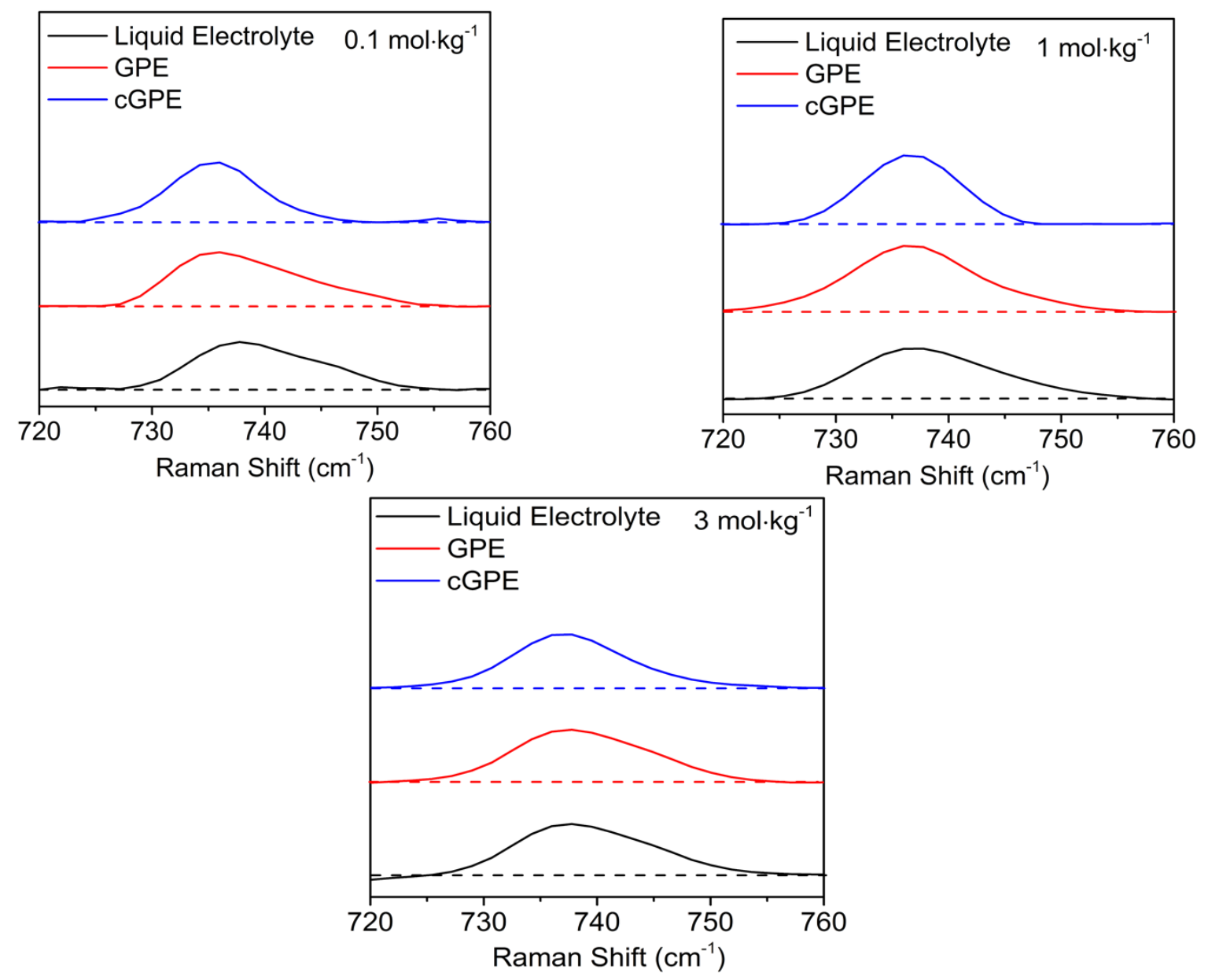

Figure 4-2: Raman spectra of Liquid electrolytes, GPEs and cGPEs with various LiTFSI salt concentrations showing Raman shifts of bounded and unbounded TFSI $^{-}$anions.

As shown in Figure 4-2, for all electrolyte samples, the addition of ETPTA polymer to liquid electrolytes with different salt concentrations does not change the shape of the TFSI ${ }^{-}$ Raman spectrum as they all exhibit two distinct Raman shifts for unbounded and bounded TFSI $^{-}$confirming that ETPTA polymer does not have any ion-trapping ability [145] and acts merely as an inert polymer. Furthermore, the addition of $1 \mathrm{wt} \% \%$ glass microfillers to the GPEs at 0.1 and $1 \mathrm{~mol} \cdot \mathrm{kg}^{-1}$ LiTFSI shows that the dissociation level of LiTFSI increases as the Raman shift of bounded TFSI- (shoulder $\geq 744 \mathrm{~cm}^{-1}$ ) was significantly reduced. However, cGPE at $3 \mathrm{~mol} \cdot \mathrm{kg}^{-1}$ LiTFSI salt concentration indicates no significant changes 
in Raman shift of bounded TFSI- ${ }^{-}$These results are entirely in agreement with reported transference numbers. To further investigate the possible interaction of glass microfiber and liquid electrolyte with ETPTA polymer in GPEs, the glass transition of GPE was also obtained. The determination of glass transition ( $\mathrm{Tg}$ ) of the polymer matrix in GPEs with a small content of polymer (20 wt.\%) is very challenging [157]. Hence to accurately determine the glass transition of ETPTA in GPE and cGPE-1\%, the GPE and cGPE-1\% with 50:50 wt.\% ETPTA: liquid electrolyte $\left(1 \mathrm{~mol} \cdot \mathrm{kg}^{-1}\right.$ salt concentration) was prepared. Figure 4-3 shows the DSC profile of GPE and cGPE-1\%. As it is clear, the glass transition of ETPTA polymer inside GPE is very close to the pure ETPTA $\left(\sim 73^{\circ} \mathrm{C}\right)$ as obtained in the previous chapter. This similarity indicates that a little interaction between electrolyte and ETPTA in GPE. Furthermore, the addition of 1wt.\% glass microfibers in GPE slightly reduce the Tg of ETPTA in cGPE- $1 \%$. As a result, reduction of polymer crystallinity is not a predominate reason for the ionic transport improvement of cGPE-1\% over GPE [106].
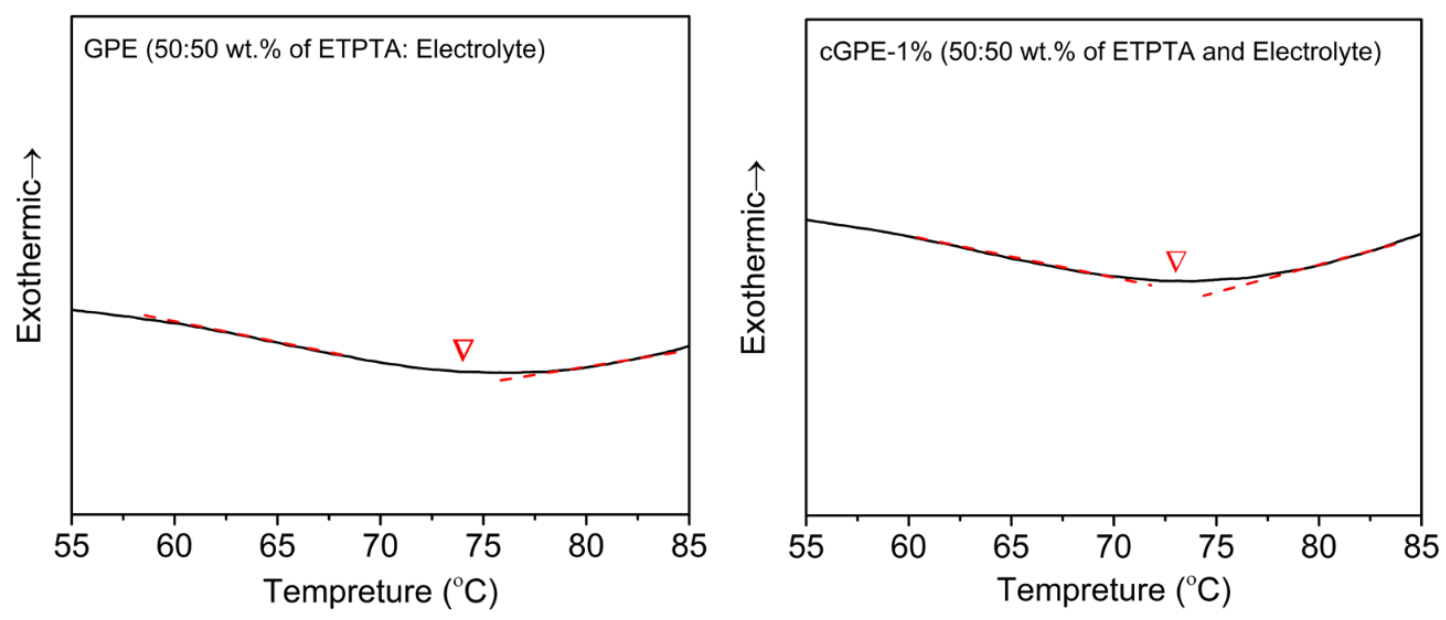

Figure 4-3: DSC profile indicating the glass transition (Tg) of (left) GPE containing 50:50 wt.\% of ETPTA: Electrolyte with $1 \mathrm{~mol} \cdot \mathrm{kg}^{-1}$ salt concentration (right) cGPE$1 \%$ with the same ETPTA and polymer content 
To examine the impact of glass microfillers on the performance of $\mathrm{Li}-\mathrm{O}_{2}$ batteries, charge/discharge cycling tests were performed at $250 \mathrm{~mA} \cdot \mathrm{g}^{-1}$ for a cycle capacity of 500 $\mathrm{mAh} \cdot \mathrm{g}^{-1}$ in a voltage window of 2.0-4.5 V. Figure 1 depicts the voltage profiles of GPEand cGPE-containing $\mathrm{Li}-\mathrm{O}_{2}$ batteries using various salt concentrations up to the first cycle after their failure (first cycle with less than $500 \mathrm{mAh} \cdot \mathrm{g}^{-1}$ ). Cells using GPE-0.1 mol $\cdot \mathrm{kg}^{-1}$ ran for 12 discharge cycles compared to the GPE-1.0 mol $\cdot \mathrm{kg}^{-1}$ and GPE-3.0 $\mathrm{mol} \cdot \mathrm{kg}^{-1}$ that ran for 29 and 40 cycles, respectively. This increase in cyclability with increased salt content has not been previously observed for GPE but was previously reported for liquid electrolytes $[142,143]$. Furthermore, cells using cGPE-0.1 mol $\cdot \mathrm{kg}^{-1}$ and cGPE-1.0 $\mathrm{mol} \cdot \mathrm{kg}^{-}$

${ }^{1}$ showed 49 and 54 consecutive discharge cycles, respectively compared to cGPE-3.0 mol. $\mathrm{kg}^{-1}$ with 43 discharge cycles. Using microfillers substantially improved the cyclability performance of $\mathrm{Li}^{-\mathrm{O}_{2}}$ battery by $400 \%$ and $86 \%$ more cycles compared to their GPE counterparts for 0.1 and $1.0 \mathrm{~mol} \cdot \mathrm{kg}^{-1}$, respectively. However, no significant improvement of cGPE over GPE was observed for $3.0 \mathrm{~mol} \cdot \mathrm{kg}^{-1}$. This observation is consistent with the transference number improvements due to the inclusion of microfillers, proving the importance of $\mathrm{Li}^{+}$transport properties of electrolytes on the $\mathrm{Li}-\mathrm{O}_{2}$ battery performance $[89,148,158]$. 

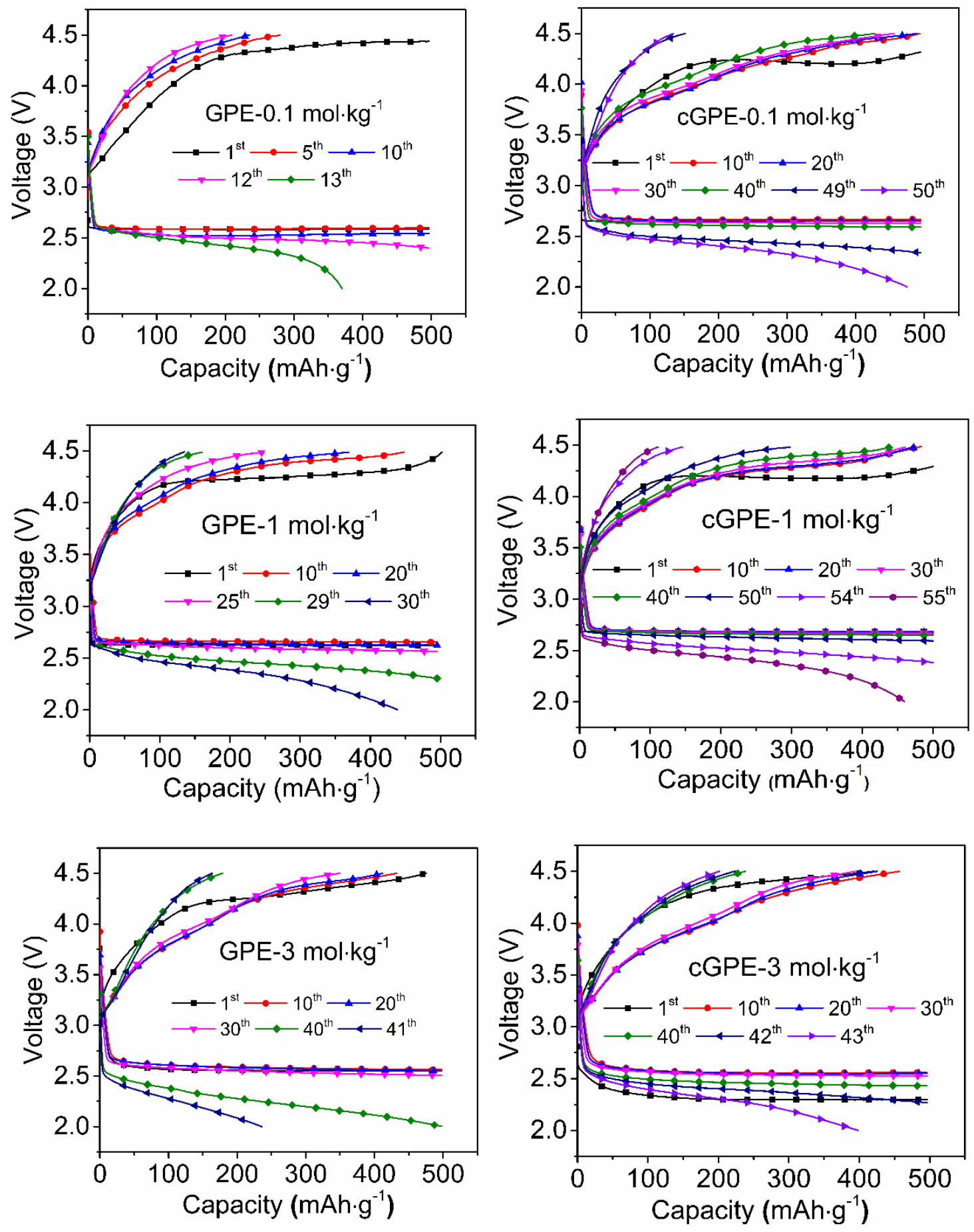

Figure 4-4: Voltage profile of $\mathrm{Li}-\mathrm{O}_{2}$ batteries using GPE and cGPE with different salt concentrations with a limited capacity of $500 \mathrm{mAh} \cdot \mathrm{g}^{-1}$ per cycle at current density of 250 $\mathrm{mA} \cdot \mathrm{g}^{-1}$. 
The formation of $\mathrm{Li}_{2} \mathrm{O}_{2}$ was confirmed by performing Raman spectroscopy on the surface of cathodes after one discharge cycle of $500 \mathrm{mAh} \cdot \mathrm{g}^{-1}$. From Figure 4-5, all spectra show a Raman shift at $\sim 800 \mathrm{~cm}^{-1}$ corresponding to the $\mathrm{Li}_{2} \mathrm{O}_{2}[120]$. The presence of $\mathrm{Li}_{2} \mathrm{O}_{2}$ confirms that the discharge capacities of all $\mathrm{Li}-\mathrm{O}_{2}$ batteries are mainly due to ORR.

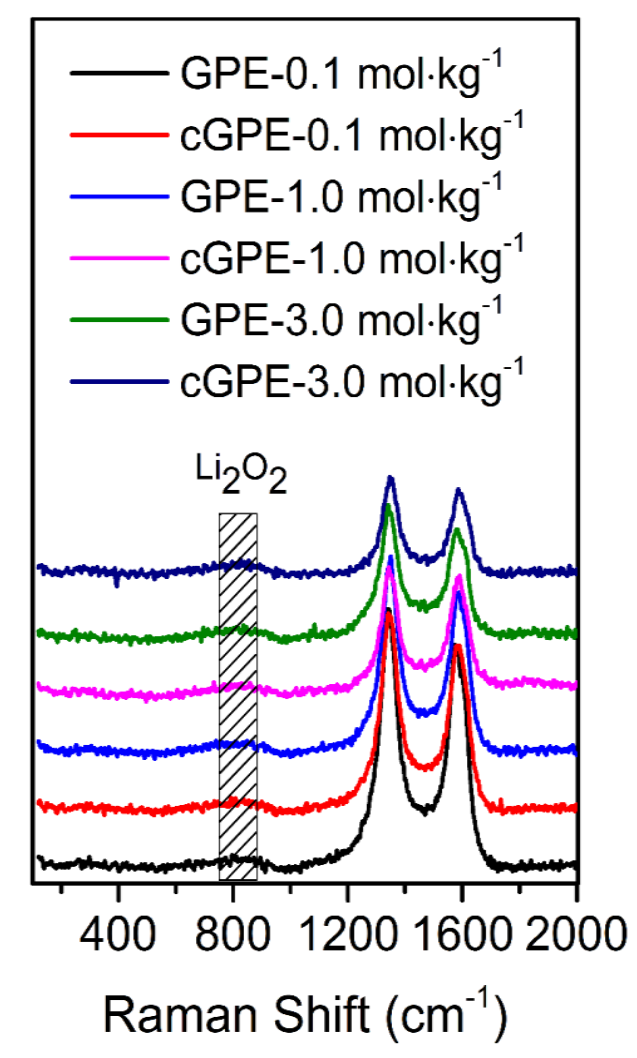

Figure 4-5: Raman spectra of $500 \mathrm{mAh} \cdot \mathrm{g}^{-1}$ predischarged cathode using GPE and cGPE with different salt concentration. (Raman shifts at $1350 \mathrm{~cm}^{-1}$ and $1580 \mathrm{~cm}^{-1}$ correspond to the D and G bands of CNTs)

EIS has been recently used in metal- $\mathrm{O}_{2}$ battery systems to conduct the in-situ determination of cell degradation mechanisms [159-162]. In this study, EIS was performed during cycling after discharge at OCV to evaluate the electrochemical behavior of GPE and cGPE. 
Figure 4-6 (a) shows an example of a Nyquist plot of a $\mathrm{Li}_{-} \mathrm{O}_{2}$ cell under oxygen using GPE$1.0 \mathrm{~mol} \cdot \mathrm{kg}^{-1}$ after the discharge of the first cycle, $10^{\text {th }}, 25^{\text {th }}$, and $29^{\text {th }}$ (failure) cycles.
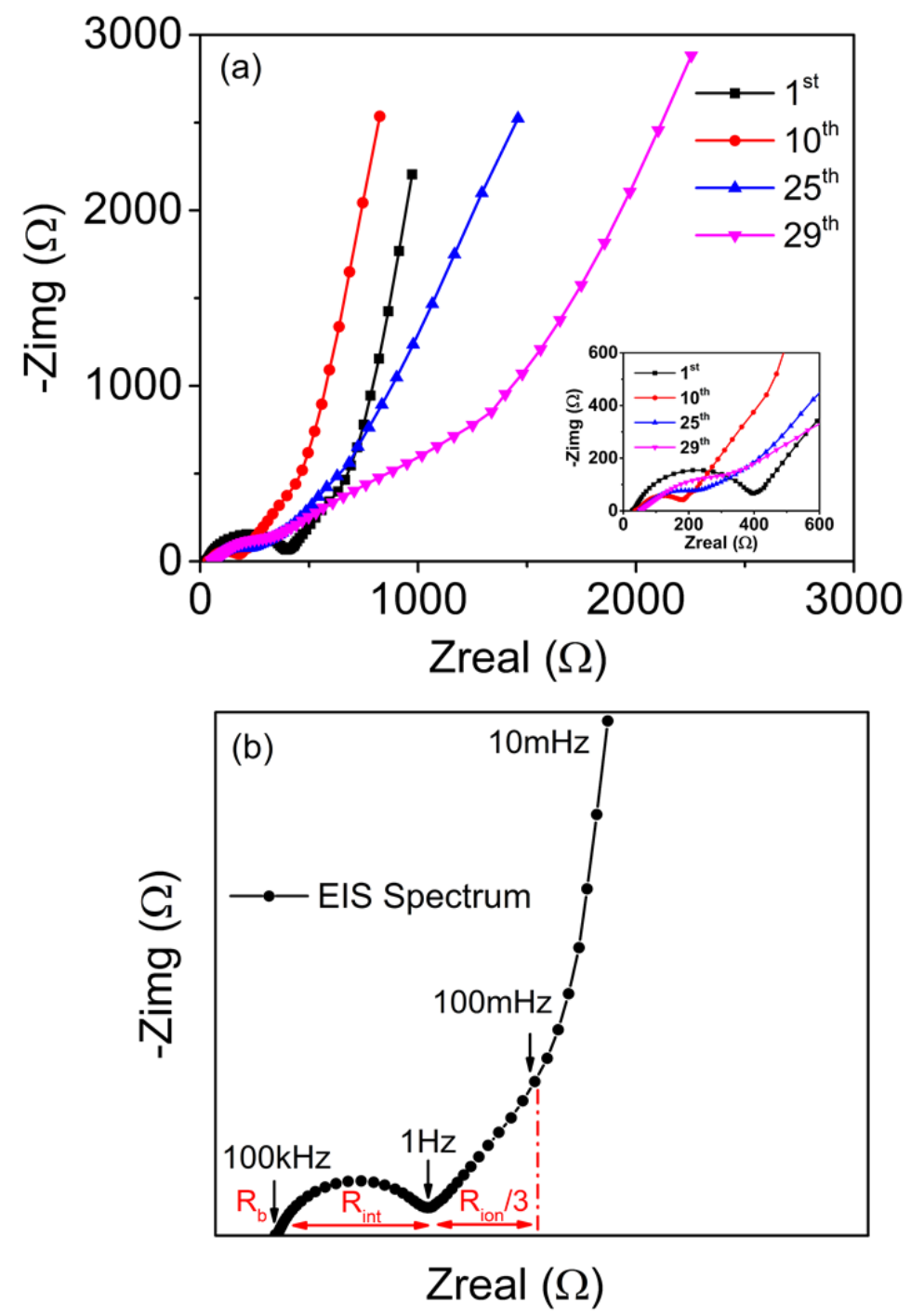

Figure 4-6: (a) Typical Nyquist plots of $\mathrm{Li}_{2} \mathrm{O}_{2}$ batteries using GPE with 1.0 $\mathrm{mol} \cdot \mathrm{kg}^{-1}$ salt concentration at OCV after first and failure cycle along with cycle $10^{\text {th }}$ and $25^{\text {th }}$ cycle (inset: shows close-up of Nyquist plots showing changes in interfacial resistances during cycling). (b) Transmission line model used to interpret the resistances of Nyquist plots. 
The Nyquist plots consisted of a semicircle corresponding to the interfacial resistance $\left(R_{\text {int }}\right)$ between the electrolyte (GPE or cGPE) and the electrodes, and a Warburg-like linear region followed by a rise, which is in agreement with other metal- $\mathrm{O}_{2}$ EIS spectra at nonfaradic conditions [159-161]. As described in chapter 2, transmission line model (TLM) has been used to determine the impedance behavior of the porous electrodes in $\mathrm{Li}$-ion and metal- $\mathrm{O}_{2}$ batteries $[85,159,160]$. In TLM, it is assumed that the Warburg-like linear region corresponds to the resistance of lithium-ion migration $\left(R_{i o n}\right)$ at the cathode $[159,160]$. Similar EIS behaviors were observed for GPE and cGPE at the other salt concentrations. The rise at low frequencies (less than $100 \mathrm{mHz}$ ) in the EIS spectra is consistent with the capacitive signal originated from the porous cathode $[159,160]$. However, it is worthy to mention that the EIS spectra deviate from the idealized porous cathode behavior as the rise at very low frequencies $(<100 \mathrm{mHZ})$ is tilted, and the slope of the Warburg-like line is not exactly $45^{\circ}$. It has been reported that this deviation is related to the frequency dispersion originating from a deficiency in the porous systems [163]. Bisquert [163,164] proposed a modified TLM circuit model to account this frequency dispersion by replacing the ideal capacitance in TLM model with constant phase element (CPE) to represent the capacitive behavior of porous cathode at non-faradic condition. Figure 4-7 (a) shows the modified TLM model used in this study. Based on this model, the ionic resistance $\left(R_{i o n}\right)$ could be estimated by the projection of Warburg-like line on the real axis of impedance as the limiting value of real impdeance of porous cathode at low frequency $(\omega \rightarrow 0)$ is eaqul to $\mathrm{R}_{\text {ion }} / 3$ [81,163-165]. The electrolyte resistance $\left(R_{b}\right)$ and interfacial resistance $\left(R_{\text {int }}\right)$ were also obtained from analyzing the real resistances of the semicircle of the EIS spectra at the high- and mid-frequency, respectively (Figure 4-7 (b)). 
(a)

Porous Electrode
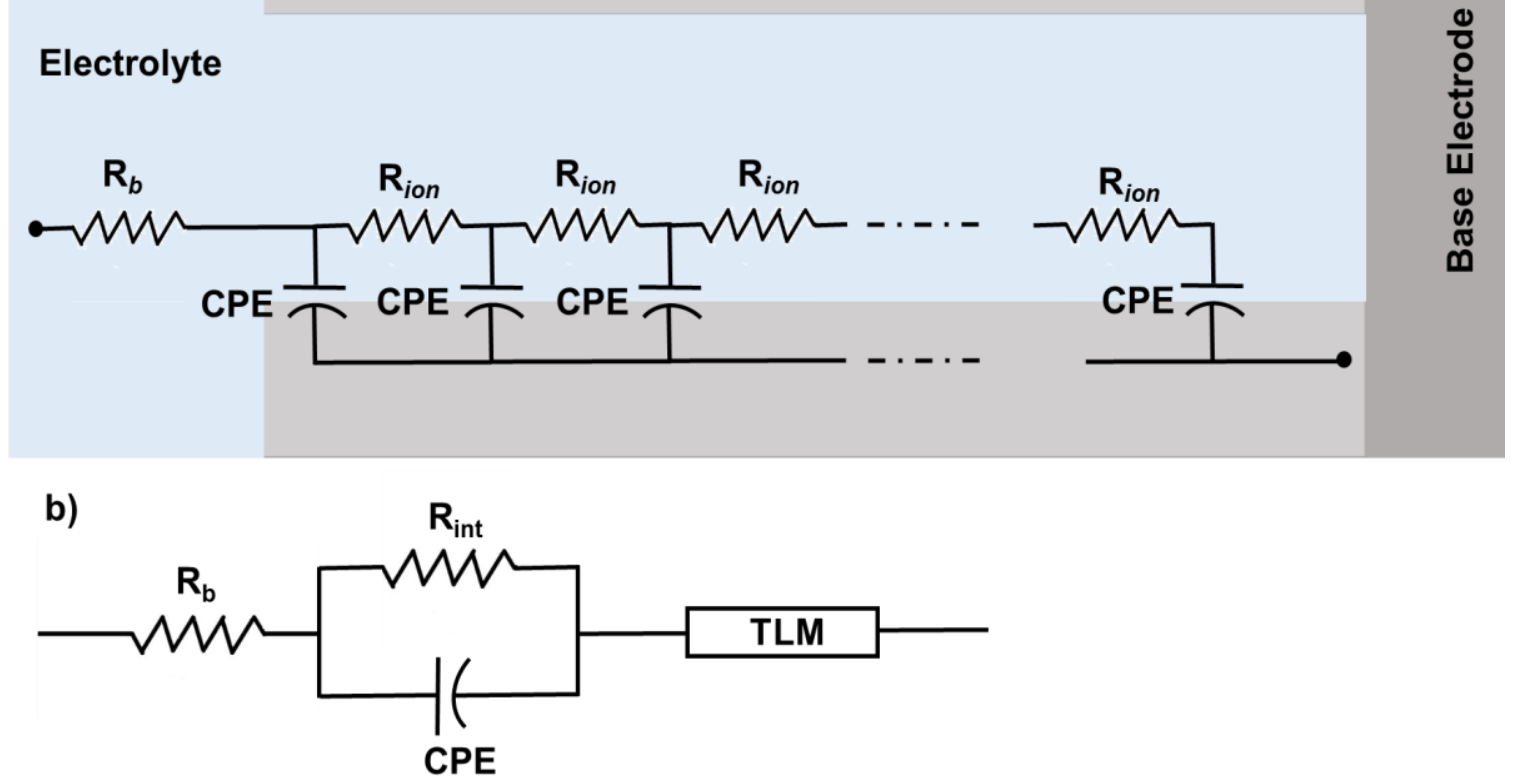

Figure 4-7: (a) Modified transmission line model (TLM) circuit model used to interpret the resistance of porous cathode. (b) The circuit model of the full cell $\mathrm{Li}^{-\mathrm{O}_{2}}$ batteries.

As can be seen from Figure 4-6 (a), the Warburg-like line's slope steadily declines upon cycling. Furthermore, the diameter of the semicircle $\left(R_{\text {int }}\right)$ is decreased in cycles 1 to 10 , and then increased in cycles 10 and higher (Figure 4-6 (a) inset). Figure 4-8 shows the change of resistances $R_{i o n}, R_{b}$ and $R_{i n t}$ versus discharge cycle numbers. $R_{i o n}$ was the dominant resistance in the cells which indicates that the increase in the resistance of cathode is the main cause of the failure. Shui et al. [32] and Knudsen et al. [160] also reported that the deactivation of the cathode was a major culprit in $\mathrm{Li}-\mathrm{O}_{2}$ battery failure. The increase in $R_{i o n}$ upon cycling indicates a physical pore is clogging within the porous cathodes caused by irreversible charge/discharge products deposition hindering $\mathrm{Li}^{+}$ transport inside the cathode [127]. 

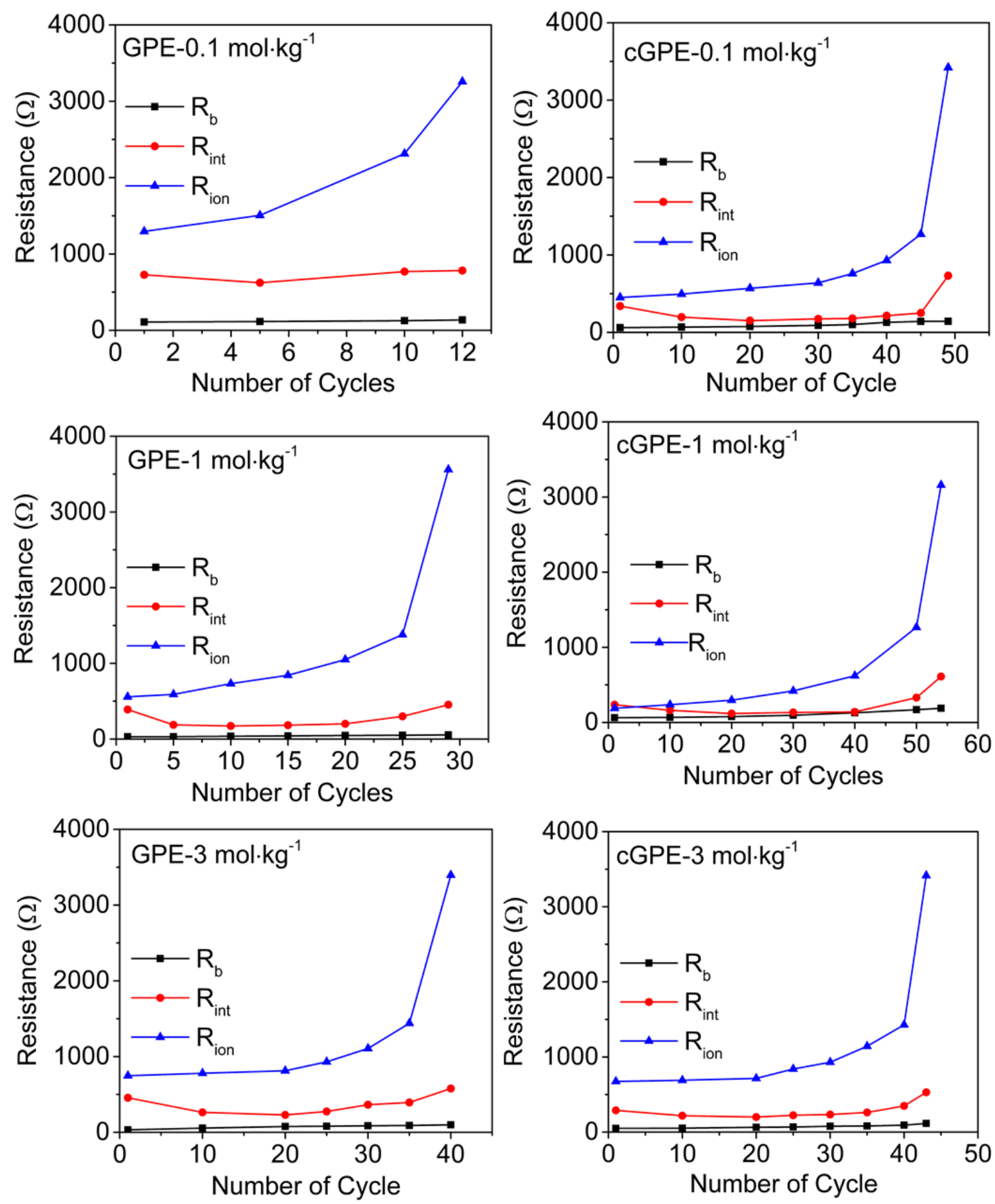

Figure 4-8: The change of resistances of $\mathrm{Li}_{-} \mathrm{O}_{2}$ batteries using GPE and cGPE with different salt concentrations during cycling up to their failure

Tracking Rion of cells using GPE- and cGPE-containing batteries at various salt concentrations (Figure 4-8) shows that for 0.1 and $1.0 \mathrm{~mol} \cdot \mathrm{kg}^{-1} \mathrm{cGPE}$-containing batteries 
had lower $R_{i o n}$ after the first discharge cycle and remained consistently lower than in their GPE-containing counterparts. In addition, the rate of growth of the $R_{\text {ion }}$ also increased at a slower rate than for GPE-containing batteries, indicating that pore-clogging depositions mainly in the cathode were less problematic in batteries containing the cGPE. However, for the GPE and cGPE with $3.0 \mathrm{~mol} \cdot \mathrm{kg}^{-1}$ no significant reduction in $R_{\text {ion }}$ growth was observed, which again suggests that the effect of the microfillers at this concentration was ineffective. This observation is consistent with the transference number and cycling comparisons previously discussed. To investigate the composition of the pore-clogging deposits, Raman spectroscopy was performed on the surface of cycled cathodes. Figure 4-9 shows the Raman spectra of cathodes using the GPE and cGPE at 0.1 and $1.0 \mathrm{~mol} \cdot \mathrm{kg}^{-1}$ recovered from $\mathrm{Li}-\mathrm{O}_{2}$ batteries after the $12^{\text {th }}$ and the $29^{\text {th }}$ discharge cycles (the failure cycles of GPE-containing batteries), respectively. Cathodes of GPE-containing batteries show pronounced Raman shifts at $1082 \mathrm{~cm}^{-1}$, which correspond to the formation of lithium carbonates $[120,166]$. Conversely, the cathodes recovered from cGPE-containing batteries cycled under the same conditions and for the same number of cycles show less pronounced Raman shifts at $1082 \mathrm{~cm}^{-1}$, indicating the lesser formation of lithium carbonates. These results confirm both the location (cathode) and nature (lithium carbonates) of the depositions leading to the pore-clogging and consequently the growth of $R_{i o n}$. The presence of lithium peroxides and lithium carbonates were also confirmed by XRD (Figure 4-10). 

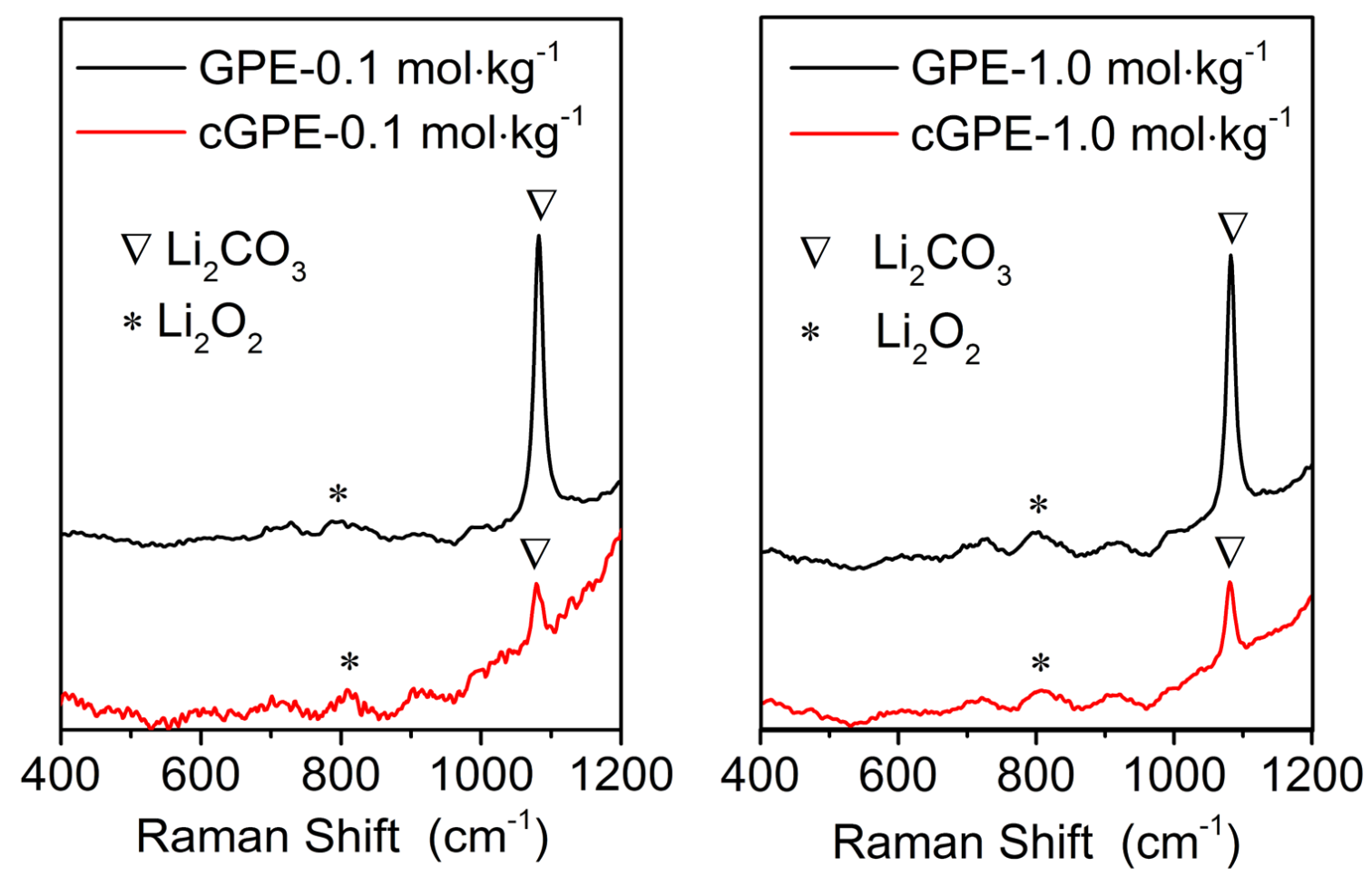

Figure 4-9: Raman spectra of cycled cathodes after discharge using GPEs and cGPEs with 0.1 and $1 \mathrm{~mol} \cdot \mathrm{kg}^{-1}$ salt concentration at cycle number where the batteries using GPEs fails (cycle $12^{\text {th }}$ for $0.1 \mathrm{~mol} \cdot \mathrm{kg}^{-1}$ and cycle $29^{\text {th }}$ for $1 \mathrm{~mol} \cdot \mathrm{kg}^{-1}$ ).

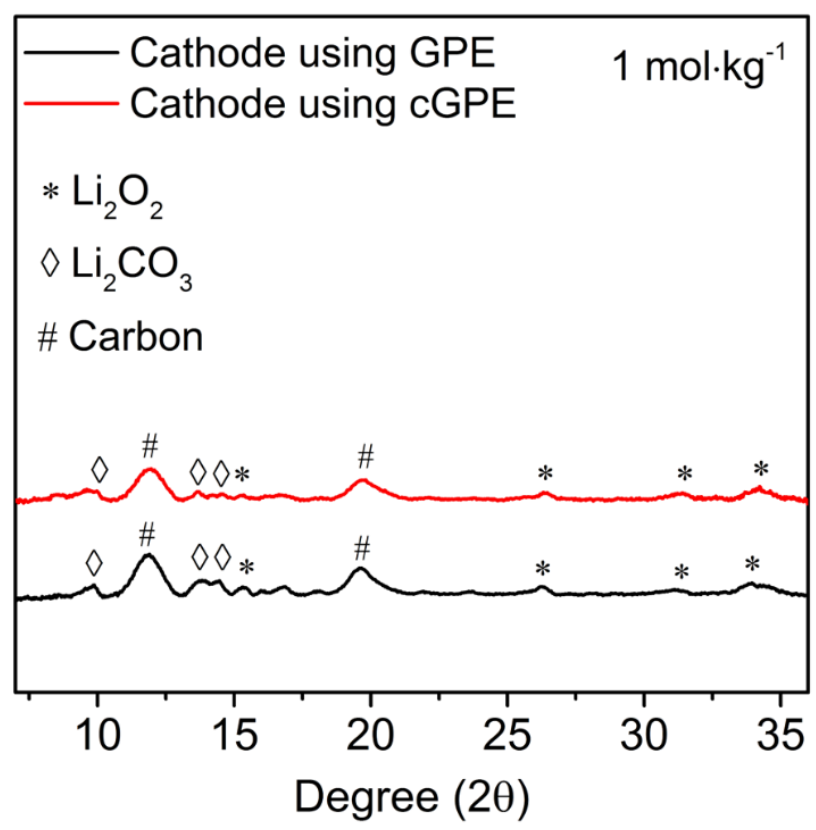

Figure 4-10: XRD patterns of cathodes using GPE and cGPE $\left(1 \mathrm{~mol} \cdot \mathrm{kg}^{-1}\right.$ LiTFSI salt concentration) showing the presence of lithium peroxide and lithium carbonates. 
Lithium carbonates can be formed by decomposition of carbon cathodes and electrolytes $[22,48,140]$. However, the formation of carbonate species during cycling of $\mathrm{Li}^{-} \mathrm{O}_{2}$ batteries using tetragylme-based electrolyte is suspected to be dominated by electrolyte decomposition [39]. This suggests that the addition of glass microfibers to the GPEs at 0.1 and $1.0 \mathrm{~mol} \cdot \mathrm{kg}^{-1}$ reduces the electrolyte decomposition.

The cathodes of cells after the failure discharge cycle (the failure cycles of GPE-containing batteries) were recovered and visually inspected using SEM.
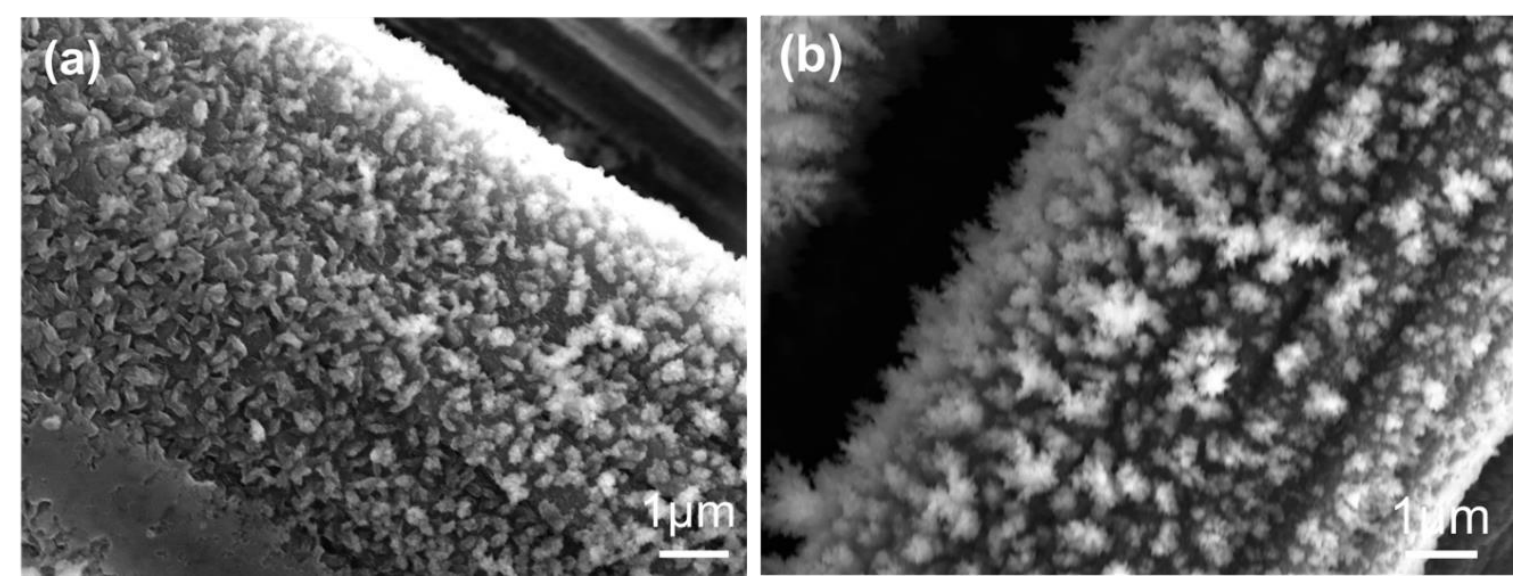

Figure 4-11: SEM micrograph of cycled cathodes in $\mathrm{Li}_{-} \mathrm{O}_{2}$ batteries using cGPE (a) and GPE (b) with $1.0 \mathrm{~mol} \cdot \mathrm{kg}^{-1}$ salt concentration after the failure discharge cycle.

In Figure 4-11, the cathode of batteries containing cGPE-1.0 mol $\mathrm{kg}^{-1}$ shows toroid-shaped discharge products (mostly $\mathrm{Li}_{2} \mathrm{O}_{2}$ ) covered by some fuzzy needle-like structures, previously reported as lithium carbonates [167]. In contrast, the cathode of batteries using GPE-1.0 mol $\cdot \mathrm{kg}^{-1}$ are mostly covered by the fuzzy needle-like structures and almost completely burying the toroid-shaped discharge products. This confirms the formation of the passivating lithium carbonates layer on the cathode. The continuous formation of these insulating lithium carbonates yielded large voltage hysteresis with an increase in cycling 
(Figure 4-4). The impact of cycling on the interfacial resistance $\left(R_{\text {int }}\right)$ in the $\mathrm{Li}-\mathrm{O}_{2}$ batteries is shown in Figure 4-12.
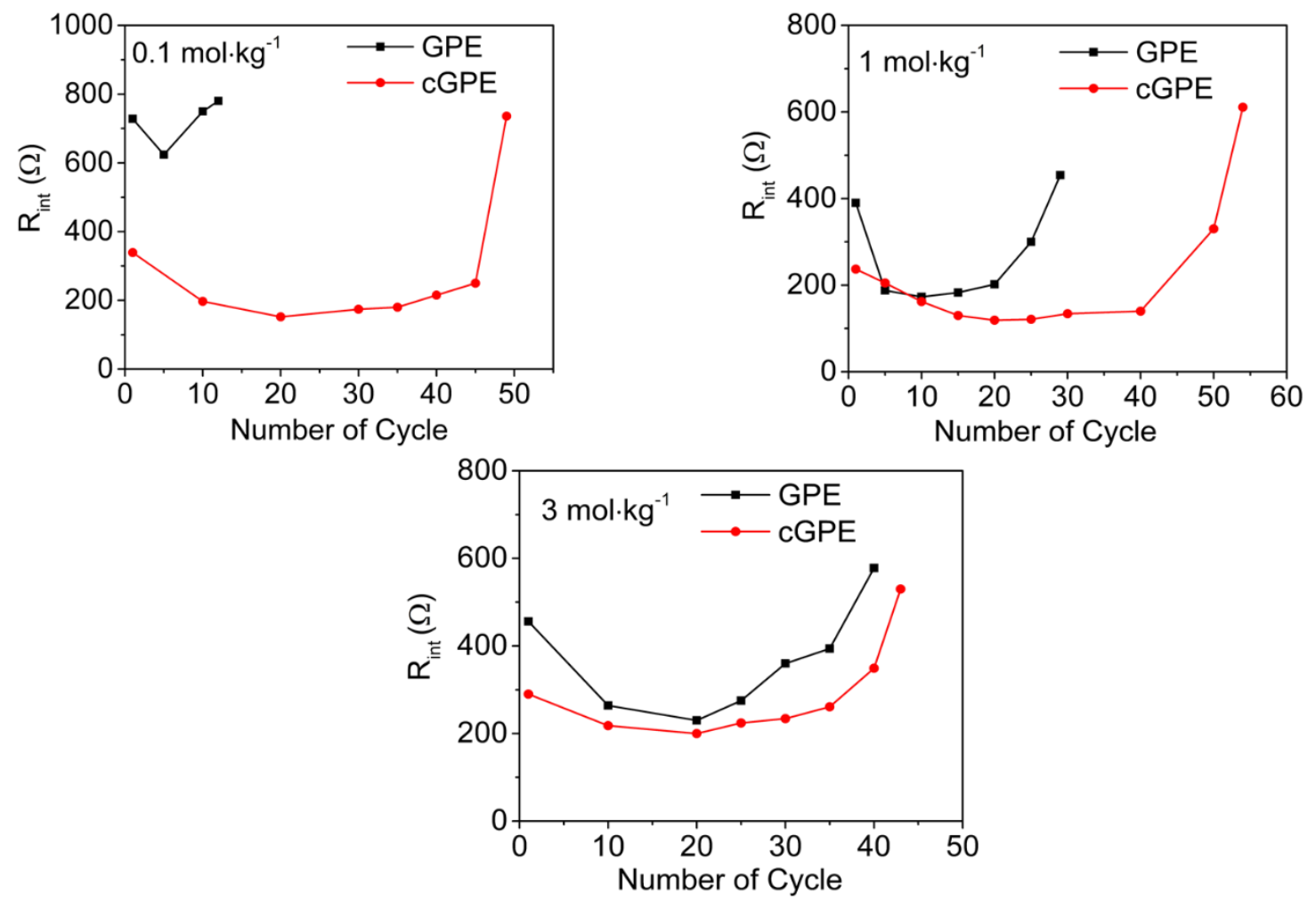

Figure 4-12: The change of interfacial resistance $\left(R_{\text {int }}\right)$ of cells using GPE and cGPE with different salt concentrations during cycling up to their failures.

The $R_{\text {int }}$ decreases in the initial cycles before it starts to grow in later cycles until the failure cycle. A similar phenomenon was also observed in our previous chapter [148]. As previously observed, the interfacial resistance of $\mathrm{Li}^{-} \mathrm{O}_{2}$ batteries is initially governed by anode/electrolyte interface $[127,160]$. Hence the decrease in the $R_{\text {int }}$ at initial cycles is mainly related to the dissolution of the passivation film on the anode/electrolyte films interface [125]. However, the increase in $R_{\text {int }}$ in later cycles could be related to the accumulation of irreversible charge/discharge by-products on the anode/electrolyte [31] 
and cathode/electrolyte interfaces [127]. To further distinguish the contribution of cathode and anode in our EIS spectra, two sets of symmetrical cells using Li/electrolyte film/Li, and cathode/electrolyte film/cathode were assembled. Potentiostatic EIS with AC amplitude of $5 \mathrm{mV}$ in the frequency range of $100 \mathrm{k} \mathrm{Hz}$ to $100 \mathrm{mHz}$ were performed on both $\mathrm{Li} / \mathrm{Li}$ and cathode/cathode symmetrical cells. In the case of cathode/cathode symmetrical cells, both precycled and fresh cathodes were used. For precycled cathode/cathode symmetrical cells, both cathodes were initially cycled 50 times for limited charge/discharge capacity of $500 \mathrm{mAh} \cdot \mathrm{g}^{-1}$ at the same current density of $250 \mathrm{~mA} \cdot \mathrm{g}^{-1}$ in separate cells before they were assembled in a new symmetrical cell. The cathodes after cycling were recovered from cells and rinsed with acetonitrile to remove the electrolyte salt before they were placed in symmetrical cells under oxygen environment. Figure 4-13 illustrates the EIS spectra of symmetrical cathode/cathode and $\mathrm{Li} / \mathrm{Li}$ symmetrical cells along with EIS spectrum of the full $\mathrm{Li}-\mathrm{O}_{2}$ cell. As can be seen, $\mathrm{Li} / \mathrm{Li}$ cell exhibits a semicircle corresponding to the interfacial resistance of the surface of Li and gel film electrolyte followed by charge transfer resistance. Fresh cathode/cathode symmetrical cell also shows a typical behavior of porous systems consisting of a Warburg diffusion resistance followed by a capacitive rise. Comparing the EIS spectrum of the full $\mathrm{Li}^{-\mathrm{O}_{2}}$ cell with fresh cathode/cathode and $\mathrm{Li} / \mathrm{Li}$ symmetrical cells confirms that the interfacial resistance of the full $\mathrm{Li}_{-} \mathrm{O}_{2}$ battery is mostly controlled by the interfacial resistance of Li/electrolyte film. On the other hand, the precycled cathode/cathode symmetrical cell shows a semicircle followed by the Warburglike resistance. This indicates that the irreversible charge/discharge products are accumulated on the cathode and contributes into the interfacial resistance upon cycling. Hence, at the beginning of cycling test, the interfacial resistance of full $\mathrm{Li}_{-} \mathrm{O}_{2}$ cell is mostly 
governed by the anode/electrolyte film interface. Then in later cycles, the cathode/electrolyte film interface was started to contribute to interfacial resistance.
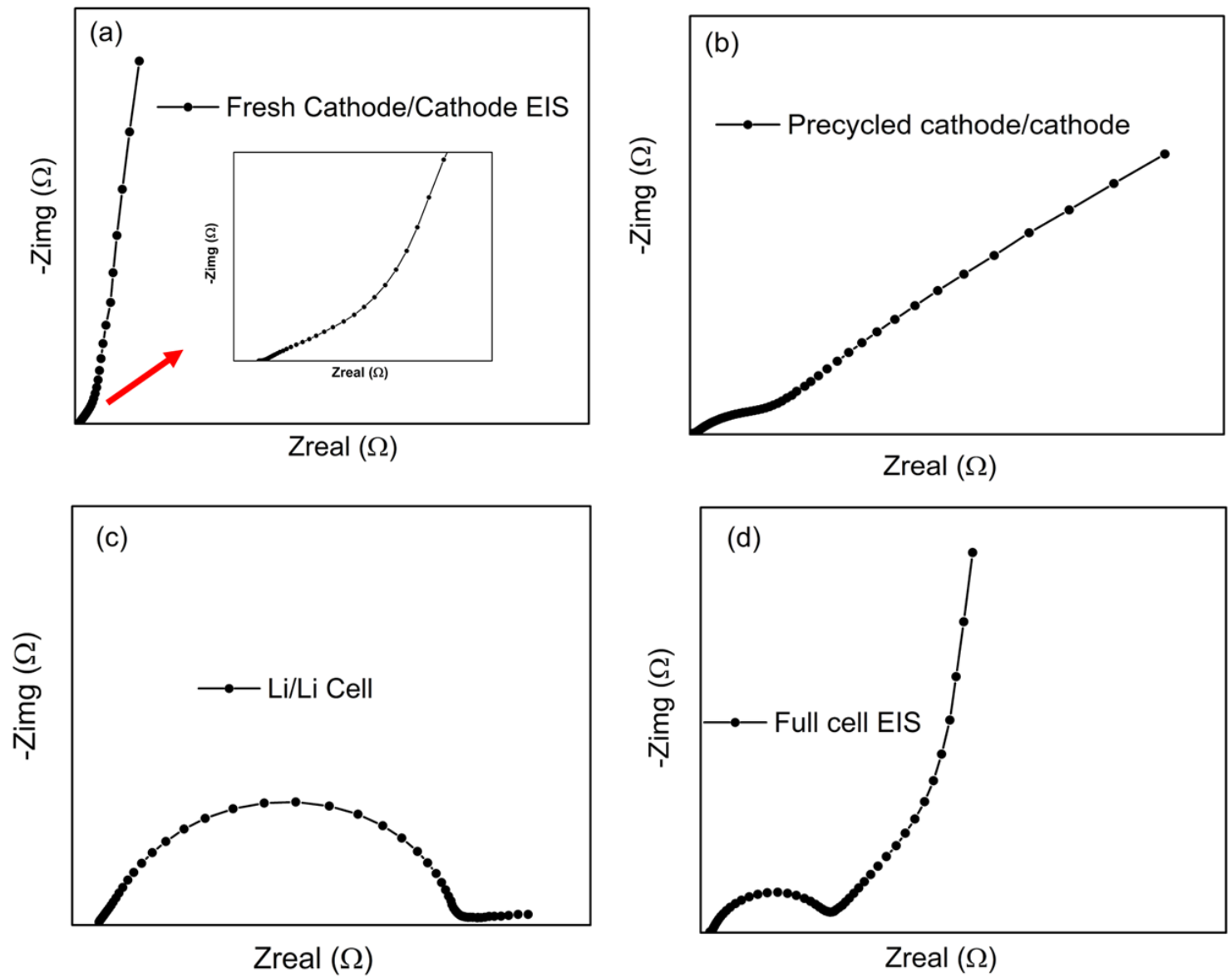

Figure 4-13: (a) EIS spectrum of (a) fresh cathode/cathode symmetrical cell (b) precycled cathode/cathode symmetrical cell (c) $\mathrm{Li} / \mathrm{Li}$ symmetrical cell (d) full $\mathrm{Li}^{-} \mathrm{O}_{2}$ battery

Yi et al. $[109,128]$ also showed that the formation of lithium carbonates by-products on the cathode/electrolyte interface could increase the interfacial resistance in $\mathrm{Li}_{-} \mathrm{O}_{2}$ batteries during cycling. The addition of microfillers (especially in 0.1 and $1.0 \mathrm{~mol} \cdot \mathrm{kg}^{-1}$ salt concentration) maintained a lower $R_{\text {int }}$ throughout the cycling, and can be credited to stabilizing the electrolyte and reducing its decomposition rate. 
To further investigate the contribution of each cell component in the failure of $\mathrm{Li}-\mathrm{O}_{2}$ batteries, the $\mathrm{Li}-\mathrm{O}_{2}$ cells using GPE and cGPE-1\% with $1 \mathrm{~mol} \cdot \mathrm{kg}^{-1}$ LiTFSI salt concentration were assembled and cycled with the limited capacity of $500 \mathrm{mAh} \cdot \mathrm{g}^{-1}$ at a current density of $250 \mathrm{~mA} \cdot \mathrm{g}^{-1}$. EIS was performed before cycling and after their failure cycles. The cells after failures were opened inside Ar-filled glovebox, and extra $20 \mu \mathrm{L}$ electrolytes were added to soak the cathode. EIS was again performed on the cells. The cells with added electrolyte rested under oxygen for 5 hours and charged/discharged at the same condition. As can be seen from Figure 4-14, the ionic resistance $\left(R_{\text {ion }}\right)$ of cells after failure increases as explained earlier. After soaking failed cathodes with extra electrolyte, the ionic resistance $\left(R_{i o n}\right)$ of cell reduced (Figure 4-14). The failed cells after soaking with extra electrolyte only ran for one cycle, and again they failed. EIS spectra of cells after their second failure was very close to their first failure EIS spectra. These results confirmed that the batteries were not failed due to the drying of cathodes. Secondly, although the ionic resistance $\left(R_{i o n}\right)$ of both cells reduced temporarily after addition of extra electrolyte, it did not prevent the failure of cells as they only ran for one cycle. The $\mathrm{Li}^{-\mathrm{O}_{2}}$ cells using GPE and cGPE-1\% were also cycled up to their failure and then their Li anodes were replaced with fresh one inside the glovebox. The cells with new Li anode and old cathode were not able to recover and they failed immediately. These results were confirmed that the Li anode is not responsible for $\mathrm{Li}_{-} \mathrm{O}_{2}$ battery failure. 

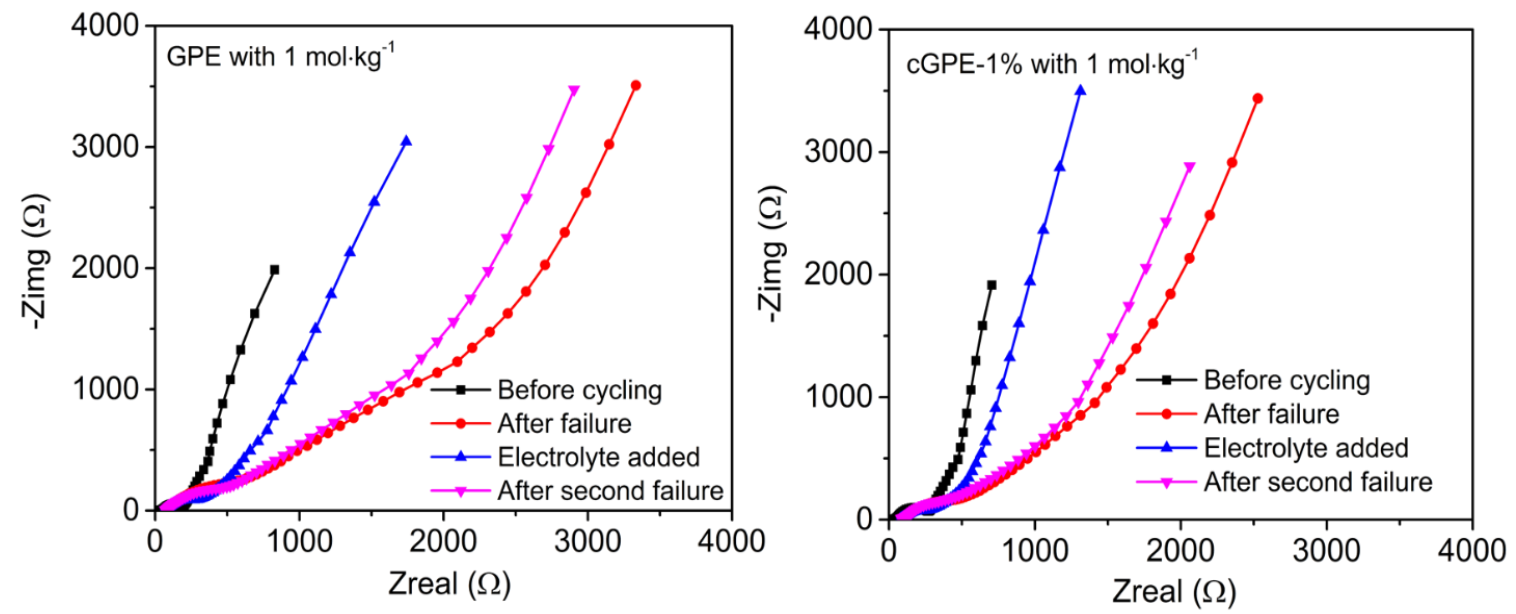

Figure 4-14: EIS spectra of $\mathrm{Li}-\mathrm{O}_{2}$ cells using GPE and cGPE-1\% in different conditions

From the results obtained using the charge/discharge cycling, EIS, and Raman spectroscopy, the improvement in $\mathrm{Li}^{+}$transport properties, especially lithium transference number correlated strongly with the improvement in cyclability of $\mathrm{Li}-\mathrm{O}_{2}$ batteries, mainly due to the stabilization of the electrolyte. At the cathode, the main source of instability of the electrolyte during discharge is the reaction of superoxide radicals with the glyme-based solvent molecules. Thotiyl et al. confirmed the prevalence of this reaction during discharge by tracking the ${ }^{13} \mathrm{C}$ isotopic species in the decomposition products [39]. These superoxide radicals under ideal conditions would be reacting with the $\mathrm{Li}^{+}$to yield $\mathrm{Li}_{2} \mathrm{O}_{2}$. However, in electrolytes with inefficient $\mathrm{Li}^{+}$transport properties, the ratio of solvated $\mathrm{Li}^{+}$to loosely bound ion pairs composed of solvated $\mathrm{Li}^{+}$and TFSI ${ }^{-}$is reduced $[151,152]$, which in turn, increases the probability of the reaction of superoxide radical with the solvent $[143,144]$ and promotes the electrolyte decomposition. Therefore, since an increase in transference properties of the electrolyte is associated with the higher ratio of solvated $\mathrm{Li}^{+}, \mathrm{GPE}$ and cGPE with improved transference numbers help reduce electrolyte degradation. The 
degradation and eventual formation of lithium carbonates can, therefore, be reduced in $\mathrm{Li}$ $\mathrm{O}_{2}$ batteries using higher transference number electrolytes such the cGPE presented in this work. Figure 4-15 demonstrates the possible mechanism of electrolyte stabilization in cGPEs.

Cathode/GPE Interface

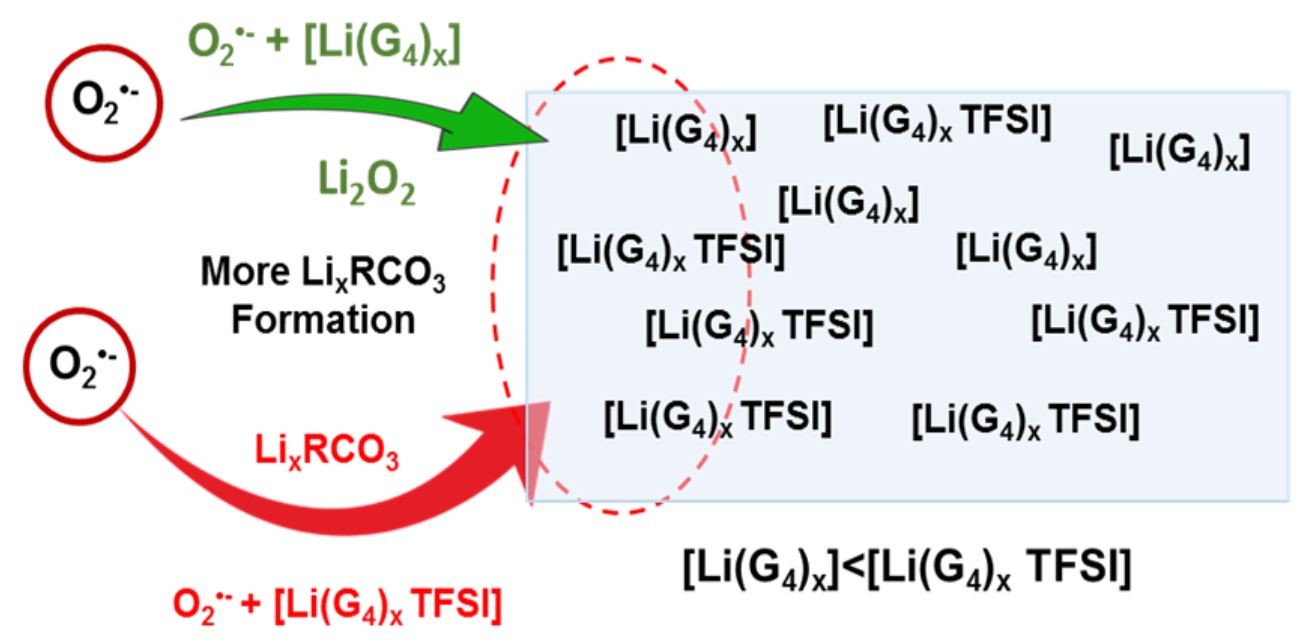

Cathode/cGPE Interface

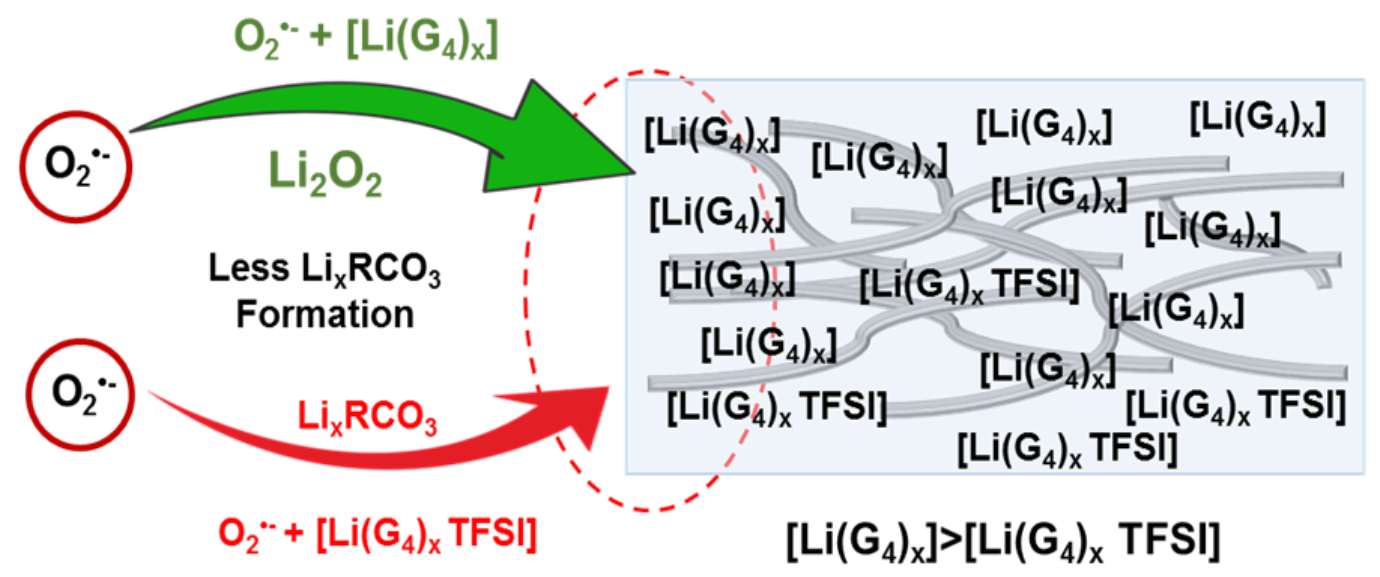

Figure 4-15: Schematic representation of proposed mechanism of electrolyte stabilization in $\mathrm{Li}-\mathrm{O}_{2}$ batteries in cGPEs over GPEs 


\subsection{Conclusions}

In this chapter, gel polymer electrolytes (GPE) and glass microfillers-containing composite GPE (cGPE) were developed for their use in $\mathrm{Li}-\mathrm{O}_{2}$ batteries. Using various concentrations of lithium salt, it was observed that the resulting cGPE had improved lithium transport properties. $\mathrm{Li}-\mathrm{O}_{2}$ batteries containing cGPE cycled up to 5 -fold more cycles of $500 \mathrm{mAh} \cdot \mathrm{g}^{-}$

1 capacity per cycle compared to batteries containing GPE. This improvement was determined to be due to the reduction of the growth of ionic resistances in the cathode and its electrolyte interface. This resistance was traced back to the formation of lithium carbonates on the cathode due to the degradation of the tetraglyme-based solvent in the electrolyte. We theorize that the improved lithium transference of the cGPE increased the ratio of solvated to coupled $\mathrm{Li}^{+}$which reduced the probability of superoxide radicals reacting with the tetraglyme-based solvent during cycling. 


\section{EFFECT OF ION PAIRS FORMATION ON THE STABILITY OF GLYME ELECTROLYTE}

\subsection{Background}

Conventional carbonate-based solvents used in Li-ion batteries were shown to be severely decomposed by reactive oxygen species $\left(\mathrm{O}_{2}^{2^{-}}\right)$during ORR process [47]. Therefore, new aprotic solvents such as Dimethyl sulfoxide (DMSO) [168], Dimethylformamide (DMF) [49] and Dimethylacetamide (DMA) [169] have been developed for $\mathrm{Li}^{-} \mathrm{O}_{2}$ batteries. Recent studies, however, proved their reactivity toward $\mathrm{Li}$ anode and superoxide species $[49,170,171,51]$. Ether-based electrolytes which are relatively stable toward Li anodes are now the common solvents used in $\mathrm{Li}_{2} \mathrm{O}_{2}$ batteries $[172,48]$. Their instabilities against the reactive oxygen species were also reported.[48,140] It is generally accepted that radical superoxides $\left(\mathrm{O}_{2}{ }^{-}\right)$attack the allylene groups close to the ethylene oxide bonds and decompose them to the carbonates groups. The subsequent reaction between these carbonates and discharge products $\left(\mathrm{Li}_{2} \mathrm{O}_{2}\right.$ and $\left.\mathrm{LiO}_{2}\right)$ forms lithium carbonates [140]. The continuous formation of parasitic lithium carbonates at the cathode during cycling cause high cell polarization and poor cyclability [39,48]. Recently, few theoretical and experimental studies suggested that the increase in the lithium salt concentration of the electrolytes improves the performance of $\mathrm{Li}_{-} \mathrm{O}_{2}$ batteries $[142,143]$. The improvement has been accredited to the increase in the number of coordinated solvent molecules with $\mathrm{Li}^{+}$, which have been shown to be more stable than uncoordinated solvent molecules towards the superoxide attack $[142,143]$. $\mathrm{Li}$ et al. also showed that the type of $\mathrm{Li}^{+}$solvation with solvent molecules could also affect the reactivity of superoxides with solvent molecules [143]. Despite these findings at concentrated electrolytes, the mechanism of electrolyte 
stabilization at relatively low lithium salt concentration is not well understood due to the complex interaction of $\mathrm{Li}^{+}$and solvent molecules. This complexity is originating from the fact that the addition of alkyl metal salts such as $\left(\mathrm{Li}^{+} \mathrm{X}^{-}\right)$to aprotic solvents forms different ionic complexes such as contact ion pairs (CIPs), solvent-separated ion pairs (SSIPs), and ion aggregates $[155,173]$. The presence of these ion pair complexes is dependent on the salt and solvent properties, and salt concentration $[155,174,152,175]$. In this chapter, we investigate the effect of $\mathrm{Li}$ cation/solvent solvation on the stability of tetragylme-based electrolytes containing various Lithium bis(trifluoromethane) sulfonamide (LiTFSI) salt concentration for the $\mathrm{Li}-\mathrm{O}_{2}$ battery application. Tetragylme-based solvent and LiTFSI salt were chosen in this study due to their popularity in the $\mathrm{Li}-\mathrm{O}_{2}$ battery systems[176]. Charge/discharge cycling, Raman spectroscopy along with various electrochemical characterization have been used to evaluate the origin of the improved performance at different salt concentrations.

\subsection{Experimental Details}

TEGDME solvent was first dried over $4 \AA$ Molecular sieve in the Ar-filled glovebox. Liquid electrolytes were prepared by dissolving different mole fraction of LiTFSI salt $\left(\mathrm{X}_{\mathrm{LiTFS}}=0.02,0.2,0.4\right)$ in TEGDME solvent. It has to be mentioned that the lithium salt concentrations used in this chapter are very similar to the previous chapter. The Ionic conductivity of liquid electrolytes was determined by AC impedance spectroscopy. The electrolytes were trapped between two stainless steel blocking electrodes by using $1 \mathrm{~mm}$ thick Teflon O-rings as described in chapter 3. Lithium transference number $\left(t_{L i}{ }^{+}\right)$was also determined using the Bruce-Vincent method. Li/electrolyte/Li symmetrical cells were prepared by soaking the Celgard 2400 polypropylene before cell assembly. Figure 5-1 
shows chronoamperometric curves of Li/electrolyte/Li cells along with their impedance spectra. Raman spectroscopy was also performed to analyze the interaction of TEGMDE molecules with LiTFSI salt. All liquid samples with different salt concentration were filled in airtight rectangular quartz cuvettes in an Ar-filled glovebox and then examined by BaySpec's Nomadic ${ }^{\mathrm{TM}}$ Raman spectrometer (excitation wavelength of $532 \mathrm{~nm}$ ). Each spectrum was recorded with the exposure time of $50 \mathrm{~s}$ using the $50 \mathrm{X}$ objective lens at $25^{\circ} \mathrm{C}$. All cathodes after discharge tests were recovered from the cells in an Ar-filled glovebox and discharge products/byproducts were further characterized by Raman Spectroscopy (BaySpec's Nomadic ${ }^{\mathrm{TM}}$ ). Galvanostatic discharge tests were performed at the constant current density of $250 \mathrm{~mA} \cdot \mathrm{g}^{-1}$ with the limited capacity of $500 \mathrm{mAh} \cdot \mathrm{g}^{-1}$ using MTI battery analyzer.
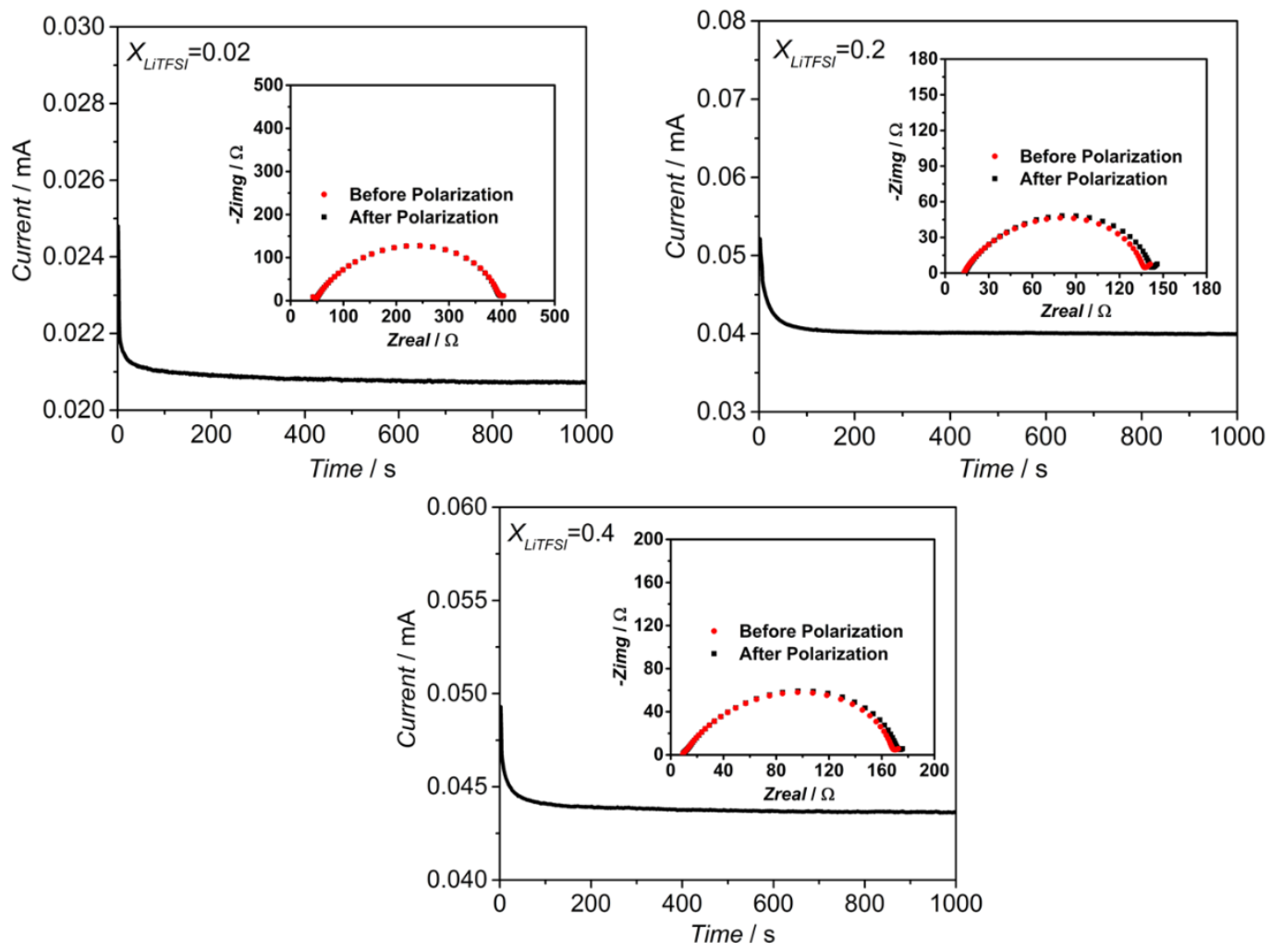

Figure 5-1: Chronoamperometric curves of Li/liquid electrolyte /Li cell after $10 \mathrm{mV}$ of DC polarization at $22^{\circ} \mathrm{C}$ where the electrolytes contain different LiTFSI salt concentration. Insets: electrochemical impedance spectra before and after polarization 
All cycling and electrochemical tests were carried out at $25^{\circ} \mathrm{C}$. Galvanostatic electrochemical impedance spectroscopy (EIS) measurements were conducted in the frequency range of $100 \mathrm{kHz}$ to $10 \mathrm{mHz}$ using $10 \%$ of DC discharge current after discharges at open circuit voltage (OCV).

\subsection{Results and Discussion}

The ionic transport properties (ionic conductivity $(\sigma)$ and Li transference number $\left(t_{L i}{ }^{+}\right)$) of electrolytes with different salt concentrations were measured at room temperature $\left(25^{\circ} \mathrm{C}\right)$, and results are shown in Table 5-1. As it is cleared, the ionic conductivity of electrolytes increases with Li salt concentration from $X_{\text {LiTFSI }}=0.02$ to $X_{\text {LiTFSI }}=0.2$ and then decreases with further increase in Li salt concentration $\left(X_{\text {LiTFSI }}=0.4\right)$. The increase in the ionic conductivity is associated with the increase in the number of charge carriers in the electrolyte [151]. However, the decrease in ionic conductivity is due to the increase in viscosity of the electrolyte which reduces the mobility of charge carriers [151]. The Li transference number of electrolytes, on the other hand, keeps increasing with Li salt concentration [151].

Table 5-1: The ionic conductivity $(\sigma)$ and transference number $\left(\mathrm{tLi}^{+}\right)$of electrolytes with various salt concentration

\begin{tabular}{ccc}
\hline Liquid Electrolyte & $\begin{array}{c}\text { Transference Number, } \\
\left(t_{L i}{ }^{+}\right)\end{array}$ & $\begin{array}{c}\text { Ionic Conductivity, } \sigma \\
\left(\mathrm{mS} \cdot \mathrm{cm}^{-1}\right)\end{array}$ \\
\hline$X_{\text {LiTFSI }}=0.02$ & 0.39 & 0.31 \\
$X_{\text {LiTFSI }}=0.2$ & 0.50 & 2.56 \\
$X_{\text {LiTFSI }}=0.4$ & 0.56 & 1.13 \\
\hline
\end{tabular}


Interestingly, the Li transference number of Liquid electrolytes are very close to those reported for GPEs indicating that the ETPTA polymer acts only as an inert polymer and EPTPA does not have any ion trapping ability. To investigate the effect of salt concentration of liquid electrolytes on the performance of $\mathrm{Li}^{-\mathrm{O}_{2}}$ batteries, galvanostatic charge/discharge cycling was performed at the current density of $250 \mathrm{mAh} \cdot \mathrm{g}^{-1}$ with the limited capacity of $500 \mathrm{mAh} \cdot \mathrm{g}^{-1}$ in the voltage window of 2.0-4.5 V. Figure 5-2 shows the voltage profile of $\mathrm{Li}-\mathrm{O} 2$ cells using electrolyte with different salt concentrations up to their failures (cycle less than $500 \mathrm{mAh} \cdot \mathrm{g}^{-1}$ ).
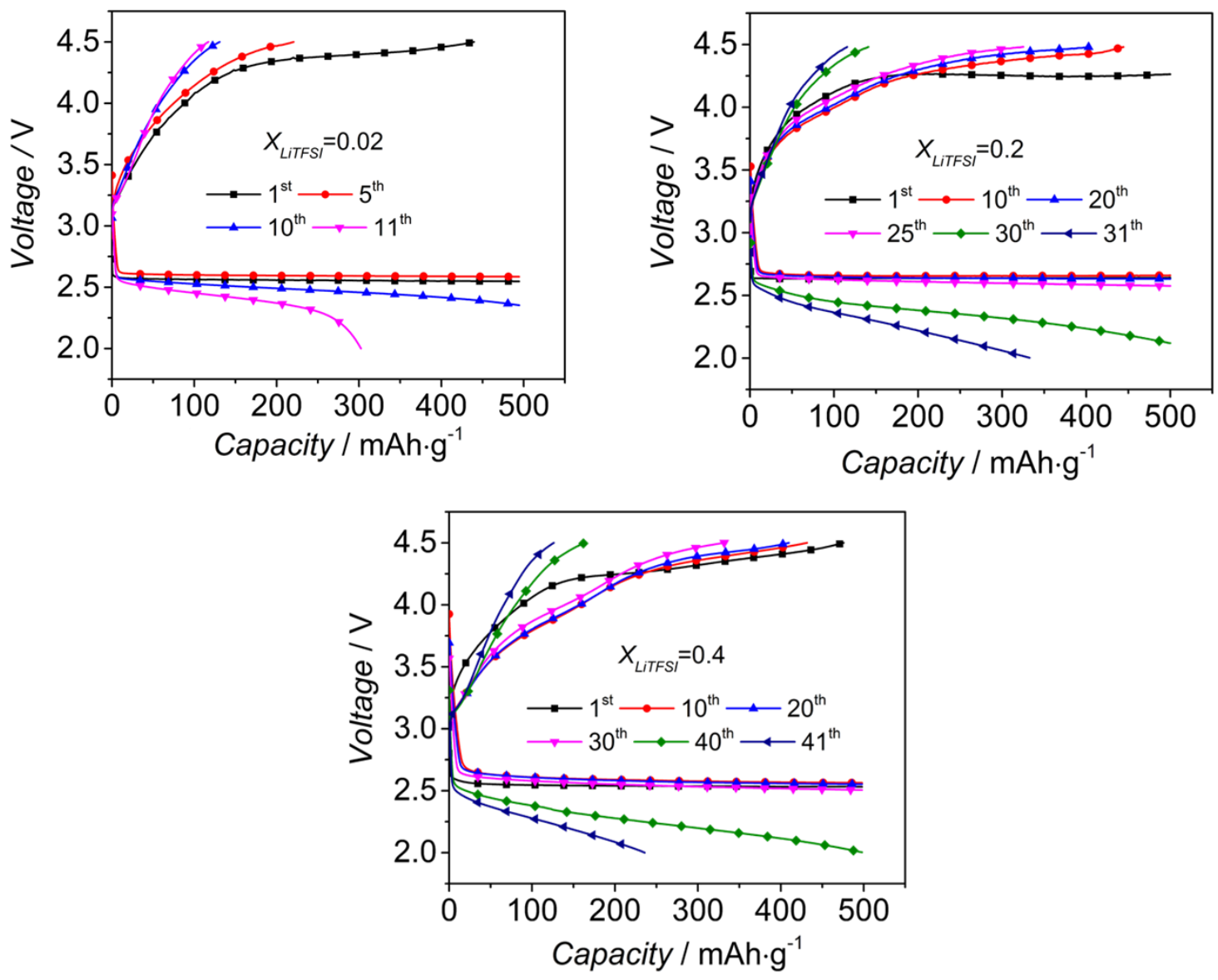

Figure 5-2: Voltage profile of $\mathrm{Li}^{-} \mathrm{O}_{2}$ batteries using TEGDME electrolyte with various LiTFSI salt concentrations with a limited capacity of $500 \mathrm{mAh} \cdot \mathrm{g}^{-1}$ per cycle at current density of $250 \mathrm{~mA} \cdot \mathrm{g}^{-1}$ in a voltage range of $2.0-4.5 \mathrm{~V}$. 
As can be seen, $\mathrm{Li}-\mathrm{O}_{2}$ cells using an electrolyte with $\mathrm{Li}$ salt mole fraction of $0.02,0.2$ and 0.4 shows 10,30 and 40 cycles, respectively. This shows that increase in salt concentration improves the cycleability of $\mathrm{Li}-\mathrm{O}_{2}$ batteries as previously was observed for ether-based electrolytes, as well [142,143]. Interestingly, the cyclability of cells using liquid electrolytes is similar to the cells using GPEs proving that the making the liquid electrolytes to the GPEs by adding ETPTA polymer does not improve the cell performance. Electrochemical impedance spectroscopy (EIS) was performed to investigate the failure mechanism of $\mathrm{Li}-\mathrm{O}_{2}$ batteries using electrolytes with different salt concentrations. In-situ EIS was carried out during cycling after discharge at open circuit voltage (OCV) under oxygen. Figure 5-3 shows the typical Nyquist plots of $\mathrm{Li}^{-\mathrm{O}_{2}}$ batteries using an electrolyte with $X_{\text {LiTFSI }}=0.2$ salt concentration after $1^{\text {st }}, 5^{\text {th }}, 25^{\text {th }}$ and $30^{\text {th }}$ (failure) discharge cycles.
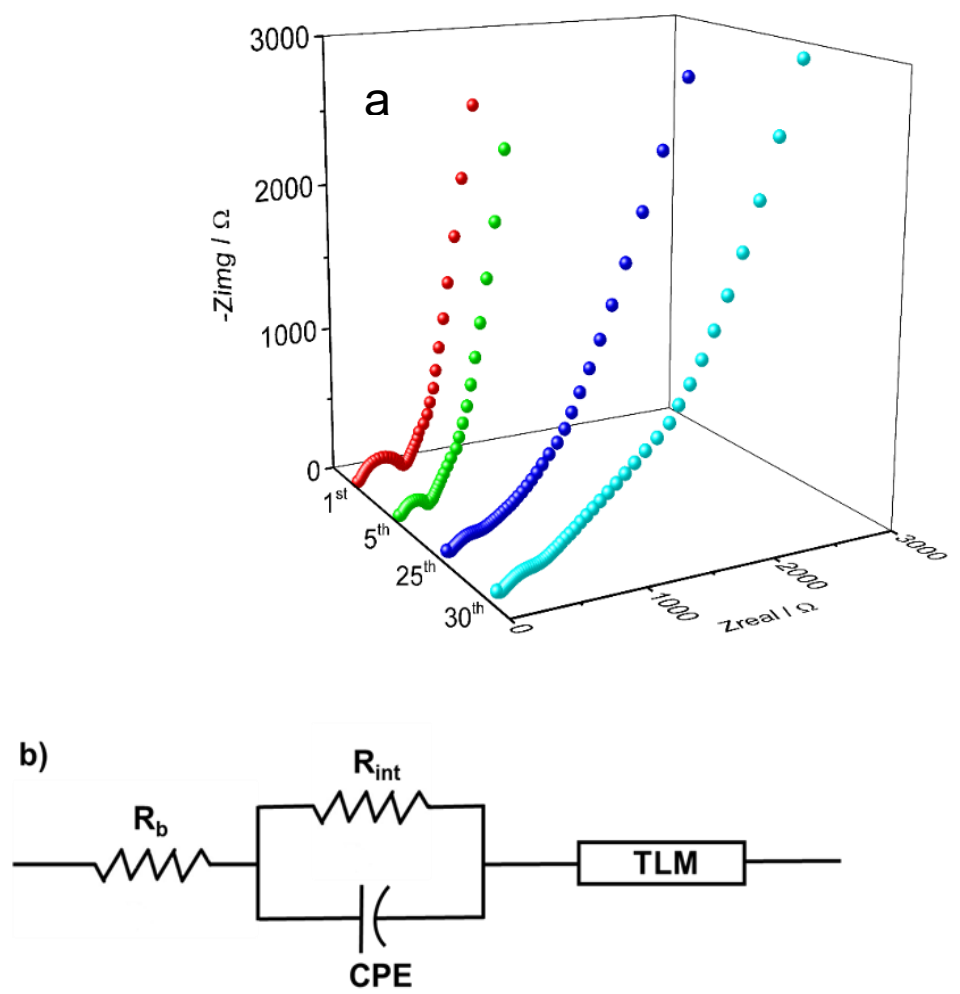

Figure 5-3: (a) Typical Nyquist plots of $\mathrm{Li}^{-\mathrm{O}_{2}}$ batteries using TEGDME electrolyte with $X_{\text {LITFSI }}=0.2$ salt concentration at OCV after first and failure cycle $\left(30^{\text {th }}\right)$ along with $5^{\text {th }}$ and $25^{\text {th }}$ cycle (b) Circuit model of the full cell as described in previous chapter 
The Nyquist plots were similar to the Nyquist plots of cells using GPEs and cGPEs. They consisted of a semicircle corresponding to the interfacial resistance $\left(R_{\text {int }}\right)$ between the electrolyte and the electrodes and a Warburg-like linear region followed by a rise at low frequencies. All impedance parameters $\left(R_{i o n}, R_{b}\right.$, and $\left.R_{i n t}\right)$ were obtained as described in the previous chapter.

Figure 5-4 shows the evolution of resistances $R_{i o n}, R_{b}$ and $R_{i n t}$ of cells using different salt concentrations versus selected discharge cycle numbers up to their failure cycle. As can be seen, $R_{i o n}$ was the dominant resistance in all cells during cycling which indicates that the resistance within the cathode is the leading cause of the battery failure. Bardenhagen et al. [127] confirmed that the deposition of irreversible charge/discharge products on the cathode hinders the $\mathrm{Li}^{+}$transport within the pores of the porous cathode and in turn increases the $R_{i o n}$. Tracking $R_{i o n}$ of cells shows that the $R_{i o n}$ increased at a slower rate with the increase in salt concentration indicating the pore clogging caused by irreversible charge/discharge products is less at high salt concentration.

Tracking the $R_{\text {int }}$ upon cycling (Figure 5-5) also indicates that the $R_{\text {int }}$ reduces at initial cycles and then starts to grow by cycling until the failure of cells as previously observed for GPEs and cGPEs. A decrease in interfacial resistance was reported for metal- $\mathrm{O}_{2}$ cells using liquid electrolyte [159] quasi-solid state electrolyte [125] and gel polymer electrolyte as described in previous chapters [148,63]. Knudsen et al. [160] and Bardenhagen et al. [127] previously reported that the interfacial resistance $\left(R_{\text {int }}\right)$ of $\mathrm{Li}^{-\mathrm{O}_{2}}$ batteries is mostly controlled by anode/electrolyte interface at initial discharge process. Consequently, the decrease in the $R_{\text {int }}$ at early cycles could be ascribed to the dissolution of the passivating film on the anode/electrolyte interface [125]. In the later cycles, however, the accumulation 
of irreversible charge/discharge by-products on electrodes/electrolyte interface $[127,31]$ causes the increase in $R_{\text {int }}$.

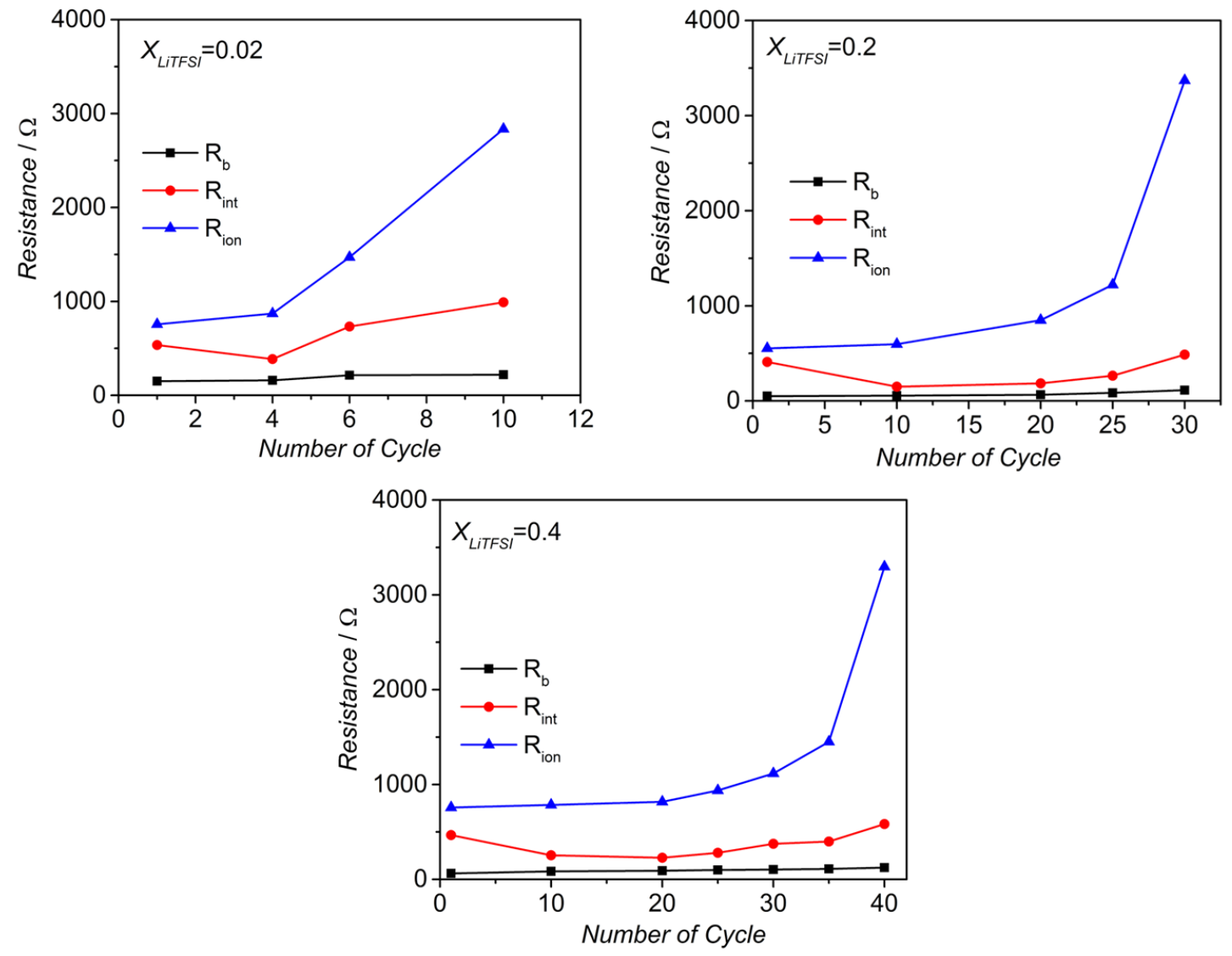

Figure 5-4: The change of resistances of $\mathrm{Li}^{-} \mathrm{O}_{2}$ batteries using TEGDME electrolyte with different salt concentrations during cycling up to their failure (cyle $10^{\text {th }}, 30^{\text {th }}$ and $40^{\text {th }}$ for $X_{\text {LiTFSI }}=0.02$ and 0.2 and 0.4 , respectively).

Furthermore, the interfacial resistance $\left(R_{\text {int }}\right)$ of $\mathrm{Li}-\mathrm{O}_{2}$ cell using $X_{\text {LiTFSI }}=0.2$ during cycling is less than that of $\mathrm{Li}-\mathrm{O}_{2}$ cells using $X_{\text {LiTFSI }}=0.02$ and $X_{\text {LiTFSI }}=0.4$ (Figure 5-5). Markus et al. also reported the same trend in interfacial resistance of $\mathrm{Li}-\mathrm{O}_{2}$ cells using different salt concentrations [177]. At low salt concentration $\left(X_{\text {LiTFSI }}=0.02\right)$, the $R_{\text {int }}$ is higher compared to other salt concentration due to diminished ionic conductivity [177]. The increase in 
lithium salt concentration from $X_{\text {LiTFSI }}=0.2$ to $X_{\text {LiTFSI }}=0.4$ also reduces the $R_{\text {int }}$. The increase in Li salt concentration increases the viscosity of electrolyte, which causes the wettability between electrolyte and electrodes become poor [178].

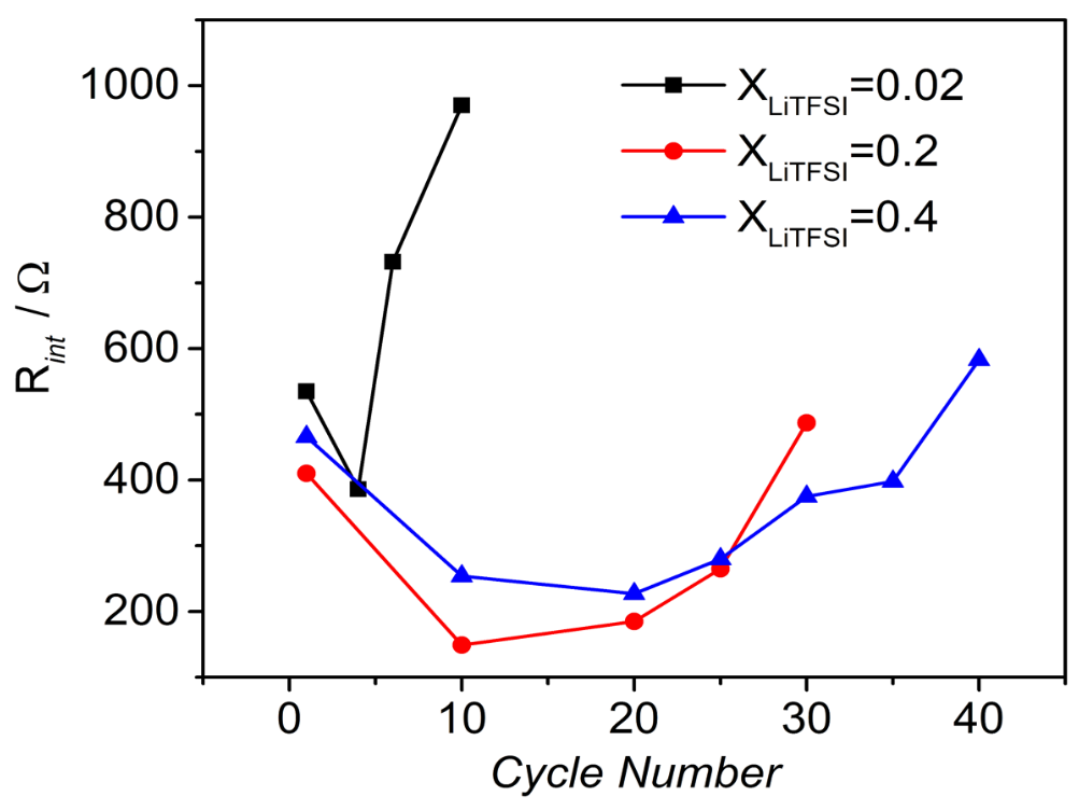

Figure 5-5: Interfacial resistance evolution of $\mathrm{Li}^{-} \mathrm{O}_{2}$ cells using liquid electrolyte with various Li salt concentration versus selected cycles until their failure

Raman spectroscopy was also performed on the cycled cathodes after their failures to investigate the cause of the increase in $R_{i o n}$ and cell failure. Figure 5-6 illustrates the Raman spectra of failed cathodes harvested from $\mathrm{Li}_{-} \mathrm{O}_{2}$ batteries with different salt concentrations. All spectra showed a Raman band at around $800 \mathrm{~cm}^{-1}$ confirming the formation of $\mathrm{Li}_{2} \mathrm{O}_{2}$ on the cathodes [120]. The presence of $\mathrm{Li}_{2} \mathrm{O}_{2}$ at all salt concentrations affirms that the discharge capacities of all batteries are due to oxygen reduction reaction (ORR). All cycled cathodes after their failures also showed a pronounced Raman band at $1082 \mathrm{~cm}^{-1}$ corresponding to the lithium carbonate species $[120,166]$. 

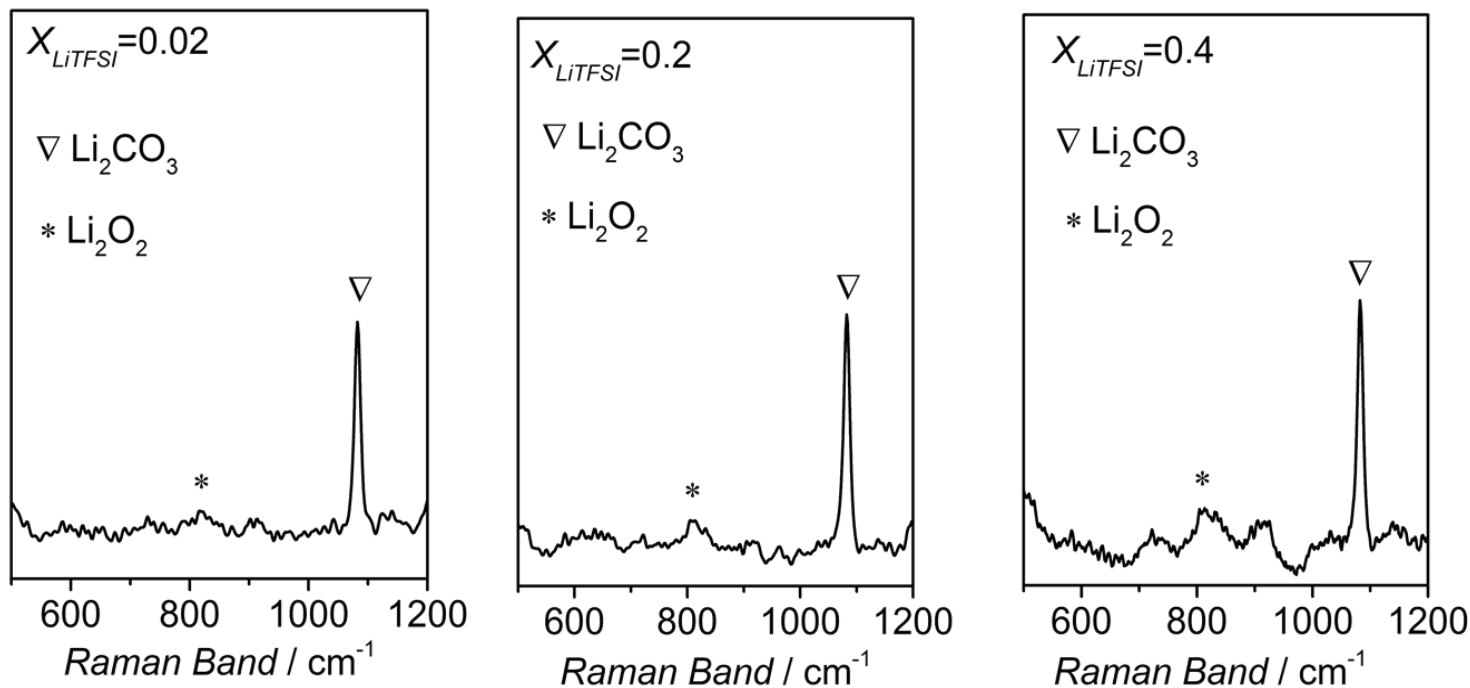

Figure 5-6: Raman spectra of cycled cathodes in $\mathrm{Li}^{-\mathrm{O}_{2}}$ cells using TEGDME electrolyte with various salt concentration after thier failure cycles (cycle $10^{\text {th }}$, cycle $30^{\text {th }}$ and cycle $40^{\text {th }}$ for cell using $X_{\text {LiTFSI }}=0.02,0.2$ and 0.4 , respectively).

As explained in previous chapter, the formation of carbonate species in $\mathrm{Li}-\mathrm{O}_{2}$ batteries has been associated with the decomposition of carbon cathodes and electrolytes [39,140,22]. However, Thotiyl et. al [39] and Xu et. al [140] proved that the majority of carbonate formation in $\mathrm{Li}-\mathrm{O}_{2}$ batteries using tetragylme electrolyte is coming from electrolyte decomposition, not carbon cathode decomposition. Therefore, the results of cycling, EIS and Raman spectroscopy suggest that increase in Li salt concentration in the Tetragylme electrolytes could improve the electrolyte stability in $\mathrm{Li}^{-} \mathrm{O}_{2}$ batteries during cycling. It has been previously shown that reaction of radical superoxides $\left(\mathrm{O}_{2}{ }^{-}\right.$and $\left.\mathrm{LiO}_{2}\right)$ with solvent molecules at the cathode could decompose solvent molecules and forms carbonate species $[39,140]$. To further investigate the effect of LiTFSI salt concentration on the stability of tetragylme electrolyte, Raman spectroscopy was performed on the electrolyte solutions. 
Figure 5-7 shows the Raman spectra of electrolyte solutions as a function of LiTFSI salt concentration. Deconvolution of Raman bands were performed by Gaussian-Lorentzian (Voigt) fitting function [179]. Pure TEGDME solvent exhibits the Raman bands at around 805,820 and $850 \mathrm{~cm}^{-1}$ corresponding to the mixture mode for $\mathrm{CH}_{2}$ rocking vibrations and C-O-C stretching vibration $[175,180]$. The addition of LiTFSI salt in the TEGMDE solvent introduced a new Raman band centered at around $740 \mathrm{~cm}^{-1}$ which could be assigned to the contraction and expansion mode of S-N coupled with $\mathrm{CF}_{3}$ bending of $\mathrm{TFSI}^{-}$anion [154]. Since the $\mathrm{TFSI}^{-}$anion weakly interacts with TEGDME solvent molecules, the changes in the Raman band around $740 \mathrm{~cm}^{-1}$ are mostly correlated to the $\mathrm{Li}^{+}$cation and $\mathrm{TFSI}^{-}$anion association [180]. Several types of solvates could be formed in TEGDME solution with various LiTFSI salt concentration due to the different $\mathrm{Li}^{+}$coordination with two conformers of the TFSI ${ }^{-}$anion (cisoid $\left(\mathrm{C}_{1}\right)$ and transoid $\left(\mathrm{C}_{2}\right)$ ) [155]. Hence it is difficult to conclusively assigned Raman bands to different solvates. However, it is generally accepted that the Raman bands between 736-742 $\mathrm{cm}^{-1}$ correspond to the unbounded $\mathrm{TFSI}^{-}$(free and solvent separated ion pairs (SSIPs)) $[155,156]$ and Raman bands $\geq 744 \mathrm{~cm}^{-1}$ describe the bounded $\mathrm{TFSI}^{-}$(contact ion pairs (CIPs) and ion aggregates (AGGs)) [155,156]. It is also known that upon addition of LiTFSI salt, a new Raman band at $\sim 865 \mathrm{~cm}^{-1}$ known as a breathing mode were also appeared due to interaction between TEGDME and TFSI ${ }^{-}$, which form cationic complexes $\left(\left[\mathrm{Li}_{\mathrm{x}}(\mathrm{TGDEM})_{\mathrm{y}}\right]^{+}\right)$[175]. As can be seen from Figure 5-7, the increase in LiTFSI salt concentration increases the intensity of Raman band at $\sim 865 \mathrm{~cm}^{-1}$ (cationic complexes) and reduces the intensity of Raman bands for free TEGDME molecules indicating the ratio of cationic complexes to free TEGDME increases. 
Figure 5-7 also indicates that $\mathrm{TFSI}^{-}$anions even at very low salt concentration $\left(X_{\text {LiTFSI }}=0.02\right)$ have a strong ionic association tendency to $\mathrm{Li}^{+}$as formation of CIPs and AGGs was confirmed in Raman spectrum (Raman band at $\geq 744 \mathrm{~cm}^{-1}$ ). The similar results were also observed for $\mathrm{TFSI}^{-}$in solvents with low Gutman donor numbers (DNs) $[181,182]$. The explanation for this high ionic association of $\mathrm{TFSI}^{-}$could be due to the competitive solvation tendency of $\mathrm{Li}^{+}$with both TEGMDE and TFSI${ }^{-}$. The ratio of bounded to unbounded $\mathrm{TFSI}^{-}$also increases with Li salt concentration confirming that the formation of anionic complexes (CIPs or AGGs, $\left.\left(\left[\mathrm{Li}_{n}\left(\mathrm{TFSI}^{-}\right)_{\mathrm{m}}\right]^{-}\right)\right)$increases with Li salt concentration. Differentiating between CIPs (TFSI ${ }^{-}$coordinated with only one cation) [183] and AGGs (TFSI ${ }^{-}$coordinated with two or more cations) [183] using vibrational Raman spectroscopy is difficult [184]; however, Suo et. al [156] suggested that the Raman bands between 744-746 $\mathrm{cm}^{-1}$ describes the formation of CIPs and Raman bands $\geq 747 \mathrm{~cm}^{-}$ ${ }^{1}$ corresponds to the AGGs. The formation of AGGs is unfavorable in electrolytes for battery applications as they significantly reduce the cationic transference number $[183,185]$. Furthermore, recent Raman spectroscopic investigation on the $\operatorname{Mg}(\mathrm{TFSI})_{2}$ salt [183] showed that AGGs with bidentate ligands are formed at higher frequency $\left(\sim 752 \mathrm{~cm}^{-}\right.$ $\left.{ }^{1}\right)$, yet the CIPs with monodentate ligands are formed at lower frequencies $\left(\sim 746 \mathrm{~cm}^{-1}\right)$. Although this distinct deconvolution of CIPs and AGGs with bidentate and monodentate ligands have not be reported for LiTFSI, Umebayashi et. al [186] confirmed the weak interaction of $\mathrm{Li}^{+}$and TFSI ${ }^{-}$at Raman bad $\sim 744 \mathrm{~cm}^{-1}$ and strong solvation of TFSI ${ }^{-}$and $\mathrm{Li}^{+}$with bidentate ligands at Raman band $\sim 750 \mathrm{~cm}^{-1}$ [186]. The formation of AGGs with bidentate ligands significantly change the Li transference number as bidentate ligands provide strong interaction between $\mathrm{Li}^{+}$and $\mathrm{TFSI}^{-}$[187]. As can be seen from Figure 5-7, 
the Raman band corresponding to the bounded $\mathrm{TFSI}^{-}$appears at $\sim 745 \mathrm{~cm}^{-1}$ and increases with the Li salt concentration, which could suggest the formation of CIPs with monodentate ligands. Thus, at the studies salt concentrations, the increase in Li salt concentration will only increase the formation of CIPs with weak $\mathrm{Li}^{+}$and $\mathrm{TFSI}^{-}$interactions, which could liberate $\mathrm{Li}^{+}$and participate in $\mathrm{Li}$ transference number. Besides, recent theoretical and experimental studies suggest that the cationic complexes are mostly contributed in the ionic transports in electrolytes rather than anionic complexes [188,189]. The Raman band corresponding to the cationic complexes at $\sim 865 \mathrm{~cm}^{-1}$ substantially increases with salt concentration, yet the Raman band for anionic complexes $\left(\sim 745 \mathrm{~cm}^{-1}\right)$ slightly increases. Hence, although both cationic and anionic complexes increase with Li salt concentration, the formation of cationic complexes are dominated in TGEMDE solutions at the studied Li salt concentrations. The increase in $\mathrm{Li}^{+}$transference number with $\mathrm{Li}$ salt concentration reported in Table 5-1 could be justified by the dominated formation of cationic complexes over anionic ones and the increase in the formation of CIPs (anionic complexes) with monodentate ligands.

Recent studies confirmed that uncoordinated glyme molecules are prone to the superoxide attacks [141], so based on the Raman spectroscopy, the formation of the cationic complexes could protect the TEGDME molecules from decomposition [142,190]. 


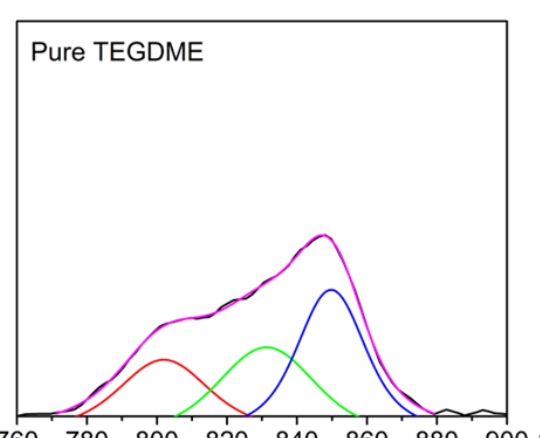

$\begin{array}{lllllllllllllllll}760 & 780 & 800 & 820 & 840 & 860 & 880 & 900 & 760 & 780 & 800 & 820 & 840 & 860 & 880 & 900\end{array}$ Raman Band $/ \mathrm{cm}^{-1}$

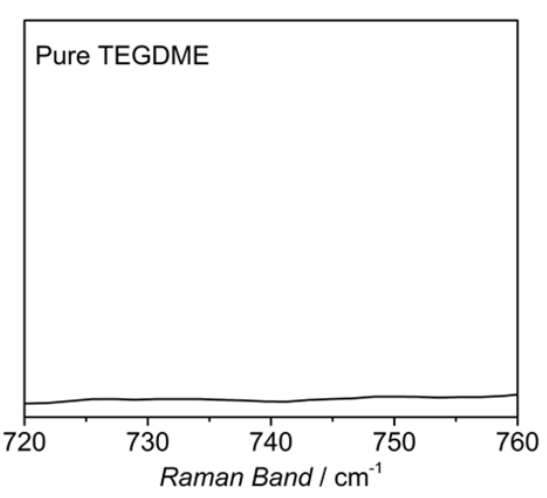

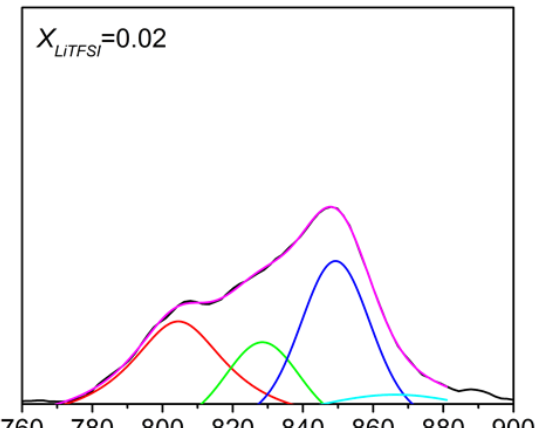

Raman Band / $\mathrm{cm}^{-1}$

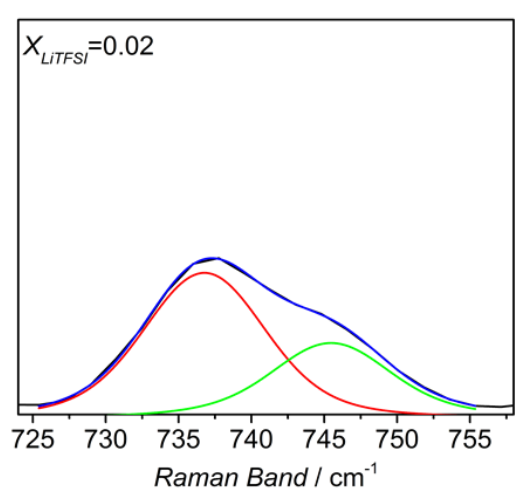

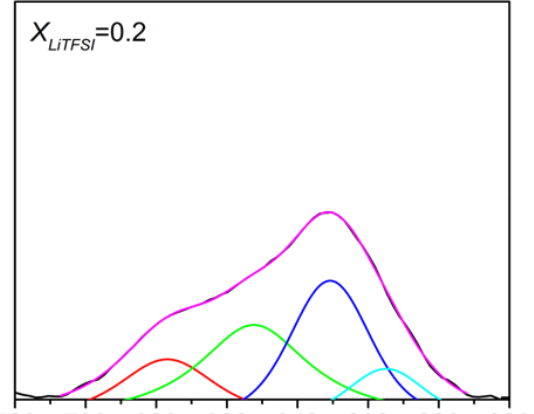

$\begin{array}{llllll}800 & 820 & 840 & 860 & 880 & 900\end{array}$ Raman Band $/ \mathrm{cm}^{-1}$

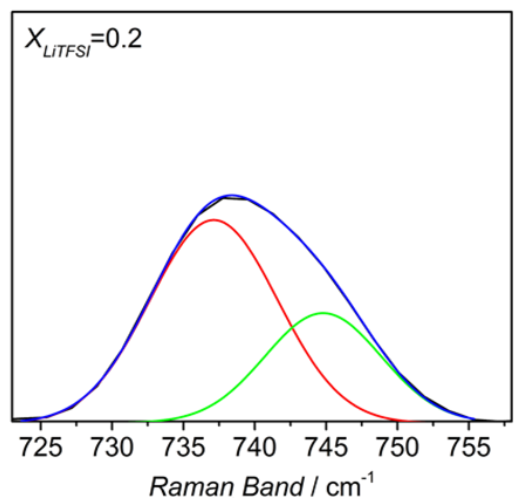

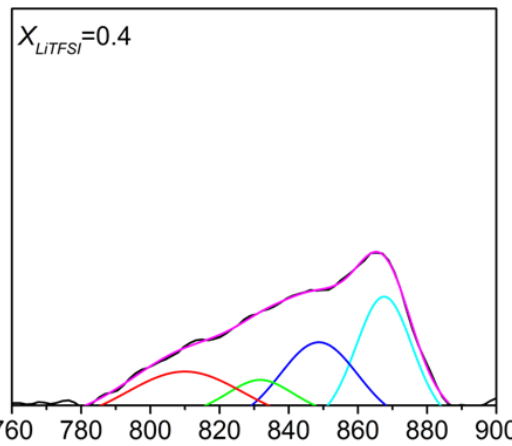

Raman Band / $\mathrm{cm}^{-1}$

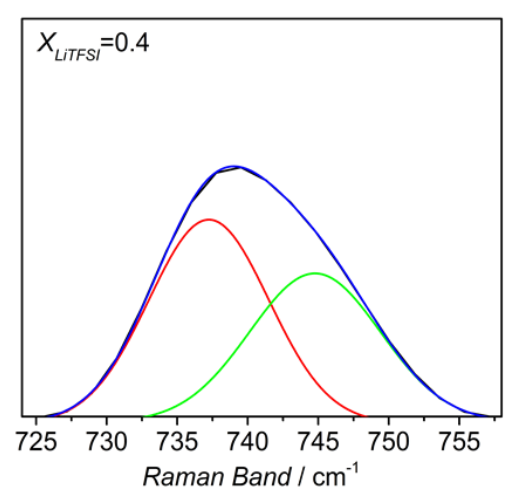

Figure 5-7: Raman spectra of electrolyte solution with various LiTFSI salt concentrations in the range of $800-900 \mathrm{~cm}^{-1}$ and 720-760 $\mathrm{cm}^{-1}$ at $22^{\circ} \mathrm{C}$. 
From the Raman spectroscopy results of electrolyte solutions, the protection mechanism of TEGDME with LiTFSI salt concentration could be explained by the fact that the ratio of solvated TEGDME with $\mathrm{Li}^{+}$to the unsolvated (free) TEGDME increases with salt concentration, which in turn protect the electrolyte from superoxide attack [142,143]. Furthermore, the Li salt concentration increases the $\mathrm{Li}$ transference number [151] in TEGDME solution and favors the reaction of superoxide with $\mathrm{Li}^{+}$instead of TEGDME molecules [143].

\subsection{Conclusion}

In this chapter, the influence of ionic complex formation in tetragylme based electrolytes with various LiTFSI concentrations on the performance of $\mathrm{Li}^{-} \mathrm{O}_{2}$ batteries have been investigated. Cycling results showed that the increase in LiTFSI concertation significantly improves the cyclability (as high as 300\%). The in-situ electrochemical impedance spectroscopy (EIS) along with Raman spectroscopy revealed that the improvement was due to a slower growth rate of carbonate species originated from tetragylme degradation within the porous cathodes. Raman spectroscopy analyses of the electrolytes at various LiTFSI concentrations suggest that the increase in the formation of cationic complexes likely lead to the stabilization of the tetragylme molecules by protecting them from reactive superoxide attacks. 


\section{CONCLUDING REMARKS AND FUTURE WORKS}

\subsection{Concluding Remarks}

Lithium-oxygen batteries have been considered as next-generation energy storage devices due to their high theoretical energy densities close to gasoline. However, many fundamental and technical challenges remain in this field. One of the most important challenges in $\mathrm{Li}-\mathrm{O}_{2}$ batteries is poor cyclability owing to the electrolyte decomposition. Recently, some attempts have been made to explore the performance of $\mathrm{Li}-\mathrm{O}_{2}$ batteries using polymer-based electrolytes (SPEs and GPEs) and their derivatives such as composite polymer electrolytes. Although some performance improvements have been reported in Li$\mathrm{O}_{2}$ batteries using polymer electrolytes and composite polymer electrolytes over liquid electrolytes, the exact source of improvement remains unknown and there are still a lot of room for improvement. The aim of this dissertation was to develop and characterize the hybrid polymer electrolytes based on UV-curable polymer, one-dimensional glass microfibers with diameter of approximately $1 \mu \mathrm{m}$ and aspect ratio exceeding 100 and the conventional glyme-based solvent with various Li salt concentrations for lithium-oxygen battery application

In the first phase of this project, the content of one-dimensional glass microfibers in hybrid polymer electrolytes (composite gel polymer electrolyte, cGPEs) was optimized based on the performance of $\mathrm{Li}_{-} \mathrm{O}_{2}$ batteries using GPE and cGPEs containing $1 \mathrm{~mol} \cdot \mathrm{kg}^{-1} \mathrm{LiTFSI}$ salt concentration with various glass microfibers content. It turned out that $\mathrm{Li}-\mathrm{O}_{2}$ batteries using cGPE with 1 wt.\% glass microfibers showed the highest cyclability (54 cycles of 500 $\mathrm{mAh} \cdot \mathrm{g}^{-1}$ ) compare to GPEs (29 cycles) and other cGPEs. The Li transport properties of GPEs and cGPEs have also revealed that at the optimum content of 1 wt.\% glass 
microfibers, the ionic conductivity and Li transference number improves as high as $37 \%$ and 28\%, respectively. Using in-situ electrochemical impedance spectroscopy (EIS), the battery performance improvement was traced to the stabilization of the interfacial resistances in the batteries owing to the improved $\mathrm{Li}^{+}$transport properties.

In the second phase of this project, the GPEs and cGPEs containing 1 wt.\% glass microfibers content with various salt concentrations ranging from $0.1,1.0$ and $3.0 \mathrm{~mol} \cdot \mathrm{kg}^{-}$

${ }^{1}$ LiTFSI salt concentration were prepared to further investigate the exact source of improvement of glass microfibers in cGPEs, the sites (cathode or anode) at which the improvements were observed and the mechanism in which such improvement occurred. The cGPEs, with 1 wt.\% of glass microfibers, demonstrated increased ionic conductivity and lithium transference number over GPE at various concentrations of lithium salt. Improvements as high as 50\% and 28\% in lithium transference number were observed for 0.1 and $1.0 \mathrm{~mol} \cdot \mathrm{kg}^{-1}$ salt concentrations, respectively. However, at LiTFSI salt concentration of $3.0 \mathrm{~mol} \cdot \mathrm{kg}^{-1}$, no significant improvement has been observed. $\mathrm{Li}^{-\mathrm{O}_{2}}$ batteries containing cGPE similarly showed superior charge/discharge cycling for 500 mAh.g ${ }^{-1}$ cycle capacity with as high as $86 \%$ and $400 \%$ increase in cycles for cGPE with 1.0 and $0.1 \mathrm{~mol} \cdot \mathrm{kg}^{-1}$ over GPEs. Similar to the ionic properties of GPEs and cGPEs with $3.0 \mathrm{~mol} \cdot \mathrm{kg}^{-1}$ LiTFSI salt concentration, a little improvement has been observed in cyclability performance of batteries using GPE and cGPE at this salt concentration. In situ EIS investigation using transmission line model (TLM) has been uncovered that the cGPEcontaining batteries reduced the growth of ionic resistances $\left(R_{i o n}\right)$ in the cathode and its electrolyte interface. This resistance was traced back to the formation of lithium carbonates on the cathode due to the degradation of the tetraglyme-based solvent in the electrolyte. 
We theorize that the improved lithium transference of the cGPE increased the ratio of solvated to coupled $\mathrm{Li}^{+}$which reduced the probability of superoxide radicals reacting with the tetraglyme-based solvent during cycling.

In the last phase of this project, the performance of $\mathrm{Li}-\mathrm{O}_{2}$ batteries using glyme-based (TGDME) liquid electrolytes with various salt concentration $\left(0.1,1\right.$ and $\left.3 \mathrm{~mol} \cdot \mathrm{kg}^{-1}\right)$ was also investigated. It turned out that the increase in LiTFSI salt concentration from 0.1 to $3.0 \mathrm{~mol} \cdot \mathrm{kg}^{-1}$ improves the cyclability of batteries as high as $200 \%$. In-situ EIS and Raman spectroscopy investigation was shown that $\mathrm{Li}-\mathrm{O}_{2}$ battery mechanism failure was an increase in ionic resistance $\left(R_{\text {ion }}\right)$ due to the accumulation of electrolyte decomposition products like lithium carbonate species on the cathode. Raman spectroscopy on the liquid electrolytes with various LiTFSI salt concentrations along with their ionic transport measurement revealed that the increase in LiTFSI salt concentration increases the ratio of solvated TEGDME with $\mathrm{Li}^{+}$. At the same time, increase in LiTFSI salt concentration improves the Li transference number, which in turn it could also increase the probability of superoxide reactions with $\mathrm{Li}^{+}$than TEGDME solvent molecules.

\subsection{Future Works}

The present dissertation has introduced the application of hybrid polymer electrolytes for $\mathrm{Li}-\mathrm{O}_{2}$ batteries. The results have shown that the introduction of one-dimensional ceramic glass microfillers in gel polymer electrolytes (GPEs) significantly improve the performance of $\mathrm{Li}-\mathrm{O}_{2}$ batteries by reducing the growth of electrolyte decomposition on the cathodes, which in turn causes the pore clogging of the porous cathode. Different spectroscopic investigations have revealed that the glass microfillers mitigate electrolyte

decomposition by changing the solvation properties of Li salt and solvent. To the best of 
our knowledge, this is the first report in the $\mathrm{Li}^{-\mathrm{O}_{2}}$ battery field showing the possible mechanism of electrolyte stabilization by using the glass microfillers in hybrid polymer electrolytes. In the author viewpoint, this research study just opened a new horizon in the application of hybrid polymer electrolytes for electrolyte stabilization in $\mathrm{Li}-\mathrm{O}_{2}$ batteries. The following describes some of the unanswered questions, which deserve further investigation. The composition and surface functionality of borosilicate glass microfibers could affect the anion trapping ability of fillers, which in turn could significantly change the performance of $\mathrm{Li}_{-} \mathrm{O}_{2}$ batteries. Further investigation on the composition of glass microfillers and tuning the content of boron element as one of the most efficient anion trapping element in glass deserve further investigation. Recently, it has been shown that the formation of singlet oxygen during charge/discharge cycling could attack the electrolyte and cause rapid electrolyte decomposition. Introducing different functional groups on the surface of glass microfillers could be one possible option to trapped these singlet oxygens to protect the electrolyte. To further investigate the proposed electrolyte stabilization mechanism, the isolation of glass microfillers in cGPEs on the anode/electrolyte interface or cathode/electrolyte interface will also reveal useful information. 


\section{REFERENCES}

[1] M.M. Thackeray, C. Wolverton, E.D. Isaacs, Electrical energy storage for transportation - approaching the limits of, and going beyond, lithium-ion batteries, Energy Environ. Sci. 5 (2012) 7854. doi:10.1039/c2ee21892e.

[2] D. Linden, T.B. Reddy, eds., Handbook of Batteries, 3rd ed., McGrow-Hill, New York, 1995.

[3] K.M. Abraham, Prospects and Limits of Energy Storage in Batteries, J. Phys. Chem. Lett. 6 (2015) 830-844. doi:10.1021/jz5026273.

[4] J.B. Goodenough, K. Park, The Li-Ion Rechargeable Battery: A Perspective, J. Am. Chem. Soc. 135 (2013) 1167-1176. doi:10.1021/ja3091438.

[5] M.S. Whittingham, Lithium Batteries and Cathode Materials, Chem. Rev. 104 (2004) 4271-4302. doi:10.1021/cr020731c.

[6] R. Chen, T. Zhao, X. Zhang, L. Li, F. Wu, Advanced cathode materials for lithiumion batteries using nanoarchitectonics, Nanoscale Horiz. 1 (2016) 423-444. doi:10.1039/C6NH00016A.

[7] N.A. Kaskhedikar, J. Maier, Lithium Storage in Carbon Nanostructures, Adv. Mater. 21 (2009) 2664-2680. doi:10.1002/adma.200901079.

[8] N. Nitta, G. Yushin, High-Capacity Anode Materials for Lithium-Ion Batteries: Choice of Elements and Structures for Active Particles, Part. Part. Syst. Charact. 31 (2014) 317-336. doi:10.1002/ppsc.201300231.

[9] S. Goriparti, E. Miele, F. De Angelis, E. Di Fabrizio, R. Proietti Zaccaria, C. Capiglia, Review on recent progress of nanostructured anode materials for $\mathrm{Li}$-ion batteries, J. Power Sources. $257 \quad$ (2014) 421-443. doi:10.1016/j.jpowsour.2013.11.103.

[10] G.E. Blomgren, The Development and Future of Lithium Ion Batteries, J. Electrochem. Soc. 164 (2017) A5019-A5025. doi:10.1149/2.0251701jes.

[11] P.G. Bruce, S. a. Freunberger, L.J. Hardwick, J.-M. Tarascon, Li-O2 and Li-S batteries with high energy storage, Nat. Mater. 11 (2011) 172-172. doi:10.1038/nmat3237.

[12] G. Girishkumar, B. McCloskey, A.C. Luntz, S. Swanson, W. Wilcke, Lithium-air battery: Promise and challenges, J. Phys. Chem. Lett. 1 (2010) 2193-2203. doi:10.1021/jz1005384.

[13] K.G. Gallagher, S. Goebel, T. Greszler, M. Mathias, W. Oelerich, D. Eroglu, V. Srinivasan, Quantifying the promise of lithium-air batteries for electric vehicles, Energy Environ. Sci. 7 (2014) 1555. doi:10.1039/c3ee43870h.

[14] A.C. Luntz, B.D. Mccloskey, Nonaqueous Li - Air Batteries : A Status Report, Chem. Rev. 114 (2014) 11721-11750. doi:10.1021/cr500054y. 
[15] N. Imanishi, A.C. Luntz, P. Bruce, The Lithium Air Battery: Fundamentals, Springer New York, New York, NY, 2014. doi:10.1007/978-1-4899-8062-5.

[16] K.M. Abraham, Z. Jiang, A Polymer Electrolyte-Based Rechargeable Lithium/Oxygen Battery, J. Electrochem. Soc. $143 \quad$ (1996) 1. doi:10.1149/1.1836378.

[17] J. Read, Characterization of the Lithium/Oxygen Organic Electrolyte Battery, J. Electrochem. Soc. 149 (2002) A1190. doi:10.1149/1.1498256.

[18] F. MIZUNO, S. NAKANISHI, Y. KOTANI, S. YOKOISHI, H. IBA, Rechargeable Li-Air Batteries with Carbonate-Based Liquid Electrolytes, Electrochemistry. 78 (2010) 403-405. doi:10.5796/electrochemistry.78.403.

[19] J. Read, Ether-Based Electrolytes for the Lithium/Oxygen Organic Electrolyte Battery, J. Electrochem. Soc. 153 (2006) A96-A100. doi:10.1149/1.2131827.

[20] C.O. Laoire, S. Mukerjee, E.J. Plichta, M.A. Hendrickson, K.M. Abraham, Rechargeable Lithium/TEGDME-LiPF6/O2 Battery, J. Electrochem. Soc. 158 (2011) A302. doi:10.1149/1.3531981.

[21] J. Lu, L. Li, J. Park, Y. Sun, F. Wu, K. Amine, Aprotic and Aqueous Li-O2 Batteries, Chem. Rev. 114 (2014) 5611-5640. doi:10.1021/cr400573b.

[22] B.D. McCloskey, A. Speidel, R. Scheffler, D.C. Miller, V. Viswanathan, J.S. Hummelshøj, J.K. Nørskov, A.C. Luntz, Twin Problems of Interfacial Carbonate Formation in Nonaqueous Li-O2 Batteries, J. Phys. Chem. Lett. 3 (2012) 997-1001. doi:10.1021/jz300243r.

[23] D. Aurbach, B.D. McCloskey, L.F. Nazar, P.G. Bruce, Advances in understanding mechanisms underpinning lithium-air batteries, Nat. Energy. 1 (2016) 16128. doi:10.1038/nenergy.2016.128.

[24] B.D. Adams, C. Radtke, R. Black, M.L. Trudeau, K. Zaghib, L.F. Nazar, Current density dependence of peroxide formation in the Li-O2 battery and its effect on charge, Energy Environ. Sci. 6 (2013) 1772. doi:10.1039/c3ee40697k.

[25] B. Horstmann, B. Gallant, R.R. Mitchell, W.G. Bessler, Y. Shao-horn, M.Z. Bazant, Rate-dependent morphology of Li 2 O 2 growth in, J. Phys. Chem. Lett. 4 (2013) 4217-4222. doi:10.1021/jz401973c.

[26] N.B. Aetukuri, B.D. McCloskey, J.M. García, L.E. Krupp, V. Viswanathan, A.C. Luntz, Solvating additives drive solution-mediated electrochemistry and enhance toroid growth in non-aqueous Li-O2 batteries, Nat. Chem. 7 (2015) 50-56. doi:10.1038/nchem.2132.

[27] L. Johnson, C. Li, Z. Liu, Y. Chen, S. a Freunberger, P.C. Ashok, B.B. Praveen, K. Dholakia, J.-M. Tarascon, P.G. Bruce, The role of LiO2 solubility in $\mathrm{O} 2$ reduction in aprotic solvents and its consequences for Li-O2 batteries., Nat. Chem. 6 (2014) 1091-9. doi:10.1038/nchem.2101. 
[28] L. Grande, E. Paillard, J. Hassoun, J.-B. Park, Y.-J. Lee, Y.-K. Sun, S. Passerini, B. Scrosati, The Lithium/Air Battery: Still an Emerging System or a Practical Reality?, Adv. Mater. 27 (2015) 784-800. doi:10.1002/adma.201403064.

[29] N. Feng, P. He, H. Zhou, Critical Challenges in Rechargeable Aprotic Li-O 2 Batteries, Adv. Energy Mater. 6 (2016) 1502303. doi:10.1002/aenm.201502303.

[30] R.S. Assary, J. Lu, P. Du, X. Luo, X. Zhang, Y. Ren, L.A. Curtiss, K. Amine, The effect of oxygen crossover on the anode of a Li-O2 battery using an ether-based solvent: Insights from experimental and computational studies, ChemSusChem. 6 (2013) 51-55. doi:10.1002/cssc.201200810.

[31] R. Younesi, M. Hahlin, M. Roberts, K. Edström, The SEI layer formed on lithium metal in the presence of oxygen: A seldom considered component in the development of the Li-O2 battery, J. Power Sources. 225 (2013) 40-45. doi:10.1016/j.jpowsour.2012.10.011.

[32] J.-L. Shui, J.S. Okasinski, P. Kenesei, H. a Dobbs, D. Zhao, J.D. Almer, D.-J. Liu, Reversibility of anodic lithium in rechargeable lithium-oxygen batteries., Nat. Commun. 4 (2013) 2255. doi:10.1038/ncomms3255.

[33] H. Lee, D.J. Lee, J.-N. Lee, J. Song, Y. Lee, M.-H. Ryou, J.-K. Park, Y.M. Lee, Chemical aspect of oxygen dissolved in a dimethyl sulfoxide-based electrolyte on lithium metal, Electrochim. Acta. 123 (2014) 419-425. doi:10.1016/j.electacta.2014.01.042.

[34] B.G. Kim, J.-S. Kim, J. Min, Y.-H. Lee, J.H. Choi, M.C. Jang, S.A. Freunberger, J.W. Choi, A Moisture- and Oxygen-Impermeable Separator for Aprotic Li-O 2 Batteries, Adv. Funct. Mater. 26 (2016) 1747-1756. doi:10.1002/adfm.201504437.

[35] Q.-C. Liu, J.-J. Xu, S. Yuan, Z.-W. Chang, D. Xu, Y.-B. Yin, L. Li, H.-X. Zhong, Y.-S. Jiang, J.-M. Yan, X.-B. Zhang, Artificial Protection Film on Lithium Metal Anode toward Long-Cycle-Life Lithium-Oxygen Batteries, Adv. Mater. 27 (2015) 5241-5247. doi:10.1002/adma.201501490.

[36] J. Hassoun, H.-G. Jung, D.-J. Lee, J.-B. Park, K. Amine, Y.-K. Sun, B. Scrosati, A Metal-Free, Lithium-Ion Oxygen Battery: A Step Forward to Safety in Lithium-Air Batteries, Nano Lett. 12 (2012) 5775-5779. doi:10.1021/nl303087j.

[37] D. Hirshberg, D. Sharon, E. De La Llave, M. Afri, A.A. Frimer, W.-J. Kwak, Y.-K. Sun, D. Aurbach, Feasibility of Full (Li-Ion)-O2 Cells Comprised of Hard Carbon Anodes, ACS Appl. Mater. Interfaces. 9 (2017) 4352-4361. doi:10.1021/acsami.6b10974.

[38] L. Ye, W. Lv, J. Cui, Y. Liang, P. Wu, X. Wang, H. He, S. Lin, W. Wang, J.H. Dickerson, W. He, Lithium-Air Batteries: Performance Interplays with Instability Factors, ChemElectroChem. 2 (2015) 312-323. doi:10.1002/celc.201402315. 
[39] M.M. Ottakam Thotiyl, S. a Freunberger, Z. Peng, P.G. Bruce, The Carbon Electrode in Nonaqueous Li-O2 Cells, J. Am. Chem. Soc. 135 (2013) 494-500. doi:10.1021/ja310258x.

[40] Z. Peng, S. a. Freunberger, Y. Chen, P.G. Bruce, A Reversible and Higher-Rate LiO2 Battery, Science (80-. ). 337 (2012) 563-566. doi:10.1126/science.1223985.

[41] B. Wu, H. Zhang, W. Zhou, M. Wang, X. Li, H. Zhang, Carbon-Free CoO Mesoporous Nanowire Array Cathode for High-Performance Aprotic Li-O2 Batteries, ACS Appl. Mater. Interfaces. 7 (2015) 23182-23189. doi:10.1021/acsami.5b07003.

[42] M.M. Ottakam Thotiyl, S. a Freunberger, Z. Peng, Y. Chen, Z. Liu, P.G. Bruce, A stable cathode for the aprotic Li-O2 battery., Nat. Mater. 12 (2013) 1050-6. doi:10.1038/nmat3737.

[43] D. Sharon, D. Hirshberg, M. Afri, A.A. Frimer, D. Aurbach, The Importance of Solvent Selection in Li-O 2 Cells, Chem. Commun. 53 (2017) 3269-3272. doi:10.1039/C6CC09086A.

[44] Y.-C. Lu, B.M. Gallant, D.G. Kwabi, J.R. Harding, R.R. Mitchell, M.S. Whittingham, Y. Shao-Horn, Lithium-oxygen batteries: bridging mechanistic understanding and battery performance, Energy Environ. Sci. 6 (2013) 750-768. doi:Doi 10.1039/C3ee23966g.

[45] X. Yao, Q. Dong, Q. Cheng, D. Wang, Why Do Lithium-Oxygen Batteries Fail: Parasitic Chemical Reactions and Their Synergistic Effect, Angew. Chemie - Int. Ed. (2016) 2-12. doi:10.1002/anie.201601783.

[46] M. Balaish, A. Kraytsberg, Y. Ein-Eli, A critical review on lithium-air battery electrolytes, Phys. Chem. Chem. Phys. 16 (2014) 2801-2822. doi:10.1039/C3CP54165G.

[47] S.A. Freunberger, Y. Chen, Z. Peng, J.M. Griffin, L.J. Hardwick, F. Bardé, P. Novák, P.G. Bruce, Reactions in the rechargeable lithium-O2 battery with alkyl carbonate electrolytes, J. Am. Chem. Soc. 133 (2011) 8040-8047. doi:10.1021/ja2021747.

[48] S.A. Freunberger, Y. Chen, N.E. Drewett, L.J. Hardwick, F. Bardé, P.G. Bruce, The Lithium-Oxygen Battery with Ether-Based Electrolytes, Angew. Chemie Int. Ed. 50 (2011) 8609-8613. doi:10.1002/anie.201102357.

[49] Y. Chen, S.A. Freunberger, Z. Peng, F. Bardé, P.G. Bruce, Li-O2 battery with a dimethylformamide electrolyte, J. Am. Chem. Soc. 134 (2012) 7952-7957. doi:10.1021/ja302178w.

[50] V. Giordani, W. Walker, V.S. Bryantsev, J. Uddin, G. V Chase, D. Addison, Synergistic Effect of Oxygen and LiNO3 on the Interfacial Stability of Lithium Metal in a Li/O2 Battery, J. Electrochem. Soc. 160 (2013) A1544-A1550. doi:10.1149/2.097309jes. 
[51] M. a Schroeder, N. Kumar, A.J. Pearse, C. Liu, S.B. Lee, G.W. Rubloff, K. Leung, M. Noked, DMSO-Li2O2 Interface in the Rechargeable Li-O2 Battery Cathode: Theoretical and Experimental Perspectives on Stability., ACS Appl. Mater. Interfaces. 7 (2015) 11402-11. doi:10.1021/acsami.5b01969.

[52] M. Kar, T.J. Simons, M. Forsyth, D.R. MacFarlane, Ionic liquid electrolytes as a platform for rechargeable metal-air batteries: a perspective, Phys. Chem. Chem. Phys. 16 (2014) 18658-18674. doi:10.1039/C4CP02533D.

[53] Y. Li, X. Wang, S. Dong, X. Chen, G. Cui, Recent Advances in Non-Aqueous Electrolyte for Rechargeable Li-O2 Batteries, Adv. Energy Mater. (2016) 1-26. doi:10.1002/aenm.201600751.

[54] F. Li, H. Kitaura, H. Zhou, The pursuit of rechargeable solid-state Li-air batteries, Energy Environ. Sci. 6 (2013) 2302. doi:10.1039/c3ee40702k.

[55] J. Kumar, B. Kumar, Development of membranes and a study of their interfaces for rechargeable lithium-air battery, J. Power Sources. 194 (2009) 1113-1119. doi:10.1016/j.jpowsour.2009.06.020.

[56] B. Kumar, J. Kumar, Cathodes for Solid-State Lithium-Oxygen Cells: Roles of Nasicon Glass-Ceramics, J. Electrochem. Soc. 157 (2010) A611. doi:10.1149/1.3356988.

[57] D.E. Fenton, J.M. Parker, P.V. Wright, Complexes of alkali metal ions with poly(ethylene oxide), Polymer (Guildf). 14 (1973) 589. doi:10.1016/00323861(73)90146-8.

[58] M. Armand, Polymer Electrolytes, $16 \quad$ (1986) 245-261. http://www.sciencedirect.com/science/article/pii/0032386173901468.

[59] C. V. Amanchukwu, J.R. Harding, Y. Shao-Horn, P.T. Hammond, Understanding the chemical stability of polymers for lithium-air batteries, Chem. Mater. 27 (2015) 550-561. doi:10.1021/cm5040003.

[60] S.N. Mohamed, N.A. Johari, A.M.M. Ali, M.K. Harun, M.Z.A. Yahya, Electrochemical studies on epoxidised natural rubber-based gel polymer electrolytes for lithium-air cells, J. Power Sources. 183 (2008) 351-354. doi:10.1016/j.jpowsour.2008.04.048.

[61] J. Yi, S. Guo, P. He, H. Zhou, Status and prospects of polymer electrolytes for solidstate Li-O 2 (air) batteries, Energy Environ. Sci. 10 (2017) 860-884. doi:10.1039/C6EE03499C.

[62] K.-N. Jung, J.J.-I. Lee, J.-H. Jung, K.-H. Shin, J.J.-I. Lee, A quasi-solid-state rechargeable lithium-oxygen battery based on a gel polymer electrolyte with an ionic liquid., Chem. Commun. (Camb). 50 (2014) 5458-61. doi:10.1039/c4cc01243g.

[63] L. Leng, X. Zeng, P. Chen, T. Shu, H. Song, Z. Fu, H. Wang, S. Liao, A novel stability-enhanced lithium-oxygen battery with cellulose-based composite polymer 
gel as the electrolyte, Electrochim. Acta. $176 \quad$ (2015) 1108-1115. doi:10.1016/j.electacta.2015.07.111.

[64] J. Yi, X. Liu, S. Guo, K. Zhu, H. Xue, H. Zhou, Novel Stable Gel Polymer Electrolyte: Toward a High Safety and Long Life Li-Air Battery, ACS Appl. Mater. Interfaces. 7 (2015) 23798-23804. doi:10.1021/acsami.5b08462.

[65] I. Kosuke, Electrochemistry in Nonaquoues Solutions, Second Ed., WILEY-VCH Verlag GmbH \& Co., 2009.

[66] C. Reichardt, T. Welton, Solvents and Solvent Equets in Organic Chemistry Solvents, Fourth Ed., Wiley-VCH Verlag \& Co., 2010. doi:10.1016/B978-0-12416677-6.00029-9.

[67] J.O.M. Bockris, A.K.N. Reddy, Modern Electrochemistry: Ionics, Second Ed., KLUWER ACADEMIC PUBLISHERS, 1974.

[68] S.-D. Han, O. Borodin, D.M. Seo, Z.-B. Zhou, W.A. Henderson, Electrolyte Solvation and Ionic Association V. Acetonitrile-Lithium Bis(fluorosulfonyl)imide (LiFSI) Mixtures, J. Electrochem. Soc. $161 \quad$ (2014) 2042-2053. doi:10.1149/2.0101414jes.

[69] J. WESTON, B. STEELE, Effects of inert fillers on the mechanical and electrochemical properties of lithium salt-poly(ethylene oxide) polymer electrolytes, Solid State Ionics. 7 (1982) 75-79. doi:10.1016/0167-2738(82)90072-8.

[70] F. Croce, G.B. Appetecchi, L. Persi, B. Scrosat, Nanocomposite polymer electrolytes for lithium batteries, Nature. 394 (1998) 456.

[71] S. Srivastava, J.L. Schaefer, Z. Yang, Z. Tu, L.A. Archer, 25th Anniversary Article: Polymer-Particle Composites: Phase Stability and Applications in Electrochemical Energy Storage, Adv. Mater. 26 (2014) 201-234. doi:10.1002/adma.201303070.

[72] A.J. Bhattacharyya, Ion Transport in Liquid Salt Solutions with Oxide Dispersions: "Soggy Sand" Electrolytes, (2012).

[73] a. J. Bhattacharyya, J. Maier, Second Phase Effects on the Conductivity of NonAqueous Salt Solutions:"Soggy Sand Electrolytes," Adv. Mater. 16 (2004) 811814. doi:10.1002/adma.200306210.

[74] A.J. Bard, L.R. Faulkner, Electrochemical Methods Fundamentals and Applications, 2 Ed., John Wiley \& Sons, Inc., 2001.

[75] K. Kontturi, S. Mafé, J.A. Manzanares, J. Pellicer, M. Vuoristo, A new method for determining transport numbers of charged membranes from convective diffusion experiments, J. Electroanal. Chem. 378 (1994) 111-116. doi:http://dx.doi.org/10.1016/0022-0728(94)87062-4.

[76] D.A. MacInnes, L.G. Longsworth, Transference Numbers by the Method of Moving Boundaries., Chem. Rev. 11 (1932) 171-230. doi:10.1021/cr60039a001. 
[77] S. Zugmann, M. Fleischmann, M. Amereller, R.M. Gschwind, H.D. Wiemhöfer, H.J. Gores, Measurement of transference numbers for lithium ion electrolytes via four different methods, a comparative study, Electrochim. Acta. 56 (2011) 39263933. doi:10.1016/j.electacta.2011.02.025.

[78] J. Evans, C.A. Vincent, P.G. Bruce, Electrochemical measurement of transference numbers in polymer electrolytes, Polymer (Guildf). 28 (1987) 2324-2328. doi:10.1016/0032-3861(87)90394-6.

[79] M.E. Orazem, B. Tribollet, Electrochemical Impedance Spectroscopy, John Wiley \& Sons, Inc., 2008. http://books.google.com/books?hl=en\&amp;lr=\&amp;id=AEwQuNTZZMC\&amp;oi=fnd\&amp;pg=PR15\&amp;dq=Electrochemical+Impedance+Spectro scopy\&amp;ots=BObQhI_2NH\&amp;sig=FOgZf4Yr9UfcRHsuxVXf9pg6Sc\%5Cnhttp://doi.wiley.com/10.1002/9780470381588.

[80] A. Lasia, Electrochemical Impedance Spectroscopy and its Applications, Springer, 2014. doi:10.1007/978-1-4614-8933-7.

[81] N. Ogihara, Y. Itou, T. Sasaki, Y. Takeuchi, Impedance spectroscopy characterization of porous electrodes under different electrode thickness using a symmetric cell for high-performance lithium-ion batteries, J. Phys. Chem. C. 119 (2015) 4612-4619. doi:10.1021/jp512564f.

[82] Use of Transmission Lines for Electrochemical Impedance Spectroscopy :Theory and Application of Transmission Line Models to High Surface Area Electrodes Purpose, (2014). https://www.gamry.com/application-notes/EIS/use-oftransmission-lines-for-eis/.

[83] J. Bisquert, A. Compte, Theory of the electrochemical impedance of anomalous diffusion, J. Electroanal. Chem. 499 (2001) 112-120. doi:10.1016/S00220728(00)00497-6.

[84] J. Bisquert, Theory of the impedance of electron diffusion and recombination in a thin layer, J. Phys. Chem. B. 106 (2002) 325-333. doi:10.1021/jp011941g.

[85] N. Ogihara, S. Kawauchi, C. Okuda, Y. Itou, Y. Takeuchi, Y. Ukyo, Theoretical and Experimental Analysis of Porous Electrodes for Lithium-Ion Batteries by Electrochemical Impedance Spectroscopy Using a Symmetric Cell, J. Electrochem. Soc. 159 (2012) A1034-A1039. doi:10.1149/2.057207jes.

[86] B.D. McCloskey, C.M. Burke, J.E. Nichols, S.E. Renfrew, Mechanistic insights for the development of Li-O2 battery materials: addressing Li2O2 conductivity limitations and electrolyte and cathode instabilities, Chem. Commun. 51 (2015) 12701-12715. doi:10.1039/C5CC04620C.

[87] Y. Shao, F. Ding, J. Xiao, J. Zhang, W. Xu, S. Park, J.G. Zhang, Y. Wang, J. Liu, Making Li-air batteries rechargeable: Material challenges, Adv. Funct. Mater. 23 (2013) 987-1004. doi:10.1002/adfm.201200688. 
[88] N. Chawla, A. Chamaani, M. Safa, B. El-Zahab, Palladium-Filled Carbon Nanotubes Cathode for Improved Electrolyte Stability and Cyclability Performance of Li-O 2 Batteries, J. Electrochem. Soc. 164 (2017) A6303-A6307. doi:10.1149/2.0491701jes.

[89] G.A. Elia, J.B. Park, Y.K. Sun, B. Scrosati, J. Hassoun, Role of the lithium salt in the performance of lithium- oxygen batteries: A comparative study, ChemElectroChem. 1 (2014) 47-50. doi:10.1002/celc.201300160.

[90] Y. Nishikami, T. Konishi, R. Omoda, Y. Aihara, K. Oyaizu, H. Nishide, Oxygenenriched electrolytes based on perfluorochemicals for high-capacity lithium-oxygen batteries, J. Mater. Chem. A. 3 (2015) 10845-10850. doi:10.1039/C5TA02219C.

[91] M. Safa, A. Chamaani, N. Chawla, B. El-Zahab, Polymeric Ionic Liquid Gel Electrolyte for Room Temperature Lithium Battery Applications, Electrochim. Acta. 213 (2016) 587-593. doi:10.1016/j.electacta.2016.07.118.

[92] Y. Zhu, S. Xiao, Y. Shi, Y. Yang, Y. Hou, Y. Wu, A composite gel polymer electrolyte with high performance based on poly(vinylidene fluoride) and polyborate for lithium ion batteries, Adv. Energy Mater. 4 (2014) 1-9. doi:10.1002/aenm.201300647.

[93] L. Long, S. Wang, M. Xiao, Y. Meng, Polymer electrolytes for lithium polymer batteries, J. Mater. Chem. A. 4 (2016) 10038-10069. doi:10.1039/C6TA02621D.

[94] J. Chai, J. Zhang, P. Hu, J. Ma, H. Du, L. Yue, J. Zhao, H. Wen, Z. Liu, G. Cui, L. Chen, A high-voltage poly(methylethyl $\alpha$-cyanoacrylate) composite polymer electrolyte for 5 V lithium batteries, J. Mater. Chem. A. 4 (2016) 5191-5197. doi:10.1039/C6TA00828C.

[95] W.-B. Luo, S.-L. Chou, J.-Z. Wang, Y.-M. Kang, Y.-C. Zhai, H.-K. Liu, A hybrid gel-solid-state polymer electrolyte for long-life lithium oxygen batteries, Chem. Commun. 51 (2015) 8269-8272. doi:10.1039/C5CC01857A.

[96] B.G. Kim, J.S. Kim, J. Min, Y.H. Lee, J.H. Choi, M.C. Jang, S.A. Freunberger, J.W. Choi, A Moisture- and Oxygen-Impermeable Separator for Aprotic Li-O2 Batteries, Adv. Funct. Mater. (2016) 1-10. doi:10.1002/adfm.201504437.

[97] T. Liu, Q.C. Liu, J.J. Xu, X.B. Zhang, Cable-Type Water-Survivable Flexible LiO2 Battery, Small. (2016) 3101-3105. doi:10.1002/smll.201600540.

[98] Q.-C. Liu, T. Liu, D.-P. Liu, Z.-J. Li, X.-B. Zhang, Y. Zhang, A Flexible and Wearable Lithium-Oxygen Battery with Record Energy Density achieved by the Interlaced Architecture inspired by Bamboo Slips, Adv. Mater. 28 (2016) 84138418. doi:10.1002/adma.201602800.

[99] H.T.T. Le, D.T. Ngo, R.S. Kalubarme, G. Cao, C.N. Park, C.J. Park, Composite Gel Polymer Electrolyte Based on Poly(vinylidene fluoride-hexafluoropropylene) (PVDF-HFP) with Modified Aluminum-Doped Lithium Lanthanum Titanate (A- 
LLTO) for High-Performance Lithium Rechargeable Batteries, ACS Appl. Mater. Interfaces. 8 (2016) 20710-20719. doi:10.1021/acsami.6b05301.

[100] G.A. Elia, J. Hassoun, A gel polymer membrane for lithium-ion oxygen battery, Solid State Ionics. 287 (2016) 22-27. doi:10.1016/j.ssi.2016.01.043.

[101] F. Croce, L.L. Persi, B. Scrosati, F. Serraino-Fiory, E. Plichta, M.A. Hendrickson, Role of the ceramic fillers in enhancing the transport properties of composite polymer electrolytes, Electrochim. Acta. 46 (2001) 2457-2461. doi:10.1016/S00134686(01)00458-3.

[102] C. Ma, J. Zhang, M. Xu, Q. Xia, J. Liu, S. Zhao, L. Chen, A. Pan, D.G. Ivey, W. Wei, Cross-linked branching nanohybrid polymer electrolyte with monodispersed TiO2 nanoparticles for high performance lithium-ion batteries, J. Power Sources. 317 (2016) 103-111. doi:10.1016/j.jpowsour.2016.03.097.

[103] D. Zhou, R. Liu, Y.B. He, F. Li, M. Liu, B. Li, Q.H. Yang, Q. Cai, F. Kang, SiO2 Hollow Nanosphere-Based Composite Solid Electrolyte for Lithium Metal Batteries to Suppress Lithium Dendrite Growth and Enhance Cycle Life, Adv. Energy Mater. 6 (2016) 1-10. doi:10.1002/aenm.201502214.

[104] P. Zhang, L.C. Yang, L.L. Li, M.L. Ding, Y.P. Wu, R. Holze, Enhanced electrochemical and mechanical properties of $\mathrm{P}(\mathrm{VDF}-\mathrm{HFP})$-based composite polymer electrolytes with SiO2 nanowires, J. Memb. Sci. 379 (2011) 80-85. doi:10.1016/j.memsci.2011.05.043.

[105] N.S.T. Do, D.M. Schaetzl, B. Dey, A.C. Seabaugh, S.K. Fullerton-Shirey, Influence of $\mathrm{Fe} 2 \mathrm{O} 3$ nanofiller shape on the conductivity and thermal properties of solid polymer electrolytes: Nanorods versus nanospheres, J. Phys. Chem. C. 116 (2012) 21216-21223. doi:10.1021/jp3059454.

[106] W. Liu, N. Liu, J. Sun, P.C. Hsu, Y. Li, H.W. Lee, Y. Cui, Ionic Conductivity Enhancement of Polymer Electrolytes with Ceramic Nanowire Fillers, Nano Lett. 15 (2015) 2740-2745. doi:10.1021/acs.nanolett.5b00600.

[107] M. Wang, X. Chen, H. Wang, H. Wu, X. Jin, C. Huang, Improved performances of lithium-ion batteries with a separator based on inorganic fibers, J. Mater. Chem. A. (2017). doi:10.1039/C6TA08404D.

[108] C. Pfaffenhuber, M. Göbel, J. Popovic, J. Maier, Soggy-sand electrolytes: status and perspectives, Phys. Chem. Chem. Phys. 15 (2013) 18318. doi:10.1039/c3cp53124d.

[109] J. Yi, S. Wu, S. Bai, Y. Liu, N. Li, H. Zhou, Interfacial construction of Li2O2 for a performance-improved polymer Li-O2 battery, J. Mater. Chem. A. 4 (2016) 24032407. doi:10.1039/C5TA10436J.

[110] S.H. Wang, Y.Y. Lin, C.Y. Teng, Y.M. Chen, P.L. Kuo, Y.L. Lee, C. Te Hsieh, H. Teng, Immobilization of Anions on Polymer Matrices for Gel Electrolytes with High Conductivity and Stability in Lithium Ion Batteries, ACS Appl. Mater. Interfaces. 8 (2016) 14776-14787. doi:10.1021/acsami.6b01753. 
[111] D. Zhang, R. Li, T. Huang, A. Yu, Novel composite polymer electrolyte for lithium air batteries, J. Power Sources. 195 (2010) 1202-1206. doi:10.1016/j.jpowsour.2009.08.063.

[112] K. Pożyczka, M. Marzantowicz, J.R. Dygas, F. Krok, IONIC CONDUCTIVITY AND LITHIUM TRANSFERENCE NUMBER OF POLY(ETHYLENE OXIDE):LiTFSI SYSTEM, Electrochim. Acta. 227 (2017) 127-135. doi:10.1016/j.electacta.2016.12.172.

[113] E.H. Kil, H.J. Ha, S.Y. Lee, A facile approach to fabricate self-standing gel-polymer electrolytes for flexible lithium-ion batteries by exploitation of UV-cured trivalent/monovalent acrylate polymer matrices, Macromol. Chem. Phys. 212 (2011) 2217-2223. doi:10.1002/macp.201100248.

[114] H. Wang, M. Matsui, Y. Takeda, O. Yamamoto, D. Im, D. Lee, N. Imanishi, Interface properties between lithium metal and a composite polymer electrolyte of PEO18Li(CF3SO2)2N-tetraethylene glycol dimethyl ether, Membranes (Basel). 3 (2013) 298-310. doi:10.3390/membranes3040298.

[115] L. Porcarelli, C. Gerbaldi, F. Bella, J.R. Nair, Super Soft All-Ethylene Oxide Polymer Electrolyte for Safe All-Solid Lithium Batteries, Sci. Rep. 6 (2016) 19892. doi:10.1038/srep19892.

[116] M. Osińska, M. Walkowiak, A. Zalewska, T. Jesionowski, Study of the role of ceramic filler in composite gel electrolytes based on microporous polymer membranes, J. Memb. Sci. $326 \quad$ (2009) 582-588. doi:10.1016/j.memsci.2008.10.036.

[117] A.J. Bhattacharyya, J. Maier, R. Bock, F.F. Lange, New class of soft matter electrolytes obtained via heterogeneous doping: Percolation effects in "soggy sand" electrolytes, Solid State Ionics. 177 (2006) 2565-2568. doi:10.1016/j.ssi.2006.02.005.

[118] Y. Liao, M. Rao, W. Li, C. Tan, J. Yi, L. Chen, Improvement in ionic conductivity of self-supported P(MMA-AN-VAc) gel electrolyte by fumed silica for lithium ion batteries, Electrochim. Acta. 54 (2009) 6396-6402. doi:10.1016/j.electacta.2009.05.081.

[119] V. Gentili, S. Panero, P. Reale, B. Scrosati, Composite gel-type polymer electrolytes for advanced, rechargeable lithium batteries, J. Power Sources. 170 (2007) 185-190. doi:10.1016/j.jpowsour.2007.04.008.

[120] F.S. Gittleson, K.P.C. Yao, D.G. Kwabi, S.Y. Sayed, W.H. Ryu, Y. Shao-Horn, A.D. Taylor, Raman Spectroscopy in Lithium-Oxygen Battery Systems, ChemElectroChem. 2 (2015) 1446-1457. doi:10.1002/celc.201500218.

[121] M. Noked, M.A. Schroeder, A.J. Pearse, G.W. Rubloff, S.B. Lee, Protocols for Evaluating and Reporting Li-O2 Cell Performance, J. Phys. Chem. Lett. 7 (2016) 211-215. doi:10.1021/acs.jpclett.5b02613. 
[122] M. Mirzaeian, P.J. Hall, Characterizing capacity loss of lithium oxygen batteries by impedance spectroscopy, J. Power Sources. 195 (2010) 6817-6824. doi:10.1016/j.jpowsour.2010.04.064.

[123] P. Kichambare, J. Kumar, S. Rodrigues, B. Kumar, Electrochemical performance of highly mesoporous nitrogen doped carbon cathode in lithium-oxygen batteries, J. Power Sources. 196 (2011) 3310-3316. doi:10.1016/j.jpowsour.2010.11.112.

[124] N. Schweikert, H. Hahn, S. Indris, Cycling behaviour of Li/Li4Ti5O12 cells studied by electrochemical impedance spectroscopy., Phys. Chem. Chem. Phys. 13 (2011) 6234-6240. doi:10.1039/c0cp01889a.

[125] H. Kim, T.Y. Kim, V. Roev, H.H.C. Lee, H.J. Kwon, H.H.C. Lee, S. Kwon, D. Im, Enhanced Electrochemical Stability of Quasi-Solid-State Electrolyte Containing $\mathrm{SiO} 2$ Nanoparticles for Li-O2 Battery Applications, ACS Appl. Mater. Interfaces. 8 (2016) 1344-1350. doi:10.1021/acsami.5b10214.

[126] K.B. Knudsen, J.E. Nichols, T. Vegge, A.C. Luntz, B.D. McCloskey, J. Hjelm, An Electrochemical Impedance Study of the Capacity Limitations in Na-O 2 Cells, J. Phys. Chem. C. 120 (2016) 10799-10805. doi:10.1021/acs.jpcc.6b02788.

[127] I. Bardenhagen, O. Yezerska, M. Augustin, D. Fenske, A. Wittstock, M. Bäumer, In situ investigation of pore clogging during discharge of a Li/O2 battery by electrochemical impedance spectroscopy, J. Power Sources. 278 (2015) 255-264. doi:10.1016/j.jpowsour.2014.12.076.

[128] J. Yi, H. Zhou, A Unique Hybrid Quasi-Solid-State Electrolyte for Li-O2 Batteries with Improved Cycle Life and Safety, ChemSusChem. 9 (2016) 2391-2396. doi:10.1002/cssc.201600536.

[129] X. Huang, H. Yu, H. Tan, J. Zhu, W. Zhang, C. Wang, J. Zhang, Y. Wang, Y. Lv, Z. Zeng, D. Liu, J. Ding, Q. Zhang, M. Srinivasan, P.M. Ajayan, H.H. Hng, Q. Yan, Carbon nanotube-encapsulated noble metal nanoparticle hybrid as a cathode material for Li-oxygen batteries, Adv. Funct. Mater. 24 (2014) 6516-6523. doi:10.1002/adfm.201400921.

[130] Y. Shao, S. Park, J. Xiao, J.G. Zhang, Y. Wang, J. Liu, Electrocatalysts for nonaqueous lithium-air batteries: Status, challenges, and perspective, ACS Catal. 2 (2012) 844-857. doi:10.1021/cs300036v.

[131] D. Kundu, R. Black, B. Adams, L.F. Nazar, A Highly Active Low Voltage Redox Mediator for Enhanced Rechargeability of Lithium-Oxygen Batteries., ACS Cent. Sci. 1 (2015) 510-515. doi:10.1021/acscentsci.5b00267.

[132] G. Bieker, M. Winter, P. Bieker, Electrochemical in situ investigations of SEI and dendrite formation on the lithium metal anode., Phys. Chem. Chem. Phys. 17 (2015) 8670-9. doi:10.1039/c4cp05865h. 
[133] R. Miao, J. Yang, Z. Xu, J. Wang, Y. Nuli, L. Sun, A new ether-based electrolyte for dendrite-free lithium-metal based rechargeable batteries., Sci. Rep. 6 (2016) 21771. doi:10.1038/srep21771.

[134] Y. Lu, M. Tikekar, R. Mohanty, K. Hendrickson, L. Ma, L.A. Archer, Stable cycling of lithium metal batteries using high transference number electrolytes, Adv. Energy Mater. 5 (2015). doi:10.1002/aenm.201402073.

[135] S.H. Kim, K.H. Choi, S.J. Cho, E.H. Kil, S.Y. Lee, Mechanically compliant and lithium dendrite growth-suppressing composite polymer electrolytes for flexible lithium-ion batteries, J. Mater. Chem. A. 1 (2013) 4949. doi:10.1039/c3ta10612h.

[136] D. Sharon, D. Hirshberg, M. Afri, A.A. Frimer, D. Aurbach, The importance of solvent selection in Li-O2 cells, Chem. Commun. 53 (2017) 3269-3272. doi:10.1039/C6CC09086A.

[137] N. Chawla, A. Chamaani, M. Safa, B. El-Zahab, Palladium-Filled Carbon Nanotubes Cathode for Improved Electrolyte Stability and Cyclability Performance of Li-O2 Batteries, J. Electrochem. Soc. 164 (2017) A6303-A6307. doi:10.1149/2.0491701jes.

[138] B.D. Adams, R. Black, Z. Williams, R. Fernandes, M. Cuisinier, E.J. Berg, P. Novak, G.K. Murphy, L.F. Nazar, Towards a stable organic electrolyte for the lithium oxygen battery, Adv. Energy Mater. 5 (2015) 1400867. doi:10.1002/aenm.201400867.

[139] D. Sharon, V. Etacheri, A. Garsuch, M. Afri, A.A. Frimer, D. Aurbach, On the challenge of electrolyte solutions for Li-air batteries: Monitoring oxygen reduction and related reactions in polyether solutions by spectroscopy and EQCM, J. Phys. Chem. Lett. 4 (2013) 127-131. doi:10.1021/jz3017842.

[140] W. Xu, J. Hu, M.H. Engelhard, S.A. Towne, J.S. Hardy, J. Xiao, J. Feng, M.Y. Hu, J. Zhang, F. Ding, M.E. Gross, J.-G. Zhang, The stability of organic solvents and carbon electrode in nonaqueous Li-O2 batteries, J. Power Sources. 215 (2012) 240247. doi:10.1016/j.jpowsour.2012.05.021.

[141] Z. Zhang, J. Lu, R.S. Assary, P. Du, H.H. Wang, Y.K. Sun, Y. Qin, K.C. Lau, J. Greeley, P.C. Redfern, H. Iddir, L.A. Curtiss, K. Amine, Increased stability toward oxygen reduction products for lithium-air batteries with oligoether-functionalized silane electrolytes, J. Phys. Chem. C. 115 (2011) 25535-25542. doi:10.1021/jp2087412.

[142] B. Liu, W. Xu, P. Yan, X. Sun, M.E. Bowden, J. Read, J. Qian, D. Mei, C.M. Wang, J.G. Zhang, Enhanced Cycling Stability of Rechargeable Li-O2 Batteries Using High-Concentration Electrolytes, Adv. Funct. Mater. 26 (2016) 605-613. doi:10.1002/adfm.201503697. 
[143] F. Li, T. Zhang, Y. Yamada, A. Yamada, H. Zhou, Enhanced cycling performance of Li-O2 batteries by the optimized electrolyte concentration of LiTFSA in glymes, Adv. Energy Mater. 3 (2013) 532-538. doi:10.1002/aenm.201200776.

[144] R. Younesi, G.M. Veith, P. Johansson, K. Edstrom, T. Vegge, Lithium salts for advanced lithium batteries: Li-metal, Li-O2, and Li-S, Energy Environ. Sci. 8 (2015) 1905-1922. doi:10.1039/C5EE01215E.

[145] J. Shim, J.S. Lee, J.H. Lee, H.J. Kim, J.-C. Lee, Gel Polymer Electrolytes Containing Anion-Trapping Boron Moieties for Lithium-Ion Battery Applications, ACS Appl. Mater. Interfaces. 8 (2016) 27740-27752. doi:10.1021/acsami.6b09601.

[146] P.L. Kuo, C.A. Wu, C.Y. Lu, C.H. Tsao, C.H. Hsu, S.S. Hou, High Performance of Transferring Lithium Ion for Polyacrylonitrile-Interpenetrating Cross linked Polyoxyethylene Network as Gel Polymer Electrolyte, ACS Appl Mater Interfaces. 6 (2014) 3156-3162. doi:10.1021/am404248b.

[147] C. V. Amanchukwu, H.-H. Chang, M. Gauthier, S. Feng, T.P. Batcho, P.T. Hammond, One-Electron Mechanism in a Gel-Polymer Electrolyte Li-O 2 Battery, Chem. Mater. 28 (2016) 7167-7177. doi:10.1021/acs.chemmater.6b03718.

[148] A. Chamaani, N. Chawla, M. Safa, B. El-Zahab, One-Dimensional Glass MicroFillers in Gel Polymer Electrolytes for Li-O2 Battery Applications, Electrochim. Acta. 235 (2017) 56-63. doi:10.1016/j.electacta.2017.03.064.

[149] K. Xu, Nonaqueous liquid electrolytes for lithium-based rechargeable batteries, Chem. Rev. 104 (2004) 4303-4417. doi:10.1021/cr030203g.

[150] I. olsen, R. Koksbang, E. Skou, Transference number measurements on a hybrid polymer electrolyte, Electrochim. Acta. 40 (1995) 1701-1706. doi:10.1016/00134686(95)00094-U.

[151] K. Yoshida, M. Tsuchiya, N. Tachikawa, K. Dokko, M. Watanabe, Change from glyme solutions to quasi-ionic liquids for binary mixtures consisting of lithium bis(trifluoromethanesulfonyl)amide and glymes, J. Phys. Chem. C. 115 (2011) 18384-18394. doi:10.1021/jp206881t.

[152] C. Zhang, K. Ueno, A. Yamazaki, K. Yoshida, H. Moon, T. Mandai, Y. Umebayashi, K. Dokko, M. Watanabe, Chelate Effects in Glyme/Lithium Bis(trifluoromethanesulfonyl)amide Solvate Ionic Liquids. I. Stability of Solvate Cations and Correlation with Electrolyte Properties, J. Phys. Chem. B. 118 (2014) 5144-5153. doi:10.1021/jp501319e.

[153] K. Sann, Investigation of composite electrolytes with structured silica materials for lithium ion batteries, Justus-Liebig-Universität Gießen, 2016.

[154] M. Herstedt, M. Smirnov, P. Johansson, M. Chami, J. Grondin, L. Servant, J.C. Lassègues, Spectroscopic characterization of the conformational states of the bis(trifluoromethanesulfonyl)imide anion (TFSI-), J. Raman Spectrosc. 36 (2005) 762-770. doi:10.1002/jrs.1347. 
[155] D.M. Seo, P.D. Boyle, R.D. Sommer, J.S. Daubert, O. Borodin, W.A. Henderson, Solvate Structures and Spectroscopic Characterization of LiTFSI Electrolytes, J. Phys. Chem. B. 118 (2014) 13601-13608. doi:10.1021/jp505006x.

[156] L. Suo, F. Zheng, Y.-S. Hu, L. Chen, FT-Raman spectroscopy study of solvent-insalt electrolytes, Chinese Phys. B. 25 (2016) 16101. doi:10.1088/16741056/25/1/016101.

[157] H.-J. Ha, E.-H. Kil, Y.H. Kwon, J.Y. Kim, C.K. Lee, S.-Y. Lee, UV-curable semiinterpenetrating polymer network-integrated, highly bendable plastic crystal composite electrolytes for shape-conformable all-solid-state lithium ion batteries, Energy Environ. Sci. 5 (2012) 6491. doi:10.1039/c2ee03025j.

[158] F.S. Gittleson, R.E. Jones, D.K. Ward, M.E. Foster, Oxygen solubility and transport in Li-air battery electrolytes: establishing criteria and strategies for electrolyte design, Energy Environ. Sci. 10 (2017) 1167-1179. doi:10.1039/C6EE02915A.

[159] K.B. Knudsen, J.E. Nichols, T. Vegge, A.C. Luntz, B.D. McCloskey, J. Hjelm, An Electrochemical Impedance Study of the Capacity Limitations in Na-O2 Cells, J. Phys. Chem. C. 120 (2016) 10799-10805. doi:10.1021/acs.jpcc.6b02788.

[160] K.B. Knudsen, T. Vegge, B.D. McCloskey, J. Hjelm, An Electrochemical Impedance Spectroscopy Study on the Effects of the Surface- and Solution-Based Mechanisms in Li-O 2 Cells, J. Electrochem. Soc. 163 (2016) A2065-A2071. doi:10.1149/2.1111609jes.

[161] A.E. Christensen, J. Højberg, P. Norby, T. Vegge, Impedance-Based Battery Management for Metal-O2 Systems, J. Electrochem. Soc. 162 (2015) A2075A2079. doi:10.1149/2.0481510jes.

[162] J. Højberg, B.D. McCloskey, J. Hjelm, T. Vegge, K. Johansen, P. Norby, A.C. Luntz, An electrochemical impedance spectroscopy investigation of the overpotentials in Li-O2 batteries, ACS Appl. Mater. Interfaces. 7 (2015) 40394047. doi:10.1021/am5083254.

[163] J. Bisquert, Influence of the boundaries in the impedance of porous film electrodes, Phys. Chem. Chem. Phys. 2 (2000) 4185-4192.

[164] J. Bisquert, G. Garcia-Belmonte, F. Fabregat-Santiago, N.S. Ferriols, P. Bogdanoff, E.C. Pereira, Doubling Exponent Models for the Analysis of Porous Film Electrodes by Impedance. Relaxation of TiO2 Nanoporous in Aqueous Solution, J. Phys. Chem. B. 104 (2000) 2287-2298. doi:10.1021/jp993148h.

[165] M.C. Lefebvre, R.B. Martin, P.G. Pickup, Characterization of ionic conductivity profiles within proton exchange membrane fuel cell gas diffusion electrodes by impedance spectroscopy, Electrochem. Solid-State Lett. 2 (1999) 259-261. doi:10.1149/1.1390804.

[166] D. Zhai, H. Wang, K.C. Lau, J. Gao, P.C. Redfern, F. Kang, B. Li, E. Indacochea, U. Das, H. Sun, H. Sun, K. Amine, L.A. Curtiss, Raman Evidence for Late Stage 
Disproportionation in a Li-O2 Battery, J. Phys. Chem. Lett. 5 (2014) 2705-2710. doi:10.1021/jz501323n.

[167] V. Giordani, D. Tozier, H. Tan, C.M. Burke, B.M. Gallant, J. Uddin, J.R. Greer, B.D. McCloskey, G. V. Chase, D. Addison, A Molten Salt Lithium-Oxygen Battery, J. Am. Chem. Soc. 138 (2016) 2656-2663. doi:10.1021/jacs.5b11744.

[168] C.O. Laoire, S. Mukerjee, K.M. Abraham, E.J. Plichta, M.A. Hendrickson, Influence of nonaqueous solvents on the electrochemistry of oxygen in the rechargeable lithium-air battery, J. Phys. Chem. C. 114 (2010) 9178-9186. doi:10.1021/jp102019y.

[169] V.S. Bryantsev, J. Uddin, V. Giordani, W. Walker, D. Addison, G. V. Chase, The Identification of Stable Solvents for Nonaqueous Rechargeable Li-Air Batteries, J. Electrochem. Soc. 160 (2012) A160-A171. doi:10.1149/2.027302jes.

[170] D. Sharon, D. Hirsberg, M. Afri, A. Garsuch, A.A. Frimer, D. Aurbach, Reactivity of amide based solutions in lithium-oxygen cells, J. Phys. Chem. C. 118 (2014) 15207-15213. doi:10.1021/jp506230v.

[171] W. Walker, V. Giordani, J. Uddin, V.S. Bryantsev, G. V Chase, D. Addison, A Rechargeable Li-O2 Battery Using a Lithium Nitrate/N,N-Dimethylacetamide Electrolyte, J. Am. Chem. Soc. 135 (2013) 2076-2079. doi:10.1021/ja311518s.

[172] B.D. McCloskey, D.S. Bethune, R.M. Shelby, G. Girishkumar, A.C. Luntz, Solvents ' Critical Role in Nonaqueous Lithium À Oxygen Battery, J. Phys. Chem. Lett. 2 (2011) 1161-1166. doi:10.1021/jz200352v.

[173] W.A. Henderson, Glyme - Lithium Salt Phase Behavior, (2006) 13177-13183. doi:10.1021/jp061516t.

[174] K. Ueno, K. Yoshida, M. Tsuchiya, N. Tachikawa, K. Dokko, M. Watanabe, Glymelithium salt equimolar molten mixtures: Concentrated solutions or solvate ionic liquids?, J. Phys. Chem. B. 116 (2012) 11323-11331. doi:10.1021/jp307378j.

[175] K. Ueno, R. Tatara, S. Tsuzuki, S. Saito, H. Doi, K. Yoshida, T. Mandai, M. Matsugami, Y. Umebayashi, K. Dokko, M. Watanabe, Li + solvation in glyme-Li salt solvate ionic liquids, Phys. Chem. Chem. Phys. 17 (2015) 8248-8257. doi:10.1039/C4CP05943C.

[176] E. Nasybulin, W. Xu, M.H. Engelhard, Z. Nie, S.D. Burton, L. Cosimbescu, M.E. Gross, J. Zhang, Effects of Electrolyte Salts on the Performance of Li-O2 Batteries, J. Phys. Chem. C. 117 (2013) 2635-2645. doi:10.1021/jp311114u.

[177] I.M. Markus, G. Jones, J.M. García, Investigation of Electrolyte Concentration Effects on the Performance of Lithium-Oxygen Batteries, J. Phys. Chem. C. 120 (2016) 5949-5957. doi:10.1021/acs.jpcc.6b01474.

[178] F. Sagane, T. Abe, Z. Ogumi, Li+ -Ion Transfer through the Interface between Li + -Ion Conductive Ceramic Electrolyte and $\mathrm{Li}+$-Ion-Concentrated Propylene 
Carbonate Solution, J. Phys. Chem. C. 113 (2009) 20135-20138. doi:10.1021/jp908623c.

[179] H. Wang, S. Sunahiro, M. Matsui, P. Zhang, Y. Takeda, O. Yamamoto, N. Imanishi, A Solvate Ionic Liquid as the Anolyte for Aqueous Rechargeable Li-O2 Batteries, ChemElectroChem. 2 (2015) 1144-1151. doi:10.1002/celc.201500113.

[180] D. Brouillette, D.E. Irish, N.J. Taylor, G. Perron, M. Odziemkowski, J.E. Desnoyers, Stable solvates in solution of lithium bis(trifluoromethylsulfone)imide in glymes and other aprotic solvents: Phase diagrams, crystallography and Raman spectroscopyElectronic supplementary information (ESI) available: Crystallographic data (single crystal, Phys. Chem. Chem. Phys. 4 (2002) 60636071. doi:10.1039/b203776a.

[181] D. Brouillette, G. Perron, J.E. Desnoyers, Apparent Molar Volume, Heat Capacity, and Conductance of Lithium Bis(trifluoromethylsulfone)imide in Glymes and Other Aprotic Solvents, J. Solution Chem. 27 (1998) 151-182. doi:10.1023/A:1022609407560.

[182] D.M. Seo, O. Borodin, S.-D. Han, Q. Ly, P.D. Boyle, W. a. Henderson, Electrolyte Solvation and Ionic Association, J. Electrochem. Soc. 159 (2012) A553. doi:10.1149/2.jes112264.

[183] G.A. Giffin, A. Moretti, S. Jeong, S. Passerini, Complex nature of ionic coordination in magnesium ionic liquid-based electrolytes: Solvates with mobile $\mathrm{Mg} 2+$ cations, J. Phys. Chem. C. 118 (2014) 9966-9973. doi:10.1021/jp502354h.

[184] J.-C. Lassègues, J. Grondin, C. Aupetit, P. Johansson, Spectroscopic Identification of the Lithium Ion Transporting Species in LiTFSI-Doped Ionic Liquids, J. Phys. Chem. A. 113 (2009) 305-314. doi:10.1021/jp806124w.

[185] T. Watkins, D.A. Buttry, Determination of Mg 2+ Speciation in a TFSI - -Based Ionic Liquid With and Without Chelating Ethers Using Raman Spectroscopy, J. Phys. Chem. B. 119 (2015) 7003-7014. doi:10.1021/acs.jpcb.5b00339.

[186] Y. Umebayashi, T. Mitsugi, S. Fukuda, T. Fujimori, K. Fujii, R. Kanzaki, M. Takeuchi, S.I. Ishiguro, Lithium ion solvation in room-temperature ionic liquids involving bis(trifluoromethanesulfonyl) imide anion studied by Raman spectroscopy and DFT calculations, J. Phys. Chem. B. 111 (2007) 13028-13032. doi:10.1021/jp076869m.

[187] I. Gunasekara, S. Mukerjee, E.J. Plichta, M. a. Hendrickson, K.M. Abraham, A Study of the Influence of Lithium Salt Anions on Oxygen Reduction Reactions in Li-Air Batteries, J. Electrochem. Soc. 162 (2015) A1055-A1066. doi:10.1149/2.0841506jes.

[188] J.-C. Lassègues, J. Grondin, D. Talaga, Lithium solvation in bis(trifluoromethanesulfonyl)imide-based ionic liquids, Phys. Chem. Chem. Phys. 8 (2006) 5629-5632. doi:10.1039/B615127B. 
[189] S. Duluard, J. Grondin, J.-L. Bruneel, I. Pianet, A. Grélard, G. Campet, M.-H. Delville, J.-C. Lassègues, Lithium solvation and diffusion in the 1-butyl-3methylimidazolium bis(trifluoromethanesulfonyl)imide ionic liquid, J. Raman Spectrosc. 39 (2008) 627-632. doi:10.1002/jrs. 1896.

[190] V. Giordani, J. Uddin, V.S. Bryantsev, G. V. Chase, D. Addison, High Concentration Lithium Nitrate/Dimethylacetamide Electrolytes for Lithium/Oxygen Cells, J. Electrochem. Soc. 163 (2016) A2673-A2678. doi:10.1149/2.0951613jes. 
VITA

\section{AMIR CHAMAANI}

2004-2008

2008-2011

2011-2012

$2012-2017$
B.Sc., Metallurgical and Materials Engineering Azad University, Science and Research Campus Tehran, Iran

M.Sc., Nanomaterials Engineering Materials and Energy Research Center (MERC)

Tehran, Iran

Research Fellow Materials and Energy Research Center (MERC) Tehran, Iran

Doctoral Candidate (Ph.D.)

Florida International University

Miami, FL, USA

\section{PUBLICATIONS}

1. Amir Chamaani, Neha Chawla, Meer Safa and Bilal El-Zahab, "One-Dimensional Glass Micro-Fillers in Gel Polymer Electrolytes for Li-O⿰冫⿰亻⿱丶⿻工二2 Battery Applications", Electrochimica Acta, 235 (2017) 56-63

2. Neha Chawla*, Amir Chamaani", Meer Safa and Bilal El-Zahab, "Palladium-Filled Carbon Nanotubes Cathode for Improved Electrolyte Stability and Cyclability Performance of $\mathrm{Li}_{-} \mathrm{O}_{2}$ Batteries", Journal of Electrochemical Society, 164 (2017) A6303A6307, * Co-first Author

3. Meer Safa, Amir Chamaani, Neha Chawla and Bilal El-Zahab, "Polymeric Ionic Liquid Gel Electrolyte for Room Temperature Lithium Battery Applications", Electrochimica Acta, 213 (2016) 587-593

4. Amir Chamaani, Meer Safa, Neha Chawla and Bilal El-Zahab, "Composite Gel Polymer Electrolytes for Improved Cyclability in Li-Oxygen Batteries (ACS Appl. Mater. Interfaces 9 (2017) 33819-33826

5. Amir Chamaani, Neha Chawla, Meer Safa and Bilal El-Zahaba, "Stabilizing Effect of Ion Complex Formation in Lithium-Oxygen Battery Electrolytes" (Journal of Electroanalytical Chemistry, under review)

6. Meer Safa, Yong Hao, Amir Chamaani, Ebenezer Adelowo, Neha Chawla, Chunlei Wang and Bilal El-Zahab, "Capacity Fading Mechanism in Lithium-Sulfur Battery using Poly(Ionic Liquid) Gel Electrolyte" (Electrochimica Acta, 10.1016/j.electacta.2017.11.185) 
7. Amir Chamaani, Neha Chawla, Meer Safa, Bilal El-Zahab, "The Effect of Li-Ion Dissociation Level in Gel Polymer Electrolytes on Electrochemical Performance of Li-O⿰冫⿰亅⿱丿丶丶 Batteries", 231 ${ }^{\text {th }}$ ECS Meeting, New Orleans, LA, May 2017

8. Neha Chawla, Amir Chamaani, Meer Safa, Bilal El-Zahab, "Investigation of Electrochemical Performance of Li- $\mathrm{O}_{2}$ Batteries Using Catalyst Containing Carbon Nanotube Cathodes", 231 $1^{\text {th }}$ ECS Meeting, New Orleans, LA, May 2017

9. Amir Chamaani, Meer Safa, Neha Chawla, and Bilal El-Zahab, "Hybrid Gel Polymer Electrolyte for Li-O⿰冫⿰亻⿱丶⿻工二2 Batteries" MRS Fall 2016 Meeting, Boston, MA, Nov 2016

10. Amir Chamaani, Meer Safa, Neha Chawla, and Bilal El-Zahab, "Electrochemical Investigation of the Effect of Inorganic Fillers in Gel Polymer Electrolytes for $\mathrm{Li}_{2} \mathrm{O}_{2}$ Batteries", $18^{\text {th }}$ International Meeting on Lithium Batteries, Chicago, IL, Jun 2016

11. Neha Chawla, Amir Chamaani, Meer Safa and Bilal El-Zahab, "Nanocatalysts for improved capacity retention in lithium-air batteries," MRS Spring Meeting 2016, March 2016

12. Neha Chawla, Amir Chamaani and Bilal El-Zahab, "Multi-Walled Carbon Nanotubes as Cathodes for Lithium-Air Batteries: Effect of Catalysts and Additives", $228^{\text {th }}$ ECS Meeting 2015, Phoenix, AZ, Oct 2015

13. Meer Safa, Amir Chamaani, and Bilal El-Zahab, "Polymeric Ionic Liquid Electrolytes: Effect of Inorganic Fillers," $227^{\text {th }}$ ECS Meeting 2015, Chicago, IL, May 2015

14. Amir Chamaani, Meer Safa, Neha Chawla and Bilal El-Zahab, "Electrochemical Behavior of Flexible Gel Polymer Electrolyte with Fiber Fillers", $2^{\text {nd }}$ Florida Statewide Graduate Student Research Symposium, Orlando, Florida, May 2015

15. Amir Chamaani, Meer Safa and Bilal El-Zahab, "Free-standing Flexible Polymer Composite Electrolyte for Li-ion Batteries", TMS 2015, Orlando, FL, March 2015

16. Meer Safa, Amir Chamaani, and Bilal El-Zahab, "Organic-Inorganic Hybrid Materials as Novel Solid-State Electrolytes for Li-ion Batteries", TMS 2015, Orlando, FL, March 2015

17. Bilal El-Zahab and Amir Chamaani, "Flexible, Thin, and Rechargeable Li-ion Battery based on Semi-Solid Electrodes”, MS\&T Meeting, Montreal, Quebec, Canada, Oct 2013 